\title{
Clinical implications of idiopathic atrial fibrillation
}

Citation for published version (APA):

Weijs, B. (2012). Clinical implications of idiopathic atrial fibrillation. [Doctoral Thesis, Maastricht University]. Maastricht University. https://doi.org/10.26481/dis.20120921bw

Document status and date:

Published: 01/01/2012

DOI:

10.26481/dis.20120921bw

Document Version:

Publisher's PDF, also known as Version of record

\section{Please check the document version of this publication:}

- A submitted manuscript is the version of the article upon submission and before peer-review. There can be important differences between the submitted version and the official published version of record.

People interested in the research are advised to contact the author for the final version of the publication, or visit the DOI to the publisher's website.

- The final author version and the galley proof are versions of the publication after peer review.

- The final published version features the final layout of the paper including the volume, issue and page numbers.

Link to publication

\footnotetext{
General rights rights.

- You may freely distribute the URL identifying the publication in the public portal. please follow below link for the End User Agreement:

www.umlib.nl/taverne-license

Take down policy

If you believe that this document breaches copyright please contact us at:

repository@maastrichtuniversity.nl

providing details and we will investigate your claim.
}

Copyright and moral rights for the publications made accessible in the public portal are retained by the authors and/or other copyright owners and it is a condition of accessing publications that users recognise and abide by the legal requirements associated with these

- Users may download and print one copy of any publication from the public portal for the purpose of private study or research.

- You may not further distribute the material or use it for any profit-making activity or commercial gain

If the publication is distributed under the terms of Article $25 \mathrm{fa}$ of the Dutch Copyright Act, indicated by the "Taverne" license above, 


\section{$C L \perp N$ I C A L \\ IMPLICATIONS OF IDIOPATHIC ATRIAL FIB R I L LATIO N}
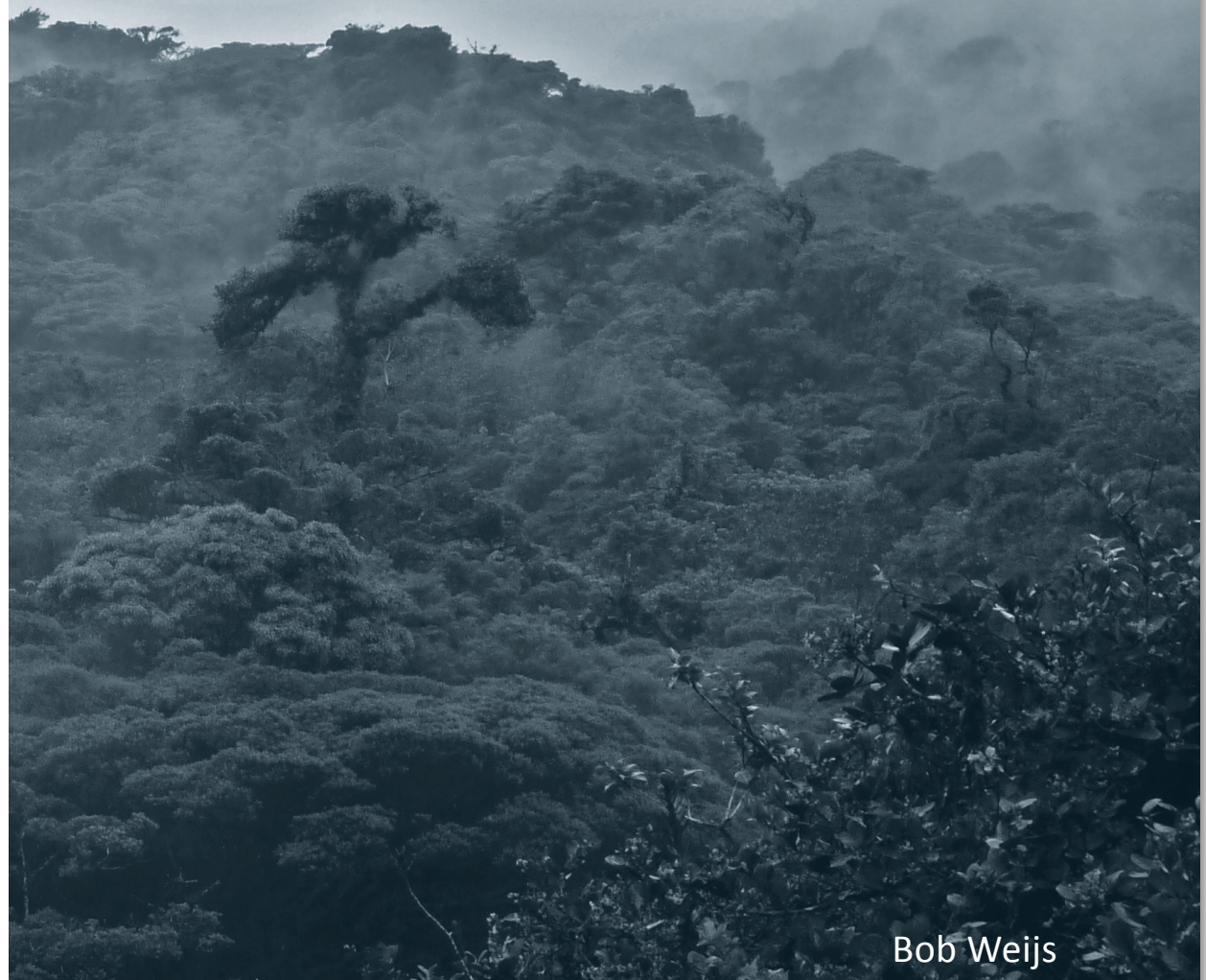

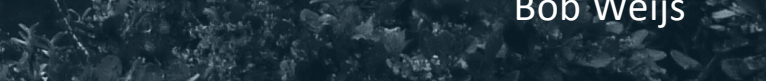




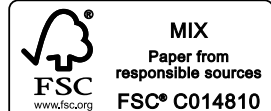

Copyright Bob Weijs, Maastricht 2012

ISBN: 9789461913722

Cover design:

Cover photography:

Production:
Bob Weijs \& Frans Schupp (www.fransschupp.nl)

Anne Custers, Monteverde Cloud Forest, Costa Rica Ipskamp Drukkers Enschede 


\title{
CLINICAL IMPLICATIONS OF IDIOPATHIC ATRIAL FIBRILLATION
}

\author{
PROEFSCHRIFT \\ ter verkrijging van de graad van doctor \\ aan de Universiteit Maastricht, \\ op gezag van de Rector Magnificus, Prof. dr. L.L.G. Soete \\ volgens het besluit van het college van decanen, \\ in het openbaar te verdedigen \\ op vrijdag 21 september 2012 om 12.00 uur
}

door

Bob Weijs

geboren op 12 januari 1984 te Heerlen 
Promotor

Prof. dr. H.J.G.M. Crijns

\section{Co-promotor}

dr. R. Pisters

\section{Beoordelingscommissie}

Prof. dr. U. Schotten

Prof. dr. I.C. Van Gelder (UMC Groningen)

Prof. dr. A.P.M. Gorgels

Prof. dr. J.L.R.M. Smeets (UMC Nijmegen)

Prof. dr. C.D.A. Stehouwer

Financial support by the Dutch Heart Foundation and Stichting Hartsvrienden RESCAR for the publication of this thesis is gratefully acknowledged. Further financial support by the Maastricht University Medical Centre, Medtronic BV, Boehringer-Ingelheim BV, Merck Sharp \& Dohme BV, Bayer BV, and Biotronik Nederland BV is equally appreciated. 
"I started out with nothing, and I still got most of it left" Seasick Steve, Warner Bros Records, 2008 


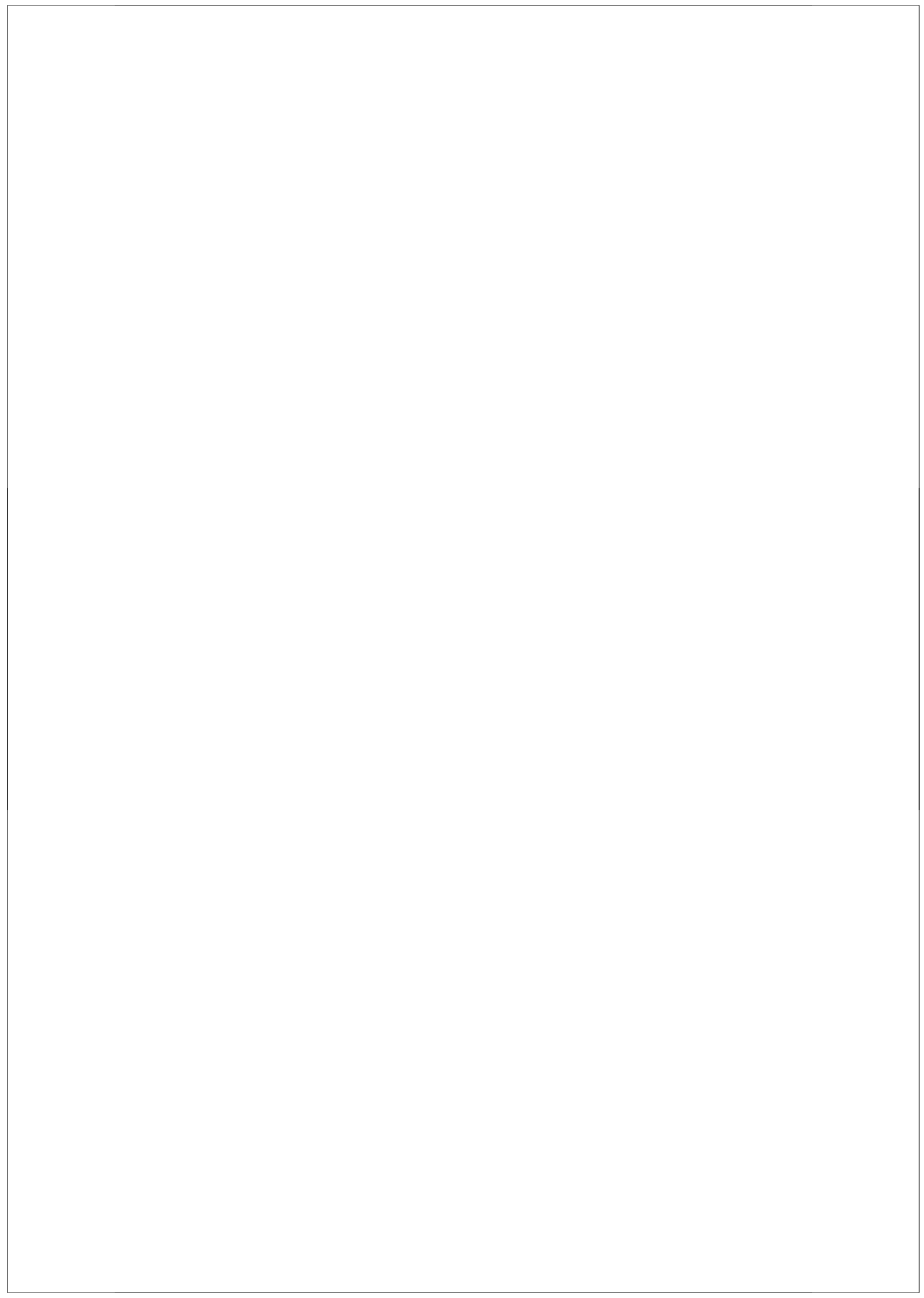




\section{CONTENTS}

Prologue 9

I. Introduction 11

PART I ELECTRO-ECHOCARDIOGRAPHIC CHARACTERIZATION OF THE ATRIAL SUBSTRATE FOR ATRIAL FIBRILLATION

II. Atrial tissue Doppler imaging for prediction of new-onset atrial fibrillation

Heart. 2009; 95(10):835-40

III. Clinical and echocardiographic correlates of intra-atrial

conduction delay

Europace. 2011;13(12):1681-1687

Editorial by Michael Y. Henein: atrial electromechanical function

Europace. 2011;13(12):1665-6

IV. The presence of an atrial electromechanical delay in

idiopathic atrial fibrillation as determined by tissue Doppler imaging

Int J Cardiol. 2012;156(1):121-2

\section{PART II THE ARRHYTHMIA IN ITS IMMACULATE FORM}

V. Idiopathic atrial fibrillation revisited in a large longitudinal clinical cohort

Europace. 2012;14(2):184-90

Editorial by D. George Wyse: idiopathic atrial fibrillation: a rose by any other name?

Europace. 2012;14(2):151-2

VI. Masked hypertension in a patient with idiopathic atrial fibrillation

Neth J Med. 2010; 68(10): 328

VII. The occurrence of cardiovascular disease during 5 year follow up in patients with idiopathic atrial fibrillation Europace 2012, in press 
PART III ATRIAL FIBRILLATION IS A VASCULAR DISEASE RATHER THAN AN ARRHYTHMIA

VIII. Patients originally diagnosed with idiopathic atrial fibrillation more often suffer from insidious coronary artery disease compared to healthy sinus rhythm controls Heart Rhythm 2012, in press

IX. Making things worse: Patients using vitamin $\mathrm{K}$ antagonists show increased levels of coronary calcification: an observational study in low-risk atrial fibrillation patients Eur Heart J. 2011;32(20):2555-62

Editorial by Nico Bruining and Ron T. van Domburg: Long term application of vitamin $\mathrm{K}$ antagonists, more harm than good? The additional value of imaging Eur Heart J. 2011;32(20):2473-5

X. General discussion

XI. Conclusion and summary

XII. Dankwoord

XIII. About the author \& publications 


\section{PROLOGUE}

The classification of diseases or nosology already dates from ancient Chinese medicine and has not stood still ever since. Currently, the World Health Organization (WHO) maintains the International Statistical Classification of Diseases (ICD-10). Regardless the structure that is used, the chances of successful classification depend on reliable and robust medical definitions.

There are several problems in trying to come up with a suitable definition, particularly through the years when new underlying aetiologies or better diagnostic tests come along. Even within frequently used definitions there are variations, uncertainties, and inconsistencies throughout the literature. Should we blame ourselves? Probably not, since nature is by far more diverse than we are able to capture in our guidelines and definitions. However, since physicians are always on the quest for a decent diagnosis and underlying causal factors of diseases, the use of the term "idiopathic" seems to be a subtle declaration of ignorance. The eventual population with an "idiopathic" disease is determined not only by definition, but also by the extent of the search for underlying causal factors and the robustness of diagnostic tools used in this perspective. How hard do we have to look for associated comorbidities and causal factors? From a scientific point of view one cannot look hard and deep enough. But the search for potential causal mechanisms has to be clinically applicable. From a clinical point of view, one needs to look for preventable and curable causes of a disease, all other 'causes' are - for the moment - clinically futile and confusing for the general clinician, and may even trigger false therapies. The current thesis deals with the transitoriness of the term idiopathic atrial fibrillation as a medical definition. 
CHAPTER I

INTRODUCTION 


\section{CLINICAL BACKGROUND}

"Auricular fibrillation" in humans was already described and captured on electrocardiography in $1906 .{ }^{1-3}$ Ever since, science concerning atrial fibrillation (AF) has never stood still and in fact, the arrhythmia nowadays is "hotter than ever" (3345 scientific articles alone in 2011 , of which $10 \%$ high impact [impact factor $>10$ ] publications, www.PubMed.com).

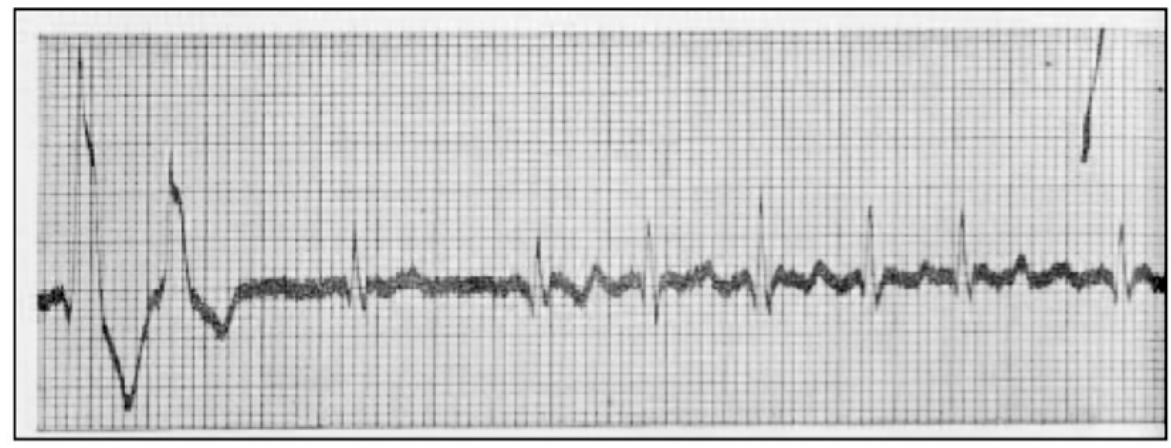

“Pulsus Inaequalis et Irregularis.” Einthoven W. Le télécardiogramme. 1906

\section{Burden of the arrhythmia and clinical implications}

Management of AF has evolved greatly in the past few years and many areas have had substantial advances or developments. ${ }^{4-6}$ This is not without reason; AF is the most common sustained cardiac rhythm disorder in clinical practice, occurring in $1-2 \%$ of the general population. ${ }^{7}$ Over 6 million Europeans suffer from this arrhythmia and it is estimated that its prevalence will at least double in the next 30-50 years because of an ageing population and improved healthcare. ${ }^{4,8,9}$ For the Netherlands, the overall prevalence of $\mathrm{AF}$ is $5.5 \%$ in the population over 55 years, corresponding to about $250,000 \mathrm{AF}$ patients, and incidence is estimated to 45,085 new AF cases per year. ${ }^{10,11}$

Although sometimes otherwise stated, AF is not a benign disease: apart from other comorbidities, death rates are doubled by the arrhythmia and stroke risk is increased five-fold. Besides, AF related strokes are more often fatal, and those patients who survive their stroke are more disabled and more likely to suffer a recurrence. ${ }^{12-16}$ Since AF is independently associated with increased morbidity and mortality, it is responsible for a significant health care and thus economic burden. ${ }^{12,17-20}$ Regarding the Netherlands, total costs of AF in 2009 amount $€ 583$ million, of which the majority $(70 \%)$ accounts hospitalizations and in-hospital procedures. ${ }^{10}$

\section{Classification and treatment}

In clinical practice, AF is classified based on the presentation and duration of the arrhythmia, resulting in five types of $A F$ : first diagnosed $A F$, paroxysmal AF (selfterminating, usually $<24 \mathrm{~h}$, but self-termination may occur even after one week, even 
in a fixed pattern), persistent AF (lasts longer than 7 days or requires termination by cardioversion), long-standing persistent AF (has lasted $>1$ year when it is decided to aim for conversion to sinus rhythm) and permanent AF (the arrhythmia is accepted). ${ }^{4}$ Over time, AF progresses from usual short and rare episodes, to more sustained forms of AF. Only a small proportion of patients will remain in paroxysmal AF over several decades. $^{21}$

It is important to realize that the increased risk for stroke is irrespective of the type of AF (paroxysmal vs. persistent or permanent). Even short runs of subclinical atrial tachyarrhythmias are associated with a significantly increased risk of ischemic stroke or systemic embolism. ${ }^{22}$ Therefore, adequate antithrombotic therapy holds a key position in AF patients and several stroke risk assessment schemes have been developed to identify those at highest risk for stroke. ${ }^{23-25}$ Ever since numerous clinical trials have demonstrated that a "rhythm-control" approach (do whatever is possible to maintain sinus rhythm) has no additional value as compared to a "rate-control" strategy (leaving AF unaffected apart from restriction of ventricular rate), AF management is aimed at reducing symptoms and at preventing severe complications associated with the arrhythmia, and thus relies on antithrombotic therapy, control of ventricular rate and adequate treatment of concomitant disease. ${ }^{4,26-29}$

\section{Structural remodelling and concomitant disease}

$\mathrm{AF}$ derives from a complex continuum of predisposing factors and its exact mechanisms are complex and incompletely understood. ${ }^{30}$ However, the true 'scene of calamity' is the atrium. Increased left atrial (LA) size is associated with increased risk of AF onset and recurrence, other cardiovascular diseases and mortality. ${ }^{31,32}$ Both atrial conduction slowing and atrial dilatation (also called electrical and structural remodelling) will favour $\mathrm{AF}$ as it results in increased total atrial conduction time, which is the time elapsed between the initiation of atrial depolarisation and the last depolarisation of the same activation front. ${ }^{33,34}$

Delayed conduction is one of the requirements for the initiation of re-entry. For that reason, the development of $\mathrm{AF}$ is strongly associated with well-known underlying cardiovascular conditions (older age, hypertension, heart failure, valvular heart disease, and diabetes mellitus), which affect the atria directly or indirectly, and eventually lead to structural remodelling. ${ }^{17,}$ 35-37 Obtaining information concerning atrial conduction in an individual patient - in a clinically feasible and patient friendly manner - could substantially add to find those at risk for AF and those with presence of subclinical underlying cardiovascular disease and may differentiate between different degrees of atrial remodelling in order to facilitate future strategies to prevent the development or complications of AF, as outlined in PART I of this thesis.

\section{Idiopathic atrial fibrillation}

Idiopathic or lone atrial fibrillation refers to AF in the absence of a cardiovascular or pulmonary disease generating the pathophysiological substrate for the arrhythmia. ${ }^{38-40}$ It has been described variously from 1927 as benign AF, functional AF, senile fibrillation, fibrillation of unknown origin and fibrillation without heart disease, until 
Evans and Swann proposed for the first time the term lone AF in $1953 .{ }^{41-45}$ All of these publications discussed short reports of cases were AF occurred in the absence of heart disease (as determined by means of diagnostic tests which were not very well established back in those days). In hindsight, most of these cases nowadays would be classified as secondary or transient AF (i.e. those cases due to alcohol intoxication, inflammatory disease, or electrocution) or due to autonomic (vagal or adrenergic) triggers. ${ }^{4,46-48}$ For example, Hay and Jones reported two very 'imaginative' cases of: "auricular fibrillation in a patient who was frightened by a dog, and climbed over a high wall, ... and another in a man who struggled with a horse..."

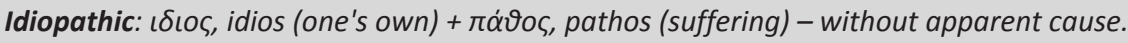

There is only limited - and more important, conflicting - evidence concerning the development, treatment and prognosis of idiopathic AF in the literature. Its reported prevalence varies widely between 2 and 30\%, which relates to ambiguous definitions, specifically with regards to age and underlying cardiopulmonary disease. ${ }^{39-}$ 41, 50-54 Presumably, these differences regarding the definition of idiopathic AF are also responsible for conflicting data on prognosis of these patients. Data from the Olmsted County database suggest that idiopathic AF is a benign disease with comparable risk of thromboembolism, congestive heart failure and mortality as the general population, whereas data from the Framingham Heart Study and the Paris Prospective Study show that idiopathic AF is associated with increased mortality and co-morbidity. ${ }^{21,39,50,51,55}$ The RACE study, performed in the Netherlands, showed an annual event rate for developing a vascular endpoint (cardiovascular death, heart failure or thromboembolic complication) of $8 \%$ in the general $\mathrm{AF}$ patient. ${ }^{27}$ In the subset of patients with idiopathic AF, annual morbidity and mortality rates comprised $4 \%$ both in the RACE Study as the Belgrade AF Study. ${ }^{56,57}$

Atrial fibrillation is a well-established risk factor for cardiovascular events such as stroke and myocardial infarction. In fact, these vascular complications form the major threat of the arrhythmia. ${ }^{4}$ Since comprehensive evidence is lacking in the scientific literature, we should - for the sake of our patients - assume that the same holds true for the idiopathic AF patient and that these patients should be treated accordingly. The short and long term development of cardiovascular disease and the influence of occurrence of mild cardiovascular disease on prognosis of patients initially diagnosed with idiopathic AF is described in PART II.

The latest guidelines on management of AF define idiopathic AF as the arrhythmia in absence of underlying cardiovascular or pulmonary disease as determined by means of routine diagnostics such as: exercise-test, echocardiography, 24 h-rhythm monitoring and thyroid function. ${ }^{4,58}$ However, it is conceivable that many other mechanisms, undetectable by these routine diagnostics, may be the underlying explanation of apparent idiopathic AF. Recent studies have identified novel risk factors such as inflammation, oxidative stress, endurance sports, obesity and sleep apnoea, or a genetic basis for the arrhythmia. ${ }^{59-66}$ 
In addition, more advanced diagnostics (i.e. high-end echocardiography, 24hblood pressure monitoring, cardiac CT angiography, and cardiac MR imaging) have become available that can be deployed at low threshold in order to detect early stage or yet subclinical cardiovascular disease. In this respect one could raise the question whether idiopathic AF exists at all or that it acts as a whistle-blower of as yet undetected underlying vascular disease. Taking this into consideration, Fowler already in 1930 (unknowingly?) postulated a very intriguing and innovative theory when he studied 10 cases with idiopathic AF entitled: "auricular fibrillation as the only manifestation of heart disease." Unfortunately, this theory has not been extensively elucidated since that time. The presence of subclinical vascular disease in patients with apparent idiopathic AF is described in PART III.

\section{AIMS AND OUTLINE OF THIS THESIS}

Although the term idiopathic atrial fibrillation is frequently mentioned, accurate data regarding development, treatment and prognosis is sparsely available in the literature. This thesis aims to characterize idiopathic AF and its cardiovascular profiles in detail and calls the correctness of its medical definition into question.

PART I focuses on electrical and structural remodelling of the left atrium as determined by a novel and non-invasive echocardiographic method (PA-TDI) that was developed and validated at our department prior to this thesis. Chapter 2 shows that this method may predict the development of new-onset AF. Chapter 3 studied the clinical and echocardiographic correlates of atrial remodelling by means of PA-TDI. In Chapter 4 we show that despite the healthy nature of idiopathic AF patients, total atrial conduction time is significantly prolonged in these patients as compared to matched sinus rhythm controls. With regards to chapter 3 , the prolonged atrial conduction time may be an expression of yet undetected underlying heart disease, which is further studied in Parts II and III.

PART II comprises a critical evaluation of the current definition as well as the short and long-term prognosis of idiopathic AF. In chapter 5 we investigated the importance of age ( $<60$ years) as a criterion in the definition of idiopathic AF using patients enrolled in the Euro Heart Survey on AF. ${ }^{36}$ This chapter also describes 1-year prognosis in patients with idiopathic AF and the impact of the presence of isolated hypertension on this 1-year prognosis in an otherwise comparable group of patients. Chapter 6 shows that certain forms of concealed cardiovascular disease may be present in the patient who presents with idiopathic AF. In chapter 7 we studied the occurrence of cardiovascular disease during 5 year follow up in patients originally diagnosed with idiopathic AF.

PART III concerns the presence of concealed coronary artery disease in patients with apparently idiopathic AF (chapter 8) and demonstrates that current treatment strategies may aggravate this process in AF patients without a significant vascular risk at the start of their arrhythmia (chapter 9). 


\section{REFERENCES}

1. Cushny AR, Edmunds CW. Paroxysmal irregularity of the heart and auricular fibrillation. In: Bulloch $W$, ed Studies in pathology Aberdeen, Scotland: Universty of Aberdeen 1906:95-110.

2. Einthoven W. Le Telecardiogramme. Arch Int Physiol. 1906;4:132-64.

3. Fye WB. Tracing atrial fibrillation--100 years. N Engl J Med. 2006 Oct 5;355(14):1412-4.

4. Camm AJ, Kirchhof P, Lip GY, Schotten U, Savelieva I, Ernst S, et al. Guidelines for the management of atrial fibrillation: the Task Force for the Management of Atrial Fibrillation of the European Society of Cardiology (ESC). European heart journal. 2010 Oct;31(19):2369-429.

5. Lip GY, Beevers DG. ABC of atrial fibrillation. History, epidemiology, and importance of atrial fibrillation. Bmj. 1995 Nov 18;311(7016):1361-3.

6. Nattel S. New ideas about atrial fibrillation 50 years on. Nature. 2002 Jan 10;415(6868):219-26.

7. Kirchhof P, Bax J, Blomstrom-Lundquist C, Calkins H, Camm AJ, Cappato R, et al. Early and comprehensive management of atrial fibrillation: proceedings from the 2nd AFNET/EHRA consensus conference on atrial fibrillation entitled 'research perspectives in atrial fibrillation'. Europace : European pacing, arrhythmias, and cardiac electrophysiology : journal of the working groups on cardiac pacing, arrhythmias, and cardiac cellular electrophysiology of the European Society of Cardiology. 2009 Jul;11(7):860-85.

8. Miyasaka Y, Barnes ME, Gersh BJ, Cha SS, Bailey KR, Abhayaratna WP, et al. Secular trends in incidence of atrial fibrillation in Olmsted County, Minnesota, 1980 to 2000, and implications on the projections for future prevalence. Circulation. 2006 Jul 11;114(2):119-25.

9. Go AS, Hylek EM, Phillips KA, Chang Y, Henault LE, Selby JV, et al. Prevalence of diagnosed atrial fibrillation in adults: national implications for rhythm management and stroke prevention: the AnTicoagulation and Risk Factors in Atrial Fibrillation (ATRIA) Study. JAMA : the journal of the American Medical Association. 2001 May 9;285(18):2370-5.

10. Heemstra HE, Nieuwlaat R, Meijboom M, Crijns HJ. The burden of atrial fibrillation in the Netherlands. Neth Heart J. 2011 Sep;19(9):373-8.

11. Heeringa J, van der Kuip DA, Hofman A, Kors JA, van Herpen G, Stricker BH, et al. Prevalence, incidence and lifetime risk of atrial fibrillation: the Rotterdam study. European heart journal. 2006 Apr;27(8):949-53.

12. Benjamin EJ, Wolf PA, D'Agostino RB, Silbershatz H, Kannel WB, Levy D. Impact of atrial fibrillation on the risk of death: the Framingham Heart Study. Circulation. 1998 Sep 8;98(10):946-52.

13. Wolf PA, Abbott RD, Kannel WB. Atrial fibrillation: a major contributor to stroke in the elderly. The Framingham Study. Arch Intern Med. 1987 Sep;147(9):1561-4. 
14. Wolf PA, Abbott RD, Kannel WB. Atrial fibrillation as an independent risk factor for stroke: the Framingham Study. Stroke. 1991 Aug;22(8):983-8.

15. Investigators AF. Risk factors for stroke and efficacy of antithrombotic therapy in atrial fibrillation. Analysis of pooled data from five randomized controlled trials. Arch Intern Med. 1994 Jul 11;154(13):1449-57.

16. Stewart S, Hart CL, Hole DJ, McMurray JJ. A population-based study of the long-term risks associated with atrial fibrillation: 20-year follow-up of the Renfrew/Paisley study. The American journal of medicine. 2002 Oct 1;113(5):359-64.

17. Benjamin EJ, Levy D, Vaziri SM, D'Agostino RB, Belanger AJ, Wolf PA. Independent risk factors for atrial fibrillation in a population-based cohort. The Framingham Heart Study. JAMA : the journal of the American Medical Association. 1994 Mar 16;271(11):840-4.

18. Holstenson E, Ringborg A, Lindgren P, Coste F, Diamand F, Nieuwlaat R, et al. Predictors of costs related to cardiovascular disease among patients with atrial fibrillation in five European countries. Europace : European pacing, arrhythmias, and cardiac electrophysiology : journal of the working groups on cardiac pacing, arrhythmias, and cardiac cellular electrophysiology of the European Society of Cardiology. 2011 Jan;13(1):23-30.

19. Kannel WB, Wolf PA, Benjamin EJ, Levy D. Prevalence, incidence, prognosis, and predisposing conditions for atrial fibrillation: population-based estimates. Am J Cardiol. 1998 Oct 16;82(8A):2N-9N.

20. Ringborg $A$, Nieuwlaat $R$, Lindgren $P$, Jonsson $B$, Fidan $D$, Maggioni $A P$, et al. Costs of atrial fibrillation in five European countries: results from the Euro Heart Survey on atrial fibrillation. Europace : European pacing, arrhythmias, and cardiac electrophysiology : journal of the working groups on cardiac pacing, arrhythmias, and cardiac cellular electrophysiology of the European Society of Cardiology. 2008 Apr;10(4):403-11.

21. Jahangir A, Lee V, Friedman PA, Trusty JM, Hodge DO, Kopecky SL, et al. Longterm progression and outcomes with aging in patients with lone atrial fibrillation: a 30-year follow-up study. Circulation. 2007 Jun 19;115(24):30506.

22. Healey JS, Connolly SJ, Gold MR, Israel CW, Van Gelder IC, Capucci A, et al. Subclinical atrial fibrillation and the risk of stroke. N Engl J Med. 2012 Jan 12;366(2):120-9.

23. Gage BF, Waterman AD, Shannon W, Boechler M, Rich MW, Radford MJ. Validation of clinical classification schemes for predicting stroke: results from the National Registry of Atrial Fibrillation. Jama. 2001 Jun 13;285(22):2864-70.

24. Lip GY, Nieuwlaat R, Pisters R, Lane DA, Crijns HJ. Refining clinical risk stratification for predicting stroke and thromboembolism in atrial fibrillation using a novel risk factor-based approach: the euro heart survey on atrial fibrillation. Chest. 2010 Feb;137(2):263-72. 
25. Pisters R, Lane DA, Nieuwlaat R, de Vos CB, Crijns HJ, Lip GY. A novel userfriendly score (HAS-BLED) to assess 1-year risk of major bleeding in patients with atrial fibrillation: the Euro Heart Survey. Chest. Nov;138(5):1093-100.

26. Van Gelder IC, Groenveld HF, Crijns HJ, Tuininga YS, Tijssen JG, Alings AM, et al. Lenient versus strict rate control in patients with atrial fibrillation. N Engl J Med. 2010 Apr 15;362(15):1363-73.

27. Van Gelder IC, Hagens VE, Bosker HA, Kingma JH, Kamp O, Kingma T, et al. A comparison of rate control and rhythm control in patients with recurrent persistent atrial fibrillation. N Engl J Med. 2002 Dec 5;347(23):1834-40.

28. Wyse DG, Waldo AL, DiMarco JP, Domanski MJ, Rosenberg Y, Schron EB, et al. A comparison of rate control and rhythm control in patients with atrial fibrillation. N Engl J Med. 2002 Dec 5;347(23):1825-33.

29. Lip GY, Tse HF, Lane DA. Atrial fibrillation. Lancet. 2011 Dec 9.

30. Allessie MA, Boyden PA, Camm AJ, Kleber AG, Lab MJ, Legato MJ, et al. Pathophysiology and prevention of atrial fibrillation. Circulation. 2001 Feb 6;103(5):769-77.

31. Benjamin EJ, D'Agostino RB, Belanger AJ, Wolf PA, Levy D. Left atrial size and the risk of stroke and death. The Framingham Heart Study. Circulation. 1995 Aug 15;92(4):835-41.

32. Osranek M, Bursi F, Bailey KR, Grossardt BR, Brown RD, Jr., Kopecky SL, et al. Left atrial volume predicts cardiovascular events in patients originally diagnosed with lone atrial fibrillation: three-decade follow-up. European heart journal. 2005 Dec;26(23):2556-61.

33. De PR, Ho SY, Salerno-Uriarte JA, Tritto M, Spadacini G. Electroanatomic analysis of sinus impulse propagation in normal human atria. Journal of cardiovascular electrophysiology. 2002 Jan;13(1):1-10.

34. Pytkowski M, Jankowska A, Maciag A, Kowalik I, Sterlinski M, Szwed H, et al. Paroxysmal atrial fibrillation is associated with increased intra-atrial conduction delay. Europace : European pacing, arrhythmias, and cardiac electrophysiology : journal of the working groups on cardiac pacing, arrhythmias, and cardiac cellular electrophysiology of the European Society of Cardiology. 2008 Dec;10(12):1415-20.

35. Nabauer M, Gerth A, Limbourg T, Schneider S, Oeff M, Kirchhof $P$, et al. The Registry of the German Competence NETwork on Atrial Fibrillation: patient characteristics and initial management. Europace : European pacing, arrhythmias, and cardiac electrophysiology : journal of the working groups on cardiac pacing, arrhythmias, and cardiac cellular electrophysiology of the European Society of Cardiology. 2009 Apr;11(4):423-34.

36. Nieuwlaat R, Capucci A, Camm AJ, Olsson SB, Andresen D, Davies DW, et al. Atrial fibrillation management: a prospective survey in ESC member countries: the Euro Heart Survey on Atrial Fibrillation. European heart journal. 2005 Nov;26(22):2422-34. 
37. Conen D, Tedrow UB, Koplan BA, Glynn RJ, Buring JE, Albert CM. Influence of systolic and diastolic blood pressure on the risk of incident atrial fibrillation in women. Circulation. 2009 Apr 28;119(16):2146-52.

38. Davidson E, Rotenberg Z, Weinberger I, Fuchs J, Agmon J. Diagnosis and characteristics of lone atrial fibrillation. Chest. 1989 May;95(5):1048-50.

39. Kopecky SL, Gersh BJ, McGoon MD, Whisnant JP, Holmes DR, Jr., Ilstrup DM, et al. The natural history of lone atrial fibrillation. A population-based study over three decades. N Engl J Med. 1987 Sep 10;317(11):669-74.

40. Kozlowski D, Budrejko S, Lip GY, Rysz J, Mikhailidis DP, Raczak G, et al. Lone atrial fibrillation: what do we know? Heart (British Cardiac Society). 2010 Apr;96(7):498-503.

41. Evans W, Swann P. Lone auricular fibrillation. British heart journal. 1954 Apr;16(2):189-94.

42. Fowler WM, Baldridge CW. Auricular fibrillation as the only manifestation of heart disease. Am Heart J. 1930;6:183-91.

43. Friedlander RD, Levine SA. Auricular fibrillation and flutter without evidence of organic heart disease. N Engl J Med. 1934;211:624.

44. Neufeld HN, Wagenvoort CA, Burchell HB, Edwards JE. Idiopathic atrial fibrillation. Am J Cardiol. 1961 Aug;8:193-7.

45. Phillips E, Levine SA. Auricular fibrillation without other evidence of heart disease; a cause of reversible heart failure. The American journal of medicine. 1949 Oct;7(4):478-89.

46. Coumel P. Cardiac arrhythmias and the autonomic nervous system. Journal of cardiovascular electrophysiology. 1993 Jun;4(3):338-55.

47. Coumel P. Paroxysmal atrial fibrillation: a disorder of autonomic tone? European heart journal. 1994 Apr;15 Suppl A:9-16.

48. de Vos CB, Nieuwlaat R, Crijns HJ, Camm AJ, LeHeuzey JY, Kirchhof CJ, et al. Autonomic trigger patterns and anti-arrhythmic treatment of paroxysmal atrial fibrillation: data from the Euro Heart Survey. European heart journal. 2008 Mar;29(5):632-9.

49. Hay J, Jones HW. Trauma as a cause of auricular fibrillation. Bmj. 1927;1:55962.

50. Brand FN, Abbott RD, Kannel WB, Wolf PA. Characteristics and prognosis of lone atrial fibrillation. 30-year follow-up in the Framingham Study. Jama. 1985 Dec 27;254(24):3449-53.

51. Jouven X, Desnos M, Guerot C, Ducimetiere P. Idiopathic atrial fibrillation as a risk factor for mortality. The Paris Prospective Study I. European heart journal. 1999 Jun;20(12):896-9.

52. Kannel WB, Abbott RD, Savage DD, McNamara PM. Epidemiologic features of chronic atrial fibrillation: the Framingham study. N Engl J Med. 1982 Apr 29;306(17):1018-22.

53. Kopecky SL. Idiopathic atrial fibrillation: prevalence, course, treatment, and prognosis. Journal of thrombosis and thrombolysis. 1999 Jan;7(1):27-31. 
54. Levy S. Epidemiology and classification of atrial fibrillation. Journal of cardiovascular electrophysiology. 1998 Aug;9(8 Suppl):S78-82.

55. Scardi S, Mazzone C, Pandullo C, Goldstein D, Poletti A, Humar F. Lone atrial fibrillation: prognostic differences between paroxysmal and chronic forms after 10 years of follow-up. Am Heart J. 1999 Apr;137(4 Pt 1):686-91.

56. Rienstra M, Hagens VE, Van Veldhuisen DJ, Bosker HA, Tijssen JG, Kamp O, et al. Clinical characteristics of persistent lone atrial fibrillation in the RACE study. Am J Cardiol. 2004 Dec 15;94(12):1486-90.

57. Potpara TS, Stankovic GR, Beleslin BD, Polovina MM, Marinkovic JM, Ostojic $\mathrm{MC}$, et al. A 12-year follow-up study of patients with newly-diagnosed lone atrial fibrillation: Implications of arrhythmia progression on prognosis: The Belgrade Atrial Fibrillation Study. Chest. 2011 May 26.

58. Fuster V, Ryden LE, Cannom DS, Crijns HJ, Curtis AB, Ellenbogen KA, et al. ACC/AHA/ESC 2006 guidelines for the management of patients with atrial fibrillation: full text: a report of the American College of Cardiology/American Heart Association Task Force on practice guidelines and the European Society of Cardiology Committee for Practice Guidelines (Writing Committee to Revise the 2001 guidelines for the management of patients with atrial fibrillation) developed in collaboration with the European Heart Rhythm Association and the Heart Rhythm Society. Europace. 2006 Sep;8(9):651-745.

59. Brugada R, Tapscott T, Czernuszewicz GZ, Marian AJ, Iglesias A, Mont L, et al. Identification of a genetic locus for familial atrial fibrillation. N Engl J Med. 1997 Mar 27;336(13):905-11.

60. Dublin S, French B, Glazer NL, Wiggins KL, Lumley T, Psaty BM, et al. Risk of new-onset atrial fibrillation in relation to body mass index. Arch Intern Med. 2006 Nov 27;166(21):2322-8.

61. Dublin S, Glazer NL, Smith NL, Psaty BM, Lumley T, Wiggins KL, et al. Diabetes mellitus, glycemic control, and risk of atrial fibrillation. J Gen Intern Med. 2010 Aug;25(8):853-8.

62. Gami AS, Hodge DO, Herges RM, Olson EJ, Nykodym J, Kara T, et al. Obstructive sleep apnea, obesity, and the risk of incident atrial fibrillation. J Am Coll Cardiol. 2007 Feb 6;49(5):565-71.

63. Porthan KM, Melin JH, Kupila JT, Venho KK, Partinen MM. Prevalence of sleep apnea syndrome in lone atrial fibrillation: a case-control study. Chest. 2004 Mar;125(3):879-85.

64. Roberts JD, Gollob MH. Impact of genetic discoveries on the classification of lone atrial fibrillation. J Am Coll Cardiol. 2010 Feb 23;55(8):705-12.

65. Rosiak M, Dziuba M, Chudzik M, Cygankiewicz I, Bartczak K, Drozdz J, et al. Risk factors for atrial fibrillation: Not always severe heart disease, not always so 'lonely'. Cardiology journal. 2010;17(5):437-42.

66. Schoonderwoerd BA, Smit MD, Pen L, Van Gelder IC. New risk factors for atrial fibrillation: causes of 'not-so-lone atrial fibrillation'. Europace. 2008 May 13. 
CHAPTER I | INTRODUCTION 
CHAPTER II ATRIAL TISSUE DOPPLER IMAGING FOR
PREDICTION OF NEW ONSET
ATRIAL FIBRILLATION

Cees B. de Vos ${ }^{1}$, Bob Weijs ${ }^{1}$, Harry J.G.M. Crijns ${ }^{1}$, Emile C. Cheriex ${ }^{1}$, A Palmans ${ }^{1}$, J Habets ${ }^{1}$, Martin H. Prins ${ }^{1}$, Ron Pisters ${ }^{1}$, R Nieuwlaat ${ }^{1}$, and Robert G. Tieleman ${ }^{2}$

${ }^{1}$ Department of Cardiology, Maastricht University Medical Centre, Maastricht, The Netherlands; and ${ }^{2}$ Martini Hospital, Groningen, The Netherlands

Heart. 2009; 95(10):835-40 


\section{ABSTRACT}

Background: The total atrial conduction time (TACT) is an independent predictor of atrial fibrillation (AF). A new transthoracic echocardiographic tool to determine TACT by tissue Doppler imaging (PA-TDI (the time from the initiation of the $P$ wave on the ECG (lead II) to the $A^{\prime}$ wave on the lateral left atrial tissue Doppler tracing)) has been developed recently.

Objective: To test the hypothesis that measurement of PA-TDI enables prediction of new-onset AF.

Methods: 249 Patients without a history of AF were studied. All patients underwent an echocardiogram and the PA-TDI interval was measured. Patient characteristics and rhythm at follow-up were recorded.

Results: During a mean (SD) follow-up of 680 (290) days, 15 patients (6\%) developed new-onset AF. These patients had a longer PA-TDI interval than patients who remained in sinus rhythm (172 (25) ms vs. 150 (20) ms, p=0.001). Furthermore, the patients developing AF were older, more often had a history of heart failure or chronic obstructive pulmonary disease, more often used a blockers, had enlarged left atria and more frequently mitral incompetence on the echocardiogram. After adjusting for potential confounders, Cox regression showed that PA-TDI was independently associated with new-onset $\mathrm{AF}(\mathrm{OR}=1.375 ; 95 \% \mathrm{Cl} 1.037$ to $1.823 ; \mathrm{p}=0.027)$. The 2-year incidence of $A F$ was $33 \%$ in patients with a PA-TDI interval $>190 \mathrm{~ms}$ versus $0 \%$ in patients with a PA-TDI interval $<130 \mathrm{~ms}(\mathrm{p}=0.002)$.

Conclusions: A prolonged PA-TDI interval may predict the development of new-onset AF. This measure may be used to identify patients at risk in future strategies to prevent the development or complications of AF. 
CHAPTER II | TISSUE DOPPLER IMAGING TO PREDICT AF

\section{INTRODUCTION}

Atrial fibrillation (AF) is the most common sustained cardiac arrhythmia and may result in life-threatening complications such as stroke and heart failure. ${ }^{1}$ Unfortunately, treatment often comes too late-for example, when stroke is the first manifestation of AF. ${ }^{2}$ Therefore, prediction and prevention of AF and its complications is essential. There has been an increase in the number of admissions to hospital for AF in recent years, demonstrating the need for primary prevention of new-onset AF. ${ }^{3}$ To enable primary prevention strategies, we have to identify which patients are at increased risk for the development of AF. Observational population studies resulted in the discovery of clinical and echocardiographic parameters that are associated with the development of $\mathrm{AF}^{4-7}$ However, the currently available risk stratification parameters have limited predictive value in the individual patient. ${ }^{8}$

Age or underlying heart disease may result in atrial dilatation or a depressed intra-atrial conduction. ${ }^{9-11}$ This will lead to an increased total atrial conduction time (TACT) and facilitate AF. Recently, we validated a new non-invasive echocardiographic method to determine the TACT, using transthoracic tissue Doppler imaging of the atria (the PA-TDI interval). ${ }^{12}$ We demonstrated that PA-TDI is an easy, fast and reliable method to estimate the TACT. This study was designed to test the hypothesis that noninvasive measurement of the TACT facilitates the identification of subjects at risk for development of AF in patients with no prior history of atrial arrhythmias.

\section{METHODS}

We prospectively studied a total of 249 consecutive patients in sinus rhythm. We included all consecutive patients from the outpatient clinic of one of our cardiologists (RGT) who were referred for a standard echocardiographic examination for various cardiovascular diseases. Patient-informed consent was obtained and the study was approved by our institutional review board. Exclusion criteria were a history of AF, atrial flutter, atrial tachycardia, age $<18$ years, previous pacemaker implantation or an implantable cardioverter-defibrillator.

\section{The echocardiogram}

An independent observer blinded for the history of the patients performed the echocardiogram while subjects were lying in the left lateral decubitus position. All patients underwent standard two-dimensional transthoracic echocardiography, including M mode, and Doppler echocardiography (Sonos 5500, Philips Medical Systems, Andover, Massachusetts, USA). Recordings were made in the standard projections (subcostal, parasternal long-axis, parasternal short-axis, four-chamber apical long-axis and two-chamber apical long-axis views). Aortic diameter, atrial volumes, ventricular wall thickness, left ventricular dimensions, left ventricular mass, left ventricular ejection fraction, caval vein width and collapse index, valve disorders, wall motion disorders and Doppler flow patterns of the mitral valve (E wave, $A$ wave) 
were determined in all patients according to the recommendations of the American Society of Echocardiography. Additionally, we determined the TACT with tissue Doppler imaging as described previously. ${ }^{12}$ In the apical four-chamber view, the pulsed-wave tissue Doppler sample was placed on the lateral wall of the left atrium just above the mitral annulus. The PA-TDI interval, defined as the time-interval from initiation of the electrocardiographic P wave recorded by the echo machine (lead II) to the peak of the $A^{\prime}$ wave of the atrial tissue Doppler tracing (fig 1), was measured in three cardiac cycles and averaged.

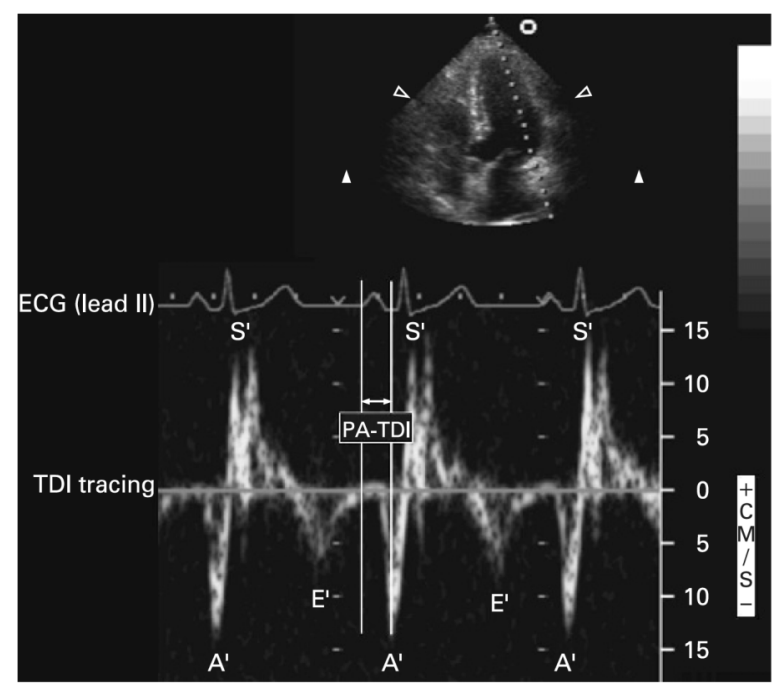

FIGURE 1 - Example measurement of the PA-TDI interval

\section{The electrocardiogram}

At the time of inclusion, all patients underwent 12-lead ECG recording obtained in the supine position using an ECG system (MAC 5000, Marquette Medical Systems, Milwaukee, Wisconsin, USA). Previous studies have shown that the surface ECG Pwave duration, also an estimate of the TACT, is a predictor for new-onset AF after cardiac surgery. ${ }^{13}$ Therefore, an independent observer who was unaware of the results from the other examinations or the patients' history did a manual P-wave duration measurement. The onset of the $P$ wave was defined as the junction between the isoelectric line and the beginning of the P-wave deflection, and the offset of the P wave as the junction between the end of the P-wave deflection and the isoelectric line. To improve accuracy, a digital caliper and magnifying glass were used to perform the measurements.

\section{Data collection}

Patient characteristics, medical history and medication at the time of echocardiography were collected. Furthermore, we verified the absence of atrial arrhythmias by examining the patient charts and our electronic medical records and an 
electronic ECG database, which stores all ECGs and Holter recordings performed in our hospital. In all patients a virtual $\mathrm{CHADS}_{2}$ score was calculated. This acronym stands for Congestive heart failure, Hypertension, Age (75 years and older), Diabetes mellitus and a history of Stroke/transient ischaemic attack ( 2 points). This scoring system allows instant classification of the relative thromboembolic risk in patients with AF, and is incorporated in the latest guidelines on the management of $A F .{ }^{14}$ During follow-up, patients were seen at 6-month intervals in our outpatient department. During every visit, symptoms of AF were thoroughly verified and an ECG was obtained. When in doubt about the rhythm status of the patient, a Holter recording was performed. As soon as patients were admitted to the first aid department with cardiac complaints, the rhythm was verified by one of our cardiologists and the presence of AF was recorded in the digital charts of our cardiology department. Since the University Hospital Maastricht has a strong regional community care function, none of the patients were lost to follow-up.

\section{Statistical analysis}

Data analysis was performed with SPSS statistical software V.15.0. Continuous variables are reported as mean (SD) and categorical variables as observed number of patients (percentage). Since our survival data were partly censored, we performed a Cox regression univariate analysis when comparing patients who developed AF during follow-up with patients who did not. When comparing 2-year incidences of AF we used $\chi^{2}$ to evaluate three or more groups and Fisher's exact test when comparing two groups. Given the limited number of events, we first determined an odds ratio (OR) for PA-TDI alone to predict AF during follow-up using Cox regression analysis. Later, we adjusted the OR for potential confounders. All parameters showing a significant univariate relation with the occurrence of new-onset AF during follow-up were included in a Cox regression model (heart failure in history, mitral incompetence on echo, chronic obstructive pulmonary disease in history, $\alpha$-blocker use, left atrial size on echocardiogram and age). We did not include the $\mathrm{CHADS}_{2}$ score in the model since it was derived from other variables included in the model (age and history of heart failure). The predictive accuracy of PA-TDI was reported using a receiver operating characteristic (ROC) curve. All tests performed were two sided. Overall, a $p$ value of $<0.05$ was considered to be significant.

\section{RESULTS}

We included 249 patients in our study. The PA-TDI interval ranged between $103 \mathrm{~ms}$ and 223 ms. The mean (SD) age of our cohort was 62 (13) years. Many patients had underlying cardiovascular disease. The most common disease was hypertension, which occurred in $61 \%$ of our patients. Table 1 presents the other baseline and electrocardiographic characteristics of our cohort. The body mass index and underlying heart disease of our cohort were in line with previous large cohort studies evaluating echocardiographic predictors of AF. ${ }^{715}$ Therefore, we believe that our population is representative of general cardiac outpatient clinics. 
TABLE 1 - Patient characteristics

\begin{tabular}{|c|c|c|c|}
\hline Characteristics & $\begin{array}{l}\text { No AF during } \\
\text { follow-up } \\
(n=234)\end{array}$ & $\begin{array}{l}\text { AF during follow-up } \\
\qquad(n=15)\end{array}$ & $P$ value \\
\hline Age (years) & $61(13)$ & $70(13)$ & 0.009 \\
\hline Female, n (\%) & $127(54)$ & $8(53)$ & 0.987 \\
\hline Body mass index $\left(\mathrm{kg} / \mathrm{m}^{2}\right)$ & $27(4)$ & $27(4)$ & 0.755 \\
\hline \multicolumn{4}{|l|}{ Underlying heart disease } \\
\hline Hypertension, n (\%) & $142(61)$ & $11(73)$ & 0.643 \\
\hline Coronary artery disease, n (\%) & $24(10)$ & $2(13)$ & 0.527 \\
\hline Diabetes mellitus, n (\%) & $27(12)$ & $2(13)$ & 0.686 \\
\hline Thromboembolic events, n (\%) & $9(4)$ & 0 & 0.633 \\
\hline Valve disease, $\mathrm{n}(\%)$ & 44 (19) & $5(33)$ & 0.091 \\
\hline Heart failure, n (\%) & $17(7)$ & $5(33)$ & 0.007 \\
\hline Stroke/TIA, n (\%) & $44(19)$ & $3(20)$ & 0.534 \\
\hline COPD, n (\%) & $13(6)$ & $4(27)$ & 0.014 \\
\hline Thyroid disease, n (\%) & $11(5)$ & $1(7)$ & 0.662 \\
\hline Virtual $\mathrm{CHADS}_{2}$ score & $1.32(1.17)$ & $2.21(1.72)$ & 0.007 \\
\hline Virtual $\mathrm{CHADS}_{2}$ score $^{\#}$ & $1(5)$ & $2(6)$ & 0.007 \\
\hline \multicolumn{4}{|l|}{ Medication } \\
\hline Oral anticoagulation, $\mathrm{n}(\%)$ & $16(7)$ & $2(13)$ & 0.279 \\
\hline Aspirin, n (\%) & $58(25)$ & $5(33)$ & 0.551 \\
\hline Sotalol, n (\%) & $8(3)$ & $1(7)$ & 0.562 \\
\hline Beta-blocker, n (\%) & $82(36)$ & $8(53)$ & 0.204 \\
\hline Verapamil, n (\%) & $13(6)$ & $1(7)$ & 0.776 \\
\hline Digitalis, n (\%) & $4(2)$ & $1(7)$ & 0.115 \\
\hline Nitrates, n (\%) & $18(8)$ & 0 & 0.520 \\
\hline ACE-inhibitor, $\mathrm{n}(\%)$ & $52(23)$ & $5(33)$ & 0.902 \\
\hline ARB, $n(\%)$ & $51(22)$ & $2(13)$ & 0.487 \\
\hline Diuretics, n (\%) & $52(23)$ & $6(40)$ & 0.256 \\
\hline Statins, n (\%) & $64(28)$ & $5(33)$ & 0.637 \\
\hline $\mathrm{D}-\mathrm{CCB}, \mathrm{n}(\%)$ & 44 (19) & $4(27)$ & 0.827 \\
\hline Alphablocker, n (\%) & $4(2)$ & $2(13)$ & 0.004 \\
\hline Number of CV drugs & $1.92(1.69)$ & $2.60(2.29)$ & 0.272 \\
\hline Nr of CV drugs ${ }^{\#}$ & $2(7)$ & $2(7)$ & 0.272 \\
\hline \multicolumn{4}{|l|}{ Electrocardiogram } \\
\hline Heart rate (bpm) & $71(14)$ & $71(11)$ & 0.977 \\
\hline P-wave duration (ms) & $89(21)$ & $97(33)$ & 0.669 \\
\hline$P Q$ interval (ms) & $157(27)$ & $170(53)$ & 0.066 \\
\hline QRS duration (ms) & $93(17)$ & $99(22)$ & 0.112 \\
\hline \multicolumn{4}{|l|}{ Tissue Doppler imaging } \\
\hline PA-TDI (ms) & $150(20)$ & $172(25)$ & 0.001 \\
\hline Maximal A' wave velocity $(\mathrm{cm} / \mathrm{s})$ & $16(5)$ & $14(4)$ & 0.215 \\
\hline \multicolumn{4}{|l|}{ Dimensions } \\
\hline Aorta diameter (mm) & $34(4)$ & $34(4)$ & 0.806 \\
\hline Left atrial dimension (mm) & $40(5)$ & $43(7)$ & 0.018 \\
\hline LV end-diastolic diameter (mm) & $49(6)$ & $49(7)$ & 0.775 \\
\hline LV end-systolic diameter (mm) & $33(7)$ & $35(10)$ & 0.223 \\
\hline Interventricular septum width (mm) & $9(1)$ & $10(2)$ & 0.689 \\
\hline Posterior wall width (mm) & $9(1)$ & $9(2)$ & 0.894 \\
\hline Left ventricular mass $(\mathrm{g})$ & $196(51)$ & $203(64)$ & 0.586 \\
\hline End-diastolic volume (ml) & $112(35)$ & 103 (19) & 0.282 \\
\hline End-systolic volume (ml) & $45(29)$ & $39(9)$ & 0.370 \\
\hline Caval vein $(\mathrm{mm})$ & $17(4)$ & $18(5)$ & 0.985 \\
\hline
\end{tabular}


CHAPTER II | TISSUE DOPPLER IMAGING TO PREDICT AF

\begin{tabular}{lccc}
\hline TABLE 1 Continued & $\begin{array}{c}\text { No AF during } \\
\text { follow-up } \\
\text { (n=234) }\end{array}$ & $\begin{array}{c}\text { AF during follow-up } \\
\text { (n=15) }\end{array}$ & P value \\
\hline Characteristics & & & \\
\hline Left ventricular function & $61(9)$ & $56(14)$ & 0.095 \\
LV ejection fraction (\%) & $38(16)$ & $4(27)$ & 0.480 \\
Hypokinesia, $n$ (\%) & & & \\
Mitral valve Doppler assessments & $74(18)$ & $78(15)$ & 0.410 \\
Maximal E-wave velocity (cm/s) & $379(150)$ & $453(216)$ & 0.301 \\
E-wave deceleration slope (m/s $\left.{ }^{2}\right)$ & $204(50)$ & $185(60)$ & 0.524 \\
E-wave deceleration time (ms) & $82(43)$ & $77(19)$ & 0.882 \\
Maximal A-wave velocity (cm/s) & $0.97(0.33)$ & $1.03(0.22)$ & 0.870 \\
E/A ratio & & & 0.749 \\
Valvular disorders & $12(5)$ & $1(7)$ & 0.009 \\
Aortic incompetence & $13(6)$ & $4(27)$ & 0.118 \\
Mitral incompetence & $12(5)$ & $2(13)$ & 0.421 \\
Tricuspid incompetence & $9(4)$ & $1(7)$ & 0.868 \\
Aortic stenosis & $1(1)$ & 0 & 0.126 \\
Mitral valve stenosis & $30(6)$ & $33(11)$ & \\
Systolic RV pressure (mmHg) &
\end{tabular}

Results are shown as mean (SD) unless stated otherwise; "Median (range); AF, atrial fibrillation; COPD, chronic obstructive pulmonary disease; ACE, angiotensin-converting enzyme inhibitor; ARB, Angiotensin-II receptor blocker; D-CCB, dihydropyridine calcium channel blocker; CV, cardiovascular; PA-TDI, the time from the initiation of the P wave on the ECG (lead II) to the $A^{\prime}$ wave on the lateral left atrial tissue Doppler tracing.

During a mean (SD) follow-up of 680 (290) days, 15 (6\%) patients developed new-onset AF. Of all patients developing AF, two (13\%) had one episode of paroxysmal AF, 12 $(80 \%)$ had recurrent episodes of paroxysmal AF and one (7\%) had permanent AF. The patients who developed AF during follow-up were older (70 (13) years vs. 61 (13) years, $p=0.01$ ) and more often had a history of heart failure and chronic obstructive pulmonary disease. $\alpha$-Blockers were used more frequently in the patients who developed AF during the follow-up period. As a result, the mean $\mathrm{CHADS}_{2}$ score was higher in these patients. No other differences were seen in baseline characteristics between the patients who demonstrated AF during follow-up and those who did not. The echocardiogram of the patients who developed AF showed a longer mean (SD) PATDI interval at baseline than patients who remained in sinus rhythm (172 (25) ms vs. 150 (20) ms, $p=0.001$ ). The standard echocardiographic examination demonstrated enlarged left atrial size and more mitral incompetence in the patient with new-onset AF during follow-up (table 1).

\section{Prediction of atrial fibrillation during follow-up}

Cox regression analysis showed that the echocardiographic PA-TDI interval was associated with the development of AF during follow-up (per $10 \mathrm{~ms} ; \mathrm{OR}=1.520 ; 95 \% \mathrm{Cl}$ 1.195 to $1.933 ; p=0.001)$. When adjusting for possible confounders as defined in the statistical section, we found an OR of 1.375 (95\% Cl 1.037 to $1.823 ; p=0.027$ ) (table 2). Figure 2 shows the ROC curve to discriminate between people who will or will not develop new-onset AF during follow-up based on the PA-TDI. The area under the curve was $0.740(95 \% \mathrm{Cl} 0.608$ to $0.871 ; \mathrm{p}=0.002)$. Using the ROC curve of PA-TDI, we 
determined the optimal cut-off value for PA-TDI to predict the occurrence of atrial fibrillation: $165 \mathrm{~ms}$ (sensitivity 67\%; specificity 77\%). A lower cut-off point (i.e., $150 \mathrm{~ms}$ ) would result in a higher sensitivity (80\%) and a lower specificity $(50 \%)$, implying that many patients would be wrongly identified as patients developing new-onset AF. The Kaplan-Meier 2-year cumulative risk for the development of AF was significantly increased for patients with a baseline PA-TDI interval $>165 \mathrm{~ms}$ (fig 3). We divided the patients into four groups according to the PATDI interval measured at baseline (for each $30 \mathrm{~ms}$ increase). The 2-year incidence of AF was 33\% in patients with a PA-TDI interval $>190 \mathrm{~ms}$ versus $0 \%$ in patients with a PA-TDI interval $<130 \mathrm{~ms}(p=0.002)$ (fig 4).

TABLE 2 - Cox regression analysis: risk of new-onset AF during follow-up in patients without a history of AF corrected for possible confounders

\begin{tabular}{lcc}
\hline Confounders & OR $(\mathbf{9 5 \%} \mathbf{C l})$ & $\boldsymbol{P}$ value \\
\hline PA-TDI (per 10 ms increase) & $1.375(1.037-1.823)$ & 0.027 \\
Heart failure in history & $1.929(0.400-9.307)$ & 0.413 \\
Mitral incompetence on echo & $2.866(0.666-12.342)$ & 0.158 \\
COPD in history & $3.383(0.827-13.848)$ & 0.090 \\
Alphablocker use & $6.800(0.933-49.568)$ & 0.059 \\
Left atrial size (per $\mathrm{mm})$ & $0.991(0.880-1.115)$ & 0.875 \\
Age (per year) & $1.016(0.956-1.081)$ & 0.606
\end{tabular}

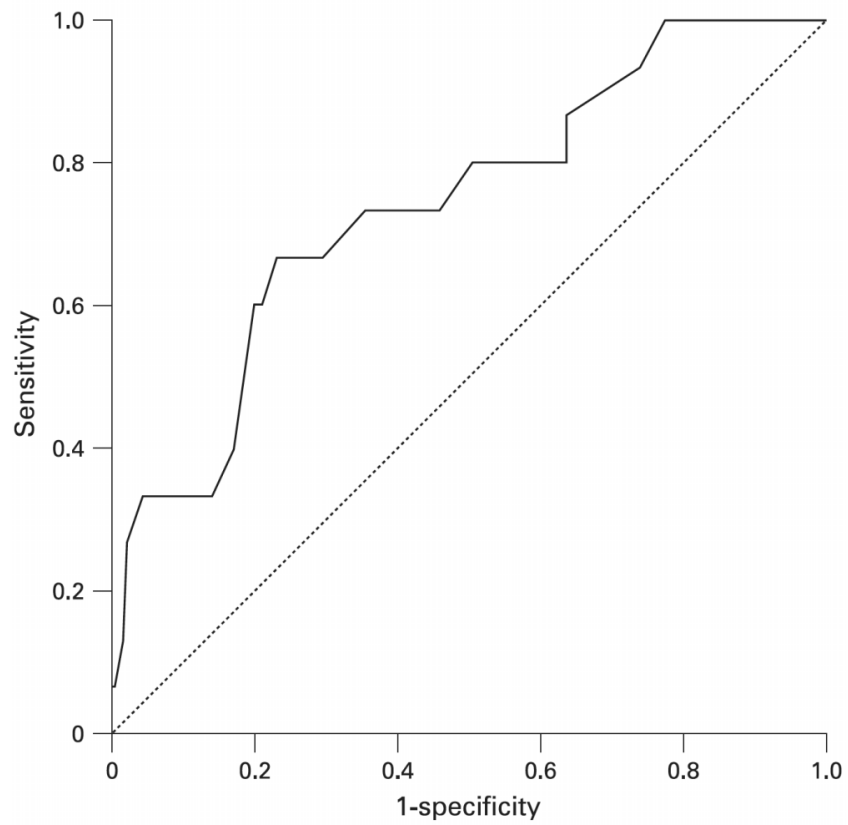

FIGURE 2 - ROC-curve of PA-TDI to predict the development of atrial fibrillation 
CHAPTER II | TISSUE DOPPLER IMAGING TO PREDICT AF

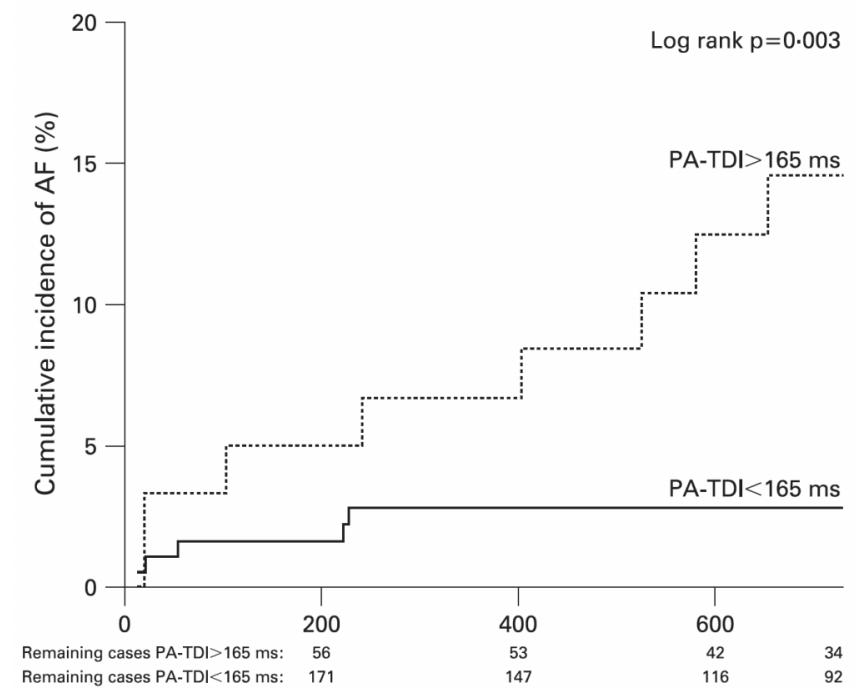

FIGURE 3 - Kaplan-Meier cumulative incidence of the first occurrence of atrial fibrillation

\section{DISCUSSION}

This study demonstrates that the TACT as determined by tissue Doppler imaging may help to identify patients with a substrate vulnerable for AF. After correcting for possible confounders, the PA-TDI interval remains the most important predictor of new-onset AF. The longer the PA-TDI interval, the higher the incidence of new-onset AF. In fact, each $10 \mathrm{~ms}$ increase of PA-TDI is associated with an increased risk of developing $A F$ of $37-52 \%$ in the next 2 years. Therefore, the PATDI interval may become a useful measure for risk stratification to improve efficiency of primary prevention of AF.

\section{Importance of predicting atrial fibrillation}

AF can result in life-threatening complications such as stroke and heart failure. Therefore, the application of adequate individual treatment is essential. ${ }^{16,17}$ Unfortunately, many patients have silent $A F{ }^{18}$ As a result, treatment may come too late. In this study, the virtual $\mathrm{CHADS}_{2}$ score in the group of patients who developed AF indicates that most of our patients do have an indication for oral anticoagulation once they develop AF. Adequate administration of oral anticoagulation will reduce the risk of thromboembolic complications by $60 \%{ }^{19}$ Therefore, one could imagine that prophylactic anticoagulation could be applied in patients with a high $\mathrm{CHADS}_{2}$ score and a long PA-TDI interval. However, this hypothesis needs to be confirmed in prospective randomized trials. Recent studies demonstrated that new-onset AF and associated stroke were significantly reduced by losartan. ${ }^{20,21}$ In our study, these "upstream" drugs did not prevent AF. However, drug treatment was not randomized, and the trend 
towards an increased number of cardiovascular drugs may in fact reflect the presence of more severe underlying heart disease.

In our study, we demonstrate that a short PA-TDI interval ( $<130 \mathrm{~ms})$ seems to prevent patients from developing AF. Therefore, one could hypothesize that these patients are not candidates for primary prevention. Patients with a PA-TDI interval $>165 \mathrm{~ms}$ have a reasonable chance of developing AF and could be candidates for primary prevention using "upstream" cardiovascular drugs. A PA-TDI interval >190 ms makes patients very vulnerable for the development of AF. These patients could be treated with prophylactic anticoagulation, especially when they have a high $\mathrm{CHADS}_{2}$ score.

In summary, the use of a simple echocardiographic measure enhances identification of patients at increased risk for AF, which may make primary prevention more cost effective by reducing the numbers needed to treat.

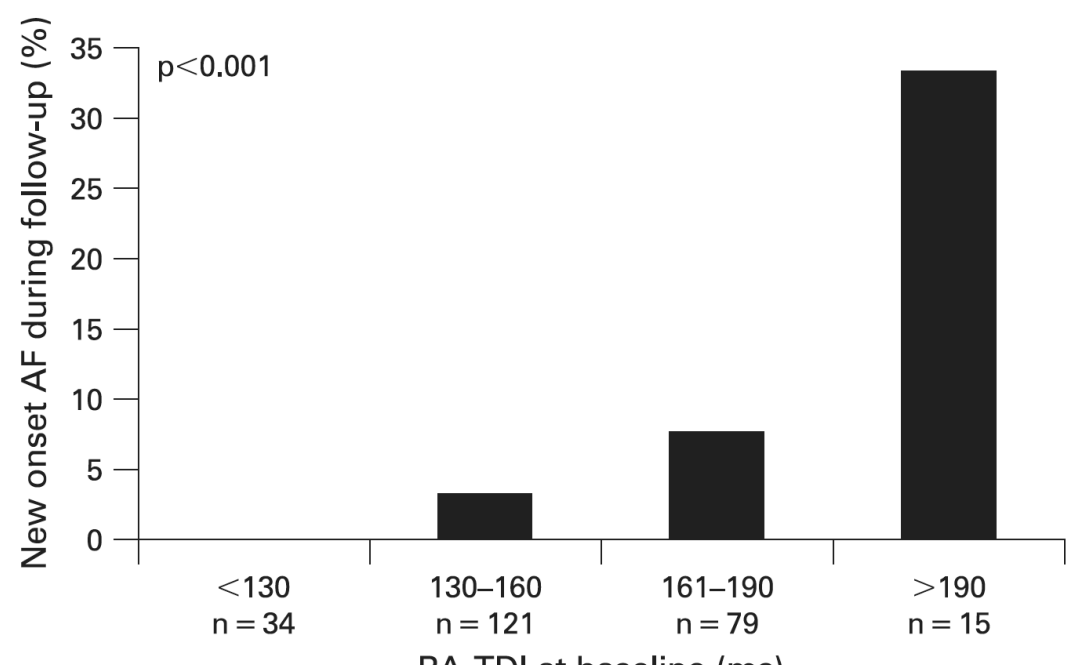

FIGURE 4 - 2-year incidence of new-onset atrial fibrillation (AF) in patients classified according to the PA-TDI interval measured at baseline

\section{Classic predictors of atrial fibrillation}

Observational population studies such as the Framingham Heart study, the Manitoba Follow-up study and the Cardiovascular Health study reported several clinical and echocardiographic parameters that are associated with the development of new-onset $\mathrm{AF}^{4-7,22,23}$ The clinical factors associated with new-onset AF are higher age, male sex, the presence of diabetes, hypertension, congestive heart failure, valve disease and coronary artery disease. Left atrial enlargement, increased left ventricular wall thickness, left ventricular diastolic dysfunction and a reduced left ventricular fractional shortening are predictive echocardiographic parameters for new-onset $\mathrm{AF}^{15,24}$ 
However, these currently available risk stratification measures have limited predictive value in the individual patient. ${ }^{8}$ This study showed that the PA-TDI interval outperformed all the previously known predictors of AF. This is possibly because the pathophysiological mechanisms by which ageing and the above-mentioned conditions leading to AF have a final common pathway, which result in prolongation of the TACT. ${ }^{9}$

\section{Role of the total atrial conduction time in the prediction of atrial fibrillation}

The multiple wavelet re-entry theory postulated the existence of multiple spatially discrete activation fronts (wavelets) resulting in re-entry at changing locations as the basis for AF. ${ }^{25,26}$ A decreased conduction velocity, leads to a shorter wavelength of the reentrant wave fronts. An increased atrial size can harbour more wave fronts of a certain size at the same time. Both will favour AF. An increased TACT, which is the time elapsed between the initiation of atrial depolarisation and the last depolarisation of the same activation front, ${ }^{27}$ incorporates both conduction slowing and atrial dilatation, and may therefore reflect the existence of a substrate vulnerable for AF. Determination of the TACT may therefore be better than the classical predictors of AF since it might not only demonstrate the presence of underlying disease but also its severity. P-wave duration on the 12-lead ECG and PA-mv using the mitral Doppler flow signal $^{28,29}$ provide estimates of the TACT. However, PA-TDI determined by transthoracic tissue Doppler imaging had the best correlation with the "gold standard" (SA-ECG P-wave duration). ${ }^{12}$ Previous studies presented a similar parameter measuring the interval between the onset of the $P$ wave on the ECG till the onset of the $A^{\prime}$ wave of the left atrial lateral wall instead of the peak of the $A^{\prime}$ wave (atrial electromechanical interval or AEMI). ${ }^{30,31}$ Post hoc analysis of our data showed similar results using both methods (data not shown).

\section{Study limitations}

The PA-TDI interval overestimates the total atrial activation time since it includes both the time required for the propagation of impulses from the sinus node area to the left atrium, and the time required for the electromechanical coupling in the left atrium. However, in a recent validation study, this electromechanical coupling appeared to be constant. ${ }^{12}$ Furthermore, there seems to be a minor delay in ECG processing on all echo machines. In our study, this delay amounts to a maximum of $5 \mathrm{~ms}$ (unpublished technical information by Philips Medical Systems, Andover, Massachusetts, USA). Fortunately, this delay is consistent and therefore unlikely to affect our results.

This study was of limited size. As a result, the exact cut-off values need to be confirmed in a larger study with a longer follow-up. This would allow a study of the contribution of PA-TDI to a prediction model including "classical" predictors of newonset AF. Nevertheless, it seems reasonable to state that a larger PA-TDI interval is related to an increased incidence of AF.

All our patients were included in a cardiology outpatient clinic. As a result, the population we studied may not be representative of the general population. On the other hand, PA-TDI is intended for patients with cardiovascular diseases. The investigator who included the patients (RGT) is a general cardiologist with a special 
interest in electrophysiology. For that reason, one might hypothesize that this led to a selection bias. On the other hand, all patients with a history of atrial arrhythmias, a pacemaker or an implantable cardioverter-defibrillator were excluded from our study and the patient characteristics of our population are representative of a general cardiac outpatient clinic.

Finally, AF incidence was derived from partly symptom driven ECG and Holter recordings. This may have led to an underestimation of the AF incidence, since a large number of AF episodes are known to be asymptomatic.

\section{CONCLUSIONS}

The total atrial conduction time as determined by tissue Doppler imaging is a feasible, non-invasive tool for the identification of patients with a substrate vulnerable for AF. A long PA-TDI interval is associated with the development of new-onset AF. Therefore, PA-TDI has the potential to become a valuable measure for risk stratification to enable primary prevention of AF and its complications.

The exact cut-off values found in this study need to be confirmed in a second study. Studying the role of PA-TDI to predict new-onset AF in a general population would require a large number of patients and a long follow-up owing to the relatively low incidence of $A F$ in this group. Alternative study designs (a selected study group) should result in a more feasible study.

\section{Funding:}

Department of Cardiology, University Hospital Maastricht, Maastricht, The Netherlands

Competing interests: None.

\section{Ethics approval:}

Ethics committee approval from the University Hospital Maastricht. 
CHAPTER II | TISSUE DOPPLER IMAGING TO PREDICT AF

\section{REFERENCES}

1. Chugh SS, Blackshear JL, Shen WK, et al. Epidemiology and natural history of atrial fibrillation: clinical implications. J Am Coll Cardiol 2001;37:371-8.

2. Wolf PA, Kannel WB, McGee DL, et al. Duration of atrial fibrillation and imminence of stroke: the Framingham study. Stroke 1983;14:664-7.

3. Wattigney WA, Mensah GA, Croft JB. Increasing trends in hospitalization for atrial fibrillation in the United States, 1985 through 1999: implications for primary prevention. Circulation 2003;108:711-6.

4. Benjamin EJ, Levy D, Vaziri SM, et al. Independent risk factors for atrial fibrillation in a population-based cohort. The Framingham Heart Study. JAMA 1994;271:840-4.

5. Kannel WB, Wolf PA, Benjamin EJ, et al. Prevalence, incidence, prognosis, and predisposing conditions for atrial fibrillation: population-based estimates. Am J Cardiol 1998;82:2N-9N.

6. Krahn AD, Manfreda J, Tate RB, et al. The natural history of atrial fibrillation: incidence, risk factors, and prognosis in the Manitoba Follow-Up Study. Am J Med 1995;98:476-84.

7. Vaziri SM, Larson MG, Benjamin EJ, et al. Echocardiographic predictors of nonrheumatic atrial fibrillation. The Framingham Heart Study. Circulation 1994;89:724-30.

8. Furberg CD, Psaty BM, Manolio TA, et al. Prevalence of atrial fibrillation in elderly subjects (the Cardiovascular Health Study). Am J Cardiol 1994;74:23641.

9. Simpson RJ Jr, Foster JR, Gettes LS. Atrial excitability and conduction in patients with interatrial conduction defects. Am J Cardiol 1982;50:1331-7.

10. Omori I, Inoue D, Shirayama T, et al. Prolonged atrial activity due to delayed conduction in the atrium of patients with paroxysmal atrial fibrillation. Heart Vessels 1991;6:224-8.

11. Kuhlkamp V, Haasis R, Seipel L. Atrial vulnerability and electrophysiology determined in patients with and without paroxysmal atrial fibrillation. Pacing Clin Electrophysiol 1992;15:71-80.

12. Merckx KL, De Vos CB, Palmans A, et al. Atrial activation time determined by transthoracic Doppler tissue imaging can be used as an estimate of the total duration of atrial electrical activation. J Am Soc Echocardiogr 2005;18:940-4.

13. Buxton $\mathrm{AE}$, Josephson $\mathrm{ME}$. The role of $\mathrm{P}$ wave duration as a predictor of postoperative atrial arrhythmias. Chest 1981;80:68-73.

14. Gage BF, Waterman AD, Shannon W, et al. Validation of clinical classification schemes for predicting stroke: results from the National Registry of Atrial Fibrillation. JAMA 2001;285:2864-70.

15. Tsang TS, Barnes ME, Bailey KR, et al. Left atrial volume: important risk marker of incident atrial fibrillation in 1655 older men and women. Mayo Clin Proc 2001;76:467-75. 
16. Wyse DG, Waldo AL, DiMarco JP, et al. A comparison of rate control and rhythm control in patients with atrial fibrillation. $N$ Engl J Med 2002;347:1825-33.

17. Van Gelder IC, Hagens VE, Bosker HA, et al. A comparison of rate control and rhythm control in patients with recurrent persistent atrial fibrillation. $\mathrm{N}$ Engl J Med 2002;347:1834-40.

18. Nieuwlaat R, Capucci A, Camm AJ, et al. Atrial fibrillation management: a prospective survey in ESC member countries: the Euro Heart Survey on Atrial Fibrillation. Eur Heart J 2005;26:2422-34.

19. Hart RG, Benavente O, McBride R, et al. Antithrombotic therapy to prevent stroke in patients with atrial fibrillation: a meta-analysis. Ann Intern Med 1999;131:492-501.

20. Wachtell K, Lehto M, Gerdts E, et al. Angiotensin II receptor blockade reduces newonset atrial fibrillation and subsequent stroke compared to atenolol: the Losartan Intervention For End Point Reduction in Hypertension (LIFE) study. J Am Coll Cardiol 2005;45:712-9.

21. Okin PM, Wachtell K, Devereux RB, et al. Regression of electrocardiographic left ventricular hypertrophy and decreased incidence of new-onset atrial fibrillation in patients with hypertension. JAMA 2006;296:1242-8.

22. Brand FN, Abbott RD, Kannel WB, et al. Characteristics and prognosis of lone atrial fibrillation. 30-Year follow-up in the Framingham Study. JAMA 1985;254:3449-53.

23. Psaty BM, Manolio TA, Kuller LH, et al. Incidence of and risk factors for atrial fibrillation in older adults. Circulation 1997;96:2455-61.

24. Tsang TS, Gersh BJ, Appleton CP, et al. Left ventricular diastolic dysfunction as a predictor of the first diagnosed nonvalvular atrial fibrillation in 840 elderly men and women. J Am Coll Cardiol 2002;40:1636-44.

25. Abildskov JA. Additions to the wavelet hypothesis of cardiac fibrillation. J Cardiovasc Electrophysiol 1994;5:553-9.

26. Moe GK, Rheinboldt WC, Abildskov JA. A computer model of atrial fibrillation. Am Heart J 1964;67:200-20

27. De PR, Ho SY, Salerno-Uriarte JA, et al. Electroanatomic analysis of sinus impulse propagation in normal human atria. J Cardiovasc Electrophysiol 2002;13:1-10.

28. Fuenmayor AJ, Ramirez L, Fuenmayor AM. Validation of inter-atrial conduction time measurement by means of echo-Doppler. Arch Cardiol Mex 2002;72:125-8.

29. Kinay O, Nazli C, Ergene O, et al. Time interval from the initiation of the electrocardiographic $P$ wave to the start of left atrial appendage ejection flow: a novel method for predicting atrial fibrillation recurrence. J Am Soc Echocardiogr 2002;15:1479-84.

30. Omi W, Nagai H, Takamura $M$, et al. Doppler tissue analysis of atrial electromechanical coupling in paroxysmal atrial fibrillation. J Am Soc Echocardiogr 2005;18:39-44. 
CHAPTER II | TISSUE DOPPLER IMAGING TO PREDICT AF

31. Roshanali F, Mandegar MH, Yousefnia MA, et al. Prediction of atrial fibrillation via atrial electromechanical interval after coronary artery bypass grafting. Circulation 2007;116:2012-7. 


\section{CHAPTER III CLINICAL AND ECHOCARDIOGRAPHIC CORRELATES OF INTRA-ATRIAL CONDUCTION DELAY}

\footnotetext{
Bob Weijs ${ }^{1}$, Cees B. de $\operatorname{Vos}^{1}$, Robert G. Tieleman ${ }^{2}$, Ron Pisters ${ }^{1}$, Emile C. Cheriex ${ }^{1}$, Martin H. Prins ${ }^{1}$, and Harry J.G.M. Crijns ${ }^{1}$

${ }^{1}$ Department of Cardiology, Maastricht University Medical Centre, Maastricht, The Netherlands; and ${ }^{2}$ Martini Hospital, Groningen, The Netherlands
}

Europace. 2011;13(12):1681-1687 


\section{ABSTRACT}

Aims: The total atrial conduction time (TACT) is an important electrophysiological parameter. We developed a new transthoracic echocardiographic tool (PA-TDI). The PA-TDI interval is a reflection of the TACT. In the present study, we evaluated the clinical and echocardiographic correlates of intra-atrial conduction delay. Methods and results: We studied 427 patients without class I anti-arrhythmic agents or amiodarone. All patients underwent an echocardiogram and the PA-TDI interval was measured. Patient characteristics were recorded. The mean PA-TDI was $157 \pm 22 \mathrm{~ms}$. Multivariate linear regression analysis revealed that atrial fibrillation (AF) in history (B = 9.7; 95\% $\mathrm{Cl}$ 5.7-13.8; $\mathrm{P}<0.001)$, hypertension $(\mathrm{B}=5.5 ; 95 \% \mathrm{Cl} 1.4-9.8 ; \mathrm{P}<0.01)$, clinically relevant valve disease $(B=5.7 ; 95 \% \mathrm{Cl} 0.5-10.8 ; \mathrm{P}<0.03)$, age $(\mathrm{B}=5 ; 95 \% \mathrm{Cl}$ 3.3-6.6; $\mathrm{P}<0.001$ ), and body mass index ( $\mathrm{BMI} ; \mathrm{B}=2.6 ; 95 \% \mathrm{Cl} 0.3-4.9 ; \mathrm{P}<0.026$ ) were independently associated with the PA-TDI interval. On the echocardiogram: the aortic diameter $(\mathrm{B}=0.7 ; 95 \% \mathrm{Cl} 0.2-1.2 ; \mathrm{P}<0.009)$, left atrial dimension $(\mathrm{B}=0.9 ; 95 \% \mathrm{Cl} 0.5-$ 1.3; $\mathrm{P}<0.001)$, mitral valve $\mathrm{E}$-wave deceleration time $(\mathrm{B}=0.1 ; 95 \% \mathrm{Cl} 0.1-0.1 ; \mathrm{P}<$ $0.001)$, aortic incompetence $(B=13 ; 95 \% \mathrm{Cl} 3.3-22.6 ; \mathrm{P}<0.008)$, and mitral incompetence $(B=11 ; 95 \% \mathrm{Cl} 3.6-17.5 ; \mathrm{P}<0.003)$ were independently associated with the PA-TDI interval.

Conclusion: This study is the largest to investigate the relation between the atrial conduction time, underlying heart diseases, and echocardiographic parameters. We found that the PA-TDI was independently prolonged in patients with a history of AF, hypertension, valve disease, higher age, and a higher BMI. Signs of diastolic dysfunction, valve incompetence, and enlarged atrium or aortic root on the echocardiogram were associated with a prolonged PA-TDI. This suggests that early and aggressive treatment of hypertension, diastolic dysfunction, and obesity could prevent intra-atrial conduction delay. 


\section{INTRODUCTION}

The total atrial conduction time (TACT) is an important electrophysiological parameter that can be determined during an electrophysiological study. ${ }^{1} \mathrm{~A}$ delay of atrial conduction is strongly associated with underlying diseases affecting the atria directly or indirectly. ${ }^{2-5}$ Delayed conduction is one of the requirements for the initiation of reentry and the development of atrial fibrillation (AF). ${ }^{6}$ This implies that prevention or amelioration of atrial conduction delay may prevent the development of atrial arrhythmias such as AF. Indeed, previous studies suggest that the TACT may be a useful target of therapy. ${ }^{7-10}$ We validated a novel non-invasive echocardiographic technique using atrial tissue Doppler imaging (PA-TDI or atrial electromechanical interval) that strongly correlates with $\mathrm{TACT}^{11}$ In previous studies, we showed that a prolonged PA-TDI is the most important predictor of new-onset $A F^{11,12}$ Other investigators confirmed our findings in different populations. ${ }^{13,14} \mathrm{~A}$ prolonged PA-TDI interval is also associated with recurrence of AF after catheter ablation. ${ }^{15}$ Knowing the conditions that prolong the TACT is essential in order to develop therapies or strategies for prevention of AF. However, the clinical determinants of a prolonged TACT were never studied before in a large population. In this report, we used the echocardiographic PA-TDI to study the clinical and echocardiographic correlates of intra-atrial conduction delay in a large group of patients.

\section{METHODS}

\section{Study population}

We studied 522 outpatient clinic patients referred to the Maastricht University Medical Centre for a standard transthoracic echocardiographic examination for various medical conditions (including AF in 273 patients). Patients were included between January 2003 and February 2007. Patients were enrolled if they were 18 years or older and had sinus rhythm during the echocardiogram. Exclusion criteria were: previous pacemaker implantation, an implantable cardioverter-defibrillator and the use of class I anti-arrhythmic agents or amiodarone. The 249 patients without previous AF have been reported in a separate paper on the role of PA-TDI in the prediction of AF. ${ }^{12}$

\section{Echocardiographic examination}

The echocardiographic examination consisted of a standard two-dimensional echocardiogram, including M-mode and Doppler echocardiography (Sonos 5500, Philips Medical Systems, Andover, MA, USA) during continuous electrocardiogram (ECG) monitoring according to the recommendations as described in the American Society of Echocardiography guidelines. Left atrial volume was obtained from the single plane area-length of the apical four-chamber view, just prior to mitral valve opening, and with the patient in the left-lateral decubitus position. Additionally, we determined the PA-TDI interval. ${ }^{11}$ In the apical four chamber view, the pulsed-wave tissue Doppler sample was placed on the lateral wall of the left atrium just above the mitral annulus. The PA-TDI interval, defined as the time-interval from initiation of the 
electrocardiographic P-wave recorded by the echo machine (lead II) to the peak of the $A^{\prime}$-wave of the atrial tissue Doppler tracing (Figure 1), was measured in three cardiac cycles and averaged. The investigator who performed the echocardiographic measurements (including PA-TDI interval) was an independent observer blinded for other patient characteristics.

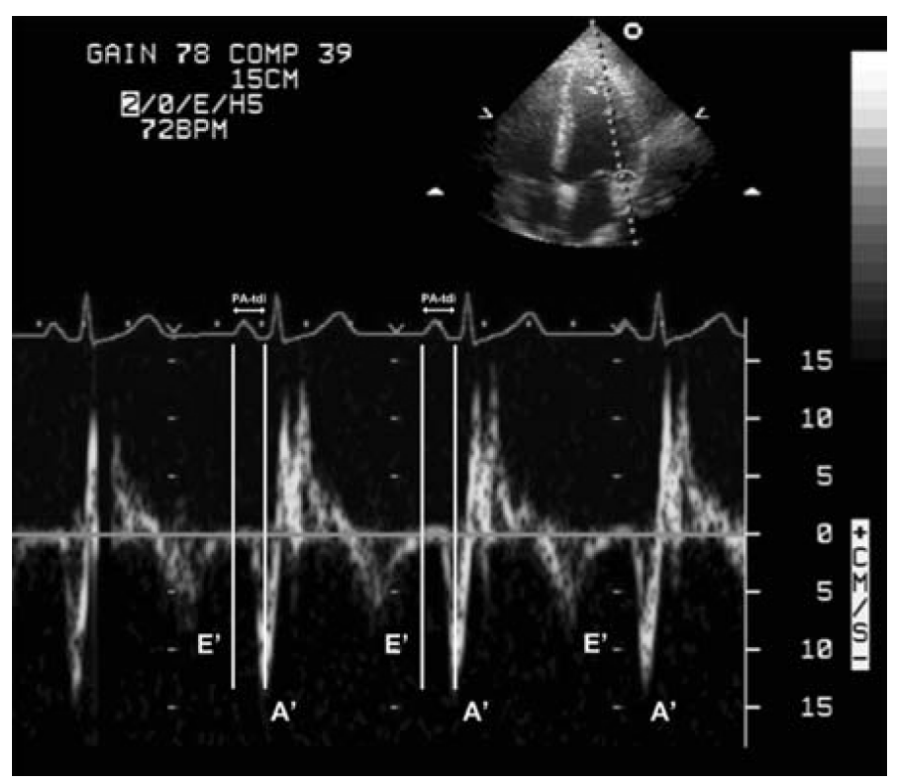

FIGURE 1 - Example of PA-TDI measurement. PA-TDI is defined as the time interval between the onset of electrocardiographic $P$ wave in lead II and the top of the $A^{\prime}$-wave on the atrial tissue Doppler velocity curve from the left atrial wall.

\section{Data collection}

Patient characteristics, including medication, (arrhythmia) history, and ECGs at the time of echocardiography were collected. Data were derived from the patient charts and electronic medical records. A diagnosis of AF in history was defined as a documented episode of AF lasting $30 \mathrm{~s}$ or more. 'Valve disease' was defined as clinically relevant valve disease at discretion of the treating physician. The study complies with the Declaration of Helsinki. Patient informed consent was obtained and the Institutional Review Board approved the study.

\section{Statistical analysis}

Continuous variables are presented as mean and standard deviation, categorical variables as observed number of patients and percentages. We used an independent $t$ test after performing Levene's test for equality of variances to compare all continuous variables. Categorical variables were tested with Fisher's exact test. Tables 1 and 2 show the $P$ values resulting from multiple uncorrected t-tests for continuous variables and Fisher's exact tests for categorical variables. This allowed us to identify parameters 
CHAPTER III | CORRELATES OF INTRA-ATRIAL CONDUCTION DELAY

to feed into the linear regression analysis. Therefore, these tables are not presenting the ultimate results of the analysis. All parameters with a $P$ value $<0.1$ resulting from the univariate comparisons in Tables 1 and 2 were included in the linear regression models presented in Table 3 . We did not include medication in the multivariate analysis presented in Table 3 since it is a reflection of the underlying diseases already included in the model. Model reduction was performed by stepwise exclusion of variables from the model with a $P$ value $<0.1$. For all continuous variables in the final regression analysis model, we determined their correlation with PA-TDI using Pearson's correlation test.

Statistical analysis was performed with SPSS statistical software (SPSS Inc. release 16.0) and statistical significance was assumed for $P<0.05$. All tests performed were two sided.

\section{RESULTS}

From the initial population of 522 patients, 95 patients were excluded because of use of conduction slowing class I antiarrhythmic agents or amiodarone leaving a final study population of 427 . The mean PA-TDI was $157 \pm 22 \mathrm{~ms}$. The shortest PA-TDI interval we measured was $103 \mathrm{~ms}$ and longest was $230 \mathrm{~ms}$.

TABLE 1 - Baseline characteristics in relation to the mean PA-TDI duration in our population

\begin{tabular}{|c|c|c|c|}
\hline & $\begin{array}{c}\text { PA-TDI <157 ms } \\
(n=222)\end{array}$ & $\begin{array}{c}\text { PA-TDI } \geq 157 \mathrm{~ms} \\
(n=205)\end{array}$ & $P$ value \\
\hline Age (years) & $60 \pm 13$ & $67 \pm 11$ & $<0.001$ \\
\hline Female, $n(\%)$ & $121(45)$ & $97(47)$ & 0.147 \\
\hline Body mass index $\left(\mathrm{kg} / \mathrm{m}^{2}\right)^{\mathrm{a}}$ & $27 \pm 4$ & $28 \pm 4$ & 0.081 \\
\hline \multicolumn{4}{|l|}{ Underlying risk factors and cardiovascular disease } \\
\hline AF in history, $n(\%)$ & $74(33)$ & $114(55)$ & $<0.001$ \\
\hline Hypertension, $n(\%)$ & $122(55)$ & $132(64)$ & 0.049 \\
\hline Coronary artery disease, $n(\%)$ & $22(10)$ & $34(17)$ & 0.045 \\
\hline Diabetes Mellitus, $n(\%)$ & $29(13)$ & $22(11)$ & 0.551 \\
\hline Valve disease, $n(\%)$ & $30(14)$ & $50(24)$ & 0.004 \\
\hline Heart failure, $n(\%)$ & $14(6)$ & $20(10)$ & 0.213 \\
\hline Thyroid disease, $n(\%)$ & $15(7)$ & $12(6)$ & 0.843 \\
\hline Chronic obstructive pulmonary disease, $n(\%)$ & $14(6)$ & $15(7)$ & 0.704 \\
\hline \multicolumn{4}{|l|}{ Medication } \\
\hline Oral anticoagulation, $n(\%)$ & $39(18)$ & $85(42)$ & $<0.001$ \\
\hline Aspirin, $n(\%)$ & $70(32)$ & $42(21)$ & 0.011 \\
\hline Beta-blocker, $n(\%)$ & $63(28)$ & $104(51)$ & $<0.001$ \\
\hline Sotalol, $n(\%)$ & $28(13)$ & $40(20)$ & 0.064 \\
\hline Verapamil, $n(\%)$ & $18(8)$ & $19(9)$ & 0.732 \\
\hline Digitalis, $n(\%)$ & $10(5)$ & $14(7)$ & 0.401 \\
\hline Nitrates, $n(\%)$ & $8(4)$ & $22(11)$ & 0.004 \\
\hline Angiotensin-II receptor blocker, $n(\%)$ & $37(17)$ & $61(30)$ & 0.002 \\
\hline Diuretics, $n(\%)$ & $33(15)$ & $56(27)$ & 0.907 \\
\hline Statins, $n(\%)$ & $64(29)$ & $54(26)$ & 0.589 \\
\hline Alpha-blocker, $n(\%)$ & $7(3)$ & $5(3)$ & 0.774 \\
\hline Dihydropyridin calcium channel blocker, $n(\%)$ & $27(12)$ & $36(18)$ & 0.133 \\
\hline
\end{tabular}


Baseline characteristics of all patients in relation to the mean PA-TDI interval in our population are shown in Table 1. Patients with a prolonged PA-TDI duration (>157 ms) were older and more often suffered from AF, hypertension, coronary artery disease, clinically relevant valve disease, and more often used oral anticoagulation, beta-blockers, nitrates, angiotensin converting enzyme (ACE)-inhibitors and diuretics. Patients with a shorter PA-TDI interval used more aspirin. Figure 2 shows the mean PATDI interval according to age in tertiles and hypertension in patients with and without AF. A history of AF was present in 188 (44\%) patients. Atrial fibrillation was paroxysmal and self-terminating in 162 (88\%) patients and persistent and previously terminated by electrical or chemical cardioversion in 21 (12\%) patients.

Echocardiographic differences according to PA-TDI duration are shown in Table 2. Patients with a longer PA-TDI interval have an increased aortic width, increased atrial dimensions, and a larger and thicker left ventricle. The E-wave deceleration slope is decreased and the E-wave deceleration time is increased in the patients with a longer PA-TDI interval. Patients with a prolonged PA-TDI interval had more aortic valve incompetence and mitral valve incompetence.

TABLE 2 - Echocardiographic parameters in relation to the mean PA-TDI duration in our population

\begin{tabular}{|c|c|c|c|}
\hline & $\begin{array}{c}\text { PA-TDI <157 ms } \\
(n=222)\end{array}$ & $\begin{array}{c}\text { PA-TDI } \geq 157 \mathrm{~ms} \\
(n=205)\end{array}$ & $P$ value \\
\hline \multicolumn{4}{|l|}{ Dimensions } \\
\hline Aorta diameter (mm) & $33.6 \pm 4$ & $35.1 \pm 4$ & $<0.001$ \\
\hline Left atrial dimension ( $\mathrm{mm}$ ) & $39 \pm 5$ & $42 \pm 5$ & $<0.001$ \\
\hline Left atrial volume (cc) & $51 \pm 20$ & $57 \pm 25$ & 0.012 \\
\hline Right atrial volume (cc) & $42 \pm 14$ & $46 \pm 16$ & 0.049 \\
\hline Left ventricular end diastolic dimension ( $\mathrm{mm}$ ) & $48 \pm 5$ & $50 \pm 5$ & $<0.001$ \\
\hline Left ventricular end systolic dimension (mm) & $32 \pm 6$ & $34 \pm 6$ & 0.002 \\
\hline Inter-ventricular septum width (mm) & $9.1 \pm 1.1$ & $9.9 \pm 5.8$ & 0.025 \\
\hline Posterior wall width (mm) & $8.7 \pm 0.9$ & $9.1 \pm 1.1$ & 0.002 \\
\hline Left ventricular mass $(\mathrm{g})$ & $185 \pm 44$ & $209 \pm 54$ & $<0.001$ \\
\hline Left ventricular end diastolic volume (cc) & $109 \pm 28$ & $120 \pm 35$ & 0.001 \\
\hline Left ventricular end systolic volume (cc) & $42 \pm 21$ & $49 \pm 27$ & 0.006 \\
\hline Caval vein $(\mathrm{mm})$ & $17 \pm 4$ & $17 \pm 4$ & 0.256 \\
\hline Right ventricular systolic pressure (mmHg) & $30 \pm 6$ & $32 \pm 8$ & 0.182 \\
\hline Left ventricular ejection fraction & $61 \pm 9$ & $60 \pm 9$ & 0.072 \\
\hline \multicolumn{4}{|l|}{ Mitral valve Doppler } \\
\hline Maximal E-wave velocity (cm/s) & $75 \pm 17$ & $73 \pm 20$ & 0.292 \\
\hline E-wave deceleration slope $\left(\mathrm{m} / \mathrm{s}^{2}\right)$ & $396 \pm 145$ & $355 \pm 157$ & 0.006 \\
\hline E-wave deceleration time (ms) & $196 \pm 44$ & $218 \pm 62$ & $<0.001$ \\
\hline Maximal A-wave velocity (cm/s) & $76 \pm 20$ & $75 \pm 21$ & 0.462 \\
\hline E/A ratio & $1.04 \pm 0.4$ & $1.06 \pm 0.6$ & 0.603 \\
\hline \multicolumn{4}{|l|}{ Valve disease } \\
\hline Aortic incompetence (> grade 1 ) & $4(2 \%)$ & $18(9 \%)$ & 0.002 \\
\hline Mitral incompetence (> grade 1 ) & $9(4 \%)$ & $28(14 \%)$ & $<0.001$ \\
\hline Tricuspid incompetence (> grade 1 ) & $14(6 \%)$ & $17(8 \%)$ & 0.460 \\
\hline Mitral valve stenosis & 0 & $2(1 \%)$ & 0.230 \\
\hline Aortic stenosis & $8(4 \%)$ & $8(4 \%)$ & 1.000 \\
\hline
\end{tabular}




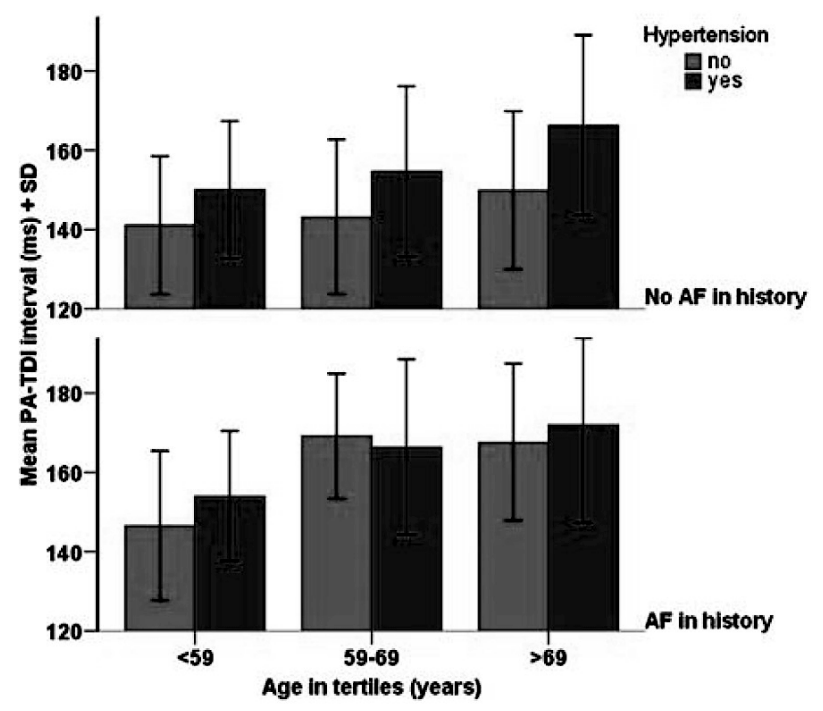

FIGURE 2 - Clinical parameters affecting the PA-TDI interval. Mean PA-TDI interval + standard deviation according to age in tertiles and hypertensive (black bars) versus non-hypertensive patients (grey bars). The upper panel shows patients without a history of atrial fibrillation and the lower panel patients with a history of atrial fibrillation.

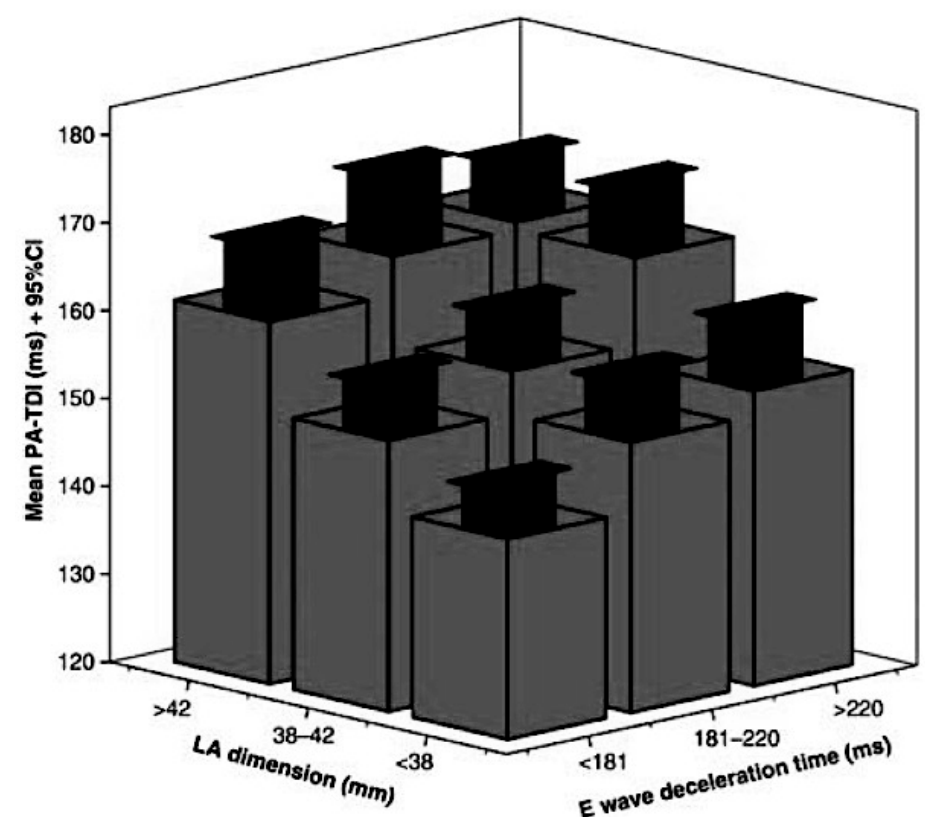

FIGURE 3 - Echocardiographic parameters affecting the PA-TDI interval. Mean PA-TDI interval and 95\% confidence intervals according to mitral valve E-wave deceleration time and left atrial dimension, both in tertiles. 
Figure 3 shows the mean PA-TDI interval according to mitral valve E-wave deceleration time and left atrial dimension.

Multivariable linear regression analysis revealed that AF in history, hypertension, clinically relevant valve disease, age, and BMI were independently associated with the PA-TDI interval (Table 3 ). When excluding patients with AF in history, hypertension ( $B=10, P<0.001)$, age $(B=5$ per 10 years increase of age, $P<$ $0.001)$, and $B M I(B=4$ per 5 points increase of $B M I, P<0.011$ ) remained significantly associated with a prolonged PA-TDI interval.

Regarding the echocardiographic parameters: the aortic diameter, left atrial dimension, mitral valve E-wave deceleration time, aortic incompetence, and mitral incompetence were independently associated with the PA-TDI interval in our population (Table 3). When excluding patients with a history of AF, the clinical parameters hypertension, age and BMI remained independently associated with the PA-TDI interval. The echocardiographic parameters aorta diameter, left atrial dimension, aortic incompetence, and mitral valve E-wave deceleration time remained independently associated with PA-TDI interval when performing multivariate linear regression analysis in patients without a history of AF.

TABLE 3 - Multivariate linear regression analysis: clinical and echocardiographic parameters that independently prolong the PA-TDI interval and correlation coefficients of all continuous variables resulting from the correlation with PA-TDI

\begin{tabular}{lccccr}
\hline & $\boldsymbol{B}(\mathrm{ms})$ & $\mathbf{9 5 \%} \mathbf{C l}$ for $(\boldsymbol{B})$ & $\boldsymbol{P}$ value & $\boldsymbol{R}^{2}$ & $\boldsymbol{P}$ value \\
\hline Demographic and clinical parameters & & & & & \\
AF in history & 9.7 & $5.7-13.8$ & $<0.001$ & & \\
Hypertension & 5.5 & $1.4-9.8$ & 0.010 & & \\
Valve disease & 5.7 & $0.5-10.8$ & 0.030 & & $<0.001$ \\
Age (per 10 years) & 5 & $3.3-6.6$ & $<0.001$ & 0.34 & 0.008 \\
BMI (per 5 kg/m ${ }^{2}$ ) & 2.6 & $0.3-4.9$ & 0.026 & 0.13 & $<0.001$ \\
Echocardiographic parameters & & & & & $<0.001$ \\
Aorta diameter (mm) & 0.7 & $0.2-1.2$ & 0.009 & 0.22 & \\
Left atrial dimension (per mm) & 0.9 & $0.5-1.3$ & $<0.001$ & 0.34 & \\
Aortic incompetence (> grade 1) & 13 & $3.3-22.6$ & 0.008 & & $<0.001$ \\
Mitral incompetence (> grade 1) & 11 & $3.6-17.5$ & 0.003 & & \\
Mitral valve E-wave dec. time (per ms) & 0.076 & $0.039-0.113$ & $<0.001$ & 0.25 & \\
\hline
\end{tabular}

\section{DISCUSSION}

The present study is the largest to investigate the relationship between PA-TDI, underlying cardiovascular diseases and echocardiographic parameters. We used the PA-TDI interval-a relatively new echocardiographic parameter ${ }^{11}$-to estimate the TACT.

\section{Clinical correlates of intra-atrial conduction delay}

In this study, PA-TDI was independently prolonged in patients with a history of AF, hypertension, clinically relevant valve disease, higher age, and a higher BMI. We found that after correcting for possible confounders, a history of AF increases PA-TDI by $~ 10$ $\mathrm{ms}$, a history of hypertension by $5 \mathrm{~ms}$ and clinically relevant valve disease by $6 \mathrm{~ms}$. 
Each additional 10 years of age increases PA-TDI with $\sim 5 \mathrm{~ms}$ and each additional 5 $\mathrm{kg} / \mathrm{m} 2$ of BMI increases PA-TDI with $3 \mathrm{~ms}$. The strong association between prolonged atrial conduction time and $A F$ is not surprising since on one hand long conduction times are a prerequisite for the development of AF and on the other hand, AF itself may induce remodelling and hence contribute to lengthening of conduction through the atria. ${ }^{6,16}$ As has been suggested previously, prevention of AF may ameliorate atrial structural remodelling and prevent further AF episodes. Since it is unlikely that available therapies reduce atrial conduction time, preventive therapy might focus especially on suppression of AF in the subset with still normal conduction. Ageing is a recognized determinant of atrial size and fibrosis but unfortunately non-modifiable with respect to prevention of conduction abnormalities. Hypertension and valve disease are associated with diastolic dysfunction inducing intermittent pressure rises and dilatation of the atria and hence atrial fibrosis. ${ }^{17,18}$ In turn, this prolongs the TACT because of 'detour conduction' in larger atria. Although BMI relates to hypertension we showed an independent impact on TACT. From our data we cannot tell whether high BMI affected an increase in TACT through obstructive sleep apnoea, which was recently described as being associated with atrial conduction slowing. ${ }^{2}$ On the other hand, the pericardial fat that overlies the cardiac surface including the inter- and intraatrial conduction system might be responsible for atrial conduction delays. Recent studies demonstrate a relation between pericardial fat and atrial conduction delay. ${ }^{19}$ Reducing body weight may ameliorate the atrial conduction time. Indeed, the effect of a high BMI on atrial conduction is likely to be reversible since obesity studies demonstrate that substantial weight loss is associated with improvement in atrial repolarization abnormalities on the ECG in obese subjects. ${ }^{20}$ Patients with a prolonged PA-TDI interval more often used oral anticoagulation, beta-blockers, nitrates, ACEinhibitors, and diuretics. It is difficult to interpret the relation between PA-TDI and the use of medication in the present study. The univariate analysis showed that in patients with a long PA-TDI interval AF, hypertension, and coronary artery disease occurred more frequently. Oral anticoagulation is typically prescribed in patients with AF, betablockers in patients with coronary artery but also in patients with hypertension and AF, nitrates are frequently applied in patients with coronary artery disease, and ACEinhibitors and diuretics are usually prescribed in patients with hypertension. Therefore, one could hypothesize that the differences found in medication use according to the length of the PA-TDI interval are the result of underlying heart disease. On the other hand, one could imagine that some medication directly influences the PA-TDI interval. Unfortunately, the present study does not provide an answer to this question.

\section{Echocardiographic correlates of intra-atrial conduction delay}

We also investigated that echocardiographic parameters were associated with PA-TDI. We found that increased left atrium (LA) dimension, increased aortic diameter, aortic, and mitral valve incompetence and a longer E-wave deceleration time are independently associated with a prolonged PA-TDI interval. The latter probably reflects mild diastolic dysfunction since it might be a sign of an impaired relaxation of the left ventricle. However, other parameters necessary to confirm this finding such as the 
pulmonary vein flow and $E / \mathrm{e}^{\prime}$ were not available in all patients. However, smaller studies using the signal averaged ECG to assess atrial conduction also demonstrate increased left atrial pressure and impaired LV relaxation in patients with delayed atrial conduction. ${ }^{21}$ The increased aortic diameter could be a reflection of the presence of aortic incompetence. However, our data show an independent relation between aortic diameter and PA-TDI. Another explanation could be inadequate management of hypertension. Since hypertension in history is also one of the clinical parameters, which was independently associated with a delay of the PA-TDI interval in this study, lowering the blood pressure is probably crucial to prevent prolongation of the TACT. An increased LA dimension could be the reflection of intermittent left atrial pressure rises typically seen in diastolic left ventricular dysfunction. ${ }^{22}$

\section{Future perspectives}

Since recent studies suggest that a prolonged PA-TDI is associated with the development of new-onset $\mathrm{AF}$ and poor outcome of rhythm control, ${ }^{10,12-15}$ one could hypothesize that reducing the duration of PA-TDI (or preventing its lengthening) improves primary and secondary prevention of AF. Our study suggests that early and aggressive treatment of hypertension, diastolic dysfunction, and obesity could prevent an increased PA-TDI. This was also suggested in smaller clinical studies. ${ }^{23}$ In addition, recent laboratory studies affirm that upstream therapy might enhance atrial conduction by reducing atrial fibrosis. ${ }^{7,23}$ PA-TDI could be used to select appropriate candidates for upstream therapy and evaluating its effect.

\section{LIMITATIONS}

The PA-TDI interval overestimates the total atrial activation time since it includes both the time required for the propagation of impulses from the sinus node area to the left atrium and the time required for the electromechanical coupling in the left atrium. Furthermore, there seems to be a minor delay in ECG processing on all echo machines. In our study, this delay amounts to a maximum of $5 \mathrm{~ms}$ (unpublished technical information by Philips Medical Systems, Andover, MA, USA). Fortunately, this delay is consistent and therefore unlikely to have affected our results. Some of the parameters in Table 2 showed only a small difference but still a significant univariate $P$ value, which may relate to the large sample size. Obviously, these differences may be of limited clinical relevance because they were at times smaller than the error in individual measurements. However, it should be noted that Tables 1 and 2 concerned univariate analyses used to identify parameters to feed the regression analysis. All our patients were included in a cardiology outpatient clinic. As a result, the population we studied may not be representative of the general population. On the other hand, PA-TDI is intended for patients with cardiovascular diseases. The investigator who included the patients (R.G.T.) is a general cardiologist with a special interest in electrophysiology. For that reason, many patients included in the present study had a history of AF. However, we verified our main findings in a group of patients excluding those with a history of AF and found similar results. 


\section{CONCLUSIONS}

The present study is the largest clinical study to investigate the relation between the atrial conduction times, underlying heart diseases, and echocardiographic parameters. We found that PA-TDI was prolonged in patients with a history of AF, hypertension, clinically relevant valve disease, higher age, and a higher BMI. On the echocardiogram, a larger left atrium, a larger aortic diameter, a longer E-wave deceleration time, and aortic and mitral incompetence were also associated with a prolonged PA-TDI interval. Since recent studies suggest that atrial conduction delay is associated with the development of new-onset AF and poor outcome of rhythm control, one could hypothesize that reducing atrial conduction time (or preventing its lengthening) improves primary and secondary prevention of AF. Based on our results, one could hypothesize that early and aggressive treatment of hypertension, diastolic dysfunction, and obesity could prevent atrial conduction delay.

\section{Acknowledgements}

The authors would like to thank the MUMC echocardiography section, with special thanks to J. Habets and A. Palmans for performing echocardiographic examinations.

\section{Conflict of interest:}

none declared.

\section{Funding}

This work was supported by the MUMC cardiology department. 


\section{REFERENCES}

1. Shimizu A, Centurion OA. Electrophysiological properties of the human atrium in atrial fibrillation. Cardiovasc Res 2002;54:302-14.

2. Yagmur J, Yetkin O, Cansel M, Acikgoz N, Ermis N, Karakus Y et al. Assessment of atrial electromechanical delay and influential factors in patients with obstructive sleep apnea. Sleep Breath 2011: [Epub ahead of print 9 January]. DOI: 10.1007/ s11325-010-0477-6.

3. Dogdu O, Yarlioglues M, Kaya MG, Ardic I, Kilinc Y, Elcik D et al. Assessment of atrial conduction time in patients with systemic lupus erythematosus. J Investig Med 2011;59:281-6.

4. Buyukoglan H, Kaya MG, Ardic I, Yarlioglues M, Dogdu O, Bol C et al. Assessment of atrial conduction time in patients with sarcoidosis. J Investig Med 2011;59: 15-21.

5. Van Beeumen K, Duytschaever M, Tavernier R, Van de Veire N, De Sutter J. Intraand interatrial asynchrony in patients with heart failure. Am J Cardiol 2007;99: 79-83.

6. Pytkowski M, Jankowska A, Maciag A, Kowalik I, Sterlinski M, Szwed H et al. Paroxysmal atrial fibrillation is associated with increased intra-atrial conduction delay. Europace 2008;10:1415-20.

7. Matsuyama N, Tsutsumi T, Kubota N, Nakajima T, Suzuki H, Takeyama Y. Direct action of an angiotensin II receptor blocker on angiotensin II-induced left atrial conduction delay in spontaneously hypertensive rats. Hypertens Res 2009;32: 721-6.

8. Verlato R, Zanon F, Bertaglia E, Turrini P, Baccillieri MS, Baracca E et al. Prevalence of conduction delay of the right atrium in patients with SSS: implications for pacing site selection. J Cardiovasc Med (Hagerstown) 2007;8:706-12.

9. Lewicka-Nowak E, Kutarski A, Dabrowska-Kugacka A, Rucinski P, Zagozdzon P, Raczak G. A novel method of multisite atrial pacing, incorporating Bachmann's bundle area and coronary sinus ostium, for electrical atrial resynchronization in patients with recurrent atrial fibrillation. Europace 2007;9: 805-11.

10. Buck S, Rienstra M, Maass AH, Nieuwland W, Van Veldhuisen DJ, Van Gelder IC. Cardiac resynchronization therapy in patients with heart failure and atrial fibrillation: importance of new-onset atrial fibrillation and total atrial conduction time. Europace 2008;10:558-65.

11. Merckx KL, De Vos CB, Palmans A, Habets J, Cheriex EC, Crijns HJ et al. Atrial activation time determined by transthoracic Doppler tissue imaging can be used as an estimate of the total duration of atrial electrical activation. J Am Soc Echocardiogr 2005;18:940-4.

12. De Vos CB,Weijs B, Crijns HJ, Cheriex EC, Palmans A, Habets J et al. Atrial tissue Doppler imaging for prediction of new-onset atrial fibrillation. Heart 2009;95: 835-40.

13. Antoni ML, Bertini M, Atary JZ, Delgado V, ten Brinke EA, Boersma E et al. Predictive value of total atrial conduction time estimated with tissue Doppler 
CHAPTER III | CORRELATES OF INTRA-ATRIAL CONDUCTION DELAY

imaging for the development of new-onset atrial fibrillation after acute myocardial infarction. Am J Cardiol 2010;106:198-203.

14. Bertini M, Borleffs CJ, Delgado V, Ng AC, Piers SR, Shanks M et al. Prediction of atrial fibrillation in patients with an implantable cardioverter-defibrillator and heart failure. Eur J Heart Fail 2010;12:1101-10.

15. Chao TF, Sung SH,Wang KL, Lin YJ, Chang SL, Lo LWet al. Associations between the atrial electromechanical interval, atrial remodelling and outcome of catheter ablation in paroxysmal atrial fibrillation. Heart 2011;97:225-30.

16. Wijffels MC, Kirchhof CJ, Dorland R, Allessie MA. Atrial fibrillation begets atrial fibrillation. A study in awake chronically instrumented goats. Circulation 1995;92: 1954-68.

17. Daccarett M, Badger TJ, Akoum N, Burgon NS, Mahnkopf C, Vergara G et al. Association of left atrial fibrosis detected by delayed-enhancement magnetic resonance imaging and the risk of stroke in patients with atrial fibrillation. J Am Coll Cardiol 2011;57:831-8.

18. AnneW, Willems R, Roskams $T$, Sergeant $P$, Herijgers $P$, Holemans $P$ et al. Matrix metalloproteinases and atrial remodeling in patients with mitral valve disease and atrial fibrillation. Cardiovasc Res 2005;67:655-66.

19. Babcock MJ, Soliman EZ, Ding J, Kronmal RA, Goff DC Jr. Pericardial fat and atrial conduction abnormalities in the Multiethnic Study of Atherosclerosis (MESA). Obesity 2011;19:179-84.

20. Duru M, Seyfeli E, Kuvandik G, Kaya H, Yalcin F. Effect of weight loss on P wave dispersion in obese subjects. Obesity 2006;14:1378-82.

21. Vranka I, Penz P, Dukat A. Atrial conduction delay and its association with left atrial dimension, left atrial pressure and left ventricular diastolic dysfunction in patients at risk of atrial fibrillation. Exp Clin Cardiol 2007;12:197-201.

22. Kojodjojo P, Peters NS, Davies DW, Kanagaratnam P. Characterization of the electroanatomical substrate in human atrial fibrillation: the relationship between changes in atrial volume, refractoriness, wavefront propagation velocities, and AF burden. J Cardiovasc Electrophysiol 2007;18:269-75.

23. Fuenmayor AJ, Moreno G, Landaeta A, Fuenmayor AM. Inter-atrial conduction time shortens after blood pressure control in hypertensive patients with left ventricular hypertrophy. Int J Cardiol 2005;102:443-6. 


\section{EDITORIAL}

As one of the four cardiac pumps, the left atrium abides by the natural properties of myocardial function, i.e. electrical stimulation, irrespective of the conduction pattern, followed by mechanical muscle contraction then stroke volume ejection. While failure of native ventricular electrical stimulation is not compatible with life, that of the atrium is tolerable and many patients may live a completely normal life in atrial fibrillation. In fact, recent evidence supports the notion that rate-controlled atrial fibrillation has a clinical outcome similar to the rhythm-controlled one. ${ }^{1}$ Patients with severe left ventricular disease, however, may respond differently and develop fast worsening symptoms with atrial fibrillation, because of the loss of the component of stroke volume pumped by the left atrium.

Full understanding of left atrial function requires critical appreciation of its detailed anatomy as well as myocardial fiber architecture. Anatomically, the left atrium is the functional opponent to the left ventricle, with reciprocal shortening and lengthening relationship between the two. The dominant myocardial fibers of the left atrium are longitudinally orientated, originating from the back of the atrium and inserting around the circumference of the mitral annulus. A smaller group of fibers run transversely around the base of the left atrium, although not covering its full circumference. $^{2}$ Thus, the main axis of the left atrial cavity shortening is longitudinal with the mitral annulus moving back towards the rear of the atrium after the P-wave and during the PR interval and returning to its resting position at the time of the first heart sound, marking end-diastole. It is worth mentioning that not only does this pattern of function mirror that of the left ventricle, although in the opposite direction, but the atrium also does not function in isolation of the ventricle. Myocardial development studies have shown close relationship between age-related changes in the function of the atrium and the ventricle which themselves are closely related. As left ventricular lengthening velocities reduce with age, those of left atrial shortening reciprocally increase in order to secure normal stroke volume entering the left ventricle. ${ }^{3}$ Conventional measurements of the left atrial size rely on longitudinal and transverse diameters as well as its area measurements. Segmental left atrial myocardial function is easily assessed from the longitudinal motion amplitude and velocity of the lateral, septal, and posterior segments as shown by the mitral annulus excursion during atrial systole. This is easily achieved using tissue Doppler or speckle tracking techniques. The amplitude of left atrial longitudinal motion is also assessed by the same techniques or by conventional M-mode.

Similar to the left ventricle, the main determinant of left atrial contractile function is its intrinsic myocardial function, which has its well-established maturation course, between fetal life and adolescence. ${ }^{4}$ As the atrium gets large in size due to various pathologies, with the commonest secondary to left ventricular and valve diseases, its overall contractile function falls and eventually pump failure and atrial fibrillation. Even in patients with paroxysmal atrial fibrillation and only small increase in atrial size we have shown significant reduction in segmental left atrial function particularly in areas adjacent to the pulmonary veins. ${ }^{5}$ Critical investigation of atrial 
function shows that such pathophysiological course is not that simple. We and others have previously shown that atrial flutter and fibrillation are commonly preceded by progressive prolongation of $\mathrm{P}$-wave duration which itself proved a good predictor for the occurrence of atrial arrhythmias. ${ }^{6,7}$ This is explained on the basis of progressive atrial enlargement and myocardial stretching, which increase its surface area and hence the prolonged depolarization time. Such behavior is similar to that occurring in dilated left ventricles with prolonged depolarization time and broad QRS duration.

Another important component of left atrial function is its electromechanical delay, similar to that seen in the left ventricle. This can easily be studied by the same Doppler echocardiographic techniques mentioned above and left atrial motion measured with reference to the onset of its electrical depolarization, the P-wave. Studies have used the onset of segmental left atrial shortening (excursion) or peak shortening velocity as two possible landmarks for electromechanical delay. Normal values for the two measurements have been determined and well documented. Normally, the three left atrial segments shorten in a synchronous fashion with no more than few milliseconds time difference between them, again a finding similar to that seen in the left ventricle. We have previously shown that such measurement is significantly abnormal and its relationship with that of the right atrium is disturbed in patients who develop atrial flutter. ${ }^{8}$ Furthermore, within the same atrium there is emerging evidence suggesting the presence of segmental left atrial dyssynchrony in patients with right heart disease, with some segments contracting significantly later than the others (unpublished data from Umea University) in response to the increase in right atrial pressures. Although left atrial contractile contribution to the stroke volume is relative to its wall thickness, it remains functioning as a pump with a need to behave in a satisfactory synchronous manner.

In this issue Weijs B et al. ${ }^{9}$ report an interesting measure of delayed atrial contraction as shown by the time interval between the onset of the P-wave and peak atrial systolic velocity. Interestingly, the authors report a number of clinical findings predicted by such measure, namely history of atrial fibrillation, hypertension, relevant valve disease, age, and body mass index. In addition, echocardiographic evidence of dilated aortic diameter, left atrial dimension, E-wave deceleration time, and aortic and mitral regurgitation were also independently associated with prolonged intraatrial conduction. It seems that most of those conditions and functional disturbances result in various degrees of raised left atrial pressure. Age and long-standing hypertension are associated with the development of stiff left ventricle and raised left atrial pressure, a known substrate for atrial fibrillation. This can clearly be manifested in the form of short E-wave deceleration time, which reflects raised left ventricular end-diastolic pressure. Significant mitral and aortic valve disease, as mentioned above increase the overload on the left ventricle, again resulting into a similar pattern of pathophysiology, and increased left atrial pressure. Finally, aortic dilatation seems to represent an external left atrial wall stress which destabilizes its function and hence atrial arrhythmia, although this finding is not well documented in the literature. The reported index seems to reflect atrial electromechanical delay in a very simple and feasible way. The onset of the P-wave is easily measured on the superimposed 
electrocardiogram and the peak atrial shortening velocity should adequately be obtained by tissue Doppler or speckle tracking techniques, making such measure highly reproducible. Finally, to the clear scientific mind such an index of atrial electromechanical delay should be seen to encompass the prolonged $\mathrm{P}$-wave as a reflection of delayed atrial depolarization in addition to the pure delay in the atrial mechanical function, if it exists.

\section{REFERENCES}

1. Fuster V, Ryde'n LE, Cannom DS, Crijns HJ, Curtis AB, Ellenbogen KA et al. 2011 ACCF/AHA/HRS focused updates incorporated into the ACC/AHA/ESC 2006 Guidelines for the management of patients with atrial fibrillation: a report of the American College of Cardiology Foundation/American Heart Association Task Force on Practice Guidelines developed in partnership with the European Society of Cardiology and in collaboration with the European Heart Rhythm Association and the Heart Rhythm Society. J Am Coll Cardiol 2011;57:e101-98.

2. Wang K, Ho SY, Gibson DG, Anderson RH. Architecture of atrial musculature in humans. Br Heart J 1995;73:559-65.

3. Henein M, Lindqvist $P$, Francis D, Mo“rner S, Waldenstro“m A, Kazzam E. Tissue Doppler analysis of age-dependency in diastolic ventricular behaviour and filling: a cross-sectional study of healthy hearts (the Umea ${ }^{\circ}$ General Population Heart Study). Eur Heart J 2002;23:162-71.

4. Gardiner HM, Pasquini L, Wolfenden J, Barlow A, Li W, Kulinskaya E et al. Myocardial tissue Doppler and long axis function in the fetal heart. Int J Cardiol 2006;113: 39-47.

5. Henein M Jr, Lindqvist P, Mo“rner S, Henein M. Effect of raised left atrial pressure on its regional and segmental chamber function: the role of speckle tracking. Scandinavian Cardiovasc J 2009;43:28.

6. Li W, Xiao HB, Henein MY, Somerville J, Gibson DG. Progressive ECG changes before the onset of atrial flutter in adult congenital heart disease patients. Heart 2001;85:703.

7. Dilaveris PE, Gialafos EJ, Sideris SK, Theopistou AM, Andrikopoulos GK, Kyriakidis $M$ et al. Simple electrocardiographic markers for the prediction of paroxysmal idiopathic atrial fibrillation. Am Heart J 1998;135:733-8.

8. Li W, Somerville J, Gibson DG, Henein MY. Disturbed atrioventricular electromechanical function long after Mustard operation for transposition of great arteries: a potential contributing factor to atrial flutter. J Am Soc Echocardiogr 2001;14: 1088-93.

9. Weijs B, de Vos CB, Tieleman RG, Pisters R, Cheriex EC, Prins MH, Crijns HJGM. Clinical and echocardiographic correlates of intra-atrial conduction delay. Europace 2011; advance access publication 15 August 2011, doi:10.1093/europace/eur261. 
CHAPTER III | CORRELATES OF INTRA-ATRIAL CONDUCTION DELAY 


\section{CHAPTER IV THE PRESENCE OF AN ATRIAL ELECTROMECHANICAL DELAY IN IDIOPATHIC ATRIAL FIBRILLATION AS DETERMINED BY TISSUE DOPPLER IMAGING}

\footnotetext{
B. Weijs ${ }^{1}$, CB de Vos $^{1}$, I Limantoro ${ }^{1}$, EC Cheriex ${ }^{1}$, RG Tieleman ${ }^{2}$, HJGM Crijns ${ }^{1}$

${ }^{1}$ Maastricht University Medical Centre \& Cardiovascular Research Institute Maastricht, The Netherlands. ${ }^{2}$ Martini Hospital Groningen, The Netherlands.
}

International journal of Cardiology. 2012 Apr 5;156(1):121-2 


\section{To the Editor:}

Atrial fibrillation (AF) derives from a complex continuum of predisposing factors. However, the true 'scene of calamity' is the atrium. Increased left atrial (LA) size is associated with increased risk of AF onset and recurrence, other cardiovascular disease and mortality. ${ }^{1,2}$ Both atrial conduction slowing and atrial dilatation will favour $\mathrm{AF}$ as it results in increased total atrial conduction time, which is the time elapsed between the initiation of atrial depolarisation and the last depolarisation of the same activation front. $^{3}$ A prolonged total atrial conduction time may reflect the electro-anatomical substrate for AF since it is associated with underlying cardiovascular disease and age. $\left[{ }^{4}\right]$ It can be easily and non-invasively determined by means of transthoracic echocardiography assessing the electromechanical PA interval with tissue Doppler imaging (PA-TDI). ${ }^{5}$ Idiopathic AF refers to $\mathrm{AF}$ in the absence of a cardiovascular or pulmonary disease generating the pathophysiological substrate for the arrhythmia. Herein, we study the electrophysiologic properties of the atria in patients with idiopathic AF using tissue Doppler imaging.

We prospectively studied 41 consecutive idiopathic AF patients and 45 healthy sinus rhythm control patients who were referred to the outpatient clinic for a standard transthoracic echocardiographic examination. Informed consent of all patients was obtained and the authors of this manuscript have certified that they comply with the Principles of Ethical Publishing in the International Journal of Cardiology. ${ }^{6}$

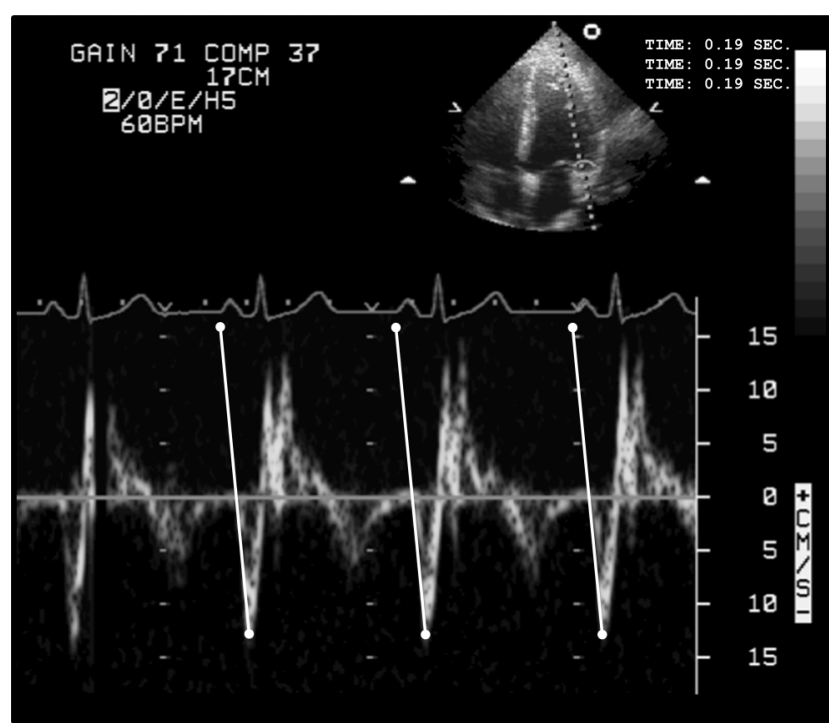

FIGURE 1 - Example of PA-TDI measurement. PA-TDI is defined as the time interval between the onset of electrocardiographic $P$ wave in lead II and the top of the $A^{\prime}$-wave on the atrial tissue Doppler velocity curve from the lateral wall of the left atrium. 
Idiopathic AF and healthy sinus rhythm was strictly defined as the absence of any cardiovascular disease including hypertension (no antihypertensive drug use [diuretics, angiotensin converting enzyme inhibitors, aldosterone receptor blockers, aldosterone receptor antagonists, non-dihydropyridine calcium antagonists, other], all previously recorded systolic blood pressures not exceeding $140 \mathrm{mmHg}$, diastolic blood pressures not exceeding $90 \mathrm{mmHg}$ and absence of left ventricular hypertrophy (interventricular septum width $>10 \mathrm{~mm}$, posterior wall width $>10 \mathrm{~mm}$ )), diabetes (fasting blood glucose $>7.0 \mathrm{mmol} / \mathrm{L}$ ), or hypercholesterolemia (total fasting cholesterol $>6.4 \mathrm{mmol} / \mathrm{L}$ and no statin use). In addition, no coronary artery disease (i.e. absence of typical exercise-related angina pectoris, an exercise stress test with significant ST-segment depression, previous acute coronary syndrome, percutaneous or surgical coronary revascularization, or previous angiographically documented coronary disease), no peripheral vascular disease, no congestive heart failure (no clinical signs or symptoms, left ventricular ejection fraction > 50\%, normal diastolic function parameters), no previous stroke, no thyroid or pulmonary disease, no significant renal dysfunction (estimated MDRD glomerular filtration rate $<60 \mathrm{ml} / \mathrm{min}$ ), no malignancy, and no evidence for structural cardiovascular disease on echocardiography including valvular heart disease.

The echocardiographic examination consisted of a standard 2-dimensional echocardiogram, including M-mode and Doppler echocardiography (Sonos 5500, Philips Medical Systems, Andover, Mass) during continuous electrocardiogram (ECG) monitoring according to the recommendations as described in the American Society of Echocardiography guidelines. Additionally, we determined the total atrial conduction time by means of PA-TDI as described in figure $1 .^{5}$ PA-TDI was measured in three cardiac cycles and averaged.

Baseline characteristics, electrocardiographic and standard echocardiographic parameters were equal in AF cases and controls. Particularly, mean \pm SD age $(56 \pm 10$ vs. $53 \pm 12$ years, $p=0.465)$, body mass index $\left(26 \pm 4\right.$ vs. $\left.27 \pm 4 \mathrm{~kg} / \mathrm{m}^{2}, \mathrm{p}=0.348\right)$, surface electrocardiographic $P$-wave duration ( $88 \pm 20$ vs. $86 \pm 17 \mathrm{~ms}, \mathrm{p}=0.521$ ) and LA diameter ( $39 \pm 5$ vs. $38 \pm 4 \mathrm{~mm}, \mathrm{p}=0.256$ ) did not differ between AF patients and controls. AF duration showed only a limited correlation to LA size (spearman's correlation coefficient: $0.365, p=0.024$ ) while LA size showed a limited correlation with PA-TDI (spearman's correlation coefficient: $0.439, \mathrm{p}<0.001$ ). However, PA-TDI interval was significantly increased in patients with idiopathic AF compared to controls ( $157 \pm 19$ vs. $141 \pm 15 \mathrm{~ms}, \mathrm{p}<0.001$ ). (Figure 2) After adjustment for those parameters showing a significant univariate relation with AF (PA-TDI, $\mathrm{P}=0.006$; Aorta diameter, $\mathrm{P}=0.055$ ), and those representing a plausible mechanism in terms of increased atrial conduction time (age, $\mathrm{P}=0.465$; sex, $\mathrm{P}=0.194$; LA diameter, $\mathrm{P}=0.256$ ), $\mathrm{PA}-\mathrm{TDI}$ (per $10 \mathrm{~ms}$ increase) remained the sole independent parameter for the presence of idiopathic $A F(P=0.024$, odds ratio 1.432, 95\% confidence interval: 1.049-1.955).

In this study, left atrial sizes were equal between patients with and without AF. It is remarkable that despite the healthy nature of the subjects and comparable atrial sizes, total atrial conduction time - as measured by means of tissue Doppler imaging is significantly prolonged in patients with idiopathic AF compared to matched sinus 
rhythm controls. Obviously, this may relate to the fact that AF itself leads to electrical and structural remodelling. ${ }^{7-9}$ However, the present study showed only a limited correlation between AF duration and LA size. Apart from previous episodes of AF, the increased atrial conduction time could therefore also be an expression of as yet undetected underlying heart disease. Given that AF could be a first manifestation of preclinical underlying cardiovascular disease, high priority should be given to robustly try to rule out concealed cardiovascular disease in patients who present with apparently idiopathic AF. PA-TDI could be a valuable tool to trace electrophysiological changes in the atria as potentially caused by concealed cardiovascular disease.

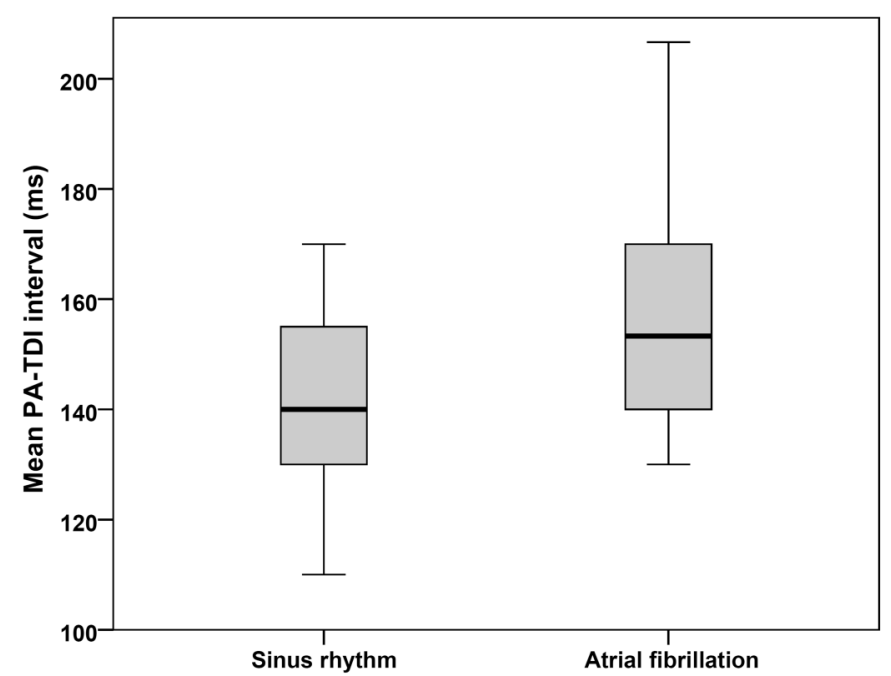

FIGURE 2 - Boxplot showing mean PA-TDI interval in healthy sinus rhythm control patients compared to idiopathic atrial fibrillation patients $(p<0.001)$. 


\section{REFERENCES}

1. Benjamin EJ, D'Agostino RB, Belanger AJ, Wolf PA, Levy D. Left atrial size and the risk of stroke and death. The Framingham Heart Study. Circulation. 1995 Aug 15;92(4):835-41.

2. Osranek M, Bursi F, Bailey KR, Grossardt BR, Brown RD, Jr., Kopecky SL, et al. Left atrial volume predicts cardiovascular events in patients originally diagnosed with lone atrial fibrillation: three-decade follow-up. European heart journal. 2005 Dec;26(23):2556-61.

3. De PR, Ho SY, Salerno-Uriarte JA, Tritto M, Spadacini G. Electroanatomic analysis of sinus impulse propagation in normal human atria. Journal of cardiovascular electrophysiology. 2002 Jan;13(1):1-10.

4. Weijs B, de Vos CB, Tieleman RG, Pisters R, Cheriex EC, Prins MH, et al. Clinical and echocardiographic correlates of intra-atrial conduction delay. Europace : European pacing, arrhythmias, and cardiac electrophysiology : journal of the working groups on cardiac pacing, arrhythmias, and cardiac cellular electrophysiology of the European Society of Cardiology. 2011 Dec;13(12):1681-7.

5. Merckx KL, De Vos CB, Palmans A, Habets J, Cheriex EC, Crijns HJ, et al. Atrial activation time determined by transthoracic Doppler tissue imaging can be used as an estimate of the total duration of atrial electrical activation. J Am Soc Echocardiogr. 2005 Sep;18(9):940-4.

6. Coats AJ. Ethical authorship and publishing. Int J Cardiol. 2009 Jan 9;131(2):149-50.

7. Sanfilippo AJ, Abascal VM, Sheehan M, Oertel LB, Harrigan P, Hughes RA, et al. Atrial enlargement as a consequence of atrial fibrillation. A prospective echocardiographic study. Circulation. 1990 Sep;82(3):792-7.

8. Wijffels MC, Kirchhof CJ, Dorland R, Allessie MA. Atrial fibrillation begets atrial fibrillation. A study in awake chronically instrumented goats. Circulation. 1995 Oct 1;92(7):1954-68.

9. Stiles MK, John B, Wong CX, Kuklik P, Brooks AG, Lau DH, et al. Paroxysmal lone atrial fibrillation is associated with an abnormal atrial substrate: characterizing the "second factor". J Am Coll Cardiol. 2009 Apr 7;53(14):118291. 


\section{CHAPTER V IDIOPATHIC ATRIAL FIBRILLATION REVISITED IN A LARGE LONGITUDINAL CLINICAL COHORT}

Bob Weijs ${ }^{1} \mathrm{MD}$; Ron Pisters ${ }^{1} \mathrm{MD}$; Robby Nieuwlaat ${ }^{2}$ PhD; Günter Breithardt ${ }^{3} \mathrm{MD}$ PhD, Jean-Yves Le Heuzey ${ }^{4}$ MD, Panos E Vardas ${ }^{5}$ MD PhD, lone Limantoro ${ }^{1} M D$, Ulrich Schotten ${ }^{1}$ MD PhD, Gregory YH Lip ${ }^{6}$ MD; Harry JGM Crijns ${ }^{1}$ MD PhD

${ }^{1}$ Cardiovascular Research Institute Maastricht, Maastricht University Medical Centre, The Netherlands. ${ }^{2}$ Population Health Research Institute, McMaster University, Hamilton, Ontario, Canada. ${ }^{3}$ Department of Cardiology and Angiology, University Hospital Münster, Germany. ${ }^{4}$ Department of Cardiology, Hôpital Européen Georges Pompidou, Paris, France. ${ }^{5}$ Department of Cardiology, University hospital of Heraklion, Greece. ${ }^{6}$ University of Birmingham Centre for Cardiovascular Sciences, City Hospital, Birmingham, United Kingdom

Europace 2011, 2012 Feb;14(2):184-90 


\section{ABSTRACT}

Aims: An age of 60 years is often used as cut off for the diagnosis of idiopathic atrial fibrillation (AF). We investigated the importance of age and atrial size in patients with idiopathic $A F$ and $A F$ patients with isolated hypertension.

Methods: Out of 3,978 AF patients in the Euro Heart Survey on AF with known followup, $119(3 \%)$ patients had idiopathic AF. We disregarded age and atrial size when selecting idiopathic AF patients since the atria may enlarge by AF itself. For comparison we selected 152 patients with isolated hypertension from the database.

Results: A total of $57(48 \%)$ of the patients were older than 60 years. Persistent or permanent AF was more prevalent in the older idiopathic AF patients (34\% in the age $<60$ vs. $66 \%$ in the age $>60$ years group, $p=0.002$ ) but mean duration of known $A F$ did not differ between these groups (310 days (IQR 60-1827) versus 430 days (IQR 88$1669), p=0.824)$. Left atrial size did not differ significantly in relation to age $(1.50 \pm 0.29$ $\mathrm{mm} / \mathrm{kg} / \mathrm{m}^{2}$ in the age $<60$ vs. $1.56 \pm 0.31 \mathrm{~mm} / \mathrm{kg} / \mathrm{m}^{2}$ in the age $\geq 60$ years group, $\mathrm{p}=0.742$ ). Only 2 paroxysmal AF patients progressed to permanent AF. No cardiovascular events occurred during 1-year follow-up. In contrast, strokes occurred in 5 patients $(6 \%)$ with isolated hypertension despite similar clinical profile and comparable atrial size as idiopathic AF patients.

Conclusion: Idiopathic AF may present at advanced age and is even then not associated with significant atrial enlargement, AF progression or an adverse short-term prognosis. In contrast, elevated blood pressure even when found in the absence of significant atrial remodelling, seems of prognostic importance. 
CHAPTER V | IDIOPATHIC AF REVISITED IN A LARGE COHORT

\section{INTRODUCTION}

Idiopathic atrial fibrillation (AF) refers to AF in the absence of a clinically relevant pathophysiological substrate for the arrhythmia. Data regarding the development, treatment and prognosis of idiopathic AF are only sparsely available. Its reported prevalence varies widely between 2 and 30\% which relates to ambiguous definitions specifically with regard to age and underlying cardiopulmonary disease, including left atrial (LA) size..$^{1-6}$ An age of 60 years has been suggested as a cut off for the diagnosis of idiopathic $A F$, but most studies included also patients above 60 years since this age limit is considered arbitrary. ${ }^{7}$ Similarly, atrial enlargement was usually not taken as an exclusion criterion probably because the atria may enlarge due to AF itself. ${ }^{8,9}$ Also cut off values for blood pressure are used variably. ${ }^{1-6}$ Taken together, these observations suggest that the clinical definition of idiopathic $A F$ needs some revision.

In the present study we investigated the importance of age and, secondary, atrial size in patients with idiopathic AF and AF patients with isolated hypertension.

\section{METHODS}

\section{Study population}

We used the large population database of the prospective Euro Heart Survey (EHS) on AF, with data collected between 2003 and 2005. A detailed study outline of the Euro Heart Survey on AF at baseline and follow-up assessment has been previously described. ${ }^{10,11}$ In summary, 5,333 ambulatory and hospitalized AF patients from 182 university, non-university, and specialized hospitals among 35 member countries of the European Society of Cardiology were enrolled. Patients had to be 18 years or older and have an ECG or Holter proven diagnosis of AF during the qualifying admission or in the preceding year. A one year follow-up assessment (completed in 3.978 patients) was performed to determine survival and major adverse cardiovascular events (cardiovascular death, stroke, transient ischemic attack, other thromboembolism, coronary artery disease, myocardial infarction or major bleeding). Medical records and medical information systems were used to populate the dataset.

Idiopathic AF was strictly defined as AF in the absence of any cardiovascular disease or comorbidities. Thus we excluded patients with a history of hypertension (defined as antihypertensive drug use [diuretics, angiotensin-converting enzyme inhibitors, angiotensin II receptor antagonists, aldosterone receptor antagonists, dihydropyridine calcium-channel blockers], or a systolic blood pressure $\geq 140 \mathrm{mmHg}$, or a diastolic blood pressure $\geq 90 \mathrm{mmHg}$ on the qualifying visit, or left ventricular hypertrophy [interventricular septum width $>10 \mathrm{~mm}$, posterior wall width $>10 \mathrm{~mm}$ ]), history of diabetes (fasting blood glucose $>7.0 \mathrm{mmol} / \mathrm{L}$ ), or hypercholesterolemia (total fasting cholesterol $>6.4 \mathrm{mmol} / \mathrm{L}$ ). In addition, patients had no history of coronary artery disease (i.e. typical exercise-related angina pectoris, an exercise stress test with significant ST-segment depression, previous acute coronary syndrome, percutaneous or surgical coronary revascularization, or previous angiographically 
documented coronary disease), peripheral vascular disease, congestive heart failure (or left ventricular ejection fraction $<50 \%$ ), previous stroke, thyroid or pulmonary disease, significant renal dysfunction (estimated glomerular filtration rate $<60 \mathrm{ml} / \mathrm{min}$ ), malignancy, or echocardiographic evidence of structural cardiovascular disease including valvular heart disease. Given the aim of our study we did not consider age as an exclusion criterion. In addition, we disregarded enlarged atria on echocardiography when selecting patients from the database since the atria may enlarge by AF itself.

Paroxysmal AF is defined as recurrent short-lasting episodes (less than 7 days, but usually within 48 hours), which will terminate spontaneously. Persistent AF is defined as long-lasting episodes ( $>7$ days), which require termination, by cardioversion (with drugs or by direct current cardioversion). Permanent AF is defined as continuous presence of $A F$, accepted by the patient (and physician). ${ }^{2}$

The echocardiographic examination consisted of a standard 2-dimensional echocardiogram, including M-mode and Doppler echocardiography during continuous electrocardiogram monitoring according to the recommendations as described in the American Society of Echocardiography guidelines. Left atrial diameter was measured using M-mode or two-dimensional echocardiography, from the posterior aortic wall to the posterior left atrial wall, in the parasternal long-axis view at the end-ventricular systole and with the patient in the left-lateral decubitus position. ${ }^{12}$

For comparison of clinical characteristics and 1 year outcome, we selected all patients from the Euro Heart Survey on AF database with isolated systemic hypertension (diagnosis of hypertension, or antihypertensive drug use) of all ages and LA sizes, but without other demonstrable structural heart disease, thus excluding left ventricular hypertrophy and any of the other disease states mentioned above.

\section{Statistical analysis}

Continuous variables are expressed as mean \pm standard deviation and categorical variables as observed number and percentage. Differences between groups for normally distributed continuous variables were tested using the independent sample $t$ test. Where continuous variables were not normally distributed, the Mann-Whitney test was used. Categorical variables were tested using Fisher's exact test.

Statistical analysis was performed with SPSS statistical software (SPSS, Inc. release 18.0) and statistical significance was assumed for $p<0.05$. 
CHAPTER V | IDIOPATHIC AF REVISITED IN A LARGE COHORT

\section{RESULTS}

Of the 3,978 AF patients in the Euro Heart Survey on AF with known follow-up, 119 (3\%) patients met our definition of idiopathic AF. The mean (SD) age was $58(14)$ years and the majority was male (72\%). A total of 57 (48\%) of the patients were older than 60 years. Baseline demographic and clinical characteristics of patients stratified for age are presented in Table 1. Persistent or permanent AF was more prevalent in the older compared to the younger idiopathic AF patients ( $n=16(33 \%)$ vs. $n=35(66 \%), p=0.002$, respectively). The mean duration of known AF did not differ between these groups (430 days (IQR 88-1669) versus 310 days (IQR 60-1827), p=0.824). (Figure 1)

Idiopathic atrial fibrillation

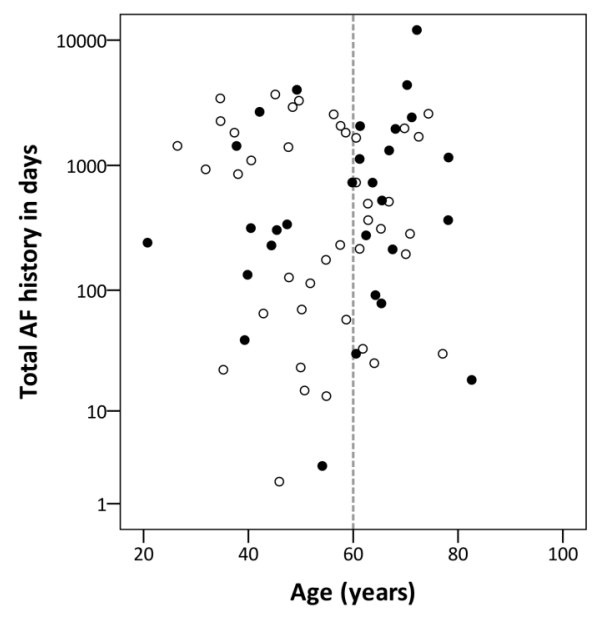

- Paroxysmal atrial fibrillation

- Persistent atrial fibrillation
Isolated hypertension

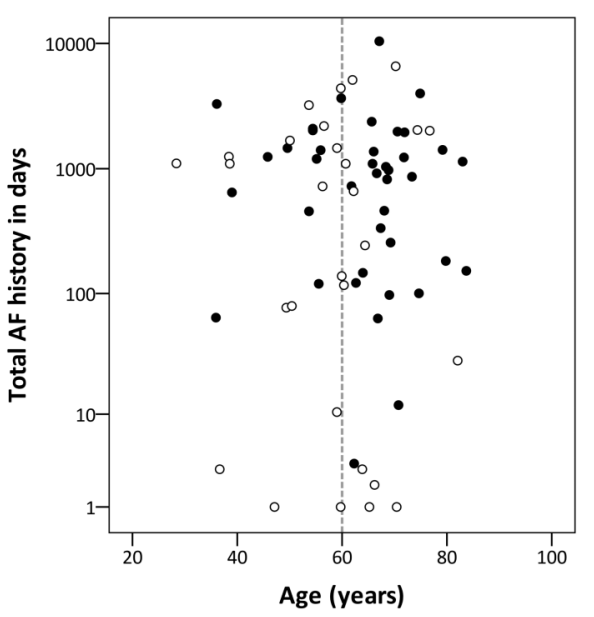

FIGURE 1 - Atrial fibrillation history according to age - No significant difference in total atrial fibrillation history was seen either between patients younger and older than 60 years or in patients with paroxysmal or persistent $\mathrm{AF}$ in both groups of patients with idiopathic atrial fibrillation or $\mathrm{AF}$ in presence of isolated hypertension.

Mean LA size was not significantly different between the older and younger idiopathic $\mathrm{AF}$ patients ( $42 \pm 6$ vs. $39 \pm 4 \mathrm{~mm}$, respectively; $\mathrm{p}=0.07$ ). Also after correction for body mass index there was no significant difference concerning left atrial size $(p=0.742)$. Mean LA sizes differed significantly when comparing patients with paroxysmal $(38 \pm 6 \mathrm{~mm})$ and persistent $(42 \pm 6 \mathrm{~mm}) \mathrm{AF}(\mathrm{p}=0.002)$. No significant agedependent difference was observed in either the persistent ( $42 \pm 4$ in the age $<60$ vs. $42 \pm 6 \mathrm{~mm}$ in the age $\geq 60$ years, $p=0.777$ ) or paroxysmal ( $37 \pm 6$ in the age $<60 \mathrm{vs.} 41 \pm 7$ $\mathrm{mm}$ in the age $\geq 60$ years, $\mathrm{p}=0.093$ ) group. (Figure 2 ) 
TABLE 1 - Baseline characteristics and follow-up by age group in adults with idiopathic atrial fibrillation and AF patients with isolated hypertension

\begin{tabular}{|c|c|c|c|c|c|c|}
\hline & \multicolumn{3}{|c|}{ Idiopathic atrial fibrillation } & \multicolumn{2}{|c|}{$\begin{array}{l}\text { Atrial fibrillation with } \\
\text { isolated hypertension* }\end{array}$} & \multirow[b]{2}{*}{$P$ value $\neq$} \\
\hline & $\begin{array}{c}\text { Age }<60 \\
(n=62)\end{array}$ & $\begin{array}{c}\text { Age } \geq 60 \\
(n=57)\end{array}$ & P valuet & $\begin{array}{c}\text { Age }<60 \\
(n=52)\end{array}$ & $\begin{array}{c}\text { Age } \geq 60 \\
(n=100)\end{array}$ & \\
\hline \multicolumn{7}{|l|}{ Demographics } \\
\hline Female, n (\%) & $11(18)$ & $22(38)$ & 0.065 & $9(17)$ & $43(43)$ & 0.002 \\
\hline Age & $43 \pm 8$ & $69 \pm 7$ & $<0.001$ & $51 \pm 8$ & $69 \pm 7$ & $<0.001$ \\
\hline Body Mass Index $\left(\mathrm{kg} / \mathrm{m}^{2}\right)$ & $26 \pm 3$ & $27 \pm 4$ & 0.395 & $28 \pm 4$ & $28 \pm 4$ & 0.578 \\
\hline Persistent or permanent AF & $16 / 47(34)$ & $35 / 53(66)$ & 0.002 & $23 / 47$ (49) & $60 / 86(70)$ & 0.024 \\
\hline AF history (days), median (IQR) & $310(60-1827)$ & $430(88-1669)$ & 0.824 & 1099 (79-1679) & $344(20-1185)$ & 0.179 \\
\hline AF symptoms, n (\%) & $35(57)$ & $38(67)$ & 0.266 & $40(77)$ & $67(67)$ & 0.262 \\
\hline Family history of AF, $\mathrm{n}(\%)$ & $5 / 51(10)$ & $1 / 53(2)$ & 0.109 & $2 / 46(4)$ & $5 / 91(6)$ & 1.0 \\
\hline $\mathrm{SBP}(\mathrm{mmHg})$ & $127 \pm 16$ & $129 \pm 12$ & 0.057 & $139 \pm 20$ & $144 \pm 20$ & 0.114 \\
\hline $\mathrm{DBP}(\mathrm{mmHg})$ & $78 \pm 9$ & $78 \pm 8$ & 0.807 & $88 \pm 11$ & $85 \pm 11$ & 0.077 \\
\hline eGFR & $82 \pm 20$ & $70 \pm 13$ & 0.020 & $85 \pm 45$ & $65 \pm 15$ & 0.247 \\
\hline \multicolumn{7}{|l|}{ Echocardiography } \\
\hline Left atrial size (mm) & $39 \pm 4$ & $42 \pm 6$ & 0.070 & $41 \pm 7$ & $42 \pm 7$ & 0.402 \\
\hline Left atrial size/BMI & $1.50 \pm 0.29$ & $1.56 \pm 0.31$ & 0.742 & $1.54 \pm 0.53$ & $1.55 \pm 0.32$ & 0.247 \\
\hline Left ventricular EF (\%) & $62 \pm 7$ & $64 \pm 9$ & 0.776 & $61 \pm 8$ & $63 \pm 8$ & 0.040 \\
\hline \multicolumn{7}{|l|}{ Medication } \\
\hline Vitamin $\mathrm{K}$ antagonists, $\mathrm{n}(\%)$ & $27(44)$ & $37(65)$ & 0.201 & $30(58)$ & $64(64)$ & 0.593 \\
\hline Aspirin, n (\%) & $11(18)$ & $6(10)$ & 0.190 & $17(33)$ & $26(26)$ & 0.446 \\
\hline Rhythm control strategy, n (\%) & $47(76)$ & $38(67)$ & 0.067 & $28(54)$ & $48(48)$ & 0.494 \\
\hline \multicolumn{7}{|l|}{ Follow up } \\
\hline Hospital visits, n (\%) & $24(39)$ & $15(26)$ & 0.025 & $18(35)$ & $22(22)$ & 0.07 \\
\hline AF related admissions & $1.09 \pm 2.16$ & $0.3 \pm 0.54$ & 0.009 & $0.65 \pm 1.15$ & $0.38 \pm 0.77$ & 0.147 \\
\hline Progression PAF - PermAF, n (\%) & $1(2)$ & $1(2)$ & 1.0 & 0 & $1(1)$ & 1.0 \\
\hline Stroke during Follow up, n (\%) & 0 & 0 & 1.0 & $1(2)$ & $4(4)$ & 0.661 \\
\hline
\end{tabular}

Data presented as mean $\pm \mathrm{SD}$, unless otherwise specified.

* Isolated hypertension is defined as: patients from the Euro Heart Survey on AF database with systemic hypertension (diagnosis of hypertension, or anti-hypertensive drug use) of all ages and left atrial sizes, but without other demonstrable structural heart disease, thus excluding left ventricular hypertrophy and any of the other disease states mentioned in our definition for idiopathic AF (see methods section).

$+P$ value for comparison between idiopathic AF groups

$\ddagger \mathrm{P}$ value for comparison between hypertension groups 
SBP: systolic blood pressure, DBP: diastolic blood pressure, eGFR: estimated glomerular filtration rate, EF: left ventricular ejection fraction, PAF: paroxysmal atrial fibrillation, PermAF: permanent atrial fibrillation.

Rhythm control was frequently applied in both age groups. However, rhythm control was slightly more often applied in the younger group compared to those aged $\geq 60$ (76\% versus 67\%; $p=0.067$ ) which related to a higher prevalence of AF symptoms

in the former group. This led to more hospital visits during follow-up in the younger group ( $n=24(39 \%)$ versus $n=15(26 \%) ; p=0.025)$. Despite the fact that all patients had a low stroke risk, many received vitamin $\mathrm{K}$ antagonists $(27(44 \%)$, in the age $<60$ vs. $37(65 \%)$ in the age $\geq 60$ years group, $p=0.201)$.

Only 2 paroxysmal AF patients progressed to permanent $A F$, and no cardiovascular events occurred during one year follow-up.

A total of 152 (4\%) patients suffered from isolated hypertension (Table 1). Except for blood pressures, the clinical profile of these patients was similar to that of idiopathic AF patients. AF history did not differ between age groups.(Figure 1) In addition, the average LA size is normal and without significant differences between age groups. (Figure 2) Only 1 patient showed progression to permanent AF. However, five patients suffered a stroke ( 4 males; mean age: $63 \pm 6$ years; mean LA size: $39 \pm 6 \mathrm{~mm})$, all in the absence of oral anticoagulation and no stroke occurred periprocedurally (cardioversion or ablation).
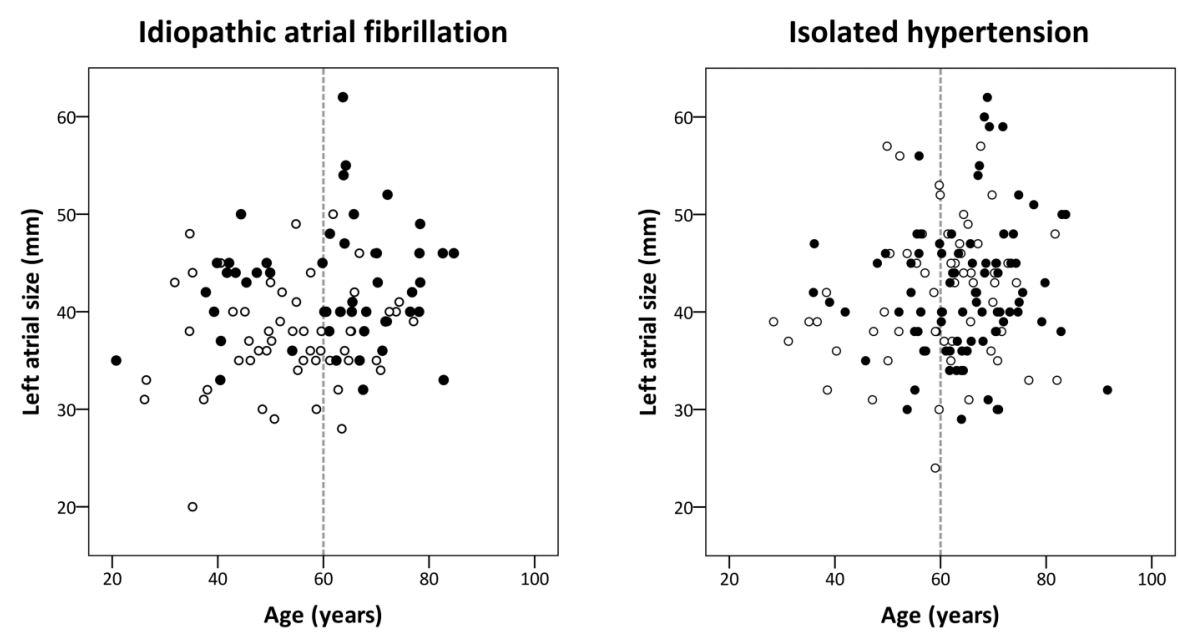

- Paroxysmal atrial fibrillation

- Persistent atrial fibrillation

FIGURE 2 - Left atrial size according to age - Left atrial size did not differ between younger and older patients in both groups of patients with idiopathic atrial fibrillation or AF in presence of isolated hypertension. 


\section{DISCUSSION}

The present study challenges the concept of using an age limit in defining idiopathic AF. It shows that the clinical profile of older and younger patients is generally similar. In particular, idiopathic AF may present at advanced age and is even then not associated with significant atrial enlargement, AF progression or an adverse short-term prognosis. However, if AF emerges at an older age there is a higher likelihood that it is persistent. Although we allowed any age and any LA size, the prevalence of idiopathic AF was only $3 \%$ in the Euro Heart Survey which is at the lower end of what has been reported previously, probably relating to our otherwise very strict definition. Of note, the total duration of AF did not differ between the young and the older idiopathic AF patients, suggesting that biological age rather than calendar age is an important determinant of the cardiovascular prognosis in idiopathic AF.

\section{The importance of age in the definition of idiopathic atrial fibrillation}

A biological basis for the age criterion in the definition of idiopathic AF is lacking. It seems a convenient cut off with which one can avoid an incorrect diagnosis of idiopathic AF as much as possible. The criterion typically stems from an era where diagnostic tools such as echocardiography, CT-angiography and cardiac MR imaging were unavailable or not yet robust. A key observation in our cohort is that idiopathic AF may start at any age (figure 1). We would therefore hypothesize that in the healthy elderly, late onset idiopathic AF may occur as in the younger patients, simply because trigger mechanisms or substrate development (or both) can occur at a later age.

Indeed, in patients who are older than 60 years, AF is a risk factor for cardiovascular events. ${ }^{4}$ Besides, age is an independent predictor of AF progression on the short and long term, as well as its complications. ${ }^{13}$ However, little is known about the importance of ageing in idiopathic AF patients. In an Olmsted County cohort of 55 patients, Kopecky et al showed that idiopathic AF occurring at an older age was a risk marker for a substantial increase in cardiovascular events. ${ }^{14}$ However, the number of patients in this cohort was small, cardiovascular risk factors were not reported, echocardiography not performed systematically to exclude cardiac disease and outcomes not adjusted for treatment. A later report from the same group suggested that an increasing left atrial size rather than age is an important determinant of cardiovascular risk. ${ }^{15}$

Age seems related to type of AF since persistent AF was more frequent in the older patients. It is possible that AF lasted - unknowingly - longer (and became persistent) in the elderly patients since AF duration is not always easy to establish. However, in most patients the duration of AF was reported and the older patients were not significantly more asymptomatic when compared to the younger patients. Notwithstanding the above, persistent AF was associated with a larger left atrial size suggesting that a continuous and therefore higher AF burden leads to LA enlargement. One may object that LA enlargement is the cause rather than the consequence of $A F$ being persistent but in the absence of any heart disease potentially causing an increase in LA size, this is not the most probable scenario. As stated above, it may be 
that older patients with AF present later after its onset, and therefore have more atrial remodelling than younger patients at the time of first detection. Taken together, a likely mechanism for the higher prevalence of persistent AF among the older idiopathic AF patients could be that elderly patients develop more readily atrial enlargement after AF onset compared to younger patients, which in turn is associated with persistent AF.

This therefore raises the question if age, apart from its general contribution to morbidity and mortality, has an additional role in the "healthy" AF patients. As a consequence, stroke risk assessment schemes may lose their predictive power in the elderly with idiopathic AF since both the $\mathrm{CHADS}_{2}$ and $\mathrm{CHA}_{2} \mathrm{DS}_{2}-\mathrm{VASc}$ scoring systems apply to patients $\geq 75$ years of age and/or 65-74 years of age. ${ }^{2}$ However, idiopathic AF patients may develop cardiovascular disease over time, especially the elderly. ${ }^{15}$ In the above mentioned Olmsted County population, Osranek et al. showed that in the very long term, approximately half of idiopathic AF patients initially younger than 60 years develop cardiovascular events, and that the occurrence of these events was associated with premature dilatation of the left atrium. ${ }^{15}$ This supports using LA size rather than age when defining idiopathic $A F$ and when assessing cardiovascular risk.

\section{Left atrial size in idiopathic atrial fibrillation}

Increased LA size is associated with increased risk of AF onset and recurrence, other cardiovascular disease and mortality. ${ }^{15,16}$ Analyses using volumetric atrial data in the past suggest that atrial enlargement may not be part of the 'normal' ageing process but may be the consequence of a greater burden of risk factors that accompanies ageing. ${ }^{17}$ Furthermore, the arrhythmia itself is a main contributor of atrial remodeling, characterized by atrial dilatation and shortening of the atrial effective refractory period, and this process can be reversed by restoration of sinus rhythm. ${ }^{8,9,18,19}$ of note, current guidelines on the management of AF suggest a maximal atrial diameter of $50 \mathrm{~mm}$ in the definition of idiopathic $A F{ }^{2,20}$ The present study indeed shows that if one critically selects idiopathic AF it is very likely that the LA size rarely exceeds $50 \mathrm{~mm}$. The present study therefore supports the notion that in a patient with seemingly lone AF a significantly enlarged LA should trigger additional investigation of underlying heart disease.

\section{Blood pressure and absent structural heart disease}

Isolated hypertension, i.e. without any other cardiovascular disease or ventricular remodelling, seems of prognostic importance in the setting of AF since it was associated with 6\% 1-year stroke rate. Arterial hypertension is the most important treatable cardiovascular risk factor for premature death, stroke, coronary heart disease, kidney disease, and heart failure. ${ }^{21}$ Even patients with so-called prehypertension (SBP of $120-139 \mathrm{mmHg}$ and DBP of $80-89 \mathrm{mmHg}$ ) or patients with increased visit-to-visit variability in systolic blood pressure are at increased risk of developing cardiovascular disease compared with those with blood pressure levels less than $120 / 80 \mathrm{mmHg}^{22-24}$ In addition, arterial hypertension but also pre-hypertension predisposes to $\mathrm{AF}$, thereby promoting cerebral embolism. ${ }^{25,26}$ 
Our results appear to confirm that hypertension in the absence of any other detectable cardiovascular disease including absence of left ventricular hypertrophy is an important driver of stroke in absence of anticoagulation. These findings emphasize the importance of regular ambulatory blood pressure monitoring and adequate treatment of early hypertension. ${ }^{27}$ This holds even more since hypertension may develop or become apparent in many patients not long after initial diagnosis of idiopathic AF. ${ }^{28}$ All in all, it could be suggested that blood pressure may be more important than age as a parameter in the definition of idiopathic AF.

\section{Idiopathic atrial fibrillation definition in the future}

AF occurs frequently, and the prevalence of AF only will get higher as the population ages. ${ }^{2}$ As prevalence increases, so does the list of associated risk factors for AF. The traditional risk factors associated with AF (i.e. age, hypertension, congestive heart failure, valvular heart disease, coronary artery disease or thyroid disease) are no longer the only conditions that we must consider in the evaluation of causal factors in a patient with first detected $A F .{ }^{6,29-32}$ As this list of possible triggers for AF expands, it seems almost impossible to diagnose a patient with AF in absence of any underlying possible causal factor. Besides, new non-invasive diagnostic tools such as cardiac CT angiography or cardiac MR imaging make it easier to detect cardiovascular disease in its early stage.

$\mathrm{AF}$ is not a benign condition and its well known complications and increased stroke risk form the major threat of the arrhythmia. Thus, it would be worthwhile to study the clinical applicability of classifying AF patients on their individual risk profile for the development of major adverse cardio- or cerebrovascular events more than we do now. In this case, the term idiopathic AF could perhaps be changed into 'low risk' AF. Over time, risk factors for major cardiovascular events may develop, emphasizing the importance of reassessment. On the basis of our results, it may be surmised that stroke prevention can be enhanced in the elderly idiopathic AF patients by regular assessment of LA size and blood pressure.

Notwithstanding the above, this study confirms that the cardiovascular outcome in patients with idiopathic AF may be closer related to the "biological age" of the cardiovascular system than to someone's "calendar age".

\section{LIMITATIONS}

We performed a subgroup analysis of the Euro Heart Survey on AF and as a result, our data should be interpreted with care. The study result was obtained in a relatively small and - by its nature - selected population and should be reproduced in other cohorts. The follow-up duration was relatively short and we could not assess development of risk factors or adverse events on the long term. Data on the higher incidence of cardiovascular events in the hypertension group may have been influenced by the above and should be interpreted with care. Further, although we meticulously tried to rule out hypertension, specific cases of masked hypertension 
could be missed since 24 hour ambulatory blood pressure monitoring was not available in the Euro Heart Survey. Parameters to calculate diastolic function, as underlying aetiology of $\mathrm{AF}$, were not measured in this cohort. However, absence of significant left atrial enlargement is a valid surrogate measure for the absence of increased left ventricular filling pressures in our population. Although comparable with other studies, the prevalence of idiopathic AF according to our definition in the Euro Heart Survey on AF is relatively low (3\%). This reflects the strict definition we used to robustly try to rule out underlying heart disease, especially with regards to hypertension.

\section{CONCLUSION}

Idiopathic AF may present at advanced age in half of patients and is even then not associated with significant atrial enlargement, AF progression or an adverse short term prognosis. In contrast, elevated blood pressure even when found in the absence of significant atrial remodelling and left ventricular hypertrophy, and in absence of anticoagulation, seems of prognostic importance. Therefore, a cut off for blood pressure rather than age should be used when defining idiopathic AF.

\section{FUNDING}

This work was supported by: AstraZeneca (main sponsor), Sanofi-Aventis (major sponsor), Eucomed (sponsor), Austrian Heart Foundation, Austrian Society of Cardiology, French Federation of Cardiology, Hellenic Cardiological Society, Netherlands Heart Foundation, Portuguese Society of Cardiology, Spanish Cardiac Society, Swedish Heart and Lung Foundation and individual centres.

\section{ACKNOWLEDGMENTS}

We thank the Euro Heart Survey team, national co-ordinators, investigators and data collection officers for performing the baseline and follow-up surveys.

\section{COMPETING INTERESTS}

None declared 


\section{REFERENCES}

1. Brand FN, Abbott RD, Kannel WB, Wolf PA. Characteristics and prognosis of lone atrial fibrillation. 30-year follow-up in the Framingham Study. Jama. 1985 Dec 27;254(24):3449-53.

2. Camm AJ, Kirchhof P, Lip GY, Schotten U, Savelieva I, Ernst S, et al. Guidelines for the management of atrial fibrillation: the Task Force for the Management of Atrial Fibrillation of the European Society of Cardiology (ESC). European heart journal. 2010 Oct;31(19):2369-429.

3. Evans W, Swann P. Lone auricular fibrillation. British heart journal. 1954 Apr;16(2):189-94.

4. Kopecky SL, Gersh BJ, McGoon MD, Whisnant JP, Holmes DR, Jr., Ilstrup DM, et al. The natural history of lone atrial fibrillation. A population-based study over three decades. N Engl J Med. 1987 Sep 10;317(11):669-74.

5. Levy S. Epidemiology and classification of atrial fibrillation. Journal of cardiovascular electrophysiology. 1998 Aug;9(8 Suppl):S78-82.

6. Kozlowski D, Budrejko S, Lip GY, Rysz J, Mikhailidis DP, Raczak G, et al. Lone atrial fibrillation: what do we know? Heart (British Cardiac Society). 2010 Apr;96(7):498-503.

7. Rienstra M, Hagens VE, Van Veldhuisen DJ, Bosker HA, Tijssen JG, Kamp O, et al. Clinical characteristics of persistent lone atrial fibrillation in the RACE study. Am J Cardiol. 2004 Dec 15;94(12):1486-90.

8. Allessie MA, Boyden PA, Camm AJ, Kleber AG, Lab MJ, Legato MJ, et al. Pathophysiology and prevention of atrial fibrillation. Circulation. 2001 Feb 6;103(5):769-77.

9. Sanfilippo AJ, Abascal VM, Sheehan M, Oertel LB, Harrigan P, Hughes RA, et al. Atrial enlargement as a consequence of atrial fibrillation. A prospective echocardiographic study. Circulation. 1990 Sep;82(3):792-7.

10. Nieuwlaat R, Capucci A, Camm AJ, Olsson SB, Andresen D, Davies DW, et al. Atrial fibrillation management: a prospective survey in ESC member countries: the Euro Heart Survey on Atrial Fibrillation. European heart journal. 2005 Nov;26(22):2422-34.

11. Nieuwlaat R, Prins MH, Le Heuzey JY, Vardas PE, Aliot E, Santini M, et al. Prognosis, disease progression, and treatment of atrial fibrillation patients during 1 year: follow-up of the Euro Heart Survey on atrial fibrillation. European heart journal. 2008 May;29(9):1181-9.

12. Lang RM, Bierig M, Devereux RB, Flachskampf FA, Foster E, Pellikka PA, et al. Recommendations for chamber quantification. Eur J Echocardiogr. 2006 Mar;7(2):79-108.

13. de Vos CB, Pisters R, Nieuwlaat R, Prins MH, Tieleman RG, Coelen RJ, et al. Progression from paroxysmal to persistent atrial fibrillation clinical correlates and prognosis. J Am Coll Cardiol. 2010 Feb 23;55(8):725-31. 
CHAPTER V | IDIOPATHIC AF REVISITED IN A LARGE COHORT

14. Kopecky SL, Gersh BJ, McGoon MD, Chu CP, Ilstrup DM, Chesebro JH, et al. Lone atrial fibrillation in elderly persons: a marker for cardiovascular risk. Arch Intern Med. 1999 May 24;159(10):1118-22.

15. Osranek M, Bursi F, Bailey KR, Grossardt BR, Brown RD, Jr., Kopecky SL, et al. Left atrial volume predicts cardiovascular events in patients originally diagnosed with lone atrial fibrillation: three-decade follow-up. European heart journal. 2005 Dec;26(23):2556-61.

16. Benjamin EJ, D'Agostino RB, Belanger AJ, Wolf PA, Levy D. Left atrial size and the risk of stroke and death. The Framingham Heart Study. Circulation. 1995 Aug 15;92(4):835-41.

17. Thomas L, Levett K, Boyd A, Leung DY, Schiller NB, Ross DL. Compensatory changes in atrial volumes with normal aging: is atrial enlargement inevitable? J Am Coll Cardiol. 2002 Nov 6;40(9):1630-5.

18. Gosselink AT, Crijns HJ, Hamer HP, Hillege H, Lie KI. Changes in left and right atrial size after cardioversion of atrial fibrillation: role of mitral valve disease. $J$ Am Coll Cardiol. 1993 Nov 15;22(6):1666-72.

19. Schotten U, de Haan S, Neuberger HR, Eijsbouts S, Blaauw Y, Tieleman R, et al. Loss of atrial contractility is primary cause of atrial dilatation during first days of atrial fibrillation. American journal of physiology. 2004 Nov;287(5):H232431.

20. Fuster V, Ryden LE, Cannom DS, Crijns HJ, Curtis AB, Ellenbogen KA, et al. ACC/AHA/ESC 2006 guidelines for the management of patients with atrial fibrillation: full text: a report of the American College of Cardiology/American Heart Association Task Force on practice guidelines and the European Society of Cardiology Committee for Practice Guidelines (Writing Committee to Revise the 2001 guidelines for the management of patients with atrial fibrillation) developed in collaboration with the European Heart Rhythm Association and the Heart Rhythm Society. Europace. 2006 Sep;8(9):651-745.

21. Ezzati M, Lopez AD, Rodgers A, Vander Hoorn S, Murray CJ. Selected major risk factors and global and regional burden of disease. Lancet. 2002 Nov 2;360(9343):1347-60.

22. Chobanian AV, Bakris GL, Black HR, Cushman WC, Green LA, Izzo JL, Jr., et al. Seventh report of the Joint National Committee on Prevention, Detection, Evaluation, and Treatment of High Blood Pressure. Hypertension. 2003 Dec;42(6):1206-52.

23. Vasan RS, Larson MG, Leip EP, Kannel WB, Levy D. Assessment of frequency of progression to hypertension in non-hypertensive participants in the Framingham Heart Study: a cohort study. Lancet. 2001 Nov 17;358(9294):1682-6.

24. Rothwell PM, Howard SC, Dolan E, O'Brien E, Dobson JE, Dahlof B, et al. Prognostic significance of visit-to-visit variability, maximum systolic blood pressure, and episodic hypertension. Lancet. 2010 Mar 13;375(9718):895905. 
25. Conen D, Tedrow UB, Koplan BA, Glynn RJ, Buring JE, Albert CM. Influence of systolic and diastolic blood pressure on the risk of incident atrial fibrillation in women. Circulation. 2009 Apr 28;119(16):2146-52.

26. Jahangir A, Lee V, Friedman PA, Trusty JM, Hodge DO, Kopecky SL, et al. Longterm progression and outcomes with aging in patients with lone atrial fibrillation: a 30-year follow-up study. Circulation. 2007 Jun 19;115(24):30506.

27. Fogari R, Mugellini A, Zoppi A, Preti P, Destro M, Lazzari P, et al. Effect of Telmisartan and Ramipril on Atrial Fibrillation Recurrence and Severity in Hypertensive Patients With Metabolic Syndrome and Recurrent Symptomatic Paroxysmal and Persistent Atrial Fibrillation. Journal of cardiovascular pharmacology and therapeutics. 2011 Feb 18;Epub ahead of print.

28. Katritsis DG, Toumpoulis IK, Giazitzoglou E, Korovesis S, Karabinos I, Paxinos $\mathrm{G}$, et al. Latent arterial hypertension in apparently lone atrial fibrillation. J Interv Card Electrophysiol. 2005 Sep;13(3):203-7.

29. Schoonderwoerd BA, Smit MD, Pen L, Van Gelder IC. New risk factors for atrial fibrillation: causes of 'not-so-lone atrial fibrillation'. Europace. 2008 Jun;10(6):668-73.

30. Mattioli AV, Bonatti S, Zennaro M, Mattioli G. The relationship between personality, socio-economic factors, acute life stress and the development, spontaneous conversion and recurrences of acute lone atrial fibrillation. Europace. 2005 May;7(3):211-20.

31. Mont L, Tamborero D, Elosua R, Molina I, Coll-Vinent B, Sitges M, et al. Physical activity, height, and left atrial size are independent risk factors for lone atrial fibrillation in middle-aged healthy individuals. Europace. 2008 Jan;10(1):15-20.

32. Rosiak M, Dziuba M, Chudzik M, Cygankiewicz I, Bartczak K, Drozdz J, et al. Risk factors for atrial fibrillation: Not always severe heart disease, not always so 'lonely'. Cardiology journal. 2010;17(5):437-42. 
CHAPTER V | IDIOPATHIC AF REVISITED IN A LARGE COHORT 


\section{EDITORIAL IDIOPATHIC ATRIAL FIBRILLATION: A ROSE BY ANY OTHER NAME?}

D. George Wyse MD, PhD

Department of Cardiac Sciences, Libin Cardiovascular Institute of Alberta, University of Calgary, Calgary, AB, Canada

Europace. 2012 Feb;14(2):151-2 


\section{EDITORIAL}

The category of idiopathic, sometimes called 'lone', atrial fibrillation (AF) is a mythic creature. A sort of 'leftover' category of 'AF with no apparent explanation or underlying etiology', idiopathic, or lone AF is often a source of fascination and frequently mentioned. Nevertheless, it is not an entity with a clear definition that is widely acknowledged and accepted. There are several problems in trying to come up with a suitable definition, particularly over different epochs of time. Even within frequently used definitions there are variations, uncertainties, and inconsistencies.

It remains uncertain whether defining idiopathic AF is in itself a useful exercise. It is noteworthy that the number of medical conditions, anthropometric measures, and genotypes associated with AF and our diagnostic capabilities have all increased dramatically over the last few decades. Thus, the task of defining idiopathic AF seems much like that of the mythic Sisyphus, who endlessly rolled a rock to the top of a hill in Hades only to have it return to the bottom, requiring him to start all over again. Just when we have a definition of idiopathic AF with which we are content, a new underlying etiology or a better diagnostic test for known underlying etiologies comes along that requires starting all over again. As a consequence, the proportion of cases of new-onset AF that truly have no explanation has become smaller and smaller ( $3 \%$ in the present report ${ }^{1}$ ) as time passes. One wonders whether this diagnosis will disappear altogether at some point in the future. Nonetheless, in this issue of the journal the definition of idiopathic AF is re-explored using patients enrolled in the Euro Heart Survey on $\mathrm{AF}^{1}{ }^{1}$

It has frequently but not always been customary to include exclusion for age, often age over 60 years, in the definition of idiopathic $\mathrm{AF}^{2}{ }^{2}$ One presumed reason for including such a provision in the definition is to exclude as yet unknown 'causes' or silent underlying etiologies for AF that are, like AF, frequently found within the aging process, given the strong relationship between age and incident $A F .^{3}$ Another reason for excluding elderly patients is that frequently the definition of idiopathic AF is applied retrospectively to a cohort after the data have already been collected.

The data set therefore may not include underlying etiologies that are actually known to be associated with AF but were not included as data were being collected, as the data set was not planned with this particular purpose in mind. Nevertheless, it is certainly seems plausible that AF may emerge in patients older than 60 years without any apparent 'cause' and in the absence of any of the known underlying etiologies for AF. Furthermore, designating anyone older than 60 years as 'elderly' seems rather quaint and outdated in the modern era. In the report of Weijs et al. it turns out that about half of the patients in the Euro Heart Survey on AF who otherwise qualified for the designation of idiopathic AF were older than 60 years. ${ }^{1}$ The age limit of 60 years does seem excessively conservative in the modern era. It seems perfectly reasonable to remove this particular age restriction from the definition of idiopathic AF. Whether there should be absolutely no age restriction whatsoever is arguable, however.

What other problems of definition are to be considered with respect to idiopathic AF? By far the most frequently encountered problems are found swirling 
around the apparent need to exclude a history of, or the presence of, hypertension again because of the strong association between hypertension and AF. ${ }^{4}$ The absence of hypertension in 1971 is not the same as the absence of hypertension in 2011. The definition of hypertension itself over the decades has been anything but constant. It is arguable that a single pressure for all ages is a suitable criterion for exclusion of hypertension. How many measurements of blood pressure must exceed the current arbitrary pressure limit to make the diagnosis of hypertension is debatable. Alternatively, how many blood pressures must be measured to exclude hypertension? Is labile or 'white coat' hypertension the same as constant hypertension with respect to pathogenesis of AF? The questions seem endless. Here again, the authors come up against the limitations of the data available in the Euro Heart Survey on AF. The definition for hypertension they chose seems reasonable enough: a history of hypertension [defined as antihypertensive drug use (diuretics, angiotensin-converting enzyme inhibitors, angiotensin II receptor antagonists, aldosterone receptor antagonists, dihydropyridine calcium-channel blockers) or a systolic blood pressure $\geq 140 \mathrm{mmHg}$ or a diastolic blood pressure $\geq 90 \mathrm{mmHg}$ on the qualifying visit, or left ventricular hypertrophy interventricular septum width $.10 \mathrm{~mm}$, posterior wall width $.10 \mathrm{~mm}]^{1}$ However, can we be sure that all hypertensives have been excluded with this definition? I think probably not. It is interesting that part of their definition of hypertension was the echocardiographic finding of left ventricular hypertrophy, a known consequence of hypertension and a frequent indicator of hypertensive heart disease. Paradoxically they did not exclude left atrial enlargement (volume, diameter, area) on the echocardiogram in their definition of idiopathic AF. In fact, they made a major point about not using left atrial size in the definition. The argument they put forward for doing so is that an enlarged left atrium can be a consequence rather than a 'cause' of AF. They are undoubtedly correct in this supposition. However, this leads into another of those endless arguments for which there is no correct answer. In patients with $A F$ is an enlarged left atrium always the consequence of AF? Certainly one sees patients in situations when one can be fairly confident that they are presenting with their first and only episode of AF and the left atrium is already enlarged and thus logically part of the 'cause' for AF. Left atrial enlargement is a frequent fellow traveller with hypertension. Thus, it seems more reasonable to take the position that left atrial enlargement can be both a 'cause' and a 'consequence' of AF. Finally, the measurement they used was a simple left atrial diameter (albeit normalized for body mass index). In reading the reports of echocardiograms I am impressed by the inconsistency and lack of agreement between simple left atrial diameter and left atrial volume, particularly when normalized for body mass index, in determination of whether the left atrium is actually enlarged. For these reasons, I think the authors are on a bit of a slippery slope in ignoring left atrial size in their definition of idiopathic AF. How convincing is the authors' argument that age and left atrial size doesn't count in defining idiopathic AF? Even within their own data a skeptic might point out a couple of their observations raise doubts. In spite of the authors' assertion that there was no difference in left atrial diameter between patients above and below the 60-year-old threshold, there does seem to be a strong trend $(P=0.07)$. 
What would the data look like if they had used left atrial volume, or a slightly different age cut-off, or had more patients?

Assuming there is some fundamental mechanistic difference between paroxysmal and persistent $A F$, one could also argue that the observation that older patients had more persistent AF than paroxysmal AF also seems to be trying to tell us something. Once again Sisyphus comes to mind. What is the purpose of the task? Getting to the top of the hill and staying there seems to be out of the question. As in previous studies the authors found that those patients who met their definition of idiopathic AF had a lower risk of morbidity over the next year. In this case, a lower risk of stroke was found compared with patients with uncomplicated hypertension and no other apparent underlying etiologic condition (including left ventricular hypertrophy) for $A F$, although the numbers are small. Finding low risk of morbidity in idiopathic AF is consistent with other lines of evidence, suggesting much of the serious morbidity and probably mortality associated with $\mathrm{AF}$ is more likely due to associated medical conditions rather than $\mathrm{AF}$ itself. ${ }^{5}$

Rather than tweaking the definition of idiopathic AF and describing the resultant population and their risk of morbidity, a potentially more interesting exercise is to try to determine why these patients actually have AF. Could there be a genetic mechanism? Would examination of such patients with new diagnostic techniques such as cardiac magnetic resonance imaging determine the presence of a common denominator that 'causes' all AF even that considered to be idiopathic? An interesting emerging candidate in this respect is fibrosis of the atria. ${ }^{6,7}$ Extrapolating from the role of fibrosis in the so-called isolated diastolic heart failure, ${ }^{8}$ an understanding of the various factors that initiate fibrosis in the heart, could lead to new upstream therapies aimed at primary prevention of AF in targeted patients. Factors that initiate fibrosis in the heart may include some previously unsuspected culprits such as remote transient viral infections or again, a genetic predisposition to atrial fibrosis.

We are a long way from understanding the fundamental basis for AF and until we have such knowledge primary prevention of AF remains a noble but elusive goal. Idiopathic AF may be a rarer and rarer problem as time passes but understanding why it happens could be an important step in developing new paradigms for the treatment of AF. As so eloquently stated by the poet Robert Frost we truly 'have miles to go before we sleep'. 
CHAPTER V | IDIOPATHIC AF REVISITED IN A LARGE COHORT

\section{CONFLICT OF INTEREST}

Disclosures for past two years: Honoraria as a member of Data Monitoring Committee-Boerhinger Ingelheim, Medtronic, Bristol Myers Squibb/Pfizer, Sanofi Aventis, Biotronik; All $<\$ 10,000$.

\section{REFERENCES}

1. Weijs B, Pisters R, Nieuwlaat R, Breithhardt G, Le Heuzey J-Y, Vardas PE et al. Idiopathic atrial fibrillation revisited in a large longitudinal clinical cohort. Europace 2012;14:184-190.

2. Jahangir A, Lee V, Friedman PA, Trusty JM, Hodge DO, Kopecky SL et al. Longterm progression and outcomes with aging in patients with lone atrial fibrillation. Circulation 2007;115:3050-6.

3. Lloyd-Jones DM,Wang TJ, Leip EP, Larson MG, Levy D, Vasan RS et al. Lifetime risk for development of atrial fibrillation: the Framingham Heart Study. Circulation 2004; 110:1042-6.

4. Mitchell GF, Vasan RS, Parise H, Wang TJ, Larson MG, D'Agostino RB et al. Pulse pressure and risk of new-onset atrial fibrillation. JAMA 2007;297:709-15.

5. Benjamin EJ,Wolf PA, D'Agostino RB, Silbershatz H, Kannel WB, Levy D. Impact of atrial fibrillation on the risk of death. Circulation 1998;98:946-52.

6. Yue L, Xie J, Nattel S. Molecular determinants of cardiac fibroblast electrical function and therapeutic implications for atrial fibrillation. Cardiovasc Res 2011;89:744-53.

7. Daccarett M, McGann CJ, Akoum NW, MacLeod RS, Marrouche NF. MRI of the left atrium: predicting clinical outcomes in patients with atrial fibrillation. Expert Rev Cardiovasc Ther 2011;9:105-11.

8. Jellis C, Martin J, Narula J, Marwick TH. Assessment of nonischemic myocardial fibrosis. J Am Coll Cardiol 2010;56:89-97. 


\section{CHAPTER VI MASKED HYPERTENSION IN A PATIENT WITH IDIOPATHIC ATRIAL FIBRILLATION}

Bob Weijs MD, Martijn W Smulders MD, Becker SN Alzand MD Department of Cardiology, CARIM, Maastricht University Medical Centre, the Netherlands

Netherlands Journal of Medicine. 2010; 68(10): 328 
CHAPTER VI | MASKED HYPERTENSION IN IDIOPATHIC AF

\section{INTRODUCTION}

Masked hypertension is: normal blood pressures (BPs) in clinical setting and high BP during ambulatory monitoring ${ }^{1}$. Although these patients are at higher cardiovascular risk, there is still no clear consensus definition of masked hypertension.

\section{Case report}

A 48-year-old male with new onset atrial fibrillation and a mean BP of 110/70 during repetitive measurements at the outpatient clinic has been scheduled for 24-hour ambulatory BP monitoring due to unexplained mild left ventricular hypertrophy. His BPs were clearly high in the evening of the ambulatory monitoring as shown in figure 1. Reassessing the date and time of measurements revealed peeks of hypertensive episodes concomitant with the goals of the FIFA 2010 world cup semi-final match Uruguay vs. Netherlands (figure 1). This high susceptibility for external influences and triggered masked hypertension is a risk factor of developing cardiovascular events. Important sport events are known to provoke a sufficient level of stress to trigger symptomatic cardiovascular events ${ }^{2,3}$.

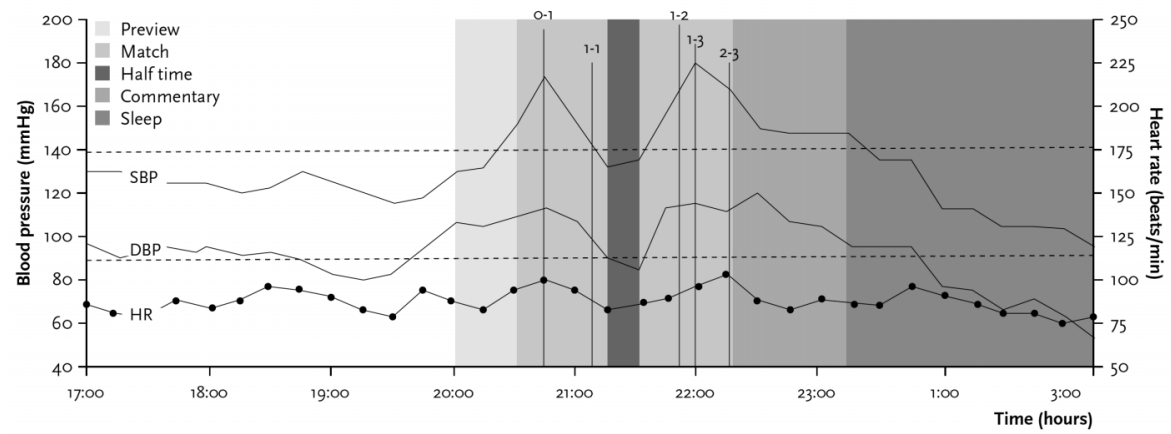

FIGURE 1 - Registration of 24-hour ambulatory blood pressure measurement (SBP: systolic blood pressure; DBP: diastolic blood pressure; HR: heart rate)

\section{REFERENCES}

1 Bobrie G, Clerson P, Ménard J, Postel-Vinay N, Chatellier G, Plouin PF. Masked hypertension: a systematic review. J Hypertension 2008; 26:1715-1725

2 Witte DR, Bots ML, Hoes AW, Grobbee DE. Cardiovascular mortality in Dutch men during 1996 European football championship: longitudinal population study. BMJ 2000; 321:1552-4

3 Wilbert-Lampen U, Leistner D, Greven S, et al. Cardiovascular events during world cup soccer. NEJM 2008; 358:475-483 
CHAPTER VII THE OCCURRENCE OF CARDIOVASCULAR DISEASE DURING 5 YEAR FOLLOW-UP IN PATIENTS WITH IDIOPATHIC ATRIAL FIBRILLATION

B Weijs ${ }^{1}$ MD, CB de $\operatorname{Vos}^{1}$ MD, RG Tieleman ${ }^{2}$ MD PhD, FECM Peeters ${ }^{1}$, I Limantoro ${ }^{1}$ MD, AA Kroon ${ }^{1}$ MD PhD, EC Cheriex ${ }^{1}$ MD PhD, R Pisters ${ }^{1}$ MD PHD, HJGM Crijns $^{1}$ MD PhD

\footnotetext{
${ }^{1}$ Maastricht University Medical Center \& Cardiovascular Research Institute Maastricht, The Netherlands. ${ }^{2}$ Martini Hospital Groningen, The Netherlands.
}

Europace 2012, in press 


\section{ABSTRACT}

Aim: Idiopathic atrial fibrillation (AF) may be an expression of as yet undetected underlying heart disease. We found it useful for clinical practice to study the long-term development of cardiovascular disease (CVD) in patients diagnosed with idiopathic AF. Methods: Forty-one consecutive idiopathic AF patients ( $56 \pm 10$ years, $66 \%$ male) were compared with 45 healthy control patients in permanent sinus rhythm. Patients were free of hypertension, antihypertensive and antiarrhythmic drugs, diabetes, congestive heart failure, coronary artery or peripheral vascular disease, previous stroke, thyroid, pulmonary and renal disease, and structural abnormalities on echocardiography.

Results: Baseline characteristics and echocardiographic parameters were equal in AF cases and controls. During a mean follow-up of $66 \pm 11$ months, CVD occurred significantly more often in idiopathic AF patients compared to controls (49\% vs. $20 \%$, $p=0.006$ ). Patients with idiopathic AF were significantly younger at the time of their first CV event compared to controls ( $59 \pm 9$ vs. $64 \pm 5$ years, $p=0.027$ ), and had more severe disease. Multivariable Cox regression analysis revealed that age, a history of AF and echocardiographic left ventricular wall width were significant predictors of CVD development.

Conclusion: Patients originally diagnosed with idiopathic AF develop CVD more often, at younger age, and with a more severe disease profile compared to healthy sinus rhythm control patients. The detection and treatment of CVD in an early stage could improve the prognosis of these patients. At present it seems prudent to regularly check idiopathic AF patients for the insidious development of CVD. 


\section{INTRODUCTION}

Idiopathic atrial fibrillation (AF) refers to the occurrence of the arrhythmia in the absence of a cardiovascular or pulmonary disease generating the pathophysiological substrate for the arrhythmia. Follow-up data in patients diagnosed with idiopathic AF is sparse and mainly based on two large observational population studies. ${ }^{1-3}$

Data from the Olmsted County database suggest that idiopathic AF is a benign disease with comparable risk of thromboembolism, congestive heart failure and mortality as the general population. In contrast, data from the Framingham Heart Study and the Paris Prospective Study show that idiopathic AF is associated with increased mortality and co-morbidity. ${ }^{1-4}$ Presumably, differences regarding the definition of idiopathic $A F$ in these studies are the main cause of these ambivalent results. Translating the data of these studies into daily clinical practice is not easily established due to the long follow-up duration (mean of 23 years), and the focus on the occurrence of major adverse cardiovascular and cerebrovascular events (MACCE: death, stroke/TIA, myocardial infarction, embolism or major bleeding) instead of cardiovascular disease itself. More recent observational studies show that ageing, development of cardiovascular disease and increased left atrial (LA) volume relate to long term prognosis of idiopathic AF patients. ${ }^{2,5,6}$

The detection and treatment of cardiovascular disease in an early stage could improve the prognosis of these patients. Since idiopathic AF may be an expression of as yet undetected underlying heart disease, we found it useful for clinical practice to study the development of cardiovascular disease over time in patients diagnosed with idiopathic AF.

\section{METHODS}

\section{Study population}

We prospectively studied 41 consecutive idiopathic AF patients and 45 healthy sinus rhythm control patients, who were referred to the outpatient clinic of one of our cardiologists (RGT) between 2004 and 2007 for a standard transthoracic echocardiographic examination (in the work up for AF or for cardiovascular screening purpose in the sinus rhythm control patients). The study was approved by the local Ethics Committee and complied with the declaration of Helsinki. Informed consent of all patients was obtained.

AF patients had to be in AF at time of enrolment or had a previous documented history of paroxysmal or persistent AF defined as a documented episode of atrial fibrillation lasting 30 seconds or more. Idiopathic AF and healthy sinus rhythm were strictly defined as the absence of any cardiovascular disease including hypertension (no antihypertensive drug use [diuretics, angiotensin converting enzyme inhibitors, aldosterone receptor blockers, aldosterone receptor antagonists, nondihydropyridine calcium antagonists, other], all previously recorded systolic blood pressures not exceeding $140 \mathrm{mmHg}$, diastolic blood pressures not exceeding $90 \mathrm{mmHg}$ and absence of left ventricular hypertrophy (interventricular septum width $>10 \mathrm{~mm}$, 
posterior wall width $>10 \mathrm{~mm}$ )), diabetes (fasting blood glucose $>7.0 \mathrm{mmol} / \mathrm{L}$ ), or hypercholesterolemia (total fasting cholesterol $>6.4 \mathrm{mmol} / \mathrm{L}$ and no statin use). In addition, no coronary artery disease (i.e. absence of typical exercise-related angina pectoris, an exercise stress test with significant ST-segment depression, previous acute coronary syndrome, percutaneous or surgical coronary revascularization, or previous angiographically documented coronary disease), no peripheral vascular disease (intermittent claudication, or previous percutaneous or surgical revascularization), no congestive heart failure (no clinical signs or symptoms, left ventricular ejection fraction $>50 \%$, normal diastolic function parameters), no previous stroke, no thyroid or pulmonary disease, no significant renal dysfunction (estimated MDRD $^{7}$ glomerular filtration rate $<60 \mathrm{ml} / \mathrm{min}$ ), no malignancy, and no evidence for structural cardiovascular disease on echocardiography including valvular heart disease.

During follow-up we collected all emerging cardiovascular diseases, including cardiovascular death, thromboembolic complications (stroke, TIA), congestive heart failure, coronary artery disease (acute coronary syndrome, percutaneous or surgical coronary revascularization, or angiographically documented coronary disease with angina pectoris), and new onset hypertension (antihypertensive drug use [diuretics, angiotensin-converting enzyme inhibitors, angiotensin II receptor antagonists, aldosterone receptor antagonists, dihydropyridine calcium-channel blockers], systolic blood pressures exceeding $140 \mathrm{mmHg}$, diastolic blood pressures exceeding $90 \mathrm{mmHg}$, or development of left ventricular hypertrophy [interventricular septum width $\geq 10$ $\mathrm{mm}$, posterior wall width $\geq 10 \mathrm{~mm}$, according to the ASE-convention] during follow-up echocardiography).

\section{The electrocardiogram}

At the time of inclusion and during follow-up, all patients underwent 12-lead electrocardiographic (ECG) recording obtained in the supine position (MAC 5000, Marquette Medical Systems, Milwaukee, Wis.).

\section{Echocardiographic examination}

The echocardiographic examination consisted of a standard 2-dimensional echocardiogram, including M-mode and Doppler echocardiography (Sonos 5500, Philips Medical Systems, Andover, Mass) during continuous electrocardiogram (ECG) monitoring according to the recommendations as described in the American Society of Echocardiography guidelines. After we obtained baseline echocardiographic data, all measurements for study purposes were made by an independent observer who was blinded for arrhythmia history and other patient characteristics. Echocardiography during follow-up was left at the discretion of the treating physician.

\section{Data collection}

Patient characteristics, including medication, (arrhythmia) history, electrocardiograms, visits to cardiac emergency department, hospital admissions and major cardiovascular events at the time of echocardiography and during follow-up were obtained and crosschecked by two independent observers. Data were derived from the patient charts 
(both hospital and general practitioner), electronic medical records and the electronic ECG database, which stores all ECGs and Holter recordings, performed in our hospital.

Progression of AF was defined as follows: development of new-onset atrial fibrillation during follow-up in control patients or paroxysmal AF at baseline becoming persistent or permanent AF during follow-up. Since the Maastricht University Medical Centre has a strong regional community care function, none of the patients were lost to follow-up. At the end of follow-up, general practitioners were contacted in order to obtain additional follow-up data.

\section{Statistical analysis}

Continuous variables are expressed as mean and standard deviation; categorical variables are expressed as absolute numbers and percentages.

Baseline variables were compared with an independent $t$ test (two-tailed) after performing Levene's test for equality of variances in all normally distributed continuous variables and Mann-Whitney test (two-tailed) in all not normally distributed variables. Categorical variables were tested with two-sided Fisher's exact test.

All parameters showing a significant Cox regression univariate relation with the occurrence of cardiovascular disease during follow-up (age, AF history, posterior wall width) were included as covariates in a Cox regression model (retention level set at 0.1 ), odds ratios and $95 \%$ confidence intervals were calculated and results were checked for colinearity (Off note, VKA use and interventricular septum width were not included since these are directly related to respectively AF history and posterior wall width).

Statistical analysis was performed with SPSS statistical software (SPSS, Inc. release 18.0) and statistical significance was assumed for $p<0.05$.

\section{RESULTS}

The overall mean (SD) age was 54 (11) years and just over half of patients was male (58\%). Baseline characteristics, electrocardiographic and standard echocardiographic parameters were equal in AF cases and controls. (Table 1) Particularly, mean \pm SD age ( $56 \pm 10$ vs. $53 \pm 12$ years, $p=0.465)$, P-wave duration ( $88 \pm 20$ vs. $86 \pm 17 \mathrm{~ms}, p=0.521$ ) and LA diameter ( $39 \pm 5$ vs. $38 \pm 4 \mathrm{~mm}, \mathrm{p}=0.254$ ) did not differ between AF patients and controls. A few sinus rhythm patients were on aspirin or a beta-blocker because their referring physician deemed these drugs necessary due to the suspicion of cardiovascular disease (not found at enrolment after full work-up including echocardiography). A total of 14 (34\%) AF patients used oral anticoagulation despite low cardiovascular risk profile. AF duration showed a statistically significant but weak correlation to LA size (spearman's correlation coefficient: $0.365, p=0.024$ ). 
Table 1 - Baseline characteristics in patients with sinus rhythm compared to patients with idiopathic atrial fibrillation

\begin{tabular}{|c|c|c|c|}
\hline & $\begin{array}{c}\text { Sinus rhythm } \\
(n=45)\end{array}$ & $\begin{array}{l}\text { Atrial fibrillation } \\
(n=41)\end{array}$ & $P$ value \\
\hline \multicolumn{4}{|l|}{ Demographics } \\
\hline Age (median, interquartile range) & $57(46-62)$ & $58(46-64)$ & $0.465+$ \\
\hline Male & $23(51)$ & $27(66)$ & $0.194 \ddagger$ \\
\hline Body mass index $\left(\mathrm{kg} / \mathrm{m}^{2}\right)$ & $26(4)$ & $27(4)$ & $0.348^{*}$ \\
\hline AF history duration (months) (median, interquartile range) & - & $1(0.6-11)$ & \\
\hline \multicolumn{4}{|l|}{ Medication } \\
\hline Oral anticoagulation & 0 & $14(34)$ & $<0.001 \ddagger$ \\
\hline Aspirin & $5(11)$ & $18(44)$ & $0.001 \ddagger$ \\
\hline Beta blocker & $7(16)$ & $13(32)$ & $0.124 \ddagger$ \\
\hline \multicolumn{4}{|l|}{ ECG } \\
\hline Heart rate (bpm) & $70(12)$ & $66(11)$ & $0.176^{*}$ \\
\hline P-wave duration (ms) & $86(17)$ & $88(20)$ & $0.521^{*}$ \\
\hline PQ duration (ms) & $153(29)$ & $158(24)$ & $0.304 *$ \\
\hline QRS duration (ms) & $93(17)$ & $93(11)$ & $0.987^{*}$ \\
\hline QTc duration (ms) & $411(19)$ & $410(18)$ & $0.820 *$ \\
\hline \multicolumn{4}{|l|}{ Echocardiography } \\
\hline Aorta diameter (mm) & $33(3)$ & $34(4)$ & $0.056^{*}$ \\
\hline Left atrial diameter $(\mathrm{mm})$ & $38(4)$ & $39(5)$ & $0.254^{*}$ \\
\hline Left ventricular end diastolic diameter (mm) & $48(4)$ & $49(4)$ & $0.191^{*}$ \\
\hline Left ventricular end systolic diameter (mm) & $32(4)$ & $33(3)$ & $0.261^{*}$ \\
\hline Interventricular septum width (mm) & $8.7(0.9)$ & $8.6(0.8)$ & $0.763+$ \\
\hline Posterior wall width (mm) & $8.4(0.8)$ & $8.5(0.7)$ & $0.693+$ \\
\hline Left ventricular ejection fraction (\%) & $62(5)$ & $62(4)$ & $0.976^{*}$ \\
\hline
\end{tabular}

Data are presented as mean $( \pm \mathrm{SD})$ or $\mathrm{n}(\%)$ unless otherwise specified.

* Normal distribution, Levene's independent samples T-test

$+\quad$ Non-normal distribution, Mann-Whitney U test

‡ Categorical data, Fisher's exact test

Follow-up was completed in all patients; mean follow-up duration was $66 \pm 11$ months. (Table 2) Cardiovascular disease occurred significantly more often in idiopathic AF patients compared to sinus rhythm controls ( $49 \%$ vs. $20 \%$, $p=0.006$ ). The Kaplan Meier 6 year cumulative risk for occurrence of cardiovascular disease was significantly increased for patients with idiopathic AF. (Figure 1)

Three patients (7\%) with idiopathic AF died (one due to myocardial infarction, one due to malignancy and the other developed a cerebrovascular accident and died later in follow-up due to malignancy), whereas none of the control patients died during follow-up. Hypertension ( $33 \%$ vs. $16 \%, p=0.123$ ) and coronary artery disease ( $12 \%$ vs. $9 \%, p=0.299)$ developed most frequently. Patients with idiopathic AF were significantly younger at the time of cardiovascular event or associated disease $159 \pm 9$ vs. $64 \pm 5$ years, $p=0.027$ ) and had developed a more severe disease profile compared to controls. (Figure 2) 
CHAPTER VII | CARDIOVASCULAR DISEASE DURING 5 YEAR FOLLOW UP

Table 2 - AF progression, cardiovascular disease and medication during Follow-up

\begin{tabular}{|c|c|c|c|}
\hline & $\begin{array}{l}\text { Sinus rhythm } \\
\quad(n=45)\end{array}$ & $\begin{array}{l}\text { Atrial fibrillation } \\
\qquad(n=41)\end{array}$ & $P$ value \\
\hline \multicolumn{4}{|l|}{ Demographics } \\
\hline AF progression in Follow-up & $2(4)$ & $6(15)$ & $0.144 \ddagger$ \\
\hline Visits cardiac emergency department & $2(4)$ & $21(66)$ & $<0.001 \ddagger$ \\
\hline $\begin{array}{l}\text { Cardiovascular (related) disease in Follow- } \\
\text { upł }\end{array}$ & $9(20)$ & $20(49)$ & $0.006 \ddagger$ \\
\hline Cardiovascular death & 0 & $1(3)$ & $0.471 \ddagger$ \\
\hline Myocardial infarction & 0 & $2(5)$ & $0.224 \ddagger$ \\
\hline Cerebrovascular accident & 0 & $2(5)$ & $0.224 \ddagger$ \\
\hline Congestive heart failure & 0 & $3(8)$ & $0.100 \ddagger$ \\
\hline Coronary artery disease & $4(9)$ & $5(12)$ & $0.299 \ddagger$ \\
\hline New onset hypertension & $7(16)$ & $12(30)$ & $0.191 \ddagger$ \\
\hline \multicolumn{4}{|l|}{ Medication } \\
\hline Oral anticoagulation & $1(2)$ & $18(45)$ & $<0.001 \ddagger$ \\
\hline Aspirin & $10(22)$ & $15(38)$ & $0.231 \ddagger$ \\
\hline Beta blocker & $5(12)$ & $12(30)$ & $0.058 \ddagger$ \\
\hline Statins & $7(16)$ & $7(18)$ & $1.000 \ddagger$ \\
\hline Antihypertensive drug use* & $7(16)$ & $12(30)$ & $0.191 \ddagger$ \\
\hline
\end{tabular}

Data are presented as mean ( \pm SD) or $n(\%)$

* ACE-inhibitor, angiotensin receptor blocker, diuretics, calcium channel blocker

† Categorical data, Fisher's exact test

¥ The tabulations of cardiovascular diseases during follow-up include the first event for each patient.

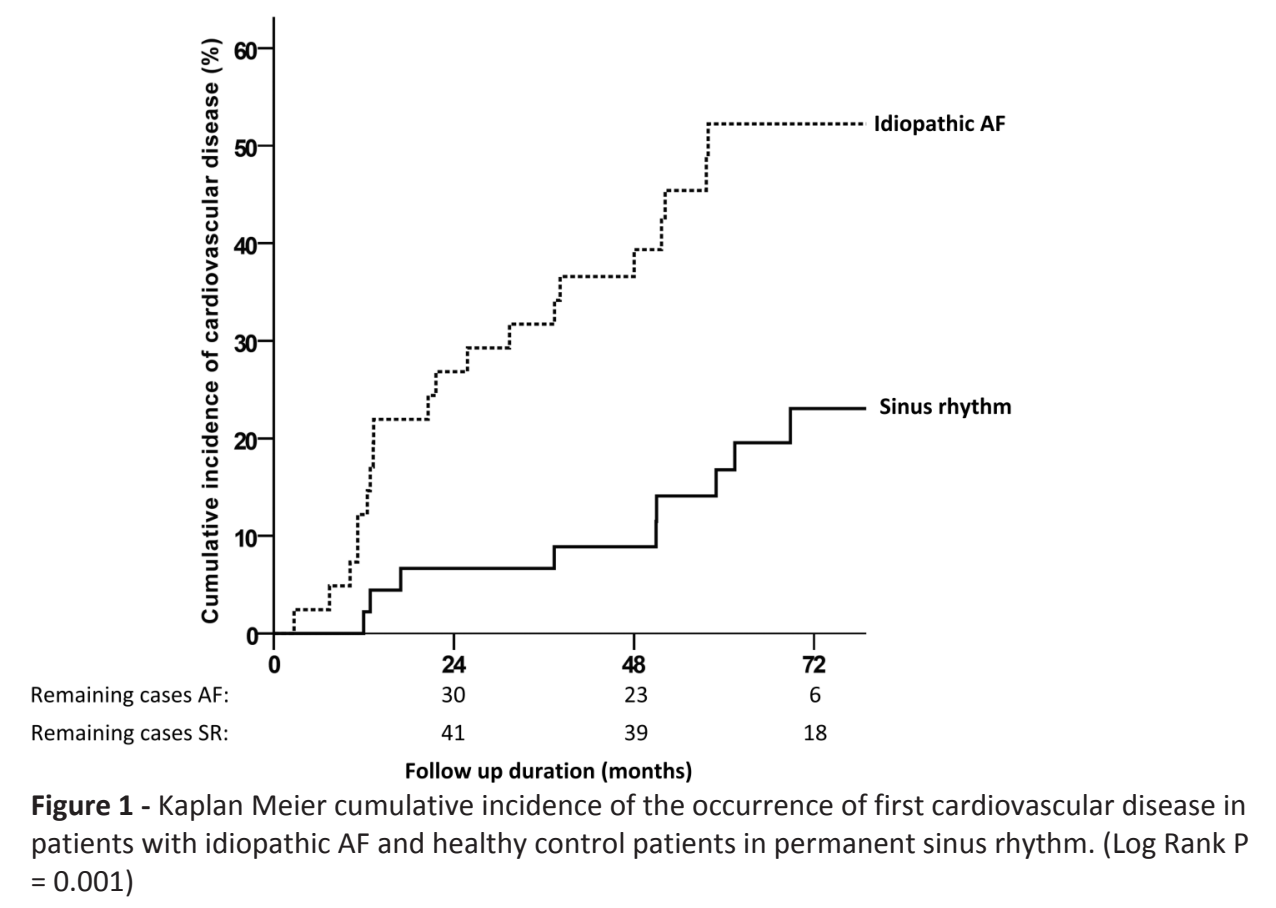




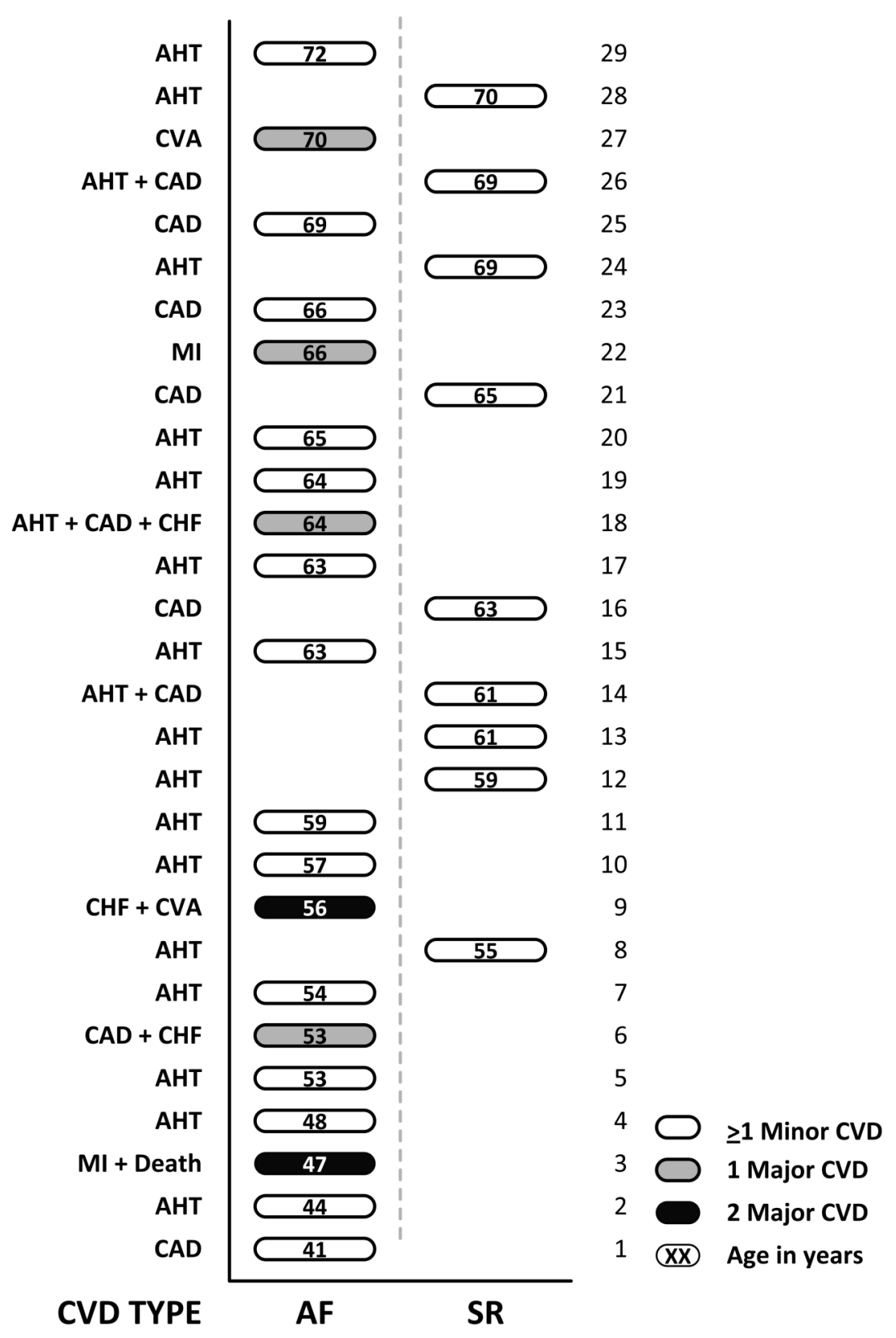

Figure 2 - Occurrence and severity of cardiovascular disease (CVD) in Follow-up per patient and according to age in patients with idiopathic AF and healthy control patients in permanent sinus rhythm. Minor CVD: arterial hypertension (AHT), coronary artery disease (CAD); Major CVD: congestive heart failure (CHF), cerebrovascular accident (CVA), myocardial infarction (MI), death. 
Echocardiography during follow-up was available in 34 patients (20 AF, 14 controls). LA diameter increased in 23 patients (AF: 15 (75\%) vs. SR: 8 (57\%), p=0.485) with a mean increase of $3.0 \pm 4 \mathrm{~mm}$ in patients with idiopathic AF vs. $0.8 \pm 3 \mathrm{~mm}$ in controls $(p=0.099)$. Patients who developed cardiovascular disease during follow-up more often showed an increase in atrial size compared to patients who did not develop cardiovascular disease (17 (90\%) vs. 6 (40\%), p=0.003). (Figure 3)

\section{Rhythm in history}

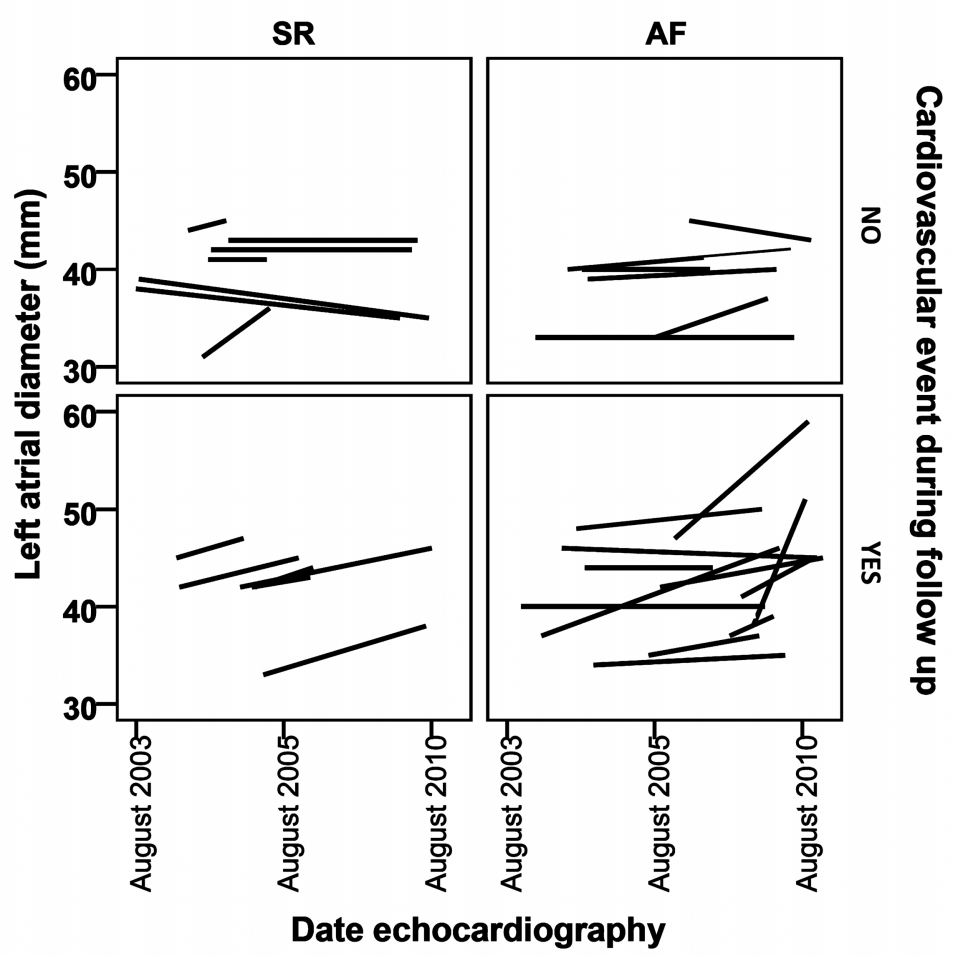

Figure 3 - Left atrial diameters during Follow-up according to the occurrence of cardiovascular events in 20 atrial fibrillation patients and 14 sinus rhythm control patients.

The following baseline parameters showed a significant Cox regression univariate relation with the occurrence of cardiovascular disease during follow-up: age, AF history, VKA use, interventricular septum width, and posterior wall width. (Table 3) Multivariable Cox regression analysis revealed that age, a history of AF and posterior wall width were predictors of cardiovascular disease development. (Table 4) 
Table 3 - Baseline characteristics in patients who did not versus did develop cardiovascular disease during follow-up.

\begin{tabular}{|c|c|c|c|}
\hline & $\begin{array}{c}\text { No CVD } \\
(n=57)\end{array}$ & $\begin{array}{c}\geq 1 \text { CVD } \\
(n=29)\end{array}$ & $P$ value \\
\hline \multicolumn{4}{|l|}{ Demographics } \\
\hline Age & $52(12)$ & $59(8)$ & $0.003+$ \\
\hline Male & $31(54)$ & $19(66)$ & $0.363 \ddagger$ \\
\hline Body mass index $\left(\mathrm{kg} / \mathrm{m}^{2}\right)$ & $25(4)$ & $28(4)$ & $0.172 *$ \\
\hline Atrial fibrillation in history & $21(37)$ & $20(69)$ & $0.005 \ddagger$ \\
\hline Follow-up duration (months) & $67(11)$ & $65(10)$ & $0.609+$ \\
\hline \multicolumn{4}{|l|}{ Medication } \\
\hline Oral anticoagulation & $5(9)$ & $9(31)$ & $0.013 \ddagger$ \\
\hline Aspirin & $15(26)$ & $8(28)$ & $1.0 \ddagger$ \\
\hline Beta blocker & $13(23)$ & $7(24)$ & $1.0 \ddagger$ \\
\hline \multicolumn{4}{|l|}{ Echocardiography } \\
\hline Aorta diameter (mm) & $33(3)$ & $34(4)$ & $0.168^{*}$ \\
\hline Left atrial diameter (mm) & $38(4)$ & $41(4)$ & $0.447^{*}$ \\
\hline Left atrial volume (cc) & $51(17)$ & $57(17)$ & $0.744^{*}$ \\
\hline Left ventricular end diastolic diameter (mm) & $48(4)$ & $50(5)$ & $0.402^{*}$ \\
\hline Left ventricular end systolic diameter (mm) & $32(3)$ & $34(4)$ & $0.109 *$ \\
\hline Interventricular septum width (mm) & $8.4(0.8)$ & $9.0(0.9)$ & $0.006+$ \\
\hline Posterior wall width (mm) & $8.3(0.6)$ & $8.8(0.8)$ & $0.005^{\dagger}$ \\
\hline Left ventricular ejection fraction (\%) & $63(4)$ & $61(5)$ & $0.294^{*}$ \\
\hline
\end{tabular}

Data are presented as mean $( \pm \mathrm{SD})$ or $\mathrm{n}(\%)$

* $\quad$ Normal distribution, Levene's independent samples T-test

$+\quad$ Non-normal distribution, Mann-Whitney U test

‡ Categorical data, Fisher's exact test

Table 4 - Multivariable Cox regression analysis: demographic and clinical variables related to occurrence of cardiovascular disease

\begin{tabular}{lccc}
\hline & OR & $95 \%$ C.I. & P \\
\hline History of AF & 3.265 & $1.470-7.250$ & 0.004 \\
Posterior wall width (mm) & 1.993 & $1.249-3.181$ & 0.004 \\
Age (years) & 1.059 & $1.013-1.106$ & 0.010 \\
\hline
\end{tabular}




\section{DISCUSSION}

This study is one of the few following idiopathic AF patients for the development of cardiovascular disease in general instead of focusing on major cardio- and cerebrovascular events only, and comparing them with patients in sinus rhythm without a cardiovascular diagnosis. It shows that in clinical practice almost half of the patients originally diagnosed with idiopathic AF develops cardiovascular disease within merely five years follow-up. Cardiovascular disease develops often, at younger age and with a more severe disease profile, in these patients compared to healthy sinus rhythm controls. This suggests that idiopathic AF is an expression of as yet undetected underlying cardiovascular disease and that these patients should be checked regularly for the development of cardiovascular disease.

Longitudinal studies on idiopathic AF are rare and the definitions used in these studies are mostly not identical and often lenient. The presence of arterial hypertension for instance was not an exclusion criterion in the Framingham Heart study on idiopathic atrial fibrillation. ${ }^{1}$ We used a very strict definition for idiopathic AF so risk wise, all patients were at low risk and similar at the outset. Yet, almost half of the patients with idiopathic AF developed cardiovascular disease or MACCE. This suggests that not only advanced AF but also idiopathic AF is associated with cardiovascular disease and events. To what extend AF on itself contributes is difficult to say. With increased levels of thrombogenesis and uncontrolled heart rate, AF could act as a mechanism in the development of stroke and congestive heart failure. ${ }^{8-11}$ But it is difficult to find a similar role for $A F$ in the development of arterial hypertension (e.g. AF may induce hypertension through concealed insidious adrenergic activation due to high heart rates) or coronary artery disease. ${ }^{12,13}$ In these cases, AF could be seen as a whistleblower of as yet undetected, clinically concealed coronary artery disease or arterial hypertension.

Arterial hypertension is a major risk factor for the development of AF and cardiovascular events but is often not recognized. This so called masked or latent hypertension has been described in patients initially diagnosed with idiopathic AF. ${ }^{14,15}$ Although patients with hypertension or left ventricular hypertrophy were excluded in the present study, posterior wall width - although within normal limits - was a predictor of cardiovascular disease. This might suggest the presence of masked hypertension or pre-hypertension (SBP of $120-139 \mathrm{mmHg}$ and DBP of $80-89 \mathrm{mmHg}$ ) in patients participating in this study. It also suggests that even normal wall sizes show a variation representing preclinical disease once wall width is found to be at the high end of normal. These patients seem to be at an increased risk of developing cardiovascular disease or atrial fibrillation compared with those with normal blood pressure levels. ${ }^{16-19}$ The present study corroborates the findings by Katritsis et al, supporting the notion that hypertension may develop or become apparent in many idiopathic AF patients ( $30 \%$ during 5 year follow-up) and emphasizes the importance of regular 24 hour ambulatory blood pressure monitoring and adequate treatment of early hypertension in patients with idiopathic AF since it relates to their vascular prognosis. 
Many clinical parameters are only indirectly related to AF. However, the true 'scene of calamity' are the atria. Increased LA size is associated with increased risk of AF onset and recurrence, other cardiovascular disease and mortality. ${ }^{6,20}$

In this study, left atrial sizes at the outset were equal between patients with and without $A F$ and were not related to the occurrence of cardiovascular disease in the overall population. On the other hand, patients with LA increase during follow-up were prone to develop cardiovascular disease. These results confirm previous findings during three decades follow-up in idiopathic AF patients. ${ }^{6}$

Idiopathic AF is often described as a benign disease. ${ }^{3,21}$ However, our data suggests that not every idiopathic AF patient has the same cardiovascular prognosis. It seems that patients with idiopathic AF can be divided into two groups following divergent courses regarding cardiovascular disease development. Those who are at true low risk on one hand, and those with deterioration of cardiovascular disease in the years after idiopathic AF diagnosis as reflected by AF progression, development of cardiovascular disease and events. This study shows that within five years follow-up almost $50 \%$ of the patients initially suffering from idiopathic AF develops cardiovascular disease. During long term follow-up in the Olmsted County population, the same number of those with idiopathic AF (50\%) developed major adverse cardiovascular events. ${ }^{6}$ It is plausible that the patients in our study are the same as the patients in the Olmsted County cohort but caught somewhat later in their vascular career. Apparently, it is possible to identify these patients since they have in common that atrial size appears to increase during follow-up. At present, it seems judicious to closely follow these patients at the outpatient department for the development of cardiovascular disease. Repeated blood pressure measurements and echocardiography (including LA size and posterior wall width) seem prudent in patients with idiopathic AF.

\section{LIMITATIONS}

The study result was obtained in a relatively small and - by its nature - highly selected population and should be reproduced in other cohorts. Nevertheless, it seems reasonable to state that a substantial part of patients originally diagnosed with idiopathic AF develop cardiovascular disease during short-term follow-up. Since sinus rhythm patients were referred for cardiovascular screening purposes rather than $\mathrm{AF}$, referral bias may have played a role but would - if anything - have led to a higher incidence of events in the control population rather than the reverse. Although we meticulously tried to rule out hypertension, specific cases of masked hypertension could be missed since 24 hour ambulatory blood pressure monitoring was not performed. Follow-up echocardiography was not available in all patients. As a result, potential surveillance bias due to echocardiography being performed for renewed suspicion or actual development of cardiac disease, could not be excluded. However, this bias holds for both groups and, in addition, does not invalidate the relationship between size increase and disease development. 


\section{CONCLUSION}

Patients originally diagnosed with idiopathic AF develop cardiovascular disease more often, earlier in time and at younger age compared to healthy sinus rhythm control patients. Age, history of $\mathrm{AF}$ and posterior wall width are significant predictors of cardiovascular disease development. The detection and treatment of cardiovascular disease in an early stage could improve the prognosis of these patients. At present it seems prudent to regularly check idiopathic AF patients for the development of CV disease.

\section{CONTRIBUTORSHIP}

All authors contributed significantly to the submitted work and have read and approved the manuscript

\section{FUNDING}

The Maastricht University Medical Centre department of cardiology funded this work.

\section{COMPETING INTERESTS}

None 


\section{REFERENCES}

1. Brand FN, Abbott RD, Kannel WB, Wolf PA. Characteristics and prognosis of lone atrial fibrillation. 30-year follow-up in the Framingham Study. Jama. 1985 Dec 27;254(24):3449-53.

2. Jahangir A, Lee V, Friedman PA, Trusty JM, Hodge DO, Kopecky SL, Packer DL, Hammill SC, Shen WK, Gersh BJ. Long-term progression and outcomes with aging in patients with lone atrial fibrillation: a 30-year follow-up study. Circulation. 2007 Jun 19;115(24):3050-6.

3. Kopecky SL, Gersh BJ, McGoon MD, Whisnant JP, Holmes DR, Jr., Ilstrup DM, Frye RL. The natural history of lone atrial fibrillation. A population-based study over three decades. N Engl J Med. 1987 Sep 10;317(11):669-74.

4. Jouven X, Desnos M, Guerot C, Ducimetiere P. Idiopathic atrial fibrillation as a risk factor for mortality. The Paris Prospective Study I. Eur Heart J. 1999 Jun;20(12):896-9.

5. Kopecky SL, Gersh BJ, McGoon MD, Chu CP, Ilstrup DM, Chesebro JH, Whisnant JP. Lone atrial fibrillation in elderly persons: a marker for cardiovascular risk. Arch Intern Med. 1999 May 24;159(10):1118-22.

6. Osranek M, Bursi F, Bailey KR, Grossardt BR, Brown RD, Jr., Kopecky SL, Tsang TS, Seward JB. Left atrial volume predicts cardiovascular events in patients originally diagnosed with lone atrial fibrillation: threedecade follow-up. Eur Heart J. 2005 Dec;26(23):2556-61.

7. Levey AS, Bosch JP, Lewis JB, Greene T, Rogers N, Roth D. A more accurate method to estimate glomerular filtration rate from serum creatinine: a new prediction equation. Modification of Diet in Renal Disease Study Group. Ann Intern Med. 1999 Mar 16;130(6):461-70.

8. Crijns HJ, Van den Berg MP, Van Gelder IC, Van Veldhuisen DJ. Management of atrial fibrillation in the setting of heart failure. Eur Heart J. 1997 May;18 Suppl C:C45-9.

9. Watson T, Shantsila E, Lip GY. Mechanisms of thrombogenesis in atrial fibrillation: Virchow's triad revisited. Lancet. 2009 Jan 10;373(9658):155-66.

10. Fu R, Wu S, Wu P, Qiu J. A study of blood soluble P-selectin, fibrinogen, and von Willebrand factor levels in idiopathic and lone atrial fibrillation. Europace. 2011 Jan;13(1):31-6.

11. Camm AJ, Kirchhof P, Lip GY, Schotten U, Savelieva I, Ernst S, Van Gelder IC, Al-Attar N, Hindricks G, Prendergast B, Heidbuchel H, Alfieri O, Angelini A, Atar D, Colonna P, De Caterina R, De Sutter J, Goette A, Gorenek B, Heldal M, Hohloser SH, Kolh P, Le Heuzey JY, Ponikowski P, 
Rutten FH. Guidelines for the management of atrial fibrillation: the Task Force for the Management of Atrial Fibrillation of the European Society of Cardiology (ESC). Eur Heart J. 2010 Oct;31(19):2369-429.

12. Akutsu Y, Kaneko K, Kodama Y, Li HL, Suyama J, Shinozuka A, Gokan T, Kawamura M, Asano T, Hamazaki Y, Tanno K, Kobayashi Y. Significance of cardiac sympathetic nervous system abnormality for predicting vascular events in patients with idiopathic paroxysmal atrial fibrillation. Eur J Nucl Med Mol Imaging. 2010 Apr;37(4):742-9.

13. de Bono JP, Stoll VM, Joshi A, Rajappan K, Bashir Y, Betts TR. Cavotricuspid isthmus dependent flutter is associated with an increased incidence of occult coronary artery disease. Europace. 2010 September;12(12):1774-7.

14. Katritsis DG, Toumpoulis IK, Giazitzoglou E, Korovesis S, Karabinos I, Paxinos G, Zambartas C, Anagnostopoulos CE. Latent arterial hypertension in apparently lone atrial fibrillation. J Interv Card Electrophysiol. 2005 Sep;13(3):203-7.

15. Weijs B, Smulders MW, Alzand BS. Semi-final masked hypertension. Neth J Med. 2010 Oct;68(10):328.

16. Chobanian AV, Bakris GL, Black HR, Cushman WC, Green LA, Izzo JL, Jr., Jones DW, Materson BJ, Oparil S, Wright JT, Jr., Roccella EJ. Seventh report of the Joint National Committee on Prevention, Detection, Evaluation, and Treatment of High Blood Pressure. Hypertension. 2003 Dec;42(6):1206-52.

17. Vasan RS, Larson MG, Leip EP, Kannel WB, Levy D. Assessment of frequency of progression to hypertension in non-hypertensive participants in the Framingham Heart Study: a cohort study. Lancet. 2001 Nov 17;358(9294):1682-6.

18. Rothwell PM, Howard SC, Dolan E, O'Brien E, Dobson JE, Dahlof B, Sever PS, Poulter NR. Prognostic significance of visit-to-visit variability, maximum systolic blood pressure, and episodic hypertension. Lancet. 2010 Mar 13;375(9718):895-905.

19. Conen D, Tedrow UB, Koplan BA, Glynn RJ, Buring JE, Albert CM. Influence of systolic and diastolic blood pressure on the risk of incident atrial fibrillation in women. Circulation. 2009 Apr 28;119(16):2146-52.

20. Benjamin EJ, D'Agostino RB, Belanger AJ, Wolf PA, Levy D. Left atrial size and the risk of stroke and death. The Framingham Heart Study. Circulation. 1995 Aug 15;92(4):835-41.

21. Davidson E, Rotenberg Z, Weinberger I, Fuchs J, Agmon J. Diagnosis and characteristics of lone atrial fibrillation. Chest. 1989 May;95(5):1048-50. 
CHAPTER VIII PATIENTS ORIGINALLY DIAGNOSED WITH
IDIOPATHIC ATRIAL FIBRILLATION MORE
OFTEN SUFFER FROM INSIDIOUS
CORONARY ARTERY DISEASE COMPARED
TO HEALTHY SINUS RHYTHM CONTROLS

B Weijs $M D^{1}$, R Pisters MD PhD ${ }^{1}$, RJ Haest $M D^{2}$, JA Kragten $M D P h D^{3}$, IA Joosen $M D^{1}$, $M$ Versteylen $\mathrm{MD}^{1}$, CCMM Timmermans MD PhD ${ }^{1}$, L Pison $\mathrm{MD}^{1}$, Y Blaauw MD PhD ${ }^{1}$, L Hofstra MD PhD ${ }^{1}$, R Nieuwlaat PhD ${ }^{4}$, J Wildberger MD PhD ${ }^{1}$, HJGM Crijns MD PhD $^{1}$.

${ }^{1}$ Maastricht University Medical Center \& Cardiovascular Research Institute Maastricht, The Netherlands. ${ }^{2}$ St. Anna Hospital, Geldrop, The Netherlands, ${ }^{3}$ Atrium Medical Center, Heerlen, The Netherlands. ${ }^{4}$ Population Health Research Institute, McMaster University, Hamilton, Ontario, Canada.

Heart Rhythm 2012, in press 


\section{ABSTRACT}

AIMS: Idiopathic atrial fibrillation (AF) refers to a clinically lacking cardiovascular or pulmonary disease generating the pathophysiological substrate for the arrhythmia. However, since idiopathic AF is associated with an increased event rate, it may act as a whistle-blower of as yet undetected underlying heart disease. We studied the prevalence of coronary artery disease (CAD) in patients diagnosed with idiopathic AF.

METHODS \& RESULTS: Out of 3.243 patients who underwent cardiac CT angiography (CTA) in our center between January 2008 and March 2011, we identified a total of 115 consecutive idiopathic AF patients who underwent CTA before electrophysiological ablation. Patients were compared with 275 age-, sex-, and PROCAM risk score-matched healthy controls in permanent sinus rhythm. All patients were free of hypertension, diabetes, congestive heart failure, previous known coronary artery and peripheral vascular disease, previous stroke, thyroid, pulmonary and renal disease, and structural abnormalities on echocardiography. Controls more often showed a family history of CAD ( $38 \%$ vs. $15 \%, \mathrm{p}<0.001)$, had a higher prevalence of smoking ( $25 \%$ vs. $14 \%, p=0.021)$, higher fasting blood glucose levels (5.5 \pm 0.7 vs. $5.4 \pm 0.6 \mathrm{mmol} / \mathrm{L}, \mathrm{p}=0.025)$, and smaller atrial diameters $(37 \pm 4$ vs. $40 \pm 5 \mathrm{~mm}, \mathrm{p}<0.001)$ compared to AF patients. Notwithstanding the above, idiopathic AF patients significantly more often suffered from subclinical CAD compared to controls (49\% vs. $34 \%, p=0.008$ ). Multivariable regression analysis revealed that beside (as expected) age and gender, a history of AF and left atrial diameter were significant predictors of underlying CAD.

CONCLUSION: Half of patients originally diagnosed with idiopathic AF show concealed underlying CAD. The detection and treatment of CAD in an early stage could improve the prognosis of these patients. 
CHAPTER VIII | INSIDIOUS CORONARY ARTERY DISEASE IN IDIOPATHIC AF

\section{INTRODUCTION}

Atrial fibrillation is a well-established risk factor for cardiovascular events such as stroke and myocardial infarction. In fact, these vascular complications represent the major threat associated with AF. ${ }^{1}$ The RACE study showed an annual event rate for developing a vascular endpoint (cardiovascular death, heart failure or thromboembolic complication) of $8 \%$ in the general AF patient. ${ }^{2}$ Even in the subset of patients who have AF in absence of any detectable cardiovascular disease, annual morbidity and mortality rates comprise $4 \%{ }^{3,4}$ Given that this so-called idiopathic AF is associated with a significant cardiovascular event rate, it may act as a whistle-blower of as yet undetected underlying vascular disease. Concerning this issue, a matched comparison between idiopathic AF patients and healthy sinus rhythm patients has never been performed before. We studied the prevalence of coronary artery disease (CAD) in patients originally diagnosed with the most immaculate form of atrial fibrillation and compared these patients with healthy sinus rhythm (SR) controls.

\section{METHODS}

\section{Study population}

We performed a case-control study in 3.243 patients who underwent cardiac CT angiography (CTA) in our center between January 2008 and March 2011. Before performing CTA, patient characteristics were collected and the PROCAM risk score was determined. ${ }^{5}$ The PROCAM risk score is a simple and accurate scoring scheme, which is widely accepted, and allows predicting the absolute 10-year risk of an acute coronary event (fatal or non-fatal myocardial infarction or acute coronary death). A PROCAM risk score $<10 \%$ is estimated as low risk, $10-20 \%$ as moderate risk, and $>20 \%$ as high risk. All patients were in SR during CTA. Blood sampling was done after an overnight fast. The Institutional Review Board approved the study and all patients gave written informed consent.

Cases had to be idiopathic paroxysmal AF patients who underwent CTA in the work-up for electrophysiological AF ablation. Controls had to be healthy permanent SR subjects, who had CTA for cardiovascular screening purposes. Anginal complaints and abnormal stress test were never an indication for CTA. Our aim was to select at least two controls per case. Cases and controls were matched on sex, age at time of CTA $( \pm 1$ year) and PROCAM risk score $( \pm 2 \%)$.

Idiopathic AF and healthy SR were defined as absence of any cardiovascular disease including significant hypertension (defined as antihypertensive drug use [diuretics, angiotensin-converting enzyme inhibitors, angiotensin II receptor antagonists, aldosterone receptor antagonists, dihydropyridine calcium-channel blockers], or a systolic blood pressure $\geq 140 \mathrm{mmHg}$, or a diastolic blood pressure $\geq 90$ $\mathrm{mmHg}$ on CTA visit, or left ventricular hypertrophy [interventricular septum width $>10$ $\mathrm{mm}$, posterior wall width $>10 \mathrm{~mm}$ ), diabetes (fasting blood glucose $>7.0 \mathrm{mmol} / \mathrm{L}$ ), or hypercholesterolemia (total fasting cholesterol $>7.0 \mathrm{mmol} / \mathrm{L}$ ). In addition, no history of CAD (i.e. typical exercise-related angina pectoris, an exercise stress test with 
significant ST-segment depression if available, previous acute coronary syndrome, percutaneous or surgical coronary revascularization, or previous angiographically documented CAD), no significant renal dysfunction (calculated creatinin clearance $<60$ $\mathrm{ml} / \mathrm{min}$, Cockcroft and Gault formula), no congestive heart failure (left ventricular ejection fraction $<50 \%$ ), no previous stroke, no malignancy, no thyroid disease or pulmonary disease, and no evidence for structural cardiovascular disease on echocardiogram, including valvular heart disease and left ventricular hypertrophy.

\section{The electrocardiogram}

All patients underwent 12-lead ECG recording obtained in the supine position (MAC 5000, Marquette Medical Systems, Milwaukee, Wis., USA).

\section{Echocardiographic examination}

The echocardiographic examination consisted of a standard 2-dimensional echocardiogram, including M-mode and Doppler echocardiography (Sonos 5500, Philips Medical Systems, Andover, Mass., USA) during continuous electrocardiogram (ECG) monitoring according to the recommendations as described in the American Society of Echocardiography guidelines.

\section{CTA data acquisition and analysis}

In all patients a prospective unenhanced coronary calcium scan was performed. For quantitative assessment of coronary artery calcification the Agatston score was calculated, using a $3 \mathrm{~mm}$ CT slice thickness and a detection threshold of $\geq 130$ Hounsfield units involving $\geq 1 \mathrm{~mm}^{2}$ area/lesion (3 pixels). Patients were categorized as having no calcium (Agatston score $=0$ ), minimal (1-10), mild (11-100), moderate (101$400)$ or severe $(>400)$ coronary calcification.

Cardiac CT angiography was performed using a collimation of $64 * 0.625 \mathrm{~mm}$ or $2 * 128 * 0.625 \mathrm{~mm}$ and a rotation time of 0.4 or 0.28 seconds, both for Brilliance 64 and Somatom Flash respectively. The tube current was $240-400 \mathrm{~mA}$ (depending on body weight), at 80-120 kV. Contrast material (lobitridol, Xenetix 350; Guerbet, Paris, France) was administered at a flow rate of $7.0 \mathrm{~mL} / \mathrm{s}$ in the antecubital vein; with volumes depending on the total scan time $(80$ to $110 \mathrm{~mL})$. Blood pressure was measured before CTA, while heart rate and ECG were monitored during CTA. In the absence of contra-indications, patients with a heart rate $\geq 60 \mathrm{bpm}$ were administered 50 to $100 \mathrm{mg}$ Metoprolol tartrate orally or 5 to $20 \mathrm{mg}$ Metoprolol intravenously. Bolus timing was performed by automated peak enhancement detection in the descending aorta using a threshold of 130 Hounsfield units. Data analysis was performed in a consensus reading by an experienced cardiologist and radiologist who were blinded to all medical data. Image analysis was performed on dedicated workstations for post processing and evaluation (Cardiac Comprehensive ${ }^{\circledR}$ Analysis software, Philips Healthcare, Best, the Netherlands). Coronary arteries were evaluated according to a 16 segments classification scheme according to the American Heart Association (AHA) classification. The quality of each segment was assessed and classified as interpretable or not. Coronary plaques were defined as structures $>1 \mathrm{~mm}^{2}$ within and/or adjacent to 
CHAPTER VIII | INSIDIOUS CORONARY ARTERY DISEASE IN IDIOPATHIC AF

the coronary artery lumen, which could be clearly distinguished from the vessel lumen and the surrounding pericardial tissue, as described previously. ${ }^{6}$ Obstructive CAD was defined as $\geq 50 \%$ luminal narrowing.

\section{Statistical analysis}

Continuous variables are expressed as mean and standard deviation; categorical variables are expressed as absolute numbers and percentages.

Baseline variables were compared with an independent $t$ test (two-tailed) after performing Levene's test for equality of variances in all normally distributed continuous variables and Mann-Whitney test (two-tailed) in all not normally distributed variables. Categorical variables were tested with two-sided Fisher's exact test.

All clinical covariates showing a univariate relation $(P<0.1)$ with the presence of CAD as determined by CTA, were included in a logistic regression model (retention level set at 0.1 ), odds ratios (OR) and 95\% confidence intervals (Cls) were calculated. We checked for colinearity and interactions among covariates and found none of significance. The discriminatory ability of the model was assessed using $c$ statistic, a measure of the area under the ROC curve. Calibration of the model was tested by the Hosmer-Lemeshow statistic.

Statistical analysis was performed with PASW statistical software (SPSS, Inc. release 18.0) and statistical significance was assumed for $p<0.05$. 


\section{RESULTS}

Baseline characteristics for cases and controls are provided in table 1. In total, 115 idiopathic paroxysmal AF patients (cases) were matched to a group of 275 healthy SR controls. The overall mean (SD) age was 55 (10) years and the majority was male (68\%). CTA was performed with a 64-slice CT scanner (Brilliance 64; Philips Healthcare, Best, The Netherlands) in 2387 patients and a $2 * 128$-slice dual-source CT scanner (Somatom Flash; Siemens Healthcare, Forchheim, Germany) in 856 patients.

AF patients less often showed a family history of CAD (15\% vs. $38 \%, p<0.001)$, smoking ( $14 \%$ vs. $25 \%, p=0.021)$, higher fasting blood glucose levels (5.4 \pm 0.6 vs. $5.5 \pm 0.7 \mathrm{mmol} / \mathrm{L}, \mathrm{p}=0.025)$, and smaller atrial diameters ( $40 \pm 5$ vs. $37 \pm 4 \mathrm{~mm}, \mathrm{p}<0.001)$ when compared to controls.

Despite a slightly more favorable baseline profile, idiopathic AF patients significantly more often suffered from subclinical CAD compared to controls as determined by CTA ( $49 \%$ vs. $34 \%, p=0.008)$. Asymptomatic significant stenosis was present in $4 \mathrm{AF}$ patients (4\%) compared to $4(2 \%)$ controls $(p=0.242)$. Mean Agatston scores differed significantly between cases and controls ( $52 \pm 118$ vs. $32 \pm 114, p=0.028$ ). The highest coronary artery calcium scores were more frequent in the AF patients whereas absence of coronary calcium was more prevalent in controls. (Figure 1).
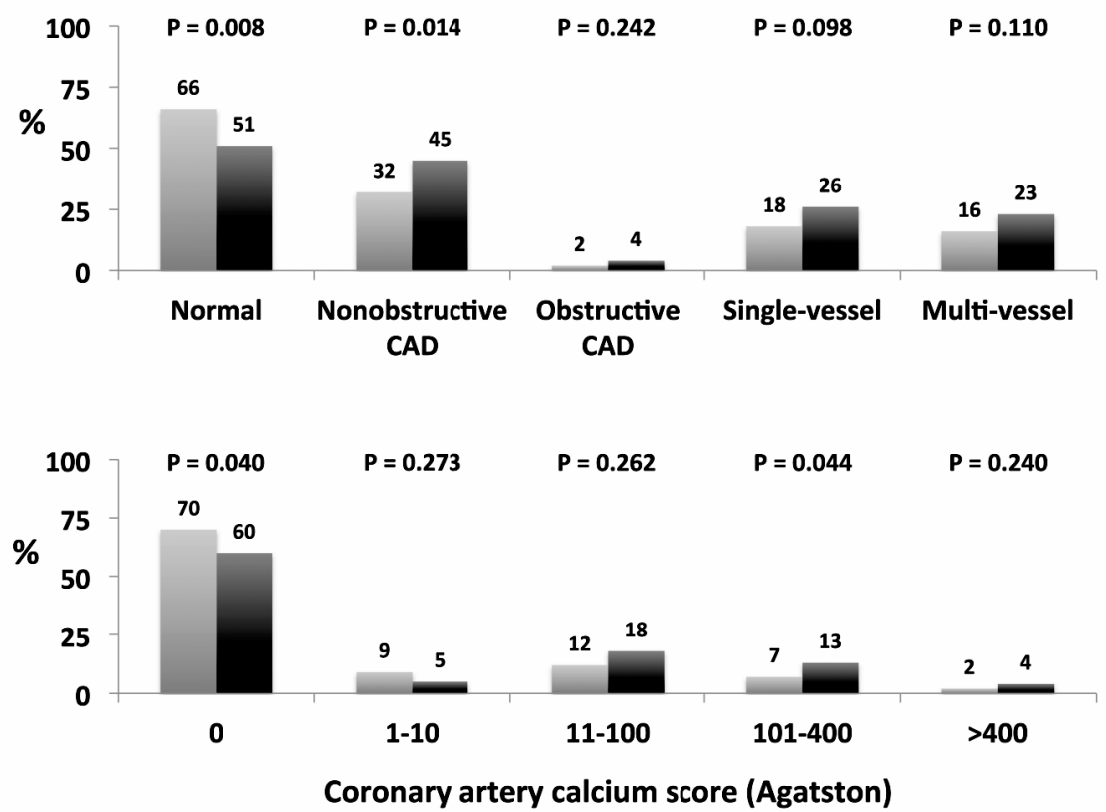

FIGURE 1 - Prevalence of coronary artery disease and Agatston score categories in patients with idiopathic $\mathrm{AF}$ (black) and matched healthy controls in permanent SR (gray). 
CHAPTER VIII | INSIDIOUS CORONARY ARTERY DISEASE IN IDIOPATHIC AF

Out of a total of 6240 coronary artery segments, 34 (0.6\%) were excluded because of impaired image quality. AF patients turned out to have a significantly higher amount of diseased segments compared to controls $(8.2 \%$ vs. $4.8 \%, p<0.001)$. More in detail, the total number of segments containing non-calcified, calcified or mixed plaques was significantly increased in cases compared to controls ( $1.6 \%$ vs. $0.6 \%$, $p<0.001 ; 4.0 \%$ vs. $2.5 \%, p=0.002 ; 2.9 \%$ vs. $1.9 \%, p=0.015$, respectively). CAD was more often located in the left coronary artery in AF patients compared to controls (right coronary artery: $14 \%$ vs. $13 \%, p=0.873$; left main: $9 \%$ vs. $3 \%, p=0.018$; left anterior descending: $45 \%$ vs. $30 \%, p=0.003$; circumflex artery: $21 \%$ vs. $11 \%, p=0.017$ ). (Figure 2 )

TABLE 1 Baseline characteristics in healthy SR controls compared to idiopathic atrial fibrillation cases.

\begin{tabular}{|c|c|c|c|}
\hline & $\begin{array}{c}\text { SINUS RHYTHM } \\
(\mathrm{N}=275)\end{array}$ & $\begin{array}{l}\text { ATRIAL FIBRILLATION } \\
\qquad(\mathrm{N}=115)\end{array}$ & P-VALUE \\
\hline \multicolumn{4}{|l|}{ DEMOGRAPHICS } \\
\hline Procam risk-score & $6.4(6)$ & $5.9(7)$ & $0.895^{\mathrm{C}}$ \\
\hline Male & $182(66)$ & $82(71)$ & $0.344^{\mathrm{A}}$ \\
\hline Age (years) & $55(10)$ & $55(10)$ & $0.819^{B}$ \\
\hline Family history of CAD & $104(38)$ & $17(15)$ & $<0.001^{A}$ \\
\hline Smoking & $67(25)$ & $16(14)$ & $0.021^{A}$ \\
\hline Systolic blood pressure ( $\mathrm{mmHg}$ ) & $126(10)$ & $125(12)$ & $0.491^{\mathrm{B}}$ \\
\hline Fasting blood glucose & $5.5(0.7)$ & $5.4(0.6)$ & $0.025^{\mathrm{B}}$ \\
\hline LDL & $3.4(0.9)$ & $3.6(0.9)$ & $0.218^{\mathrm{B}}$ \\
\hline HDL & $1.3(0.4)$ & $1.2(0.34)$ & $0.004^{\mathrm{B}}$ \\
\hline Triglycerides & $1.6(0.9)$ & $1.6(0.9)$ & $0.833^{C}$ \\
\hline Total cholesterol & $5.5(1.0)$ & $5.5(1.0)$ & $0.857^{\mathrm{B}}$ \\
\hline Body mass index $\left(\mathrm{kg} / \mathrm{m}^{2}\right)$ & $26(4)$ & $26(3)$ & $0.555^{\mathrm{B}}$ \\
\hline Creatinine clearance $(\mathrm{mL} / \mathrm{min})$ & $96(27)$ & $99(23)$ & $0.258^{C}$ \\
\hline AF history (months) & & 27 IQR 6-74 & \\
\hline \multicolumn{4}{|l|}{ MEDICATION } \\
\hline VKA use & 0 & $41(36)$ & $<0.001^{\mathrm{A}}$ \\
\hline Rate control drugs & $39(15)$ & $63(55)$ & $<0.001^{\mathrm{A}}$ \\
\hline Betablocker & $39(15)$ & $45(40)$ & $<0.001^{A}$ \\
\hline Isoptin & 0 & $12(11)$ & $<0.001^{\mathrm{A}}$ \\
\hline Lanoxin & 0 & $11(10)$ & $<0.001^{\mathrm{A}}$ \\
\hline Anti-arrhythmic drugs & 0 & $71(62)$ & $<0.001^{\mathrm{A}}$ \\
\hline Sotalol & 0 & $27(24)$ & $<0.001^{A}$ \\
\hline Amiodarone & 0 & $7(6)$ & $<0.001^{A}$ \\
\hline Flecainide & 0 & $33(29)$ & $<0.001^{\mathrm{A}}$ \\
\hline Disopyramide & 0 & $4(4)$ & $0.007^{\mathrm{A}}$ \\
\hline Propafenone & 0 & $2(2)$ & $0.087^{A}$ \\
\hline \multicolumn{4}{|l|}{ ECHOCARDIOGRAPHY } \\
\hline Aorta diameter (mm) & $33(4)$ & $34(3)$ & $<0.001^{\mathrm{C}}$ \\
\hline Left atrial diameter ( $\mathrm{mm})$ & $37(4)$ & $40(5)$ & $<0.001^{c}$ \\
\hline IVS (mm) & $8.6(1.1)$ & $8.5(0.8)$ & $0.271^{C}$ \\
\hline PWW (mm) & $8.5(1.1)$ & $8.4(0.7)$ & $0.245^{c}$ \\
\hline Left ventricular mass (gr.) & $168(40)$ & $160(26)$ & $0.073^{B}$ \\
\hline LV ejection fraction (\%) & $60(5)$ & $61(6)$ & $0.110^{\mathrm{C}}$ \\
\hline
\end{tabular}

Data are displayed as mean (SD) unless otherwise specified

${ }^{\text {A }}$ Categorical data, Fischer's exact test.

${ }^{B}$ Normal distribution, Levene's independent samples $T$-test.

${ }^{\mathrm{C}}$ Non-normal distribution, Mann-Whitney U-test. 
The following baseline parameters showed a significant univariate relation with the presence of CAD on cardiac CTA: male sex ( $78 \%$ vs. $61 \%, p=0.001)$, age $(58 \pm 8$ vs. $53 \pm 10, p<0.001), H D L(1.3 \pm 0.4$ vs. $1.3 \pm 0.4 \mathrm{mmol} / \mathrm{L}, \mathrm{p}=0.080)$, AF history $(38 \%$ vs. $25 \%, p=0.008)$, Aorta diameter ( $33 \pm 3$ vs. $34 \pm 4 \mathrm{~mm}, \mathrm{p}=0.001)$, LA diameter ( $40 \pm 5$ vs. $37 \pm 5 \mathrm{~mm}, p<0.001)$, posterior wall width $(8.8 \pm 0.9$ vs. $8.5 \pm 1.0 \mathrm{~mm}, p=0.008)$, use of vitamin $\mathrm{K}$ antagonists ( $16 \%$ vs. $7 \%, \mathrm{p}=0.017)$, and use of rate control drugs ( $36 \% \mathrm{vs.}$ $23 \%, p=0.018)$. Multivariable regression analysis revealed that age, male sex, history of AF and left atrial diameter were predictors of presence of CAD. (Table 2) The model had a good discriminatory ability ( $c$ statistic $=0.8$ ) and the Hosmer-Lemeshow test for goodness-of-fit was not statistically significant $(P=0.854)$ which is in accordance with a good calibration. Since the use of vitamin K antagonists (VKA) is associated with increased levels of coronary artery calcification ${ }^{7}$, we repeated these analyses in those patients free of VKA. Omitting these patients did not change our results (data not shown).

TABLE 2 Multivariable regression analysis: demographic and clinical variables related to the presence of coronary artery disease as assessed by cardiac CT angiography

\begin{tabular}{lccc}
\hline & OR & P value & 95\% Cl \\
\hline Age & 1.111 & $<0.001$ & $1.073-1.150$ \\
Male sex & 2.381 & 0.006 & $1.290-4.393$ \\
AF history & 1.897 & 0.030 & $1.062-3.387$ \\
Left atrial diameter & 1.066 & 0.033 & $1.005-1.131$ \\
\hline
\end{tabular}

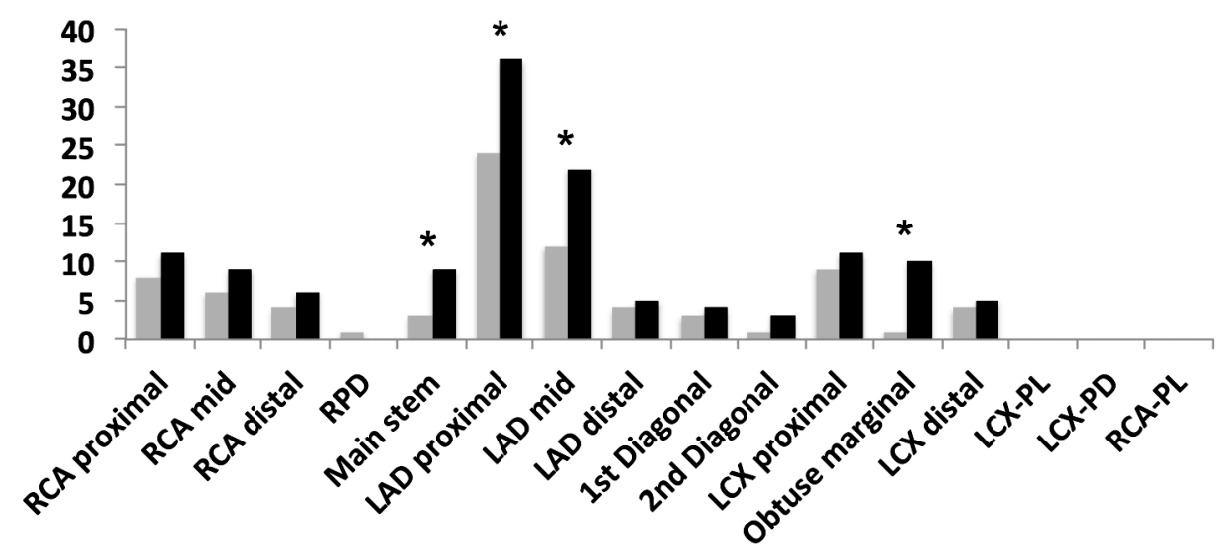

Figure 2 - $\quad$ Presence of coronary artery disease per coronary artery segment in patients with idiopathic AF (black) and matched healthy controls in permanent SR (gray). (RCA: right coronary artery; RPD: right posterior descending; LAD: left anterior descending artery; LCX: circumflex artery; PL: posterolateral; PD: posterior descending; ${ }^{*}$ : $P<0.02$ ) 


\section{DISCUSSION}

In this study, we investigated the prevalence of unsuspected CAD using cardiac CT angiography in a well-defined population of idiopathic AF patients compared to healthy SR controls. We found that despite a more favorable baseline profile, half of patients originally diagnosed with idiopathic AF show concealed and sometimesadvanced underlying CAD. Beside (as expected) age and gender, a history of AF and left atrial diameter were predictors for the presence of coronary artery disease.

Idiopathic AF is often regarded as a benign disease with a favourable prognosis. ${ }^{8}$ However, several studies showed that the incidence of new vascular disease and even cardiovascular events is substantial. ${ }^{3,4,9,10}$ The present study suggests that - using CTA - idiopathic AF is more than expected associated with subclinical coronary artery disease. Obviously, subclinical disease may form the basis for future cardiac events and may thus be a marker for susceptibility to vascular disease in general. The present findings may shed light upon previous findings that in the long term half of idiopathic AF patients may develop cardiovascular disease including stroke, myocardial infarction and heart failure. ${ }^{10}$ Given these results, AF may be considered a vascular disease rather than an arrhythmia.

CAD is a significant risk factor for AF in the Western world. ${ }^{11-13}$ Atrial ischemia could create a substrate for AF by causing fibrosis and scarring of the atrial wall, resulting in areas with reduced or even blocked conduction. Ischemia itself may also contribute as it shortens the refractory period and decreases conduction velocity in the atria, potentially facilitating re-entry processes. ${ }^{14}$ In addition, intermittent ischemia could lead to ventricular diastolic dysfunction resulting in increased atrial filling pressures thus promoting AF. ${ }^{15}$ The prevalence of AF in patients with established CAD or risk factors for atherothrombosis is substantially higher compared with the general population. ${ }^{16,17}$ Also, the presence of the arrhythmia in patients with CAD is associated with worse cardiovascular outcome. ${ }^{17,18}$ Some clinical observations would also support a relationship between atrial ischemia and AF. Atrial ischemia is known to play an important role in the genesis of supraventricular tachyarrhythmias secondary to acute myocardial infarction. ${ }^{19}$ Range et al reported a significant impairment of myocardial perfusion in male patients suffering from persistent AF. Skalidis and colleagues described isolated microvascular dysfunction in patients with lone recurrent AF by measuring peak coronary blood flow velocity. ${ }^{20,21}$

In the clinical AF population, the presence of $C A D$, as visualized by means of conventional coronary angiography (luminography), is estimated around $30 \%$ (Bono et al: 26\%; Androulakis et al: 32\%; Kralev et al: 34\%). ${ }^{22-24}$ Since CTA not only allows the detection of coronary artery stenosis but also has the possibility to visualize coronary atherosclerotic plaque (vasculography), it seems obvious to assume that this percentage will be higher if CAD is determined by means of CTA. In a high risk/chest pain population of patients with $A F, C T A$ revealed CAD in $82 \%$ of patients. ${ }^{25}$

Our study is the first to describe the prevalence of CAD as assessed by CTA in a well-defined population of idiopathic AF patients compared to matched healthy SR 
subjects. We found a higher prevalence of CTA-CAD among idiopathic AF patients as compared with healthy SR controls ( $49 \%$ vs. $34 \%$ ). Overall, it seems that mainly nonobstructive CAD is largely present already in patients with early and uncomplicated AF. This is also consistent with other studies, which show that the presence of CAD in AF is not associated with a higher burden of ischemia in these patients. ${ }^{26-28}$

Whether $\mathrm{AF}$ is the consequence and sometimes even the first expression of yet subclinical coronary artery disease, or that $A F$ and CAD have a common causal mechanism via an insidious and complex vascular inflammatory process that is going on in your patient remains to be elucidated.

Regardless the mechanism, the findings of our study could have clinical implications on all three main branches of AF management. Since management of AF patients is aimed at reducing symptoms and at preventing severe complications associated with AF, it relies on antithrombotic therapy, control of ventricular rate, and adequate treatment of concomitant disease. ${ }^{1}$

AF confers a five-fold increase in stroke risk. In order to easily assess stroke risk in an individual patient, various stroke risk schemes - based on clinical and echocardiographic parameters related to an increased risk of stroke in AF- have been published. The recent ESC guidelines on the management of atrial fibrillation introduced the $\mathrm{CHA}_{2} \mathrm{DS}_{2}-\mathrm{VASc}$ score (acronym: congestive heart failure, hypertension, age $>75$ [doubled], diabetes, stroke [doubled], vascular disease, age 65-74, and sex category [female]). ${ }^{1}{ }^{29}$ Unlike previous stroke risk scores, the presence of atherosclerotic vascular disease (previous myocardial infarction, complex aortic plaque, and peripheral artery disease [i.e. angiographic evidence of peripheral artery disease]) has now been incorporated as it may contribute to stroke risk. ${ }^{30}$ The recommendations for antithrombotic therapy are based on the presence (or absence) of the $\mathrm{CHA}_{2} \mathrm{DS}_{2-}$ VASc risk factors. Idiopathic AF patients have a stroke risk score of zero without the need for oral anticoagulation. Considering the present results, half of these patients previously diagnosed with idiopathic $A F$ in fact show atherosclerotic vascular disease and hence $\mathrm{CHA}_{2} \mathrm{DS}_{2}$-VASc score should be one. There is no evidence regarding the question if CTA-CAD patients need comparable vascular- and thromboprophylaxis as patients with conventional angiographic CAD (CCA-CAD), but it has been stated that acute coronary syndromes usually result from rupture of atheromatous plaques that are frequently non-obstructive and have previously been asymptomatic. ${ }^{31}$ Further, since aortic plaques and angiographic evidence of peripheral artery disease are defined as vascular disease in $\mathrm{CHA}_{2} \mathrm{DS}_{2}$-VASc risk score, one should at least consider prescribing oral anticoagulation at a low threshold in idiopathic $\mathrm{AF}$ patients who have CTA-CAD (especially females and those with age towards 65). The basis for such strategy is - we admit - narrow, because of the lack of decent follow up in randomized controlled trials studying the potential benefit of vascular and antithrombotic therapy in patients with the presence of CTA-CAD (both for AF as SR patients). Nevertheless, in these cases the new oral anticoagulants (Dabigatran, Rivaroxaban and Apixaban) may form a welcome alternative since vitamin $\mathrm{K}$ antagonists have been associated with an increase in coronary artery calcification. ${ }^{7}$ 
CHAPTER VIII | INSIDIOUS CORONARY ARTERY DISEASE IN IDIOPATHIC AF

Regarding control of ventricular rate, many patients with AF may be candidates for drug therapy with class Ic antiarrhythmic drugs such as Flecainide. These drugs can be proarrhythmic, particularly in the setting of acute myocardial ischemia or previous myocardial wall infarction. ${ }^{32}$ For this reason, the presence of CAD has been regarded as a relative contraindication to the use of class Ic antiarrhythmic drugs. Again, it has to be further investigated whether the presence of CTA-CAD in AF patients would have the same consequences as CCA-CAD.

The presence of CTA-CAD influences AF substrate and progression of the arrhythmia. The use of upstream therapy (i.e. angiotensin converting enzyme inhibitors, angiotensin II receptor blockers, statins, aldosterone receptor antagonists) in these patients could slow the progress of vascular disease and have beneficial influence on AF substrate. ${ }^{33}$

The findings of our study and the potential clinical implications may be strengthened by follow up data. However, based on the estimated low short-term incidence of major adverse cardio- and cerebrovascular events, contributory follow up data would require many patient-years concerning the estimated low short-term event rate in this relatively healthy population.

\section{LIMITATIONS}

The study result was obtained in a -by its nature- selected population and should be reproduced in other cohorts. Although we meticulously tried to rule out hypertension, specific cases of masked hypertension could be missed since 24 hour ambulatory blood pressure monitoring was not performed. Further, CTA data were obtained by means of two different scanners (64-multislice computed tomography and 128-slice dual-source (T). This can also be stated in a positive way: as during the enrolment of patients, the most recent state-of-the-art scanning system was used. Further, cases and controls were equally distributed among both scanners and previous head-tohead comparisons revealed comparable results. ${ }^{34,35}$

\section{CONCLUSION}

Patients originally diagnosed with idiopathic AF have more concealed and sometimes advanced underlying CAD as compared to healthy SR controls. Age, male sex, a history of $\mathrm{AF}$ and left atrial diameter were predictors of presence of coronary artery disease. The detection and treatment of CAD in an early stage could improve the prognosis of these patients. At present it seems potentially beneficial to check idiopathic AF patients for the presence of CAD. 


\section{REFERENCES}

1. Camm AJ, Kirchhof P, Lip GY, Schotten U, Savelieva I, Ernst S, Van Gelder IC, Al-Attar N, Hindricks G, Prendergast B, Heidbuchel H, Alfieri O, Angelini A, Atar D, Colonna P, De Caterina R, De Sutter J, Goette A, Gorenek B, Heldal M, Hohloser SH, Kolh P, Le Heuzey JY, Ponikowski P, Rutten FH. Guidelines for the management of atrial fibrillation: the Task Force for the Management of Atrial Fibrillation of the European Society of Cardiology (ESC). European heart journal. 2010 Oct;31(19):2369-429.

2. Van Gelder IC, Hagens VE, Bosker HA, Kingma JH, Kamp O, Kingma T, Said SA, Darmanata JI, Timmermans AJ, Tijssen JG, Crijns HJ. A comparison of rate control and rhythm control in patients with recurrent persistent atrial fibrillation. N Engl J Med. 2002 Dec 5;347(23):1834-40.

3. Rienstra M, Hagens VE, Van Veldhuisen DJ, Bosker HA, Tijssen JG, Kamp O, Bouma J, Veeger NJ, Crijns HJ, Van Gelder IC. Clinical characteristics of persistent lone atrial fibrillation in the RACE study. Am J Cardiol. 2004 Dec 15;94(12):1486-90.

4. Potpara TS, Stankovic GR, Beleslin BD, Polovina MM, Marinkovic JM, Ostojic MC, Lip GY. A 12-year follow-up study of patients with newly-diagnosed lone atrial fibrillation: Implications of arrhythmia progression on prognosis: The Belgrade Atrial Fibrillation Study. Chest. 2011 May 26.

5. Assmann G, Cullen P, Schulte H. Simple scoring scheme for calculating the risk of acute coronary events based on the 10-year follow-up of the prospective cardiovascular Munster (PROCAM) study. Circulation. 2002 Jan 22;105(3):3105 .

6. Leber AW, Knez A, Becker A, Becker C, von Ziegler F, Nikolaou K, Rist C, Reiser M, White C, Steinbeck G, Boekstegers P. Accuracy of multidetector spiral computed tomography in identifying and differentiating the composition of coronary atherosclerotic plaques: a comparative study with intracoronary ultrasound. J Am Coll Cardiol. 2004 Apr 7;43(7):1241-7.

7. Weijs B, Blaauw Y, Rennenberg RJ, Schurgers LJ, Timmermans CC, Pison L, Nieuwlaat R, Hofstra L, Kroon AA, Wildberger J, Crijns HJ. Patients using vitamin $\mathrm{K}$ antagonists show increased levels of coronary calcification: an observational study in low-risk atrial fibrillation patients. European heart journal. 2011 Oct;32(20):2555-62.

8. Jahangir A, Lee V, Friedman PA, Trusty JM, Hodge DO, Kopecky SL, Packer DL, Hammill SC, Shen WK, Gersh BJ. Long-term progression and outcomes with aging in patients with lone atrial fibrillation: a 30-year follow-up study. Circulation. 2007 Jun 19;115(24):3050-6.

9. Katritsis DG, Toumpoulis IK, Giazitzoglou E, Korovesis S, Karabinos I, Paxinos G, Zambartas C, Anagnostopoulos CE. Latent arterial hypertension in apparently Ione atrial fibrillation. J Interv Card Electrophysiol. 2005 Sep;13(3):203-7.

10. Osranek M, Bursi F, Bailey KR, Grossardt BR, Brown RD, Jr., Kopecky SL, Tsang TS, Seward JB. Left atrial volume predicts cardiovascular events in patients 
CHAPTER VIII | INSIDIOUS CORONARY ARTERY DISEASE IN IDIOPATHIC AF

originally diagnosed with lone atrial fibrillation: three-decade follow-up. European heart journal. 2005 Dec;26(23):2556-61.

11. Lip GY, Beevers DG. ABC of atrial fibrillation. History, epidemiology, and importance of atrial fibrillation. Bmj. 1995 Nov 18;311(7016):1361-3.

12. Heeringa J, van der Kuip DA, Hofman A, Kors JA, van Rooij FJ, Lip GY, Witteman JC. Subclinical atherosclerosis and risk of atrial fibrillation: the rotterdam study. Arch Intern Med. 2007 Feb 26;167(4):382-7.

13. Krahn AD, Manfreda J, Tate RB, Mathewson FA, Cuddy TE. The natural history of atrial fibrillation: incidence, risk factors, and prognosis in the Manitoba Follow-Up Study. Am J Med. 1995 May;98(5):476-84.

14. Sinno H, Derakhchan K, Libersan D, Merhi Y, Leung TK, Nattel S. Atrial ischemia promotes atrial fibrillation in dogs. Circulation. $2003 \mathrm{Apr}$ 15;107(14):1930-6.

15. Schoonderwoerd BA, Van Gelder IC, Crijns HJ. Left ventricular ischemia due to coronary stenosis as an unexpected treatable cause of paroxysmal atrial fibrillation. Journal of cardiovascular electrophysiology. 1999 Feb;10(2):224-8.

16. Feinberg WM, Blackshear JL, Laupacis A, Kronmal R, Hart RG. Prevalence, age distribution, and gender of patients with atrial fibrillation. Analysis and implications. Arch Intern Med. 1995 Mar 13;155(5):469-73.

17. Goto S, Bhatt DL, Rother J, Alberts M, Hill MD, Ikeda Y, Uchiyama S, D'Agostino R, Ohman EM, Liau CS, Hirsch AT, Mas JL, Wilson PW, Corbalan R, Aichner F, Steg PG. Prevalence, clinical profile, and cardiovascular outcomes of atrial fibrillation patients with atherothrombosis. Am Heart J. 2008 Nov;156(5):855-63, 63 e2.

18. Zusman O, Amit G, Gilutz H, Zahger D. The significance of new onset atrial fibrillation complicating acute myocardial infarction. Clin Res Cardiol. 2011 Sep 11.

19. Tjandrawidjaja MC, Fu Y, Kim DH, Burton JR, Lindholm L, Armstrong PW. Compromised atrial coronary anatomy is associated with atrial arrhythmias and atrioventricular block complicating acute myocardial infarction. J Electrocardiol. 2005 Jul;38(3):271-8.

20. Range FT, Schafers M, Acil T, Schafers KP, Kies P, Paul M, Hermann S, Brisse B, Breithardt G, Schober O, Wichter T. Impaired myocardial perfusion and perfusion reserve associated with increased coronary resistance in persistent idiopathic atrial fibrillation. European heart journal. 2007 Sep;28(18):2223-30.

21. Skalidis El, Hamilos MI, Karalis IK, Chlouverakis G, Kochiadakis GE, Vardas PE. Isolated atrial microvascular dysfunction in patients with lone recurrent atrial fibrillation. J Am Coll Cardiol. 2008 May 27;51(21):2053-7.

22. Androulakis A, Aznaouridis KA, Aggeli CJ, Roussakis GN, Michaelides AP, Kartalis AN, Stougiannos PN, Dilaveris PE, Misovoulos PI, Stefanadis Cl, Kallikazaros IE. Transient ST-segment depression during paroxysms of atrial fibrillation in otherwise normal individuals: relation with underlying coronary artery disease. J Am Coll Cardiol. 2007 Nov 6;50(19):1909-11. 
23. de Bono JP, Stoll VM, Joshi A, Rajappan K, Bashir Y, Betts TR. Cavotricuspid isthmus dependent flutter is associated with an increased incidence of occult coronary artery disease. Europace. 2010 September;12(12):1774-7.

24. Kralev S, Schneider K, Lang S, Suselbeck T, Borggrefe M. Incidence and severity of coronary artery disease in patients with atrial fibrillation undergoing first-time coronary angiography. PLoS One. 2011;6(9):e24964.

25. Nucifora G, Schuijf JD, Tops LF, van Werkhoven JM, Kajander S, Jukema JW, Schreur JH, Heijenbrok MW, Trines SA, Gaemperli O, Turta O, Kaufmann PA, Knuuti J, Schalij MJ, Bax JJ. Prevalence of coronary artery disease assessed by multislice computed tomography coronary angiography in patients with paroxysmal or persistent atrial fibrillation. Circ Cardiovasc Imaging. 2009 Mar;2(2):100-6.

26. Askew JW, Miller TD, Hodge DO, Gibbons RJ. The value of myocardial perfusion single-photon emission computed tomography in screening asymptomatic patients with atrial fibrillation for coronary artery disease. J Am Coll Cardiol. 2007 Sep 11;50(11):1080-5.

27. Nucifora G, Schuijf JD, van Werkhoven JM, Trines SA, Kajander S, Tops LF, Turta O, Jukema JW, Schreur JH, Heijenbrok MW, Gaemperli O, Kaufmann PA, Knuuti J, van der Wall EE, Schalij MJ, Bax JJ. Relationship between obstructive coronary artery disease and abnormal stress testing in patients with paroxysmal or persistent atrial fibrillation. Int J Cardiovasc Imaging. 2011 Jul;27(6):777-85.

28. Smit MD, Tio RA, Slart RH, Zijlstra F, Van Gelder IC. Myocardial perfusion imaging does not adequately assess the risk of coronary artery disease in patients with atrial fibrillation. Europace : European pacing, arrhythmias, and cardiac electrophysiology : journal of the working groups on cardiac pacing, arrhythmias, and cardiac cellular electrophysiology of the European Society of Cardiology. 2010 May;12(5):643-8.

29. Lip GY, Nieuwlaat R, Pisters R, Lane DA, Crijns HJ. Refining clinical risk stratification for predicting stroke and thromboembolism in atrial fibrillation using a novel risk factor-based approach: the euro heart survey on atrial fibrillation. Chest. 2010 Feb;137(2):263-72.

30. Violi F, Lip GY, Basili S. Peripheral artery disease and atrial fibrillation: a potentially dangerous combination. Intern Emerg Med. 2011 Jun 11.

31. Little WC, Constantinescu M, Applegate RJ, Kutcher MA, Burrows MT, Kahl FR, Santamore WP. Can coronary angiography predict the site of a subsequent myocardial infarction in patients with mild-to-moderate coronary artery disease? Circulation. 1988 Nov;78(5 Pt 1):1157-66.

32. Greenberg HM, Dwyer EM, Jr., Hochman JS, Steinberg JS, Echt DS, Peters RW. Interaction of ischaemia and encainide/flecainide treatment: a proposed mechanism for the increased mortality in CAST I. British heart journal. 1995 Dec;74(6):631-5.

33. Smit MD, Van Gelder IC. Upstream therapy of atrial fibrillation. Expert Rev Cardiovasc Ther. 2009 Jul;7(7):763-78. 
CHAPTER VIII | INSIDIOUS CORONARY ARTERY DISEASE IN IDIOPATHIC AF

34. Achenbach S, Ropers U, Kuettner A, Anders K, Pflederer T, Komatsu S, Bautz W, Daniel WG, Ropers D. Randomized comparison of 64-slice single- and dualsource computed tomography coronary angiography for the detection of coronary artery disease. JACC Cardiovasc Imaging. 2008 Mar;1(2):177-86.

35. Ghadri JR, Kuest SM, Goetti R, Fiechter M, Pazhenkottil AP, Nkoulou RN, Kuhn FP, Pietsch C, von Schulthess P, Gaemperli O, Templin C, Kaufmann PA. Image quality and radiation dose comparison of prospectively triggered low-dose CCTA: 128-slice dual-source high-pitch spiral versus 64-slice single-source sequential acquisition. Int J Cardiovasc Imaging. 2011 Jul 10. 
CHAPTER IX

\section{PATIENTS USING VITAMIN K ANTAGONISTS SHOW INCREASED LEVELS OF CORONARY CALCIFICATION: AN OBSERVATIONAL STUDY IN LOW-RISK ATRIAL FIBRILLATION PATIENTS}

Bob Weijs ${ }^{1}$ MD; Yuri Blaauw ${ }^{1}$ MD PhD; Roger JMW Rennenberg ${ }^{1}$ MD; Leon J Schurgers ${ }^{1,2}$ PhD; Carl CMM Timmermans ${ }^{1}$ MD PhD; Laurent Pison ${ }^{1}$ MD; Robby Nieuwlaat ${ }^{3}$ PhD; Leonard Hofstra ${ }^{1}$ MD PhD; Abraham A Kroon ${ }^{1}$ MD PhD; Joachim Wildberger ${ }^{1}$ MD PhD, Harry JGM Crijns ${ }^{1}$ MD PhD

\footnotetext{
${ }^{1}$ Maastricht University Medical Centre and Cardiovascular Research Institute Maastricht (CARIM), The Netherlands. ${ }^{2}$ VitaK and Dept. of Biochemistry, Maastricht

University, Maastricht, The Netherlands ${ }^{3}$ Population Health Research Institute,

McMaster University, Hamilton, Ontario, Canada.
}

European Heart Journal. 2011;32(20):2555-62 


\section{ABSTRACT}

Aims: Vitamin $\mathrm{K}$ antagonists (VKA) are currently the most frequently used drug to prevent ischemic stroke in AF patients. However, VKA use has been associated with increased vascular calcification. The aim of this study was to investigate the contribution of VKA use to coronary artery calcification in low risk AF patients.

Methods and results: A prospective coronary calcium scan was performed in $157 \mathrm{AF}$ patients without significant cardiovascular disease (108 male; mean age $57 \pm 9$ years). A total of $71(45 \%)$ patients were chronic VKA users. The duration of VKA treatment varied between 6 and 143 months (mean 46 months). No significant differences in clinical characteristics were found between patients on VKA treatment and nonanticoagulated patients. However, median coronary artery calcium scores differed significantly between patients without and patients with VKA treatment $(0$, IQR 0 to 40 , versus 29, IQR 0 to 184; $P=0.001$ ) Mean coronary calcium scores increased with the duration of VKA use (no VKA: $53 \pm 115 ; 6$ to 60 months on VKA: $90 \pm 167$ and $>60$ months on VKA: $236 \pm 278 ; p<0.001)$. Multivariable logistic regression analysis revealed that age and VKA treatment were significantly related to increased coronary calcium score.

Conclusion: Patients using VKA show increased levels of coronary calcification. Age and VKA treatment were independently related to increased coronary calcium score. 
CHAPTER IX | CORONARY CALCIFICATION AND VITAMIN K ANTAGONISTS

\section{INTRODUCTION}

Apart from other well-described clinical complications, atrial fibrillation (AF) is associated with complex thromboembolic mechanisms raising the risk of ischemic stroke. ${ }^{1-4}$ This being the most feared complication, AF patients need intensive stroke prevention therapy. Oral vitamin $\mathrm{K}$ antagonists (VKA) are currently the most frequently used drug to prevent thromboembolic complications in AF patients with a high stroke risk. ${ }^{5,6}$

Recently, it has been suggested that the use of VKA is associated with enhanced tissue calcification. Experimental data suggest that VKA may decrease activity of matrix Gla-protein, a strong inhibitor of soft tissue calcification. ${ }^{711}$ Rennenberg et al showed that long term use of VKA is associated with enhanced extracoronary vascular calcification in patients. ${ }^{12}$

It is unknown whether VKA also increase calcification of the coronary arteries. Obviously, considering the clinical evidence, potential deleterious calcification by VKA is outweighed by the stroke preventive effects of VKA. However, it cannot be excluded that a subset of high risk AF patients does develop detrimental calcification induced by chronic VKA therapy. This may also occur in a substantial number of low risk AF patients many of whom are overtreated with VKA. ${ }^{13,14}$ In these patients potential benefits of long term stroke prevention may not weigh up to the risks of vascular calcification. We investigated the contribution of VKA use to the degree of coronary artery calcification as assessed by multislice computed tomography (MSCT) in AF patients without clinically significant cardiovascular disease.

\section{METHODS}

\section{Study population}

We performed a cross-sectional observational study in 157 consecutive patients with paroxysmal AF and a low cardiovascular risk. All patients had either a cardiac multislice computed tomography (CCT) for work-up before an electrophysiological ablation of their AF (58\%) or consented to undergo CCT to assess coronary artery calcification for the purpose of this study. Before CCT patient characteristics were collected and the PROCAM risk score was determined. ${ }^{15}$ This simple and accurate scoring scheme is widely accepted, particularly in Europe, and allows to predict the absolute 10-year risk of an acute coronary event (fatal or non-fatal myocardial infarction or acute coronary death, PROCAM risk score $<10 \%$ estimated as low risk, $10-20 \%$ moderate risk, $>20 \%$ high risk). Blood sampling was done after an overnight fast. All patients were in sinus rhythm during CCT. The study was approved by the Institutional Review Board and all patients gave written informed consent.

Low cardiovascular risk was defined as a PROCAM risk score $<10 \%$, age below 70 years and absence of any cardiovascular disease including significant hypertension, diabetes (fasting blood glucose $<7.0 \mathrm{mmol} / \mathrm{L}$ ), or hypercholesterolemia (total fasting cholesterol $<6.4 \mathrm{mmol} / \mathrm{L}$ ). In addition, no history of coronary artery disease (i.e. typical exercise-related angina pectoris, an exercise stress test with significant ST-segment 
depression if available, previous acute coronary syndrome, percutaneous or surgical coronary revascularization, or previous angiographically documented coronary disease), no significant renal dysfunction (calculated creatinin clearance $>60 \mathrm{ml} / \mathrm{min}$, Cockcroft and Gault formula), no congestive heart failure (left ventricular ejection fraction $>50 \%$ ), no previous stroke, no malignancy, no thyroid disease or pulmonary disease, and no evidence for structural cardiovascular disease on echocardiogram, including absence of left ventricular hypertrophy defined as interventricular septum and posterior wall widths $<10 \mathrm{~mm}$. For the purpose of this study, we excluded all patients not fulfilling these criteria as well as patients in whom CCT was contraindicated.

\section{CCT data acquisition and analysis}

In all patients a prospective nonenhanced coronary calcium scan was performed with a 64-slice MSCT scanner (Brilliance 64; Philips Healthcare, Best, The Netherlands). For quantitative assessment of coronary artery calcification the Agatston score was calculated, using a $3 \mathrm{~mm}$ CT slice thickness and a detection threshold of $\geq 130$ Hounsfield units involving $\geq 1 \mathrm{~mm}^{2}$ area/lesion (3 pixels). Patients were categorized as having no calcium (Agatston score $=0$ ), or minimal (1-10), mild (11-100), moderate (101-400) or severe (> 400) coronary calcification.

Cardiac CT angiography was performed using a collimation of $64 * 0.625 \mathrm{~mm}$ and a rotation time of 0.4 seconds. The tube current was $240-400 \mathrm{~mA}$ (depending on body weight), at $120 \mathrm{kV}$. Contrast material (lobitridol, Xenetix 350; Guerbet, Paris, France) at a flow rate of $7.0 \mathrm{~mL} / \mathrm{s}$ was administered in the antecubital vein; with volumes depending on the total scan time $(80$ to $110 \mathrm{~mL})$. Blood pressure and heart rate were monitored before the examination. In the absence of contra-indications, patients with a heart rate $\geq 60 \mathrm{bpm}$ were administered 50 to $100 \mathrm{mg}$ Metoprolol, oral or 5 to $15 \mathrm{mg}$ Metoprolol intravenous. Bolus timing was performed by automated peak enhancement detection in the descending aorta using a threshold of 130 Hounsfield units. Data analysis was performed in a consensus reading by an experienced cardiologist and radiologist who were blinded to all medical data. Image analysis was performed on dedicated workstations for post processing and evaluation (Cardiac Comprehensive ${ }^{\circledR}$ Analysis software, Philips Healthcare, Best, the Netherlands).

\section{Echocardiography}

An independent observer performed the echocardiogram while subjects were lying in the left lateral decubitus position. All patients underwent standard two-dimensional transthoracic echocardiography, including $\mathrm{M}$ mode, and Doppler echocardiography (Sonos 5500, Philips Medical Systems, Andover, Massachusetts, USA). Recordings were made in the standard projections (subcostal, parasternal long-axis, parasternal shortaxis, four-chamber apical long-axis and two-chamber apical long-axis views). Aortic diameter, atrial volumes, ventricular wall thickness, left ventricular dimensions, left ventricular mass, left ventricular ejection fraction, caval vein width and collapse index, valve disorders, wall motion disorders and Doppler flow patterns of the mitral valve ( $E$ wave, A wave) were determined in all patients according to the recommendations of the American Society of Echocardiography. ${ }^{16}$ 


\section{Statistical analysis}

Continuous variables are expressed as mean and standard deviation; categorical variables are expressed as absolute numbers and percentages. Baseline variables were compared with an independent $t$ test (two-tailed) after performing Levene's test for equality of variances in all normally distributed continuous variables and MannWhitney test (two-tailed) in all not normally distributed variables. Categorical variables were tested with two-sided Fisher's exact test. Spearman's rank correlation coefficient was used for testing correlation between mean Agatston score and duration of VKA use.

All parameters showing a significant univariate relation with an increased coronary Agatston score and those representing a plausible mechanism in terms of calcification ${ }^{17,18}$ (age, VKA duration, left atrium diameter, posterior wall width, statins, ACE-inhibitors) were included as covariates in a logistic regression model (retention level set at 0.1 ), odds ratios and $95 \%$ confidence intervals were calculated, results were checked for interaction (of note, aspirin was not included in the model since it naturally mirrors VKA use in patients with atrial fibrillation). The final selected model included the following patient variables: age and VKA duration. The discriminatory power of the final logistic regression model was measured by the area under the ROC curve.

Since patients were not randomly assigned to the use of VKA, we adjusted for factors favouring VKA prescription using propensity score in order to reduce the selection bias. We entered all confounders showing a significant univariate relation with prescription of VKA (sex, BMI, rhythm control, LA diameter) as covariates in a binary regression model in order to estimate the propensity score for each patient. ${ }^{19}$ This score reflected the probability that a patient would receive VKA. After fitting the model, we ranked all patients by their estimated propensity score and grouped patients within quintiles of equal size based on the estimated propensity score. We calculated the hazard ratio (HR) and 95\% confidence interval $(\mathrm{Cl})$ for coronary calcium score comparing within each quintile patients who received VKA treatment and those who did not. The area under the ROC curve was used to assess the discriminatory ability of the model and we examined the model calibration using Hosmer-Lemeshow goodness-of-fit test.

Statistical analysis was performed with SPSS statistical software (SPSS, Inc. release 18.0) and statistical significance was assumed for $p<0.05$. 


\section{RESULTS}

Baseline characteristics are shown in Table 1. Out of the total of 157 patients, 79 (50\%) had an increased coronary artery calcium score. The other 78 patients did not have any detectable calcium in the coronary vessels. Patients with increased Agatston score were older than those with Agatston $=0(60 \pm 7$ versus $54 \pm 9$ years, $p<0.001)$. Out of the total of 157 patients, 71 (45\%) were chronic VKA users although their $\mathrm{CHA}_{2} \mathrm{DS}_{2}$ VASc score was $0(n=55)$ or $1\left(n=16\right.$, because of female sex category). ${ }^{20}$ The other 86 patients were not on VKA and had not used anticoagulants before. There were significantly more VKA users among patients with increased Agatston score than in those with Agatston score $=0(58 \%$ versus $32 \%, p=0.001)$. The duration of VKA treatment varied between 6 and 143 months (mean 46 months).

TABLE 1 - Baseline characteristics according to absence or presence of coronary artery calcification

\begin{tabular}{|c|c|c|c|}
\hline & Agatston 0 ( $n=78)$ & Agatston $>0 \quad(n=79)$ & $P$ value \\
\hline \multicolumn{4}{|l|}{ Demographics } \\
\hline Age (years) & $54(9.4)$ & $60(7.4)$ & $<0.001+$ \\
\hline Male & $52(66.7)$ & 56 (70.9) & $0.608 \ddagger$ \\
\hline Family history of $C A D^{\wedge}$ & $9(13.6)$ & $8(11.6)$ & $0.798 \ddagger$ \\
\hline Smoking^^ & $10(14.9)$ & $9(13.0)$ & $0.808 \ddagger$ \\
\hline Systolic blood pressure (mmHg) & $124(10)$ & $125(11)$ & $0.473^{*}$ \\
\hline Fasting glucose (mmol/L) & $5.4(0.5)$ & $5.4(0.6)$ & $0.896+$ \\
\hline Total cholesterol (mmol/L) & $5.5(1.0)$ & $5.5(1.0)$ & $0.966^{*}$ \\
\hline $\mathrm{HDL}(\mathrm{mmol} / \mathrm{L})$ & $1.2(0.3)$ & $1.2(0.4)$ & $0.392+$ \\
\hline LDL (mmol/L) & $3.5(0.8)$ & $3.5(1.0)$ & $0.908^{*}$ \\
\hline Triglycerides (mmol/L) & $1.7(1.1)$ & $1.6(0.8)$ & $0.886+$ \\
\hline Creatinin clearance (ml/min) & $87(13.7)$ & $88(13.4)$ & $0.699 *$ \\
\hline Body mass index $\left(\mathrm{kg} / \mathrm{m}^{2}\right)$ & $27(3.4)$ & $27(3.2)$ & $0.480 *$ \\
\hline AF history (months) & $61(61)$ & $81(80)$ & $0.084+$ \\
\hline \multicolumn{4}{|l|}{ Medication } \\
\hline VKA & $25(32)$ & $46(58)$ & $0.001 \ddagger$ \\
\hline VKA duration (months) & $31(17)$ & $54(35)$ & $0.006+$ \\
\hline Aspirin & $46(59)$ & $29(37)$ & $0.010 \ddagger$ \\
\hline Beta-blocker & $25(33)$ & $27(34)$ & $0.865 \ddagger$ \\
\hline ACE-inhibitor & $8(10)$ & $12(15)$ & $0.473 \ddagger$ \\
\hline Statin & $11(14)$ & $15(19)$ & $0.520 \ddagger$ \\
\hline Rhythm control & $50(65)$ & $52(66)$ & $0.866 \ddagger$ \\
\hline Rate control & $41(53)$ & $40(51)$ & $0.873 \ddagger$ \\
\hline \multicolumn{4}{|l|}{ Echocardiography } \\
\hline Left atrial dimension ( $\mathrm{mm}$ ) & $40(4.7)$ & $42(5.5)$ & $0.014^{*}$ \\
\hline Left atrial volume $(\mathrm{mL})$ & $70(16.7)$ & $79(26.5)$ & $0.165^{+}$ \\
\hline Right atrial volume (mL) & $59(20.1)$ & $59(21.3)$ & $0.882+$ \\
\hline Interventricular septum width (mm) & $8.5(0.8)$ & $8.7(0.8)$ & $0.166^{\dagger}$ \\
\hline Posterior wall width $(\mathrm{mm})$ & $8.4(0.7)$ & $8.6(0.8)$ & $0.023+$ \\
\hline Left ventricular ejection fraction (\%) & $61(6.2)$ & $61(6.4)$ & $0.816+$ \\
\hline Data are presented as mean $( \pm S D)$ or & & & \\
\hline$\wedge \quad$ First-degree relative (father, $r$ & er, sister, brother) w & CAD before the age & ears \\
\hline Current or past smoking & & & \\
\hline Normal distribution, Levene's & pendent samples T- $t$ & & \\
\hline Non-normal distribution, Mar & hitney U test & & \\
\hline Categorical data, Fisher's & test & & \\
\hline
\end{tabular}


In line with the low cardiovascular risk of this population no differences in clinical characteristics were found between patients on VKA treatment and nonanticoagulated patients (Table 2). Despite the on average normal left atrial dimensions in both groups, atria in the VKA treatment group were significantly larger, most likely because of longer AF history.

TABLE 2 - Baseline characteristics according to VKA use

\begin{tabular}{|c|c|c|c|}
\hline & No VKA $(n=86)$ & VKA (n=71) & $P$ value \\
\hline \multicolumn{4}{|l|}{ Demographics } \\
\hline Age (years) & $56(9.1)$ & $58(9.0)$ & $0.115 \ddagger$ \\
\hline Male & $53(61.6)$ & $55(77.5)$ & $0.039 \ddagger$ \\
\hline Family history of $\mathrm{CAD}^{\wedge}$ & $10(13.0)$ & $7(12.1)$ & $1.000 \ddagger$ \\
\hline Smoking^^ & $11(14.5)$ & $8(13.3)$ & $1.000 \ddagger$ \\
\hline Systolic blood pressure (mmHg) & $125(10)$ & $124(11)$ & $0.509 *$ \\
\hline Fasting glucose (mmol/L) & $5.4(0.5)$ & $5.3(0.6)$ & $0.201+$ \\
\hline Total cholesterol (mmol/L) & $5.4(0.9)$ & $5.5(1.1)$ & $0.802 *$ \\
\hline $\mathrm{HDL}(\mathrm{mmol} / \mathrm{L})$ & $1.2(0.3)$ & $1.2(0.4)$ & $0.483+$ \\
\hline LDL (mmol/L) & $3.5(0.8)$ & $3.5(1.0)$ & $0.911^{*}$ \\
\hline Triglycerides (mmol/L) & $1.6(0.8)$ & $1.8(1.1)$ & $0.197+$ \\
\hline Creatinin clearance (ml/min) & $95.5(22.2)$ & $96.6(21.5)$ & $0.871^{*}$ \\
\hline Body mass index $\left(\mathrm{kg} / \mathrm{m}^{2}\right)$ & $26.6(3.3)$ & $27.5(3.2)$ & $0.145^{*}$ \\
\hline AF history (months) & $63(63.4)$ & $80(80)$ & $0.050+$ \\
\hline \multicolumn{4}{|l|}{ Echocardiography } \\
\hline Left atrial dimension (mm) & $40.0(5.1)$ & $42.5(5.0)$ & $0.003^{*}$ \\
\hline Left atrial volume (mL) & $70(22)$ & $80(22)$ & $0.002+$ \\
\hline Right atrial volume $(\mathrm{mL})$ & $57(18)$ & $62(22)$ & $0.243+$ \\
\hline Interventricular septum width (mm) & $8.5(0.8)$ & $8.7(0.8)$ & $0.147+$ \\
\hline Posterior wall width $(\mathrm{mm})$ & $8.5(0.7)$ & $8.6(0.8)$ & $0.187+$ \\
\hline Left ventricular ejection fraction (\%) & $61(6.1)$ & $61(6.5)$ & $0.764+$ \\
\hline \multicolumn{4}{|c|}{ Data are presented as mean $( \pm S D)$ or $n(\%)$} \\
\hline \multicolumn{4}{|c|}{$\wedge \quad$ First-degree relative (father, mother, sister, brother) with CAD before the age of 60 years } \\
\hline \multicolumn{4}{|c|}{$\wedge \wedge \quad$ Current or past smoking } \\
\hline * $\quad$ Normal distribution, Levene's & endent samples T & & \\
\hline Non-normal distribution, Mar & itney U test & & \\
\hline Categorical data, Fisher's exac & & & \\
\hline
\end{tabular}

A total of $25(35 \%)$ patients using VKA had a coronary artery calcium score of zero compared to $53(62 \%)$ patients in the non-anticoagulated group $(P=0.001)$. Median coronary artery calcium scores differed significantly between patients without and patients with VKA treatment $(0$, interquartile range 0 to 40 , versus 29 , interquartile range 0 to $184 ; \mathrm{P}=0.001$ ). Out of a total of 2.512 coronary artery segments, $37(1.5 \%)$ were excluded because of impaired image quality. The total number of segments containing focal calcified lesions was $43(3.2 \%)$ in patients not using VKA versus $94(8.4 \%)$ in those using VKA $(P<0.001)$. The total amount of coronary artery segments containing a mixed plaque (plaque composed of a mixture of soft plaque and calcification) was not significantly different between the nonanticoagulated and the anticoagulated group (3.3\% versus $3.5 \%, P=0.567)$. Mean Agatston scores increased significantly with the duration of VKA use (no VKA: $53 \pm 115$; 6 to 60 months on VKA: $90 \pm 167$ and $>60$ months on VKA: $236 \pm 278 ; r=0.453, P<0.001$ ). Figure 1 shows the dispersion of different Agatston score categories in patients with different duration of VKA use according to different age groups. 


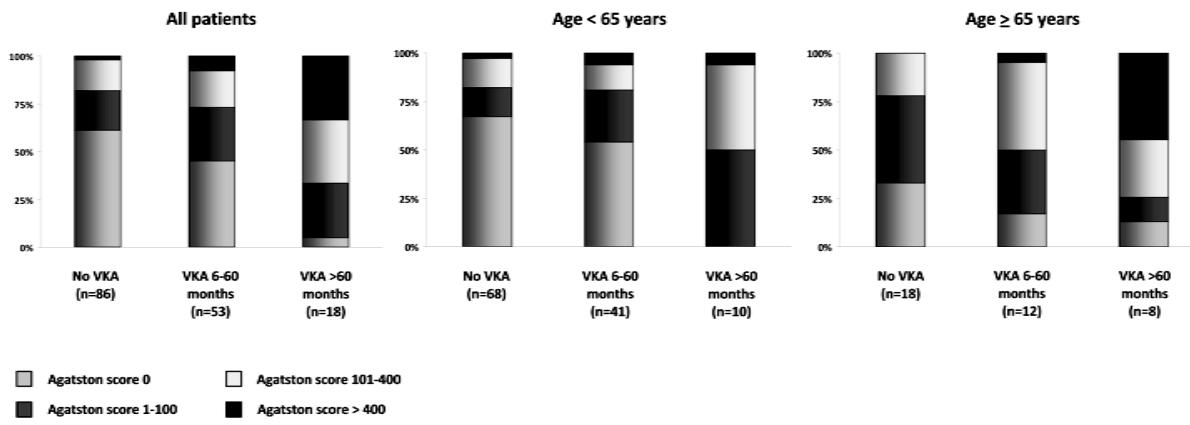

FIGURE 1 - Coronary artery calcium score categories in patients with different duration of VKA use according to all patients and two different age groups. $\mathrm{P}<0.001$ for comparison between the three groups in the pooled cohort. $P=0.031$ for comparison between the three groups in patients with age $<65$ years. $P<0.001$ for comparison between the three groups in patients with age $\geq 65$.

Multivariable logistic regression analysis revealed that age and VKA treatment duration (months) were significantly related to increased coronary calcium score (Table 3). This final model had a good discriminative power with a c-statistic of 0.8 . Of note, including VKA duration as a categorical variable (no VKA, 6-60 months, >60 months) or binominal variable (VKA use yes/no) to the model did not change the results. Repeating this analysis after addition of the propensity score as a continuous variable did not change the effects of VKA treatment on coronary calcium score. The propensity score model had a good discriminatory ability (c-statistic $=0.7$ ) and the Hosmer-Lemeshow test for goodness-of-fit was not statistically significant $(P=0.916)$, which is in accordance with a good calibration.

TABLE 3 - Multivariable logistic regression analysis: demographic and clinical variables related to increased Agatston score

\begin{tabular}{lccc}
\hline & OR & $95 \%$ C.I. & P \\
\hline Age (years) & 1.092 & $1.020-1.170$ & 0.012 \\
VKA duration (months) & 1.028 & $1.002-1.055$ & 0.034 \\
Statin use (yes/no) & 0.300 & $0.070-1.294$ & 0.107 \\
Left atrial dimension (mm) & 1.048 & $0.925-1.187$ & 0.461 \\
Ace-inhibitor use (yes/no) & 0.526 & $0.089-3.094$ & 0.477 \\
Posterior wall width (mm) & 1.105 & $0.489-2.494$ & 0.811 \\
\hline
\end{tabular}

After matching patients according to propensity score quintiles (Q1: $<0.32388$, Q2: 0.32389-0.40409, Q3: 0.40410-0.50302, Q4: 0.50303-0.57883, Q5: $>0.57883$ ), the use of VKA was associated with an increased Agatston score in Quintile 2 (15\% vs. $70 \%, \mathrm{HR}=13.222,95 \% \mathrm{Cl} 2.129-82.129, \mathrm{P}=0.006)$ and quintile $5(50 \%$ vs. $84 \%, \mathrm{HR} 5.333,95 \% \mathrm{Cl} 1.000-28.435, \mathrm{P}=0.050$ ). (Table 4 ) In the other quintiles, a nonsignificant trend of an increased Agatston score was observed in patients using VKA. (Figure 2) 
CHAPTER IX | CORONARY CALCIFICATION AND VITAMIN K ANTAGONISTS

TABLE 4 - Logistic regression results on the impact of VKA use on coronary calcification by propensity subgroups (quintiles)

\begin{tabular}{lccc}
\hline & HR & 95\% C.I. & P \\
\hline Quintile 1 & 3.818 & $0.641-22.744$ & 0.141 \\
Quintile 2 & 13.222 & $2.129-82.129$ & 0.006 \\
Quintile 3 & 1.200 & $0.299-4.817$ & 0.797 \\
Quintile 4 & 1.286 & $0.305-5.426$ & 0.732 \\
Quintile 5 & 5.333 & $1.000-28.435$ & 0.050 \\
\hline
\end{tabular}

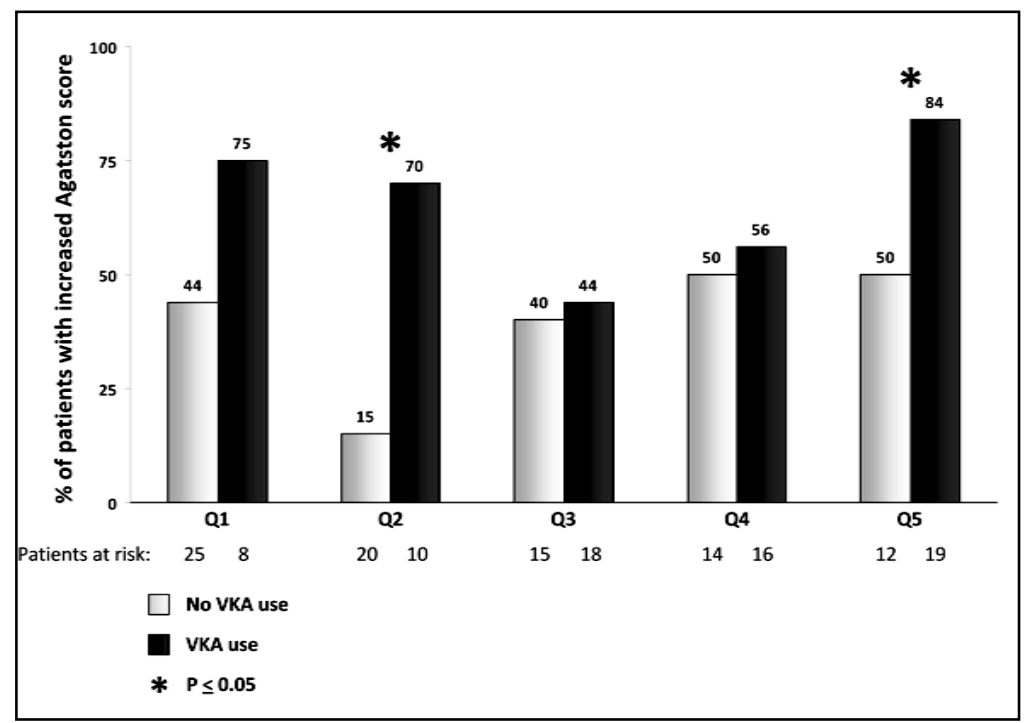

FIGURE 2 - Increased Agatston score according to propensity subgroups ( $Q=$ =quintiles).

In comparison with the other subgroups, patients with the most likelihood of receiving VKA (quintile 5) were more often male, more often used anti-arrhythmic drugs, were more likely to have higher body mass index, and had larger atrial size. (Table 5)

TABLE 5 - Significant differences in patient characteristics by propensity subgroups (quintiles)

\begin{tabular}{lcccccc}
\hline & Q1 $(\mathbf{n}=\mathbf{3 3})$ & $\mathbf{Q 2}(\mathbf{n}=\mathbf{3 0})$ & $\mathbf{Q 3}(\mathbf{n}=\mathbf{3 3})$ & $\mathbf{Q 4}(\mathbf{n}=\mathbf{3 0})$ & $\mathbf{Q 5}(\mathbf{n}=\mathbf{3 1})$ & $\mathbf{P}$ \\
\hline Male & $4(12)$ & $18(60)$ & $28(85)$ & $27(90)$ & $31(100)$ & $<0.001$ \\
BMI $\left(\mathrm{kg} / \mathrm{m}^{2}\right)$ & $25 \pm 4$ & $26 \pm 3$ & $27 \pm 3$ & $28 \pm 3$ & $29 \pm 3$ & $<0.001$ \\
Rhythm control & $12(36)$ & $15(52)$ & $21(64)$ & $26(87)$ & $28(93)$ & $<0.001$ \\
LA diameter $(\mathrm{mm})$ & $35 \pm 3$ & $39 \pm 4$ & $41 \pm 3$ & $44 \pm 3$ & $47 \pm 3$ & $<0.001$ \\
\hline
\end{tabular}

Data are presented as mean ( \pm SD) or $n(\%)$. BMI: body mass index; LA: left atrium. 


\section{DISCUSSION}

This is the first study showing that AF patients using VKA despite a low vascular risk show increased levels of coronary calcification. Mean coronary artery calcium scores were highest in patients with longest VKA use and logistic regression analysis indicated VKA use, together with age as independently related to increased coronary calcium score. These results suggest that chronic use of VKA may enhance potentially harmful coronary calcification in a subset of low risk AF patients.

\section{Vitamin $\mathrm{K}$ antagonists and arterial calcification}

Vitamin $\mathrm{K}$ is an essential micronutrient that serves as a cofactor for the transformation of selective glutamic acid residues into $\gamma$-carboxyglutamic acid (Gla) during the biosynthesis of the so-called Gla-proteins. ${ }^{21}$ Matrix-Gla-protein (MGP), a vitamin Kdependent protein, is produced by vascular smooth muscle cells (VSMCs) and chondrocytes. ${ }^{21}$ MGP is one of the strongest inhibitors of soft tissue calcification due to an effect on bone morphogenetic protein type 2 and binding of mineral and mineral ions in the matrix. ${ }^{7}$ It has been demonstrated that MGP-deficient mice develop extensive medial calcification of the arteries. ${ }^{9}$ In animal studies, the use of warfarin, a VKA derivative induced inactive MGP and subsequent vascular calcification. ${ }^{10}$ Circulating MGP levels are inversely correlated with the severity of coronary artery calcium as assessed by electron-beam computed tomography. ${ }^{8,} 9$ Recently Koos et al suggested that long-term VKA treatment may decrease circulating MGP levels leading to increased aortic valve calcifications. ${ }^{22}$ The excess coronary calcification as seen in our study might be mediated through inhibition of MGP carboxylation by VKA's.

\section{The role of calcification in coronary artery disease}

Pathomorphologically, there are at least two distinct forms of vascular calcification. Intima calcification of the coronary arteries (atherosclerosis) is an active process and can be seen in more advanced stages of atherosclerotic plaque development. ${ }^{23,24} \mathrm{It}$ occurs only at sites of atherosclerotic plaques, where there is already a combination of cellular necrosis, inflammation and cholesterol deposition, and is more frequent in advanced lesions and in the elderly. ${ }^{25,}{ }^{26}$ Calcification of the media (arteriosclerosis), also known as Mönckeberg's sclerosis, can occur independently of atherosclerosis and is almost exclusively associated with VSMCs. ${ }^{27}$ It is particularly common in the setting of metabolic disorders such as diabetes mellitus and chronic kidney disease. Besides, it is shown that MGP expression is lower in the media of arteries of patients with Mönckeberg's sclerosis than in normal vessels. ${ }^{28}$ Cardiac CT is unable to directly distinguish between medial and intimal calcification, as the minimal voxel size for 64slice scanners has been reported as $0.4 \mathrm{~mm}^{3}$ (using dedicated acquisition techniques, e.g. z-flying focal spot). ${ }^{29}$ In this study, we showed that focal calcifications were significantly more prevalent in the VKA treatment group, which could be an expression of inactive MGP induced medial calcification. Irrespective of the above it must be noted that calcification, independent from mixed or focal pattern, is a well-established cardiovascular risk factor. 
Apart from age, we revealed an independent relation between coronary artery calcification and VKA. This implicates that the use of VKA in low risk AF patients accelerates the process of calcification and atherosclerosis in patients with heretoforeunknown CAD.

The exact contribution of coronary artery calcification to the stability of atherosclerotic plaques is not clearly defined. Some studies describe that plaque calcification initially destabilizes a plaque by providing areas of interface between high and low density where a plaque is more prone to rupture. ${ }^{30}$ Plaques may also rupture because of physical stress exerted by calcified nodules. ${ }^{31,32}$ However, calcification may also represent beneficial scaffolding which could be seen as protective by strengthening atherosclerotic plaque prone to rupture. But still then enhancing the process of calcification by VKA may promote vasomotor dysfunction in the coronary arterial tree.

MSCT is a non-invasive technique that can easily detect CAD at its earliest stages reflected by the presence and severity of coronary artery calcification. ${ }^{33,}{ }^{34}$ The coronary artery calcium score is an important marker which is used to identify a high risk group of asymptomatic patients who have clinically important silent ischemia. ${ }^{35}$ Even a low coronary artery calcium score could provide information about the vascular status of a patient. Minor lesions in the main coronary arteries could be a sign of advanced vascular disease in the microvasculature, which may lead to important ischemia, possibly even influencing the AF substrate. A recent meta-analysis among 30 prospective studies revealed that the presence of calcifications is associated with a 3-4 fold higher risk for mortality and cardiovascular events. ${ }^{36,37}$

\section{Low risk atrial fibrillation and the use of vitamin $\mathrm{K}$ antagonists}

VKA are among the most widely used drugs to prevent stroke in AF. However, the long-term effects on coronary artery calcifications have not been studied in detail. AF is often associated with vascular disease; in particular hypertension, coronary artery disease and diabetes mellitus. A large population-based study recently showed that there is a high prevalence of AF among patients with, or at high risk of, atherosclerosis. $^{38}$ The same study found that AF in patients with CAD was associated with a major increase in cardiovascular mortality and morbidity. Even in lone AF vascular complications have been described in $50 \%$ of patients during long term follow-up. ${ }^{39}$ Besides, atrial myocardial perfusion abnormalities are common in patients with lone recurrent AF. ${ }^{40}$ These data suggest that a significant proportion of low risk AF patients is susceptible to vascular disease and that every effort should be taken to avoid and control risk factors. Considering the findings of our study and the fact that many low risk AF patients are overtreated with VKA in clinical practice ${ }^{13}$, future studies need to clarify the risks VKA treatment represents in terms of coronary calcification. Until then overtreatment should be avoided, especially in the young low risk AF patient whom faces a lifelong career as a VKA user. In this respect, new anticoagulants such as Dabigatran may form a welcome alternative. ${ }^{41,42}$ 


\section{Study limitations}

This study has several limitations that should be reported. At first, this is a crosssectional analysis. A cause and effect relationship could therefore not be investigated. Secondly, vitamin D and parathyroid hormone (PTH) homeostasis and serum matrixGLA protein were not studied but could have added to understanding biological pathways leading to VKA induced calcification. On the other hand, it is likely that vitamin D or PTH homeostasis in this low risk population with normal renal function would probably be normal or near normal and therefore would not change the results significantly. Thirdly, no follow-up data are available at this point. However, the strength of our study is that we selected low risk AF patients to reduce the impact of associated vascular disease usually seen in high risk patients, thereby enhancing identification of potentially deleterious effects of VKA. In previous studies, patients with advanced disease were studied focusing on valve and vessel wall. ${ }^{8,43}$ However, showing an independent effect of VKA may be impossible in these patients because of other calcification processes related to their vascular or valvular disease.

This was a small non-randomized study. While the findings are potentially very important, the results should not be overstated. Although we optimally tried to take into account the selection bias for those who did vs. those who did not receive VKA by means of multivariable modelling and propensity score analysis, both techniques cannot account for unknown or unmeasured potential confounding factors. Moreover, the effect of VKA on coronary calcification was not entirely comparable within propensity score quintiles. We have no clear explanation for these imbalances other than the low patient number per quintile. Nevertheless, we would like to emphasize that three out of five quintiles show a clear difference regarding increased Agatston score in VKA users and there is a trend towards the same finding in the other 2 quintiles. In addition one should also bear in mind that all these patients actually had no strict indication for oral anticoagulation since they had low risk AF.

A long-term large-scale randomized study may corroborate our results even in high-risk patients, in particular by comparing VKA to one of the new oral anticoagulants.

\section{CONCLUSION}

Patients using VKA despite a low risk of cardiovascular events show increased levels of coronary calcification as detected by computed tomographic angiography. A long-term large-scale randomized study is needed to corroborate the current observations.

\section{ACKNOWLEDGEMENT}

The authors are grateful to Sandra van Wijk, Maastricht, the Netherlands; and Ron Pisters, Maastricht, the Netherlands for valuable statistical support.

\section{FUNDING}

The MUMC cardiology department supported this work. 
CHAPTER IX | CORONARY CALCIFICATION AND VITAMIN K ANTAGONISTS

\section{REFERENCES}

1. Fuster V, Ryden LE, Cannom DS, Crijns HJ, Curtis AB, Ellenbogen KA, et al. ACC/AHA/ESC 2006 guidelines for the management of patients with atrial fibrillation: full text: a report of the American College of Cardiology/American Heart Association Task Force on practice guidelines and the European Society of Cardiology Committee for Practice Guidelines (Writing Committee to Revise the 2001 guidelines for the management of patients with atrial fibrillation) developed in collaboration with the European Heart Rhythm Association and the Heart Rhythm Society. Europace. 2006 Sep;8(9):651-745.

2. Halperin JL, Hart RG. Atrial fibrillation and stroke: new ideas, persisting dilemmas. Stroke. 1988 Aug;19(8):937-41.

3. Kannel WB, Abbott RD, Savage DD, McNamara PM. Epidemiologic features of chronic atrial fibrillation: the Framingham study. N Engl J Med. 1982 Apr 29;306(17):1018-22.

4. Krahn AD, Manfreda J, Tate RB, Mathewson FA, Cuddy TE. The natural history of atrial fibrillation: incidence, risk factors, and prognosis in the Manitoba Follow-Up Study. Am J Med. 1995 May;98(5):476-84.

5. Go AS, Hylek EM, Chang Y, Phillips KA, Henault LE, Capra AM, et al. Anticoagulation therapy for stroke prevention in atrial fibrillation: how well do randomized trials translate into clinical practice? Jama. 2003 Nov 26;290(20):2685-92.

6. Hart RG, Pearce LA, Aguilar MI. Meta-analysis: antithrombotic therapy to prevent stroke in patients who have nonvalvular atrial fibrillation. Annals of internal medicine. 2007 Jun 19;146(12):857-67.

7. Cranenburg EC, Schurgers LJ, Vermeer C. Vitamin K: the coagulation vitamin that became omnipotent. Thrombosis and haemostasis. 2007 Jul;98(1):120-5.

8. Jono S, Ikari Y, Vermeer C, Dissel P, Hasegawa K, Shioi A, et al. Matrix Gla protein is associated with coronary artery calcification as assessed by electron-beam computed tomography. Thrombosis and haemostasis. 2004 Apr;91(4):790-4.

9. Luo G, Ducy P, McKee MD, Pinero GJ, Loyer E, Behringer RR, et al. Spontaneous calcification of arteries and cartilage in mice lacking matrix GLA protein. Nature. 1997 Mar 6;386(6620):78-81.

10. Price PA, Faus SA, Williamson MK. Warfarin causes rapid calcification of the elastic lamellae in rat arteries and heart valves. Arteriosclerosis, thrombosis, and vascular biology. 1998 Sep;18(9):1400-7.

11. Schurgers LJ, Aebert H, Vermeer C, Bultmann B, Janzen J. Oral anticoagulant treatment: friend or foe in cardiovascular disease? Blood. 2004 Nov $15 ; 104(10): 3231-2$.

12. Rennenberg RJ, van Varik BJ, Schurgers LJ, Hamulyak K, Ten Cate H, Leiner T, et al. Chronic coumarin treatment is associated with increased extra-coronary arterial calcification in humans. Blood. 2010 Mar 30;Epub ahead of print.

13. Nieuwlaat R, Capucci A, Lip GY, Olsson SB, Prins MH, Nieman FH, et al. Antithrombotic treatment in real-life atrial fibrillation patients: a report from 
the Euro Heart Survey on Atrial Fibrillation. European heart journal. 2006 Dec;27(24):3018-26.

14. Nieuwlaat R, Olsson SB, Lip GY, Camm AJ, Breithardt G, Capucci A, et al. Guideline-adherent antithrombotic treatment is associated with improved outcomes compared with undertreatment in high-risk patients with atrial fibrillation. The Euro Heart Survey on Atrial Fibrillation. Am Heart J. 2007 Jun;153(6):1006-12.

15. Assmann G, Cullen P, Schulte H. Simple scoring scheme for calculating the risk of acute coronary events based on the 10-year follow-up of the prospective cardiovascular Munster (PROCAM) study. Circulation. 2002 Jan 22;105(3):3105 .

16. Gottdiener JS, Bednarz J, Devereux R, Gardin J, Klein A, Manning WJ, et al. American Society of Echocardiography recommendations for use of echocardiography in clinical trials. J Am Soc Echocardiogr. 2004 Oct;17(10):1086-119.

17. Aikawa E, Nahrendorf M, Figueiredo JL, Swirski FK, Shtatland T, Kohler RH, et al. Osteogenesis associates with inflammation in early-stage atherosclerosis evaluated by molecular imaging in vivo. Circulation. 2007 Dec $11 ; 116(24): 2841-50$.

18. Pfohl M, Athanasiadis A, Koch M, Clemens $\mathrm{P}$, Benda $\mathrm{N}$, Haring $\mathrm{HU}$, et al. Insertion/deletion polymorphism of the angiotensin I-converting enzyme gene is associated with coronary artery plaque calcification as assessed by intravascular ultrasound. J Am Coll Cardiol. 1998 Apr;31(5):987-91.

19. Heinze G, Juni P. An overview of the objectives of and the approaches to propensity score analyses. European heart journal. Feb 28.

20. Camm AJ, Kirchhof P, Lip GY, Schotten U, Savelieva I, Ernst S, et al. Guidelines for the management of atrial fibrillation: the Task Force for the Management of Atrial Fibrillation of the European Society of Cardiology (ESC). European heart journal. 2010 Oct;31(19):2369-429.

21. Schurgers LJ, Cranenburg EC, Vermeer C. Matrix Gla-protein: the calcification inhibitor in need of vitamin K. Thrombosis and haemostasis. 2008 Oct;100(4):593-603.

22. Koos R, Krueger T, Westenfeld R, Kuhl HP, Brandenburg V, Mahnken AH, et al. Relation of circulating Matrix Gla-Protein and anticoagulation status in patients with aortic valve calcification. Thrombosis and haemostasis. 2009 Apr;101(4):706-13.

23. Hirota S, Imakita M, Kohri K, Ito A, Morii E, Adachi S, et al. Expression of osteopontin messenger RNA by macrophages in atherosclerotic plaques. A possible association with calcification. The American journal of pathology. 1993 Oct;143(4):1003-8.

24. Shanahan CM, Cary NR, Metcalfe JC, Weissberg PL. High expression of genes for calcification-regulating proteins in human atherosclerotic plaques. The Journal of clinical investigation. 1994 Jun;93(6):2393-402. 
25. Johnson RC, Leopold JA, Loscalzo J. Vascular calcification: pathobiological mechanisms and clinical implications. Circulation research. 2006 Nov 10;99(10):1044-59.

26. Hoff JA, Chomka EV, Krainik AJ, Daviglus M, Rich S, Kondos GT. Age and gender distributions of coronary artery calcium detected by electron beam tomography in 35,246 adults. Am J Cardiol. 2001 Jun 15;87(12):1335-9.

27. Amann K. Media calcification and intima calcification are distinct entities in chronic kidney disease. Clin J Am Soc Nephrol. 2008 Nov;3(6):1599-605.

28. Shanahan CM, Cary NR, Salisbury JR, Proudfoot D, Weissberg PL, Edmonds ME. Medial localization of mineralization-regulating proteins in association with Monckeberg's sclerosis: evidence for smooth muscle cell-mediated vascular calcification. Circulation. 1999 Nov 23;100(21):2168-76.

29. Rist C, Nikolaou K, Flohr T, Wintersperger BJ, Reiser MF, Becker CR. Highresolution ex vivo imaging of coronary artery stents using 64-slice computed tomography--initial experience. European radiology. 2006 Jul;16(7):1564-9.

30. Abedin M, Tintut $Y$, Demer LL. Vascular calcification: mechanisms and clinical ramifications. Arteriosclerosis, thrombosis, and vascular biology. 2004 Jul;24(7):1161-70.

31. Virmani R, Burke AP, Farb A. Plaque morphology in sudden coronary death. Cardiologia (Rome, Italy). 1998 Mar;43(3):267-71.

32. Vengrenyuk Y, Carlier S, Xanthos S, Cardoso L, Ganatos P, Virmani R, et al. A hypothesis for vulnerable plaque rupture due to stress-induced debonding around cellular microcalcifications in thin fibrous caps. Proceedings of the National Academy of Sciences of the United States of America. 2006 Oct 3;103(40):14678-83.

33. Rumberger JA, Sheedy PF, Breen JF, Schwartz RS. Electron beam computed tomographic coronary calcium score cutpoints and severity of associated angiographic lumen stenosis. J Am Coll Cardiol. 1997 Jun;29(7):1542-8.

34. Agatston AS, Janowitz WR, Hildner FJ, Zusmer NR, Viamonte M, Jr., Detrano R. Quantification of coronary artery calcium using ultrafast computed tomography. J Am Coll Cardiol. 1990 Mar 15;15(4):827-32.

35. He ZX, Hedrick TD, Pratt CM, Verani MS, Aquino V, Roberts R, et al. Severity of coronary artery calcification by electron beam computed tomography predicts silent myocardial ischemia. Circulation. 2000 Jan 25;101(3):244-51.

36. Rennenberg RJ, Kessels AG, Schurgers LJ, van Engelshoven JM, de Leeuw PW, Kroon AA. Vascular calcifications as a marker of increased cardiovascular risk: a meta-analysis. Vascular health and risk management. 2009;5(1):185-97.

37. Budoff MJ, Gul KM. Expert review on coronary calcium. Vascular health and risk management. 2008;4(2):315-24.

38. Goto S, Bhatt DL, Rother J, Alberts M, Hill MD, Ikeda Y, et al. Prevalence, clinical profile, and cardiovascular outcomes of atrial fibrillation patients with atherothrombosis. Am Heart J. 2008 Nov;156(5):855-63, 63 e2.

39. Osranek M, Bursi F, Bailey KR, Grossardt BR, Brown RD, Jr., Kopecky SL, et al. Left atrial volume predicts cardiovascular events in patients originally 
diagnosed with lone atrial fibrillation: three-decade follow-up. European heart journal. 2005 Dec;26(23):2556-61.

40. Skalidis El, Hamilos MI, Karalis IK, Chlouverakis G, Kochiadakis GE, Vardas PE. Isolated atrial microvascular dysfunction in patients with lone recurrent atrial fibrillation. J Am Coll Cardiol. 2008 May 27;51(21):2053-7.

41. Connolly SJ, Ezekowitz MD, Yusuf S, Eikelboom J, Oldgren J, Parekh A, et al. Dabigatran versus warfarin in patients with atrial fibrillation. N Engl J Med. 2009 Sep 17;361(12):1139-51.

42. Usman MH, Notaro LA, Patel H, Ezekowitz MD. New developments in anticoagulation for atrial fibrillation. Current treatment options in cardiovascular medicine. 2008 Sep;10(5):388-97.

43. Koos R, Mahnken AH, Muhlenbruch G, Brandenburg V, Pflueger B, Wildberger $\mathrm{JE}$, et al. Relation of oral anticoagulation to cardiac valvular and coronary calcium assessed by multislice spiral computed tomography. Am J Cardiol. 2005 Sep 15;96(6):747-9. 
CHAPTER IX | CORONARY CALCIFICATION AND VITAMIN K ANTAGONISTS 
EDITORIAL

LONG-TERM APPLICATION OF VITAMIN K ANTAGONISTS, MORE HARM THAN GOOD? THE ADDITIONAL VALUE OF

IMAGING

N Bruining PhD and RT van Domburg MD, PhD

Eramus MC, Thoraxcenter, 3015 GD Rotterdam, The Netherlands

European Heart Journal. 2011;32(20):2473-5 


\section{EDITORIAL}

As Weijs et al. ${ }^{1}$ have described, most patients diagnosed with paroxysmal atrium fibrillation (AF) are currently treated by prescribing life-long use of vitamin $K$ antagonists (VKAs) to prevent thrombo-embolic complications. ${ }^{2}$ By applying minimal invasive multislice computed tomography (MSCT) imaging, the authors found a possible adverse treatment effect in patients who were receiving VKAs for relatively longer, showing significant higher levels of calcium in their coronary arteries compared with patients with a shorter time on VKAs. This could have serious consequences for current clinical practice. ${ }^{2}$

In contrast to many other patient populations with cardiovascular diseases, a subgroup of patients exists in which AF is diagnosed at a relatively young age. With this in mind, the long-term safety of the pharmaceutical treatment (in this case prevention) is therefore of great importance. Until recently, the effects of long-term treatment strategies on coronary vessel wall morphology, whose primary objective is not to be used to treat coronary artery disease (CAD), were impossible to study in humans other than by using invasive coronary imaging techniques such as intravascular ultrasound (IVUS) or optical coherence tomography (OCT). ${ }^{3,4}$ These modalities can only be used in conjunction with invasive coronary angiography, which obviously will not be performed unless there is an indication for the presence of CAD. Furthermore, it would be necessary to image the complete coronary artery tree, which is not an easy task for catheter-based imaging modalities, and consequently a challenging and tedious analysis is required. A good example is the study design of the PROSPECT trial. ${ }^{5}$ Fortunately, there is also currently the possibility to image these patients by applying minimally invasive coronary $\mathrm{MSCT},{ }^{6}$ elegantly described by Weijs et al. ${ }^{1}$ It entails, within its limitations, imaging the complete coronary artery tree in a rapid fashion. In contrast to invasive coronary angiography, there is only the need to administer a small amount of contrast medium intravenously to visualize the coronary artery lumen, ${ }^{7}$ and naturally radiation exposure is a factor, and is not completely neglible. ${ }^{8}$

Applying minimally invasive coronary MSCT imaging, within a population of AF patients with low cardiovascular risk, Weijs et al. observed that patients who are receiving VKAs for relatively longer have significantly more coronary calcification compared with patients who are receiving this treatment over a shorter time span (Figure 1). Corroborating experimental data suggest that VKAs may decrease the activity of matrix Gla-protein, ${ }^{9}$ a strong inhibitor of soft tissue calcification. The authors concluded that the patient population of low risk AF who are on VKAs needs to be studied more in depth to judge if the current treatment strategy needs to be adapted to other possible options. The authors' finding requires and justifies a randomized long-term study to corroborate their data and to evaluate if a change in treatment strategy would be warranted by, for example, a change to one of the new anticoagulants as suggested by the authors. 

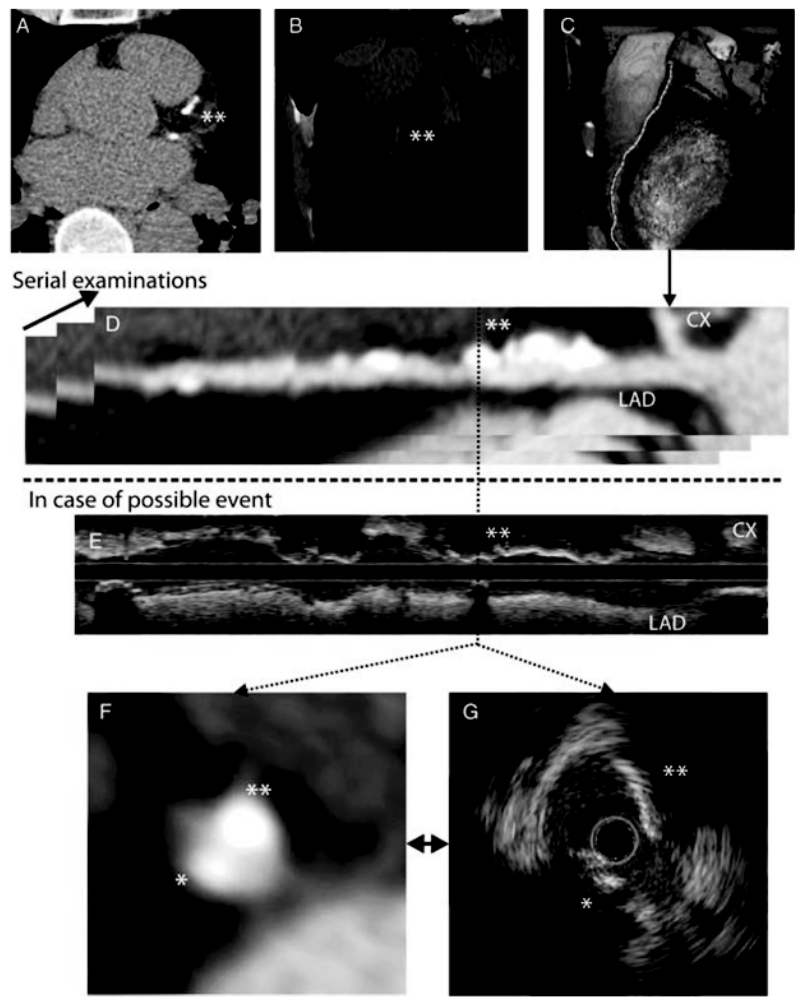

FIGURE 1 - (A) A cross-sectional multislice computed tomography (MSCT) image of a calcium score scan. Due to the high attenuation of calcium in MSCT scans it can be detected easily as bright areas within the images, as indicated here by **, of calcium present in the proximal left anterior descending (LAD). This is the examination set-up as described by Weijs et al. ${ }^{1}$ (B) A three-dimensional (3D) reconstruction of this calcium score acquisition in a similar projection to the 3Dreconstruction of the contrast enhanced scan in (C). Using this contrast-enhanced scan the LAD can be extracted from the MSCT image data and a comprehensive longitudinal reconstruction of the LAD (D) can be computed. Ideally these examinations should be performed longitudinally so that serial changes of the coronary artery vessel wall morphology could be evaluated over time. In such a fashion not only could the changes in the amount of calcium be detected but also serial remodelling of lesser-advanced stages of coronary artery disease and its development can be followed. In the case where a patient in this population suffers a coronary event which needs an intervention, then an additional intracoronary imaging examination, such as presented here by applying intravascular ultrasound (IVUS) (E and F), could reveal more details of the location of the calcium and other plaque components. $D$ and $E$, and $F$ and $G$ are matched, so there is a one-to-one link between these images. The different appearances of the calcium, brightexaggerated areas in MSCT ( $D$ and F), and bright rims with shadowing behind in IVUS ( $E$ and $G)$, can be appreciated. 
Rapid developments in coronary imaging have made it possible to study a variety of treatment effects as described by the authors. The newer generation of MSCT scanners are able to image the coronary artery tree at high speeds by using more detectors (320-slice scanners), avoiding motion artifacts, and, even more importantly, at much lower radiation levels compared with the scanners of the recent past. ${ }^{8}$ One could suggest that those patients who need to undergo treatments which might have an effect, negative or possibly even positive, on the coronary artery vessel wall morphology should be imaged in a standard way by MSCT. When performed prior to the commencement of a treatment this would allow observers to study serial patient-specific changes (Figure 1). Many longitudinal IVUS studies suggest that there might be an improved accuracy to detect treatment effects by applying serial measurements as opposed to being limited to only an individual measurement at one single point in time. ${ }^{10}$ Unfortunately, the calcium score, known as the Agatston score, ${ }^{11}$ applied by Weijs et al. ${ }^{1}$ was measured at one single time point only and so differential changes in coronary artery calcification levels in individual patient are lacking (Figure 1). Although the patients were relatively young, it cannot be excluded that they already had significant CAD present at the time of the start of the VKA treatment, as has been shown in the past. ${ }^{12} A$ repeated (e.g. differential) measurement would therefore be of utmost importance in future studies investigating the current hypothesis of the suspicion of the effects of VKAs. Although the authors present their findings as an adverse effect, it has been shown in IVUS-driven studies that increased levels of plaque calcification accompanied by negative coronary vessel wall remodeling could be signs of plaque stabilization. ${ }^{10}$ These are questions left unanswered in the study of Weijs et al. which need to be addressed in future studies.

Another intriguing aspect arose from the study of Weijs et al.: what is the underlying mechanism here? Although MSCT is very sensitive at picking up coronary calcification, it cannot determine the precise location of the calcium within the coronary artery. Due to the high attenuation values of calcium it is visualized as exaggerated very bright areas, making it difficult to determine their exact location in the coronary artery (Figure 1). As the authors describe it could be within coronary plaques, which is atherosclerosis, but it could also be within the media, called Mönckenberg disease. This distinction can only be made by use of intravascular imaging modalities (Figure 1). Therefore, it would be of great importance if patients on long-term VKA therapy who might end up with CAD requiring a coronary intervention should be also be additionally imaged by IVUS and/or OCT; the PROSPECT trial ${ }^{5}$ was designed in a similar fashion. Although it must be emphasized that these intravascular imaging modalities are not the gold standard, which is still histopathology, when applied as a complementary imaging tool they could be of great added value. However, care must be taken as these intracoronary imaging methods also need specific methods of analyses as they also suffer from calcium-related imaging artefacts $^{13}$ (Figure 1). In contrast to MSCT, IVUS shows calcium as bright rims with dark areas behind them (called acoustic shadowing). However, due to the tomographic cross-sectional imaging of the vessel, it allows accurate determination of the location of calcification as compared with MSCT (of course in cases where the vessel is not circumferentially calcified over long lengths). ${ }^{3}$ 
As long-term randomized controlled trials will take several years, another possibility to investigate the association between long-term use of a VKA and calcification is to use MSCT data from existing hospital databases. By applying propensity analyses, it is feasible to compare patients treated with a VKA with patients not treated with a VKA in larger cohorts of patients compared with the study of Weijs et al., investigating more in depth by increasing the power of the study whether the use of a VKA really induces increased levels of CAD.

The study by Weijs et al. 'tickles' scientific curiosity to determine what exactly is taking place in this particular patient population who are on long-term VKAs. However, from a cost-benefit approach we are facing difficult financial times in which it can be tough to justify the extra diagnostics, and their financial costs, required to perform these (in our opinion) necessary evaluations. We do hope that the evidence presented in the study of Weijs et al., and published in such an authoritative journal as the European Heart Journal, could serve to convince those who are mandated to authorize the necessary finances for the extra diagnostics for these types of long-term follow-up studies. These studies are needed to learn and study, and, perhaps even more importantly, to prevent a patient's exposure to possible adverse treatment effects, which were unexpected at the time of the start of the treatment.

\section{ACKNOWLEDGEMENTS}

The authors wish to express their gratitude to Mr. P. Cummins for his editorial work on this manuscript.

\section{CONFLICT OF INTEREST}

None declared. 


\section{REFERENCES}

1. Weijs B, Blaauw Y, Rennenberg RJMW, Schurgers LJ, Timmermans CCMM, Pison L, et al. Patients using vitamin $\mathrm{K}$ antagonists show increased levels of coronary calcification: an observational study in low-risk atrial fibrillation patients. Eur Heart J. 2011;32(20):2555-62

2. Fuster V, Ryden LE, Cannom DS, Crijns HJ, Curtis AB, Ellenbogen KA, et al. ACC/AHA/ESC 2006 guidelines for the management of patients with atrial fibrillation- executive summary: a report of the American College of Cardiology/ American Heart Association Task Force on Practice Guidelines and the European Society of Cardiology Committee for Practice Guidelines. Eur Heart J 2006;27:1979-2030.

3. Mintz GS, Popma JJ, Pichard AD, Kent KM, Satler LF, Chuang YC, et al. Patterns of calcification in coronary artery disease. A statistical analysis of intravascular ultrasound and coronary angiography in 1155 lesions. Circulation 1995;91:1959-1965.

4. Kume T, Okura H, Kawamoto T, Yamada R, Miyamoto Y, Hayashida A, et al. Assessment of the coronary calcification by optical coherence tomography. Eurolntervention 2011;6: 768-772.

5. Stone GW, Maehara A, Lansky AJ, de Bruyne B, Cristea E, Mintz GS, et al. A prospective natural-history study of coronary atherosclerosis. N Engl J Med 2011;364:226-235.

6. Achenbach S, Moselewski F, Ropers D, Ferencik M, Hoffmann U, MacNeill B, et al. Detection of calcified and noncalcified coronary atherosclerotic plaque by contrast-enhanced, submillimeter multidetector spiral computed tomography: a segment-based comparison with intravascular ultrasound. Circulation 2004;109:14-17.

7. Cademartiri F, La Grutta L, Palumbo A, Malagutti P, Pugliese F, Meijboom $W B$, et al. Non-invasive visualization of coronary atherosclerosis: state-ofart. J Cardiovasc Med (Hagerstown) 2007;8: 129-137.

8. de Graaf FR, Schuijf JD, Delgado V, van Velzen JE, Kroft LJ, de Roos A, et al. Clinical application of CT coronary angiography: state of the art. Heart Lung Circ 2010;19:107-116.

9. Luo G, Ducy P, McKee MD, Pinero GJ, Loyer E, Behringer RR, et al. Spontaneous calcification of arteries and cartilage in mice lacking matrix GLA protein. Nature 1997;386:78-81.

10. Rodriguez-Granillo GA, de Winter S, Bruining N, Ligthart JM, Garcia-Garcia $\mathrm{HM}$, Valgimigli $M$, et al. Effect of perindopril on coronary remodelling: insights from a multicentre, randomized study. Eur Heart J 2007;28: 23262331.

11. Agatston AS, Janowitz WR, Hildner FJ, Zusmer NR, Viamonte M Jr, Detrano R. Quantification of coronary artery calcium using ultrafast computed tomography. J Am Coll Cardiol 1990;15:827-832. 
12. Enos WF, Holmes RH, Beyer J. Coronary disease among United States soldiers killed in action in Korea; preliminary report. J Am Med Assoc 1953;152: 1090-1093.

13. Bruining N, de Winter S, Roelandt JR, Rodriguez-Granillo GA, Heller I, van Domburg RT, et al. Coronary calcium significantly affects quantitative analysis of coronary ultrasound: importance for atherosclerosis progression/regression studies. Coron Artery Dis 2009;20:409-414. 
CHAPTER X DISCUSSION 


\section{General reflection of this thesis}

The term idiopathic atrial fibrillation (AF) is commonly used, but the correctness of this designation is doubtful. Indeed the arrhythmia may appear in the young and apparently healthy, and it is thought that these idiopathic AF patients have a good prognosis with low risk for comorbidities and major adverse events. ${ }^{1-3}$ However, since AF in general is associated with underlying cardiovascular disease and cardiovascular events such as stroke and myocardial infarction, the 'idiopathic' type of the arrhythmia may act as a whistle-blower of subclinical heart disease.

This thesis provides more insight in the fundamental basis for idiopathic AF and questions the robustness of its definition. Therefore, we described characteristics of the atrial electro-mechanical substrate in idiopathic AF patients, studied clinical patient profiles and follow up in a large clinical cohort with idiopathic AF, and - in the hunt for concealed root causes of idiopathic AF - the presence and occurrence of cardiovascular disease in these patients were studied. The present chapter critically reflects the obtained results and proposes future research topics.

\section{Idiopathic atrial fibrillation: trigger, substrate or interplay?}

The electrocardiogram is one of the simplest, oldest and cheapest cardiac investigations available, yet it can provide a wealth of useful information and remains an essential tool to evaluate the heart as it is able to identify the majority of cardiac diseases. ${ }^{4}$ As the clinical presentation of various supraventricular tachycardias may be similar to AF (dyspnoea, palpitations, fatigue, dizziness), confirmation of the presence of the arrhythmia by means of electrocardiography is vital. ${ }^{1,5} \mathrm{AF}$ can be easily diagnosed on the surface electrocardiogram by means of characteristic features as absence of evident atrial activity ( $P$ waves) together with irregular $R-R$ intervals. However, the electrocardiogram does not provide much information on the many possible causes and mechanisms of the arrhythmia in the individual patient. In fact, since AF is associated with an impaired prognosis, and different treatments of the arrhythmia itself (rate vs. rhythm control) do not affect outcome, it is clear that AF is a more complex entity than a sheer electrocardiographic phenomenon. ${ }^{6-9}$ Besides, the progressive nature of AF is partly caused by AF itself, but also reflects progression of underlying structural heart diseases. This mandates the search for underlying root causes and mechanisms of the arrhythmia.

AF can be initiated by either a single source or by multiple sources. In case of single source $A F$, the arrhythmia is driven by an automatic focal discharge (often located in the myocardial 'sleeves' of the pulmonary veins), or a single re-entrant circuit (i.e. a mother wave: a single stable macro re-entrant circuit with a short cycle length). On the other hand, AF may be initiated by automatic foci at multiple sites, multiple circuits, multiple wavelets or a combination of foci and wavelets. ${ }^{10-23}$

Moe and co-workers emphasized the role of independent wandering wavelets in the persistence of $A F{ }^{15}$ Their multiple circuit re-entry model has been the dominant model of AF for years and is still considered to be of major importance for maintenance of AF. At a certain wavelength, i.e. the product of refractory period and conduction velocity, large atria can harbour more independent re-entrant wave fronts. 
On the other hand, a reduction in conduction velocity or refractory period reduces the wavelength, which will increase the number of wave fronts in atria of a certain size. An enlarged atrial volume and a reduced conduction velocity will lead to an increase in the total atrial conduction time (TACT). Therefore, a prolonged TACT may express a substrate vulnerable for AF.

All in all, apart from an initiating trigger, AF often requires an underlying substrate. ${ }^{24}$ Numerous clinical conditions (table 1) contribute to a progressive process of atrial remodelling (via changes in ion channel function, $\mathrm{Ca}^{2+}$ homeostasis, cellular hypertrophy and fibrosis). These alterations may both favour the occurrence of triggers for AF that initiate the arrhythmia and enhance the formation of an atrial substrate for AF that promotes its perpetuation. ${ }^{16,17,25}$

TABLE 1 - clinical conditions and risk factors associated with atrial fibrillation., 1, 5, 26-42

\begin{tabular}{|c|c|c|c|}
\hline $\begin{array}{l}\text { Ageing } \\
\text { Male gender }\end{array}$ & NON-MODIFIABLE & $\begin{array}{l}\text { Blood pressure } \\
\text { Auto-immune disease }\end{array}$ & \\
\hline Hypertension & MODIFIABLE & Increased sympathetic activity & \\
\hline Heart failure & & Obesity & LIFESTYLE \\
\hline Valvular heart disease & & Stature & \\
\hline Coronary heart disease & & Alcohol & \\
\hline Diabetes Mellitus & & Coffee & \\
\hline Thyroid dysfunction & & Drugs & \\
\hline Renal dysfunction & CLINICAL & COPD (smoking) & \\
\hline Other arrhythmias & CHARACTERISTICS & Endurance sports & \\
\hline Cardiomyopathies & & Family history & GENETIC CAUSES \\
\hline Pulmonary disease & & Channelopathy & \\
\hline Sleep apnoea & & Birth weight $>4 \mathrm{~kg}$ & NEWER RISK \\
\hline $\begin{array}{l}\text { Congenital heart } \\
\text { disease }\end{array}$ & & Preclinical atherosclerosis & FACTORS \\
\hline Malignancy & & Anger and hostility & \\
\hline
\end{tabular}

With regards to idiopathic $A F$, it is thought that in particular the young idiopathic AF patient suffers from so-called 'focal AF', initiated by triggers that can be localized at preferential sites (mainly the pulmonary veins), whereas in the older idiopathic AF patient the interaction between trigger and substrate prevails. ${ }^{10,12,43,44}$ However, in the healthy elderly, late onset idiopathic AF may occur like in the younger patients simply because also trigger mechanisms occur at a later age in the absence of advanced substrate development (CHAPTER V). These patients may however more often show persistent or permanent AF since older patients may harbour subtle signs of atrial substrate with more advanced fibrosis, usually associated with somewhat larger left atrial size. The latter was not apparent in our population, i.e. there was no significant difference in atrial sizes as measured with echocardiography, also not after correcting for body mass index or height of the patients (Figure 1). 

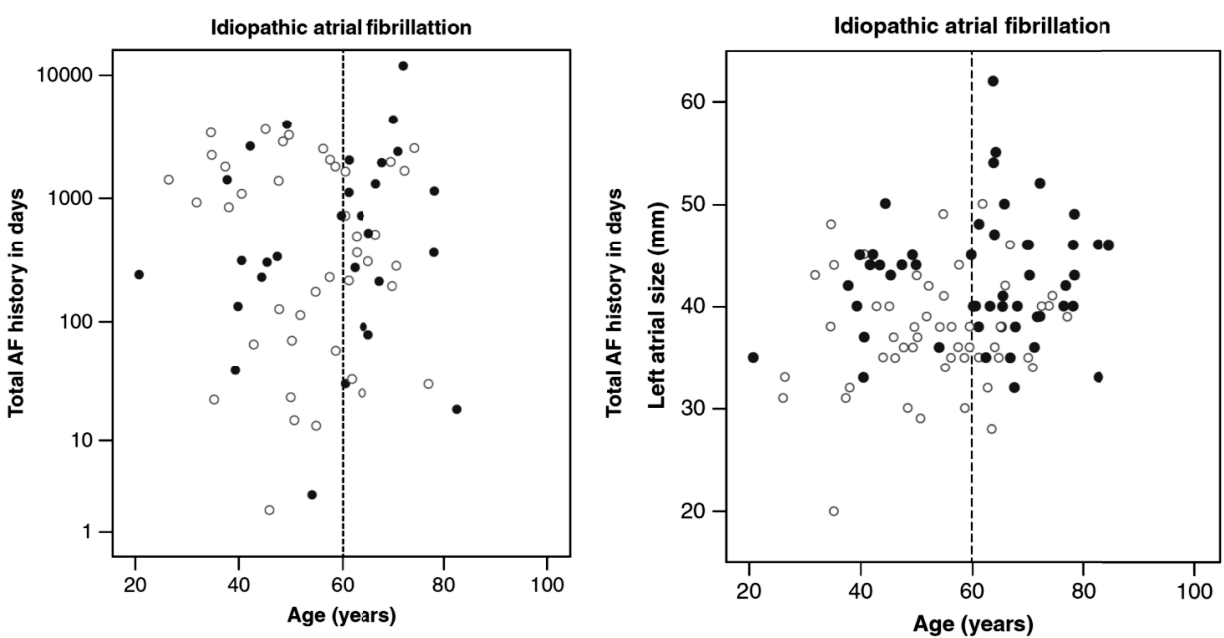

- Paroxysmal atrial fibrillation

- Persistent atrial fibrillation

FIGURE 1 - Total AF history (in days) and left atrial size (in $\mathrm{mm}$ ) according to age.

The triggers that underlie focal AF often originate in extensions of left atrial myocardium in the pulmonary veins (a.k.a myocardial sleeves)..$^{10,12,43,45-50}$ It has been shown that some pulmonary vein myocytes show characteristic features of pacemaker cells, like in the sino-atrial node, favouring enhanced automaticity as causal mechanism of the arrhythmia. ${ }^{45,51,52}$ In addition, triggered activity could also play a crucial role. This is defined as pacemaker activity that arises after an initial impulse has been generated within the myocyte and manifests as either early or delayed afterdepolarizations. ${ }^{17,53}$ Although both enhanced automaticity and triggered activity represent a plausible explanation for the onset of focal $A F$, the literature omits data why idiopathic AF eventually emerges. 
The majority of studies regarding pulmonary vein activity indicate that the pulmonary veins are not spontaneously active under normal conditions, but automaticity and triggered activity can be induced by a high adrenergic state or certain treatment. ${ }^{54-58}$ Further, both Hassink and Saito showed that myocardial extension in the pulmonary veins is present not only in patients with $A F$, but also in the majority or even every single sinus rhythm control patient. ${ }^{46,49}$ Given the fact that the anatomical substrate for ectopic foci is present in both AF patients as well as controls, it seems obvious that additional factors are necessary to "trigger the triggers" and initiate idiopathic focal AF. In this respect, the findings that the peripheral zone of myocardial sleeves contains extensive fibrosis and that hypertrophic myocytes are often present in AF patients, may be significant from an electrophysiological point of view. ${ }^{46,49,59}$ These findings suggest that even in the idiopathic focal AF patient subclinical cardiovascular conditions (e.g. atrial ischemia, ageing, masked hypertension) might create an early - concealed - atrial substrate facilitating automaticity and maybe also triggered activity (i.e. a concealed substrate to evoke triggers, Figure 2).
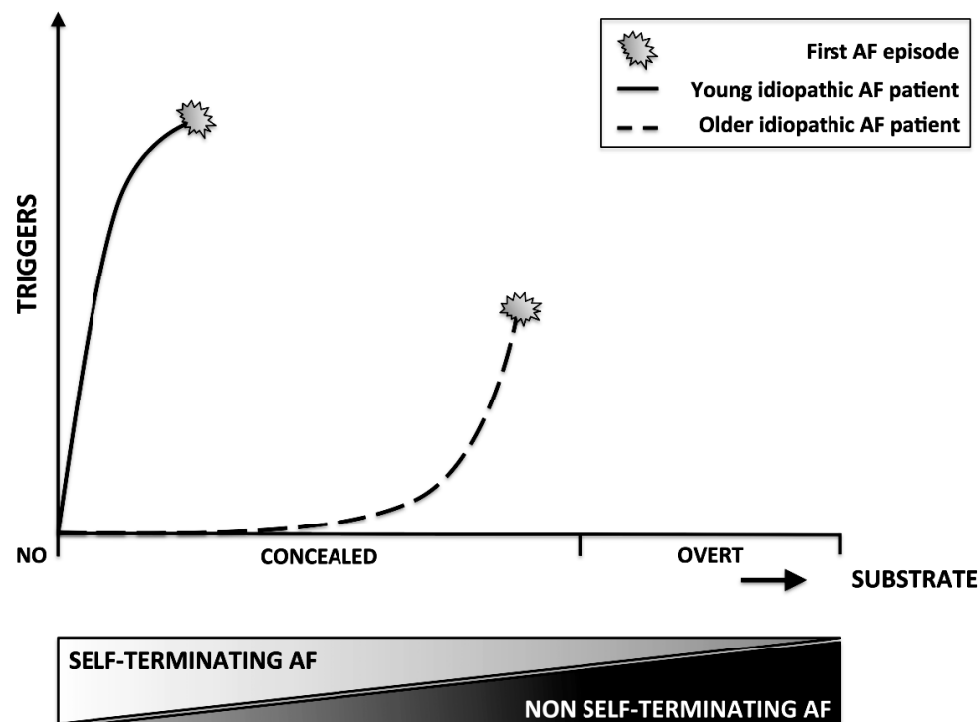

FIGURE 2 - Relation between the degree of underlying (concealed) substrate and triggers with regards to the first idiopathic AF episode in the young and older patient. 
Since an atrial substrate for AF implies, in essence, a prolongation of the TACT, we developed a highly reproducible and non-invasive echocardiographic tool to determine the TACT (the PA-TDI interval or PA-TDI: defined as the time interval between the onset of the electrocardiographic $P$ wave in lead II and the peak of the $A^{\prime}$ wave on the atrial tissue Doppler velocity curve from the left atrial wall). This method is able to predict the development of new-onset AF in a cardiologic outpatient clinic population (CHAPTER II). ${ }^{60}$ Several well-known clinical cardiovascular conditions contribute to intra-atrial conduction delay; this was studied by means of PA-TDI in CHAPTER III. ${ }^{61}$ According to the evidence above, we subsequently hypothesized that even in the idiopathic AF patient (in absence of cardiovascular or pulmonary disease) an early atrial substrate may be present. We studied the electrophysiologic properties of the atria in patients with idiopathic AF using tissue Doppler imaging and found that despite the healthy nature of the AF patients and comparable atrial sizes, TACT was significantly prolonged compared to matched healthy sinus rhythm control patients (CHAPTER IV). ${ }^{62}$ Since there was only a limited correlation between AF duration and left atrial size, the increased conduction time could therefore - apart from previous episodes of AF - be an expression of early and subclinical underlying cardiovascular disease creating a concealed substrate for triggers.

\section{Vascular disease or arrhythmia?}

During the embryologic development of the heart, the primitive single heart tube which eventually folds into the complex four-chambered heart - originates from the first intra-embryonic vasculature. ${ }^{63}$ Basically, the heart used to be a blood vessel. AF is a disorder of the heart, which is strongly associated with vascular complications such as stroke, heart failure and myocardial infarction, and in fact these complications form the major threat of the arrhythmia. ${ }^{5,264-67}$ This raises the question if AF should be regarded as a vascular disease or as part of a vascular syndrome rather than an arrhythmia?

Since all rate vs. rhythm control trials have shown that a rate control approach is not inferior for prevention of morbidity and mortality in AF patients, there is no evidence that the arrhythmia itself deteriorates outcome in AF patients. ${ }^{8,9,68-71}$ At present it is an unsettled issue whether early and effective ablation of AF reduces major cardiovascular and cerebrovascular events (MACCE). Currently, ablationists have focused their hope on the notion that the burden of AF, i.e. the number and duration of AF episodes, is linked to MACCE. ${ }^{72-75}$ By reducing the AF burden by early ablation, MACCE might thus be reduced. This is the key question in the upcoming EAST and CABANA trials. The notion that AF is a vascular disease is supported by the fact that vascular treatments (rather than arrhythmia interventions) including anticoagulation, statins and inhibition of the renin-angiotensin system prevent $A F$ recurrences and $A F$ associated major adverse cardiovascular and cerebrovascular events (MACCE). ${ }^{76-82}$ 
There is evidence for atrial vascular dysfunction in patients with AF and atrial ischemia has been linked to occurrence of the arrhythmia. ${ }^{39,83-88}$

Atrial ischemia may create a substrate for AF by causing fibrosis and scarring of the atrial wall, resulting in areas with reduced or even blocked conduction. Ischemia itself may also contribute as it shortens the refractory period and decreases conduction velocity in the atria, potentially facilitating re-entry processes. ${ }^{83}$ In addition, atrial ischemia may cause atrial triggers due to abnormal automaticity. Intermittent ischemia may also lead to ventricular diastolic dysfunction resulting in increased atrial filling pressures thus promoting AF by several mechanisms. ${ }^{89}$ However, the association between vascular disease and AF might also be related to common mechanisms underlying both atherosclerotic alterations and proarrhythmic mechanisms. Several pathophysiological mechanisms, like enhanced oxidative stress or inflammation, are both involved in vascular remodelling and extracellular tissue formation potentially leading to conduction disturbances and AF. ${ }^{17,90-92}$

The clinical relevance of concealed coronary vascular disease in patients with idiopathic AF is as yet not known. Very long term follow-up of idiopathic AF patients in the Olmsted county study showed that half of patients develop MACCE ${ }^{65}$. Annual cardiovascular morbidity and mortality with idiopathic AF in the RACE and Belgrade AF Study was approximately $4 \% .{ }^{93,94}$ Conceivably, hidden vascular disease is the basis for these events in idiopathic AF patients. In addition, it may be conjectured that idiopathic AF patients with concealed vascular disease have a worse arrhythmia prognosis since the vascular disease may be implicated in causing either AF itself or enhance symptoms during arrhythmia attacks.

In CHAPTER V we found that idiopathic AF was not associated with an adverse 1-year prognosis. In contrast, the presence of isolated mild hypertension in absence of significant atrial remodelling in otherwise comparable "idiopathic" AF patients seemed of prognostic importance since it was associated with $6 \% 1$-year stroke rate. ${ }^{95}$ Finding low risk of short-term morbidity in idiopathic AF is consistent with other studies, suggesting that the majority of the serious morbidity associated with AF is more likely due to associated yet subclinical medical conditions rather than AF itself. ${ }^{2,}{ }^{96}$ In CHAPTER VII we followed patients originally diagnosed with idiopathic AF for the development of cardiovascular disease during 5-year follow-up. It is remarkable that these "supposed-to-be" healthy patients turned out to develop cardiovascular disease significantly more often, at younger age, and with a more severe disease profile compared to healthy sinus rhythm controls. This ratifies our hypothesis that idiopathic AF might be a first manifestation of underlying subclinical cardiovascular disease, which eventually will determine outcome.

In order to find out whether early stage vascular disease could be a concealed root cause of so called "idiopathic" AF, we studied the presence of subclinical coronary artery disease by means of coronary CT angiography in idiopathic AF patients and compared our findings to a matched sinus rhythm control population (CHAPTER VIII). We found that half of patients originally diagnosed with idiopathic AF showed concealed underlying CAD. 
With this in our mind, rather than considering $A F$ to be a sole electrophysiological problem, which we can solve by means of ablation, we have to face the scope of the vascular consequences that accompany the arrhythmia. In other words: "It is a matter of getting the message of progressive deleterious vascular remodelling in stead of shooting the messenger AF."

Does the current knowledge affect current treatment modalities?

Since the management of patients with AF is aimed at reducing symptoms and preventing complications, it relies on antithrombotic therapy, control of ventricular rate, and adequate treatment of concomitant disease. ${ }^{1,5}$ The findings of this thesis could have clinical implications on current AF management.

The risk for stroke is increased five-fold in patients with AF. ${ }^{66,67}$ Oral anticoagulation by means of vitamin $\mathrm{K}$ antagonists (VKA) is highly effective in preventing these thromboembolic events in patients with AF. ${ }^{97-99}$ However, these agents have major limitations necessitating frequent monitoring and dietary and drug restrictions. Besides, the use of VKA may be associated with serious side effects such as haemorrhagic stroke. In order to guide adequate anticoagulant treatment, stroke risk stratification of the individual AF patient is obligatory. During the past years, various risk factors have been identified as contributing to the risk for stroke in AF. This resulted in multiple stroke risk stratification schemes of which $\mathrm{CHA}_{2} \mathrm{DS}_{2}$-VASc (acronym: congestive heart failure, hypertension, age $\geq 75$ [doubled], diabetes, stroke [doubled], vascular disease, age 65-74, and sex category [female]) is the most recent. ${ }^{1,}$ 5, 100, 101 As the opinion regarding potential stroke risk factors has changed over the years, the indication for oral anticoagulation in AF shifted continuously towards a lower threshold. Currently, only AF patients showing a $\mathrm{CHA}_{2} \mathrm{DS}_{2}-\mathrm{VASc}$ score of zero i.e. idiopathic $A F-$ do not require oral anticoagulation therapy. ${ }^{5,101}$

Obviously, information about the absence of congestive heart failure, hypertension, older age, diabetes, previous stroke, and female sex is easy to obtain. However, the question is how active one should search for the presence of underlying subclinical vascular disease in order to comply with a true $\mathrm{CHA}_{2} \mathrm{DS}_{2}$-VASc score of zero. This could be viewed in the light of the fact that, peripheral artery disease and myocardial infarction, but also complex aortic plaque all increase thromboembolic risk in AF and hence necessitate oral anticoagulation. ${ }^{5,102-106}$ Some of these conditions remain concealed for absence of clinical signs and symptoms, but should obviously be searched for with the standard diagnostic program. In how far new diagnostic modalities like CT-angiography - able to detect early preclinical vascular disease should be used in stroke risk stratification is at present unknown. 


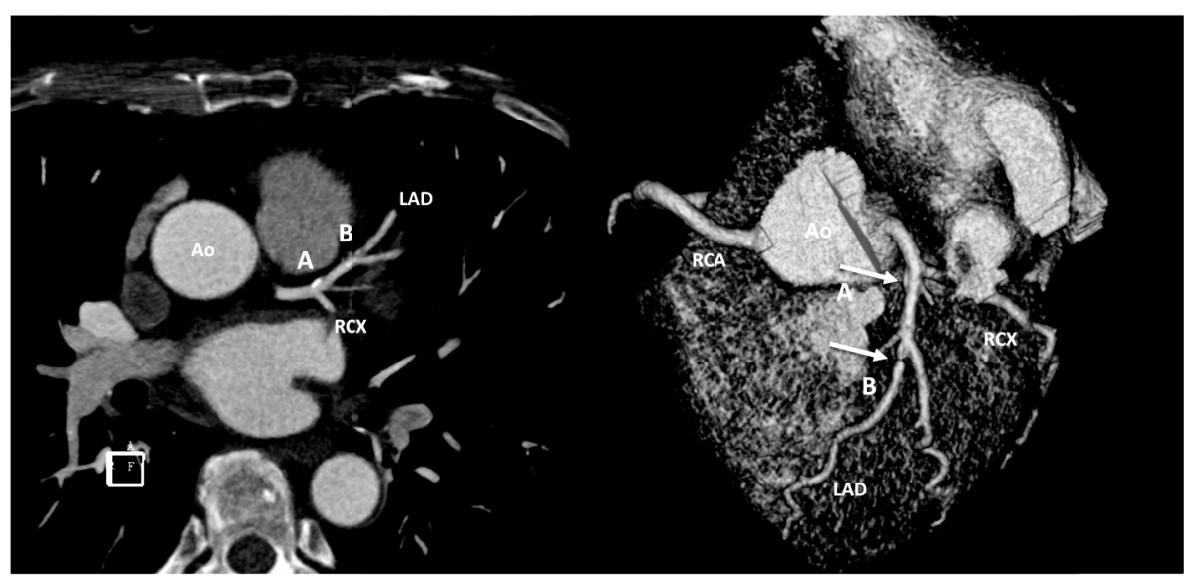

FIGURE 3 - Example of cardiac CT imaging (left: raw data; right: volume rendered image).

$A$, non-significant mixed plaque of the proximal left anterior descending artery (LAD) with outward remodelling; $B$, significant mixed plaque of the $L A D$, distal to diagonal branch.

(Ao, aorta; RCX, circumflex artery; RCA, right coronary artery)

Cardiac computed tomographic angiography (CTA) is a non-invasive technique that can easily detect $C A D$ at its earliest stages, reflected by the detection and quantification of coronary artery calcification and the possibility to characterize noncalcified coronary atherosclerotic plaques (Figure 3). ${ }^{107-110}$ The presence of (coronary) calcification as determined by CTA is associated with a three- to four-fold higher risk for mortality and cardiovascular events. ${ }^{111-115}$ Currently, performing CTA in AF patients to rule out vascular disease is not considered common clinical practice. In other words, one can never be sure if $\mathrm{CHA}_{2} \mathrm{DS}_{2}$-VASc score is truly low. Our data (CHAPTER VIII) that half of patients originally diagnosed with idiopathic AF show concealed underlying $C A D$, suggest that many $A F$ patients in fact are incorrectly considered to be at low risk for stroke. The use of CTA may decrease undertreatment of oral anticoagulants in these patients. The basis for such strategy is - we admit - narrow, because of the lack of decent follow up in randomized controlled trials studying the potential benefit of vascular and antithrombotic therapy in patients with the presence of CTA-CAD (both for AF as SR patients).

Being sure to meticulously rule out the presence of vascular disease in AF patients is also worth performing CTA since overtreatment with vitamin $\mathrm{K}$ antagonists in absence of stroke risk factors including vascular disease may enhance atherosclerosis by several mechanisms. ${ }^{116,}{ }^{117}$ VKA counteract not only the procoagulant clotting factors II, VII, IX, and X, but also the anticoagulant and antiinflammatory proteins $\mathrm{C}$ and $\mathrm{S}$, which are vitamin $\mathrm{K}$ dependent. Diminished function of these proteins is associated with increased incidence of venous and arterial thromboembolic events and enhances atherosclerosis. ${ }^{116,118-121}$ Further, VKA enhance tissue calcification by decreasing the activity of vitamin $K$ dependent matrix- $\gamma$ carboxyglutamic acid (GLA) protein, a strong inhibitor of soft tissue calcification. ${ }^{122-126}$ 
These drugs have been associated with increased levels of (coronary) vascular calcification in low-risk (AF) patients. ${ }^{117,}{ }^{127}$ In this respect, the new anticoagulants (dabigatran, rivaroxaban and apixaban) may form an attractive alternative in the patient with $\mathrm{AF}$ and vascular disease since these agents directly inhibit only a single coagulation factor instead of multiple by interfering in vitamin $\mathrm{K}$ homeostasis. ${ }^{128-130}$

The presence of coronary artery disease in AF patients also has consequences for pharmacological rhythm control. Many patients with AF may be candidates for drug therapy with class Ic antiarrhythmic drugs such as flecainide or propafenone. These drugs can be proarrhythmic, particularly in the setting of myocardial ischemia or previous myocardial wall infarction. ${ }^{131}$ For this reason, the presence of CAD has been regarded as a relative contraindication for the use of class Ic antiarrhythmic drugs. This holds especially since these patients may have a (concealed) ventricular substrate or develop a substrate once unstable plaques develop with acute and chronic myocardial ischemia. Indeed, it has to be elucidated whether the presence of CAD as determined by CTA in AF patients has the same consequences as CAD determined by conventional angiography. In addition, it is uncertain whether CTA-CAD without a detectable ventricular substrate (e.g. by echocardiography or cardiac magnetic resonance imaging) should be considered a contra-indication for class Ic drugs. At this point, it is preferable to avoid these drugs in AF patients with known CAD (including CTA-CAD). A lot of satisfied class Ic drug-users have had no additional imaging of the coronary arteries, from a practical point of view there is as yet no reason to cease these drugs in these patients, as long as patients are aware of alarming symptoms and a ventricular substrate has been ruled out as much as possible.

With the advent of new stroke risk stratification schemes that incorporate new risk factors, the guidelines on the management of atrial fibrillation not only should address recommendations on the antithrombotic treatment regimens in AF patients, but also give direction on how to diagnose separate stroke risk parameters. Especially since the difference between lifelong need for anticoagulant therapy or no antithrombotic therapy at all is based on only a single risk factor. Further, the probability of stroke in young patients with idiopathic AF appears to increase with advancing age or development of hypertension or vascular disease, emphasizing the importance of re-assessment of risk factors for stroke over time (CHAPTERS V and VII).

Currently, the proposed diagnostic work-up in AF patients consists of an echocardiogram, exercise test, 24-hour rhythm monitoring, measurement of blood pressure, and a full blood count (including thyroid function test, creatinin, and fasting glucose measurement). ${ }^{5}$ One could argue whether or not the proposed diagnostic tests are able to rule out the presence of hypertension and vascular disease as defined within the $\mathrm{CHA}_{2} \mathrm{DS}_{2}-\mathrm{VASc}$ score. At present it is almost medieval to rely on a single inoffice blood pressure measurement to detect or rule out the presence of arterial hypertension (CHAPTER VI). With 24-hour ambulatory blood pressure monitoring (ABPM) easily available in clinical practice, physicians should not fail to use these reliable and patient friendly tools to exclude specific cases of masked hypertension. With respect to the importance of vascular disease on prognosis in AF patients, one should doubt whether an exercise test is the appropriate diagnostic test to rule out 
underlying vascular disease in these patients. Cardiac CT angiography can easily detect $C A D$, and has incremental value over clinical predictors and exercise testing. ${ }^{132,133}$ In the past years, CTA technology has developed rapidly, resulting in high-resolution imaging of the coronary arteries and surrounding structures at low radiation dose. Especially, new generations of scanners (dual-source CT) and the availability of dose modulation and prospective ECG gating have drastically reduced patient radiation dose with excellent image quality. ${ }^{107,}{ }^{134-136}$ In addition, since CAD is associated with peripheral artery disease and complex aortic plaque, CTA could therefore be used as a marker for the presence of vascular disease in order to enhance individual stroke risk assessment in the patient with AF.

\section{FUTURE PERSPECTIVES}

Given that $A F$ is the final arrhythmic expression of underlying vascular diseases such as arterial hypertension and $C A D$, it should be classified as a vascular disease. In order to prevent our patients from AF progression or AF related complications, high priority should be given to understand identifiable predisposing factors, to characterize the type of AF in the individual patient, and to detect root causes of AF in such a way that preventative measures can accurately be deployed.

The traditional risk factors associated with AF are no longer the only conditions that we must consider in the evaluation of causal factors in a patient with first detected AF. Large clinical trials will need to evaluate the benefit and costeffectiveness of standardization of the use of more advanced diagnostic tools, such as ABPM and CTA, in the diagnostic work-up of early AF patients, and whether an aggressive treatment of underlying subclinical vascular disease will improve the prognosis of these patients. Besides, as diagnostic modalities improve, it will get easier to detect (early stages of) predisposing cardiovascular disease. Hence, it seems almost impossible to diagnose a patient with $A F$ in absence of any underlying possible causal factor. In this respect, adhering to the term 'idiopathic AF' seems obsolete. Since AF is not a benign condition and its increased stroke risk forms the major threat, it would be worthwhile to study the clinical applicability of classifying AF patients on their individual risk profile for the development of MACCE. In this case, the now outdated term 'idiopathic AF' could be changed for instance into 'low-risk AF' in those cases in which underlying pathologies are assuredly excluded.

Novel non-invasive (imaging) modalities have become available that are able to obtain information about the atria, the AF substrate and AF complexity in such high detail, allowing to characterize type of $A F$ and determine accompanying risk for $A F$ progression and MACCE in the individual patient. This may provide important information in order to refine and enhance AF treatment, which eventually will improve prognosis. Echocardiographic tissue velocity imaging of the fibrillating atrial myocardium provides essential information about the complexity of AF (by means of $A F$ cycle length $[A F-C L]$ measurement which reflects the functional atrial refractory period) and degree of structural atrial remodelling (by mapping atrial fibrillatory wall movements by means of AF velocity [AFV]) in AF patients. ${ }^{137-139}$ These parameters may predict the response to drug treatment and ablation as well as long-term arrhythmia 
outcome and therefore provide valuable information on the adequate approach in the treatment of AF. Equally, body surface electrocardiography or mapping (BSM), by analysis of simultaneous recorded non-invasive surface potentials in 256-channels on the back and front torso of the patient, may also unmask the complexity of the AF process by revealing fibrillation waves in body surface potential recordings. ${ }^{140} \mathrm{P}$-wave dispersion as determined by BSM may be used to identify people at risk for development of $\mathrm{AF}$ in patients with sinus rhythm. Apart from determining the presence of CAD, CTA could have a much larger role in AF treatment. This technique may reveal electro-anatomic features which may be relevant in the work-up for ablation: e.g. maximal circumference of pulmonary veins in relation to available sizes of cryoballoon-catheters or radiofrequency clamps as used for minimally invasive thoracoscopic hybrid treatment; assessment of accessory pulmonary veins; anatomy of left and right atrium as marker of atrial remodelling and treatment success; vascularization of the atria (Figure 4).

\section{FIRST DIAGNOSED EPISODE OF ATRIAL FIBRILLATION}
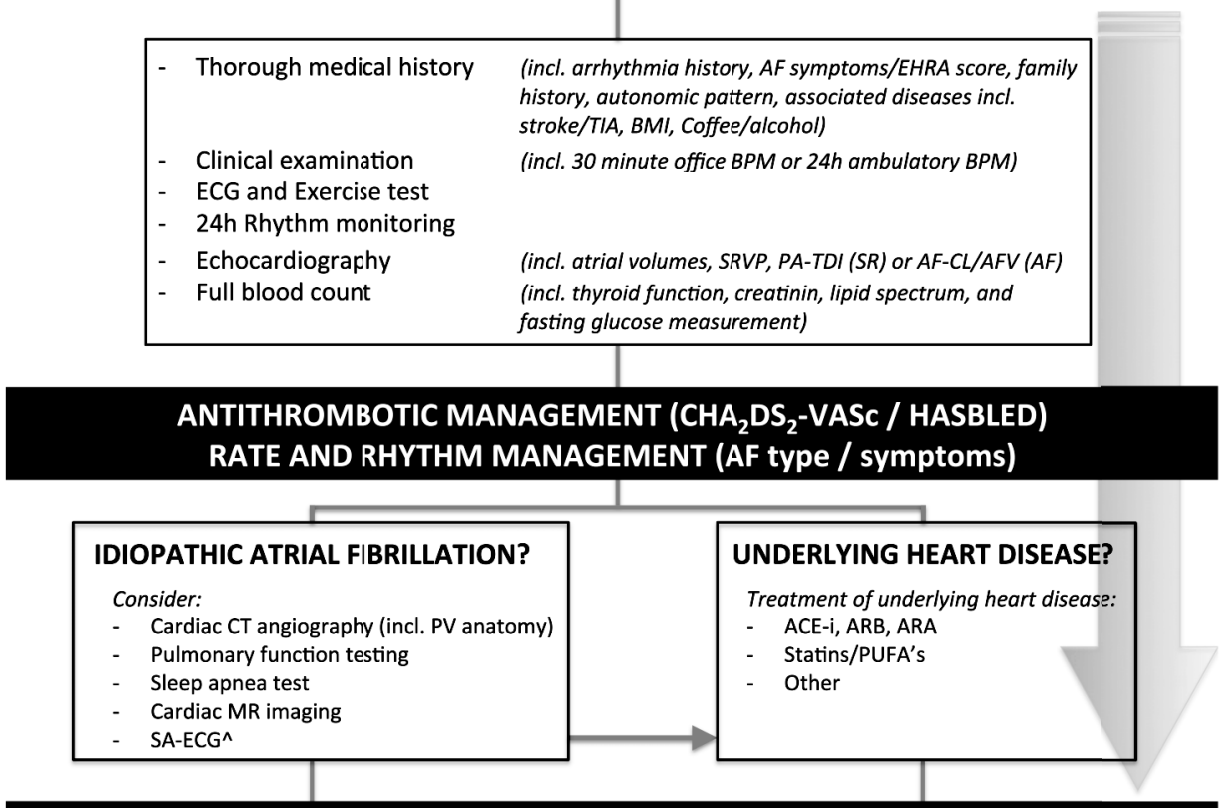

REASSESSMENT OF UNDERLYING HEART DISEASE* \& STROKE RISK FACTORS

FIGURE 4 - Diagnostic cascade for patients with first diagnosed episode of atrial fibrillation (EHRA, European Heart Rhythm Association [EHRA I, no symptoms; EHRA II, Mild symptoms; EHRA III, Severe symptoms; EHRA $I V$, Disabling symptoms]; TIA, transient ischemic attack; $B M I$, body mass index $\left[\mathrm{kg} / \mathrm{m}^{2}\right] ; B P M$, blood pressure measurement; SRVP, systolic right ventricular pressure; $S R$, sinus rhythm; $A F-C L$, atrial fibrillation cyclelength; AFV, atrial fibrillation velocity; PV, pulmonary vein; $M R$, magnetic resonance; ACE-I, angiotensinconverting-enzyme inhibitor; $A R B$, angiotensin-ll-receptor blocker; ARA, aldosterone receptor antagonist; PUFA, poly-unsaturated fatty acid; ^ genetic testing/Ajmalin test as needed; * including atrial volumes) 
As yet, vascular disease including coronary artery disease (CAD) has not received much attention as a cause of $A F$ and its complications. ${ }^{141-143}$ Besides, the clinical relevance of concealed coronary vascular disease in patients originally diagnosed with idiopathic $A F$ is as yet not known. It may be conjectured that idiopathic AF patients with concealed vascular disease have a worse arrhythmia prognosis since the vascular disease may be implicated in causing either AF itself or enhance symptoms, complications or AF progression. Clinical evaluation of coronary disease in AF patients is usually restricted to history taking, ECG and exercise testing. Similarly, evaluation of vascular disease in AF patients is mainly limited to single blood pressure measurement and assessing the presence of cardiovascular risk factors. Clarifying the vascular status in apparently idiopathic AF patients has never been done systematically before. New diagnostic modalities such as CTA, ABPM, non-invasive assessment of endothelial function and specific vascular biomarkers enable early assessment of vascular disease. We foresee that these new tools will help uncovering the pathophysiology of vascular disease in AF and potentially improve diagnosis, treatment and prognosis in these patients. 
CHAPTER X | DISCUSSION

\section{REFERENCES}

1. Fuster V, Ryden LE, Cannom DS, Crijns HJ, Curtis AB, Ellenbogen KA, et al. ACC/AHA/ESC 2006 guidelines for the management of patients with atrial fibrillation: full text: a report of the American College of Cardiology/American Heart Association Task Force on practice guidelines and the European Society of Cardiology Committee for Practice Guidelines (Writing Committee to Revise the 2001 guidelines for the management of patients with atrial fibrillation) developed in collaboration with the European Heart Rhythm Association and the Heart Rhythm Society. Europace. 2006 Sep;8(9):651-745.

2. Jahangir A, Lee V, Friedman PA, Trusty JM, Hodge DO, Kopecky SL, et al. Longterm progression and outcomes with aging in patients with lone atrial fibrillation: a 30-year follow-up study. Circulation. 2007 Jun 19;115(24):30506.

3. Kopecky SL. Idiopathic atrial fibrillation: prevalence, course, treatment, and prognosis. Journal of thrombosis and thrombolysis. 1999 Jan;7(1):27-31.

4. Einthoven W. Le Telecardiogramme. Arch Int Physiol. 1906;4:132-64.

5. Camm AJ, Kirchhof P, Lip GY, Schotten U, Savelieva I, Ernst S, et al. Guidelines for the management of atrial fibrillation: the Task Force for the Management of Atrial Fibrillation of the European Society of Cardiology (ESC). European heart journal. 2010 Oct;31(19):2369-429.

6. Allessie MA, Boyden PA, Camm AJ, Kleber AG, Lab MJ, Legato MJ, et al. Pathophysiology and prevention of atrial fibrillation. Circulation. 2001 Feb 6;103(5):769-77.

7. Stiles MK, John B, Wong CX, Kuklik P, Brooks AG, Lau DH, et al. Paroxysmal lone atrial fibrillation is associated with an abnormal atrial substrate: characterizing the "second factor". J Am Coll Cardiol. 2009 Apr 7;53(14):118291.

8. Van Gelder IC, Hagens VE, Bosker HA, Kingma JH, Kamp O, Kingma T, et al. A comparison of rate control and rhythm control in patients with recurrent persistent atrial fibrillation. N Engl J Med. 2002 Dec 5;347(23):1834-40.

9. Wyse DG, Waldo AL, DiMarco JP, Domanski MJ, Rosenberg Y, Schron EB, et al. A comparison of rate control and rhythm control in patients with atrial fibrillation. N Engl J Med. 2002 Dec 5;347(23):1825-33.

10. Haissaguerre M, Jais P, Shah DC, Takahashi A, Hocini M, Quiniou G, et al. Spontaneous initiation of atrial fibrillation by ectopic beats originating in the pulmonary veins. N Engl J Med. 1998 Sep 3;339(10):659-66.

11. Hocini $M$, Haissaguerre $M$, Shah D, Jais P, Peng JT, Yamane T, et al. Multiple sources initiating atrial fibrillation from a single pulmonary vein identified by a circumferential catheter. Pacing and clinical electrophysiology : PACE. 2000 Nov;23(11 Pt 2):1828-31.

12. Jais $P$, Shah DC, Haissaguerre M, Hocini M, Garrigue S, Clementy J. Atrial fibrillation: role of arrhythmogenic foci. Journal of interventional cardiac 
electrophysiology : an international journal of arrhythmias and pacing. 2000 Jan;4 Suppl 1:29-37.

13. Mandapati R, Skanes A, Chen J, Berenfeld O, Jalife J. Stable microreentrant sources as a mechanism of atrial fibrillation in the isolated sheep heart. Circulation. 2000 Jan 18;101(2):194-9.

14. Moe GK. A conceptual model of atrial fibrillation. J Electrocardiol. 1968;1(2):145-6.

15. Moe GK, Rheinboldt WC, Abildskov JA. A Computer Model of Atrial Fibrillation. Am Heart J. 1964 Feb;67:200-20.

16. Nattel S, Li D, Yue L. Basic mechanisms of atrial fibrillation--very new insights into very old ideas. Annu Rev Physiol. 2000;62:51-77.

17. Schotten U, Verheule S, Kirchhof P, Goette A. Pathophysiological mechanisms of atrial fibrillation: a translational appraisal. Physiol Rev. 2011 Jan;91(1):265325.

18. Shiroshita-Takeshita A, Brundel BJ, Nattel S. Atrial fibrillation: basic mechanisms, remodeling and triggers. Journal of interventional cardiac electrophysiology : an international journal of arrhythmias and pacing. 2005 Sep;13(3):181-93.

19. Allessie MA, Bonke FI, Schopman FJ. Circus movement in rabbit atrial muscle as a mechanism of trachycardia. Circulation research. 1973 Jul;33(1):54-62.

20. Lammers WJ, Allessie MA. Pathophysiology of atrial fibrillation: current aspects. Herz. 1993 Feb;18(1):1-8.

21. Wijffels MC, Kirchhof CJ, Dorland R, Allessie MA. Atrial fibrillation begets atrial fibrillation. A study in awake chronically instrumented goats. Circulation. 1995 Oct 1;92(7):1954-68.

22. Allessie MA, Konings K, Kirchhof CJ, Wijffels M. Electrophysiologic mechanisms of perpetuation of atrial fibrillation. Am J Cardiol. 1996 Jan 25;77(3):10A-23A.

23. Ravelli F, Allessie M. Effects of atrial dilatation on refractory period and vulnerability to atrial fibrillation in the isolated Langendorff-perfused rabbit heart. Circulation. 1997 Sep 2;96(5):1686-95.

24. Khan IA. Atrial fibrillation: interaction between the trigger and the substrate. Int J Cardiol. 2003 Feb;87(2-3):301-2.

25. Nattel S. New ideas about atrial fibrillation 50 years on. Nature. 2002 Jan 10;415(6868):219-26.

26. Benjamin EJ, Levy D, Vaziri SM, D'Agostino RB, Belanger AJ, Wolf PA. Independent risk factors for atrial fibrillation in a population-based cohort. The Framingham Heart Study. JAMA : the journal of the American Medical Association. 1994 Mar 16;271(11):840-4.

27. Kannel WB, Wolf PA, Benjamin EJ, Levy D. Prevalence, incidence, prognosis, and predisposing conditions for atrial fibrillation: population-based estimates. Am J Cardiol. 1998 Oct 16;82(8A):2N-9N. 
28. Psaty BM, Manolio TA, Kuller LH, Kronmal RA, Cushman M, Fried LP, et al. Incidence of and risk factors for atrial fibrillation in older adults. Circulation. 1997 Oct 7;96(7):2455-61.

29. Rosiak M, Dziuba M, Chudzik M, Cygankiewicz I, Bartczak K, Drozdz J, et al. Risk factors for atrial fibrillation: Not always severe heart disease, not always so 'lonely'. Cardiology journal. 2010;17(5):437-42.

30. Schnabel RB, Sullivan LM, Levy D, Pencina MJ, Massaro JM, D'Agostino RB, Sr., et al. Development of a risk score for atrial fibrillation (Framingham Heart Study): a community-based cohort study. Lancet. 2009 Feb 28;373(9665):73945.

31. Asselbergs FW, van den Berg MP, Diercks GF, van Gilst WH, van Veldhuisen DJ. C-reactive protein and microalbuminuria are associated with atrial fibrillation. International journal of cardiology. 2005 Jan;98(1):73-7.

32. Auer J, Scheibner P, Mische T, Langsteger W, Eber O, Eber B. Subclinical hyperthyroidism as a risk factor for atrial fibrillation. Am Heart J. 2001 Nov;142(5):838-42.

33. Buch P, Friberg J, Scharling $\mathrm{H}$, Lange $\mathrm{P}$, Prescott $\mathrm{E}$. Reduced lung function and risk of atrial fibrillation in the Copenhagen City Heart Study. Eur Respir J. 2003 Jun;21(6):1012-6.

34. Conen D, Tedrow UB, Cook NR, Buring JE, Albert CM. Birth weight is a significant risk factor for incident atrial fibrillation. Circulation. 2010 Aug 24;122(8):764-70.

35. Conen D, Tedrow UB, Koplan BA, Glynn RJ, Buring JE, Albert CM. Influence of systolic and diastolic blood pressure on the risk of incident atrial fibrillation in women. Circulation. 2009 Apr 28;119(16):2146-52.

36. Djousse L, Levy D, Benjamin EJ, Blease SJ, Russ A, Larson MG, et al. Long-term alcohol consumption and the risk of atrial fibrillation in the Framingham Study. Am J Cardiol. 2004 Mar 15;93(6):710-3.

37. Eaker ED, Sullivan LM, Kelly-Hayes M, D'Agostino RB, Sr., Benjamin EJ. Anger and hostility predict the development of atrial fibrillation in men in the Framingham Offspring Study. Circulation. 2004 Mar 16;109(10):1267-71.

38. Gami AS, Hodge DO, Herges RM, Olson EJ, Nykodym J, Kara T, et al. Obstructive sleep apnea, obesity, and the risk of incident atrial fibrillation. J Am Coll Cardiol. 2007 Feb 6;49(5):565-71.

39. Heeringa J, van der Kuip DA, Hofman A, Kors JA, van Rooij FJ, Lip GY, et al. Subclinical atherosclerosis and risk of atrial fibrillation: the rotterdam study. Arch Intern Med. 2007 Feb 26;167(4):382-7.

40. Horio T, Iwashima Y, Kamide K, Tokudome T, Yoshihara F, Nakamura S, et al. Chronic kidney disease as an independent risk factor for new-onset atrial fibrillation in hypertensive patients. J Hypertens. 2010 Aug;28(8):1738-44.

41. Mitchell GF, Vasan RS, Keyes MJ, Parise H, Wang TJ, Larson MG, et al. Pulse pressure and risk of new-onset atrial fibrillation. Jama. 2007 Feb 21;297(7):709-15. 
42. Mont L, Tamborero D, Elosua R, Molina I, Coll-Vinent B, Sitges M, et al. Physical activity, height, and left atrial size are independent risk factors for lone atrial fibrillation in middle-aged healthy individuals. Europace. 2008 Jan;10(1):15-20.

43. Chen SA, Hsieh MH, Tai CT, Tsai CF, Prakash VS, Yu WC, et al. Initiation of atrial fibrillation by ectopic beats originating from the pulmonary veins: electrophysiological characteristics, pharmacological responses, and effects of radiofrequency ablation. Circulation. 1999 Nov 2;100(18):1879-86.

44. Cosio FG, Aliot E, Botto GL, Heidbuchel H, Geller CJ, Kirchhof P, et al. Delayed rhythm control of atrial fibrillation may be a cause of failure to prevent recurrences: reasons for change to active antiarrhythmic treatment at the time of the first detected episode. Europace : European pacing, arrhythmias, and cardiac electrophysiology : journal of the working groups on cardiac pacing, arrhythmias, and cardiac cellular electrophysiology of the European Society of Cardiology. 2008 Jan;10(1):21-7.

45. Chen YJ, Chen SA, Chang MS, Lin Cl. Arrhythmogenic activity of cardiac muscle in pulmonary veins of the dog: implication for the genesis of atrial fibrillation. Cardiovasc Res. 2000 Nov;48(2):265-73.

46. Hassink RJ, Aretz HT, Ruskin J, Keane D. Morphology of atrial myocardium in human pulmonary veins: a postmortem analysis in patients with and without atrial fibrillation. J Am Coll Cardiol. 2003 Sep 17;42(6):1108-14.

47. Khan R. Identifying and understanding the role of pulmonary vein activity in atrial fibrillation. Cardiovasc Res. 2004 Dec 1;64(3):387-94.

48. Nathan $\mathrm{H}$, Eliakim M. The junction between the left atrium and the pulmonary veins. An anatomic study of human hearts. Circulation. 1966 Sep;34(3):41222.

49. Saito T, Waki K, Becker AE. Left atrial myocardial extension onto pulmonary veins in humans: anatomic observations relevant for atrial arrhythmias. Journal of cardiovascular electrophysiology. 2000 Aug;11(8):888-94.

50. Tagawa M, Higuchi K, Chinushi M, Washizuka T, Ushiki T, Ishihara N, et al. Myocardium extending from the left atrium onto the pulmonary veins: a comparison between subjects with and without atrial fibrillation. Pacing and clinical electrophysiology : PACE. 2001 Oct;24(10):1459-63.

51. Blom NA, Gittenberger-de Groot AC, DeRuiter MC, Poelmann RE, Mentink MM, Ottenkamp J. Development of the cardiac conduction tissue in human embryos using HNK-1 antigen expression: possible relevance for understanding of abnormal atrial automaticity. Circulation. 1999 Feb 16;99(6):800-6.

52. Jongbloed MR, Schalij MJ, Poelmann RE, Blom NA, Fekkes ML, Wang Z, et al. Embryonic conduction tissue: a spatial correlation with adult arrhythmogenic areas. Journal of cardiovascular electrophysiology. 2004 Mar;15(3):349-55.

53. Zipes DP. Mechanisms of clinical arrhythmias. Pacing and clinical electrophysiology : PACE. 2003 Aug;26(8):1778-92. 
54. Cha TJ, Ehrlich JR, Zhang L, Nattel S. Atrial ionic remodeling induced by atrial tachycardia in the presence of congestive heart failure. Circulation. 2004 Sep 21;110(12):1520-6.

55. Honjo H, Boyett MR, Niwa R, Inada S, Yamamoto M, Mitsui K, et al. Pacinginduced spontaneous activity in myocardial sleeves of pulmonary veins after treatment with ryanodine. Circulation. 2003 Apr 15;107(14):1937-43.

56. Maupoil V, Bronquard C, Freslon JL, Cosnay P, Findlay I. Ectopic activity in the rat pulmonary vein can arise from simultaneous activation of alpha1- and beta1-adrenoceptors. Br J Pharmacol. 2007 Apr;150(7):899-905.

57. Bode F, Sachs F, Franz MR. Tarantula peptide inhibits atrial fibrillation. Nature. 2001 Jan 4;409(6816):35-6.

58. Patterson E, Jackman WM, Beckman KJ, Lazzara R, Lockwood D, Scherlag BJ, et al. Spontaneous pulmonary vein firing in man: relationship to tachycardiapause early afterdepolarizations and triggered arrhythmia in canine pulmonary veins in vitro. Journal of cardiovascular electrophysiology. 2007 Sep;18(10):1067-75.

59. Frustaci A, Chimenti C, Bellocci F, Morgante E, Russo MA, Maseri A. Histological substrate of atrial biopsies in patients with lone atrial fibrillation. Circulation. 1997 Aug 19;96(4):1180-4.

60. De Vos CB, Weijs B, Crijns HJ, Cheriex EC, Palmans A, Habets J, et al. Atrial tissue Doppler imaging for prediction of new-onset atrial fibrillation. Heart (British Cardiac Society). 2009 May;95(10):835-40.

61. Weijs B, de Vos CB, Tieleman RG, Pisters R, Cheriex EC, Prins MH, et al. Clinical and echocardiographic correlates of intra-atrial conduction delay. Europace : European pacing, arrhythmias, and cardiac electrophysiology : journal of the working groups on cardiac pacing, arrhythmias, and cardiac cellular electrophysiology of the European Society of Cardiology. 2011 Dec;13(12):1681-7.

62. Weijs B, de Vos CB, Limantoro I, Cheriex EC, Tieleman RG, Crijns HJ. The presence of an atrial electromechanical delay in idiopathic atrial fibrillation as determined by tissue Doppler imaging. International journal of cardiology. 2012 Apr 5;156(1):121-2.

63. Abdulla R, Blew GA, Holterman MJ. Cardiovascular embryology. Pediatr Cardiol. 2004 May-Jun;25(3):191-200.

64. Benjamin EJ, Wolf PA, D'Agostino RB, Silbershatz H, Kannel WB, Levy D. Impact of atrial fibrillation on the risk of death: the Framingham Heart Study. Circulation. 1998 Sep 8;98(10):946-52.

65. Osranek M, Bursi F, Bailey KR, Grossardt BR, Brown RD, Jr., Kopecky SL, et al. Left atrial volume predicts cardiovascular events in patients originally diagnosed with lone atrial fibrillation: three-decade follow-up. European heart journal. 2005 Dec;26(23):2556-61.

66. Wolf PA, Abbott RD, Kannel WB. Atrial fibrillation: a major contributor to stroke in the elderly. The Framingham Study. Arch Intern Med. 1987 Sep;147(9):1561-4. 
67. Wolf PA, Abbott RD, Kannel WB. Atrial fibrillation as an independent risk factor for stroke: the Framingham Study. Stroke. 1991 Aug;22(8):983-8.

68. Van Gelder IC, Groenveld HF, Crijns HJ, Tuininga YS, Tijssen JG, Alings AM, et al. Lenient versus strict rate control in patients with atrial fibrillation. $\mathrm{N}$ Engl J Med. 2010 Apr 15;362(15):1363-73.

69. Carlsson J, Miketic S, Windeler J, Cuneo A, Haun S, Micus S, et al. Randomized trial of rate-control versus rhythm-control in persistent atrial fibrillation: the Strategies of Treatment of Atrial Fibrillation (STAF) study. J Am Coll Cardiol. 2003 May 21;41(10):1690-6.

70. Hohnloser SH, Kuck KH, Lilienthal J. Rhythm or rate control in atrial fibrillation--Pharmacological Intervention in Atrial Fibrillation (PIAF): a randomised trial. Lancet. 2000 Nov 25;356(9244):1789-94.

71. Opolski G, Torbicki A, Kosior DA, Szulc M, Wozakowska-Kaplon B, Kolodziej P, et al. Rate control vs rhythm control in patients with nonvalvular persistent atrial fibrillation: the results of the Polish How to Treat Chronic Atrial Fibrillation (HOT CAFE) Study. Chest. 2004 Aug;126(2):476-86.

72. Hohnloser SH, Crijns HJ, van Eickels M, Gaudin C, Page RL, Torp-Pedersen C, et al. Effect of dronedarone on cardiovascular events in atrial fibrillation. $\mathrm{N}$ Engl J Med. 2009 Feb 12;360(7):668-78.

73. Van Gelder IC, Haegeli LM, Brandes A, Heidbuchel H, Aliot E, Kautzner J, et al. Rationale and current perspective for early rhythm control therapy in atrial fibrillation. Europace : European pacing, arrhythmias, and cardiac electrophysiology : journal of the working groups on cardiac pacing, arrhythmias, and cardiac cellular electrophysiology of the European Society of Cardiology. 2011 Nov;13(11):1517-25.

74. Healey JS, Connolly SJ, Gold MR, Israel CW, Van Gelder IC, Capucci A, et al. Subclinical atrial fibrillation and the risk of stroke. N Engl J Med. 2012 Jan 12;366(2):120-9.

75. Botto GL, Padeletti L, Santini M, Capucci A, Gulizia M, Zolezzi F, et al. Presence and duration of atrial fibrillation detected by continuous monitoring: crucial implications for the risk of thromboembolic events. Journal of cardiovascular electrophysiology. 2009 Mar;20(3):241-8.

76. Dobrev D, Nattel S. New antiarrhythmic drugs for treatment of atrial fibrillation. Lancet. 2010 Apr 3;375(9721):1212-23.

77. Fogari R, Mugellini A, Zoppi A, Preti P, Destro M, Lazzari P, et al. Effect of Telmisartan and Ramipril on Atrial Fibrillation Recurrence and Severity in Hypertensive Patients With Metabolic Syndrome and Recurrent Symptomatic Paroxysmal and Persistent Atrial Fibrillation. Journal of cardiovascular pharmacology and therapeutics. 2011 Feb 18; Epub ahead of print.

78. Lally JA, Gnall EM, Seltzer J, Kowey PR. Non-antiarrhythmic drugs in atrial fibrillation: a review of non-antiarrhythmic agents in prevention of atrial fibrillation. Journal of cardiovascular electrophysiology. 2007 Nov;18(11):1222-8. 
79. Mancia G, Jakobsen A, Heroys J, Ralph A, Rees T, Shaw M. Cardiac and vascular protection: the potential of ONTARGET. Medscape J Med. 2008;10 Suppl:S7.

80. Savelieva I, Kakouros N, Kourliouros A, Camm AJ. Upstream therapies for management of atrial fibrillation: review of clinical evidence and implications for European Society of Cardiology guidelines. Part II: secondary prevention. Europace : European pacing, arrhythmias, and cardiac electrophysiology : journal of the working groups on cardiac pacing, arrhythmias, and cardiac cellular electrophysiology of the European Society of Cardiology. 2011 May;13(5):610-25.

81. Sicouri S, Cordeiro JM, Talarico M, Antzelevitch C. Antiarrhythmic effects of losartan and enalapril in canine pulmonary vein sleeve preparations. Journal of cardiovascular electrophysiology. 2011 Jun;22(6):698-705.

82. Smit MD, Van Gelder IC. Upstream therapy of atrial fibrillation. Expert Rev Cardiovasc Ther. 2009 Jul;7(7):763-78.

83. Sinno H, Derakhchan K, Libersan D, Merhi Y, Leung TK, Nattel S. Atrial ischemia promotes atrial fibrillation in dogs. Circulation. 2003 Apr 15;107(14):1930-6.

84. Skalidis EI, Hamilos MI, Karalis IK, Chlouverakis G, Kochiadakis GE, Vardas PE. Isolated atrial microvascular dysfunction in patients with lone recurrent atrial fibrillation. J Am Coll Cardiol. 2008 May 27;51(21):2053-7.

85. Skalidis El, Zacharis EA, Tsetis DK, Pagonidis K, Chlouverakis G, Yarmenitis S, et al. Endothelial cell function during atrial fibrillation and after restoration of sinus rhythm. Am J Cardiol. 2007 May 1;99(9):1258-62.

86. Alasady M, Abhayaratna WP, Leong DP, Lim HS, Abed HS, Brooks AG, et al. Coronary artery disease affecting the atrial branches is an independent determinant of atrial fibrillation after myocardial infarction. Heart rhythm : the official journal of the Heart Rhythm Society. 2011 Jul;8(7):955-60.

87. Krahn AD, Manfreda J, Tate RB, Mathewson FA, Cuddy TE. The natural history of atrial fibrillation: incidence, risk factors, and prognosis in the Manitoba Follow-Up Study. Am J Med. 1995 May;98(5):476-84.

88. Lip GY, Beevers DG. ABC of atrial fibrillation. History, epidemiology, and importance of atrial fibrillation. Bmj. 1995 Nov 18;311(7016):1361-3.

89. Schoonderwoerd BA, Van Gelder IC, Crijns HJ. Left ventricular ischemia due to coronary stenosis as an unexpected treatable cause of paroxysmal atrial fibrillation. Journal of cardiovascular electrophysiology. 1999 Feb;10(2):224-8.

90. Duprez DA. Role of the renin-angiotensin-aldosterone system in vascular remodeling and inflammation: a clinical review. J Hypertens. 2006 Jun;24(6):983-91.

91. Duprez DA, Somasundaram PE, Sigurdsson G, Hoke L, Florea N, Cohn JN. Relationship between C-reactive protein and arterial stiffness in an asymptomatic population. J Hum Hypertens. 2005 Jul;19(7):515-9. 
92. Pu Q, Neves MF, Virdis A, Touyz RM, Schiffrin EL. Endothelin antagonism on aldosterone-induced oxidative stress and vascular remodeling. Hypertension. 2003 Jul;42(1):49-55.

93. Potpara TS, Stankovic GR, Beleslin BD, Polovina MM, Marinkovic JM, Ostojic $\mathrm{MC}$, et al. A 12-year follow-up study of patients with newly-diagnosed lone atrial fibrillation: Implications of arrhythmia progression on prognosis: The Belgrade Atrial Fibrillation Study. Chest. 2011 May 26.

94. Rienstra M, Hagens VE, Van Veldhuisen DJ, Bosker HA, Tijssen JG, Kamp O, et al. Clinical characteristics of persistent lone atrial fibrillation in the RACE study. Am J Cardiol. 2004 Dec 15;94(12):1486-90.

95. Weijs B, Pisters R, Nieuwlaat R, Breithardt G, Le Heuzey JY, Vardas PE, et al. Idiopathic atrial fibrillation revisited in a large longitudinal clinical cohort. Europace : European pacing, arrhythmias, and cardiac electrophysiology : journal of the working groups on cardiac pacing, arrhythmias, and cardiac cellular electrophysiology of the European Society of Cardiology. 2012 Feb;14(2):184-90.

96. Kopecky SL, Gersh BJ, McGoon MD, Whisnant JP, Holmes DR, Jr., Ilstrup DM, et al. The natural history of lone atrial fibrillation. A population-based study over three decades. N Engl J Med. 1987 Sep 10;317(11):669-74.

97. Go AS, Hylek EM, Chang Y, Phillips KA, Henault LE, Capra AM, et al. Anticoagulation therapy for stroke prevention in atrial fibrillation: how well do randomized trials translate into clinical practice? Jama. 2003 Nov 26;290(20):2685-92.

98. Go AS, Hylek EM, Phillips KA, Chang Y, Henault LE, Selby JV, et al. Prevalence of diagnosed atrial fibrillation in adults: national implications for rhythm management and stroke prevention: the AnTicoagulation and Risk Factors in Atrial Fibrillation (ATRIA) Study. JAMA : the journal of the American Medical Association. 2001 May 9;285(18):2370-5.

99. Hart RG, Pearce LA, Aguilar MI. Meta-analysis: antithrombotic therapy to prevent stroke in patients who have nonvalvular atrial fibrillation. Annals of internal medicine. 2007 Jun 19;146(12):857-67.

100. Gage BF, Waterman AD, Shannon W, Boechler M, Rich MW, Radford MJ. Validation of clinical classification schemes for predicting stroke: results from the National Registry of Atrial Fibrillation. Jama. 2001 Jun 13;285(22):2864-70.

101. Lip GY, Nieuwlaat R, Pisters R, Lane DA, Crijns HJ. Refining clinical risk stratification for predicting stroke and thromboembolism in atrial fibrillation using a novel risk factor-based approach: the euro heart survey on atrial fibrillation. Chest. 2010 Feb;137(2):263-72.

102. Conway DS, Lip GY. Comparison of outcomes of patients with symptomatic peripheral artery disease with and without atrial fibrillation (the West Birmingham Atrial Fibrillation Project). Am J Cardiol. 2004 Jun 1;93(11):14225, A10.

103. Lip GY. Coronary artery disease and ischemic stroke in atrial fibrillation. Chest. 2007 Jul;132(1):8-10. 
104. Schmitt J, Duray G, Gersh BJ, Hohnloser SH. Atrial fibrillation in acute myocardial infarction: a systematic review of the incidence, clinical features and prognostic implications. European heart journal. 2009 May;30(9):103845.

105. Siu CW, Jim MH, Ho HH, Miu R, Lee SW, Lau CP, et al. Transient atrial fibrillation complicating acute inferior myocardial infarction: implications for future risk of ischemic stroke. Chest. 2007 Jul;132(1):44-9.

106. Zabalgoitia M, Halperin JL, Pearce LA, Blackshear JL, Asinger RW, Hart RG. Transesophageal echocardiographic correlates of clinical risk of thromboembolism in nonvalvular atrial fibrillation. Stroke Prevention in Atrial Fibrillation III Investigators. J Am Coll Cardiol. 1998 Jun;31(7):1622-6.

107. Achenbach S, Raggi P. Imaging of coronary atherosclerosis by computed tomography. European heart journal. 2010 Jun;31(12):1442-8.

108. Achenbach S, Schmermund A, Erbel R, Silber S, Haberl R, Moshage W, et al. [Detection of coronary calcifications by electron beam tomography and multislice spiral CT: clinical relevance]. Z Kardiol. 2003 Nov;92(11):899-907.

109. Agatston AS, Janowitz WR, Hildner FJ, Zusmer NR, Viamonte M, Jr., Detrano R. Quantification of coronary artery calcium using ultrafast computed tomography. J Am Coll Cardiol. 1990 Mar 15;15(4):827-32.

110. Rumberger JA, Sheedy PF, Breen JF, Schwartz RS. Electron beam computed tomographic coronary calcium score cutpoints and severity of associated angiographic lumen stenosis. J Am Coll Cardiol. 1997 Jun;29(7):1542-8.

111. Budoff MJ, Gul KM. Expert review on coronary calcium. Vascular health and risk management. 2008;4(2):315-24.

112. Budoff MJ, McClelland RL, Nasir K, Greenland P, Kronmal RA, Kondos GT, et al. Cardiovascular events with absent or minimal coronary calcification: the Multi-Ethnic Study of Atherosclerosis (MESA). Am Heart J. 2009 Oct;158(4):554-61.

113. Budoff MJ, Shaw LJ, Liu ST, Weinstein SR, Mosler TP, Tseng PH, et al. Longterm prognosis associated with coronary calcification: observations from a registry of 25,253 patients. J Am Coll Cardiol. 2007 May 8;49(18):1860-70.

114. Vliegenthart $R$, Hollander $M$, Breteler MM, van der Kuip DA, Hofman A, Oudkerk $M$, et al. Stroke is associated with coronary calcification as detected by electron-beam CT: the Rotterdam Coronary Calcification Study. Stroke. 2002 Feb;33(2):462-5.

115. Vliegenthart R, Oudkerk M, Song B, van der Kuip DA, Hofman A, Witteman JC. Coronary calcification detected by electron-beam computed tomography and myocardial infarction. The Rotterdam Coronary Calcification Study. European heart journal. 2002 Oct;23(20):1596-603.

116. Borissoff JI, Spronk HM, ten Cate H. The hemostatic system as a modulator of atherosclerosis. N Engl J Med. 2011 May 5;364(18):1746-60.

117. Weijs B, Blaauw $Y$, Rennenberg RJ, Schurgers LJ, Timmermans CC, Pison L, et al. Patients using vitamin $\mathrm{K}$ antagonists show increased levels of coronary 
calcification: an observational study in low-risk atrial fibrillation patients. European heart journal. 2011 Oct;32(20):2555-62.

118. Mahmoodi BK, Brouwer JL, Ten Kate MK, Lijfering WM, Veeger NJ, Mulder AB, et al. A prospective cohort study on the absolute risks of venous thromboembolism and predictive value of screening asymptomatic relatives of patients with hereditary deficiencies of protein $\mathrm{S}$, protein $\mathrm{C}$ or antithrombin. J Thromb Haemost. 2010 Jun;8(6):1193-200.

119. Mahmoodi BK, Brouwer JL, Veeger NJ, van der Meer J. Hereditary deficiency of protein $\mathrm{C}$ or protein $\mathrm{S}$ confers increased risk of arterial thromboembolic events at a young age: results from a large family cohort study. Circulation. 2008 Oct 14;118(16):1659-67.

120. Matsumoto K, Yano Y, Gabazza EC, Araki R, Bruno NE, Suematsu M, et al. Inverse correlation between activated protein $\mathrm{C}$ generation and carotid atherosclerosis in Type 2 diabetic patients. Diabet Med. 2007 Dec;24(12):1322-8.

121. Zorio E, Navarro S, Medina P, Estelles A, Osa A, Rueda J, et al. Circulating activated protein $\mathrm{C}$ is reduced in young survivors of myocardial infarction and inversely correlates with the severity of coronary lesions. J Thromb Haemost. 2006 Jul;4(7):1530-6.

122. Cranenburg EC, Schurgers LJ, Vermeer C. Vitamin K: the coagulation vitamin that became omnipotent. Thrombosis and haemostasis. 2007 Jul;98(1):120-5.

123. Jono S, Ikari Y, Vermeer C, Dissel P, Hasegawa K, Shioi A, et al. Matrix Gla protein is associated with coronary artery calcification as assessed by electron-beam computed tomography. Thrombosis and haemostasis. 2004 Apr;91(4):790-4.

124. Luo G, Ducy P, McKee MD, Pinero GJ, Loyer E, Behringer RR, et al. Spontaneous calcification of arteries and cartilage in mice lacking matrix GLA protein. Nature. 1997 Mar 6;386(6620):78-81.

125. Price PA, Faus SA, Williamson MK. Warfarin causes rapid calcification of the elastic lamellae in rat arteries and heart valves. Arteriosclerosis, thrombosis, and vascular biology. 1998 Sep;18(9):1400-7.

126. Schurgers $\mathrm{L}$, Aebert $\mathrm{H}$, Vermeer $\mathrm{C}$, Bultmann B, Janzen J. Oral anticoagulant treatment: friend or foe in cardiovascular disease? Blood. 2004 Nov 15;104(10):3231-2.

127. Rennenberg RJ, van Varik BJ, Schurgers LJ, Hamulyak K, Ten Cate H, Leiner T, et al. Chronic coumarin treatment is associated with increased extra-coronary arterial calcification in humans. Blood. 2010 Mar 30;Epub ahead of print.

128. Connolly SJ, Ezekowitz MD, Yusuf S, Eikelboom J, Oldgren J, Parekh A, et al. Dabigatran versus warfarin in patients with atrial fibrillation. N Engl J Med. 2009 Sep 17;361(12):1139-51.

129. Granger CB, Alexander JH, McMurray JJ, Lopes RD, Hylek EM, Hanna M, et al. Apixaban versus warfarin in patients with atrial fibrillation. $N$ Engl J Med. 2011 Sep 15;365(11):981-92. 
130. Patel MR, Mahaffey KW, Garg J, Pan G, Singer DE, Hacke W, et al. Rivaroxaban versus warfarin in nonvalvular atrial fibrillation. N Engl J Med. 2011 Sep 8;365(10):883-91.

131. Greenberg HM, Dwyer EM, Jr., Hochman JS, Steinberg JS, Echt DS, Peters RW. Interaction of ischaemia and encainide/flecainide treatment: a proposed mechanism for the increased mortality in CAST I. British heart journal. 1995 Dec;74(6):631-5.

132. de Azevedo CF, Hadlich MS, Bezerra SG, Petriz JL, Alves RR, de Souza O, et al. Prognostic value of CT angiography in patients with inconclusive functional stress tests. JACC Cardiovasc Imaging. 2011 Jul;4(7):740-51.

133. Dedic A, Genders TS, Ferket BS, Galema TW, Mollet NR, Moelker A, et al. Stable angina pectoris: head-to-head comparison of prognostic value of cardiac CT and exercise testing. Radiology. 2011 Nov;261(2):428-36.

134. Achenbach S, Ropers U, Kuettner A, Anders K, Pflederer T, Komatsu S, et al. Randomized comparison of 64-slice single- and dual-source computed tomography coronary angiography for the detection of coronary artery disease. JACC Cardiovasc Imaging. 2008 Mar;1(2):177-86.

135. Husmann L, Herzog BA, Gaemperli O, Tatsugami F, Burkhard N, Valenta I, et al. Diagnostic accuracy of computed tomography coronary angiography and evaluation of stress-only single-photon emission computed tomography/computed tomography hybrid imaging: comparison of prospective electrocardiogram-triggering vs. retrospective gating. European heart journal. 2009 Mar;30(5):600-7.

136. Maruyama T, Takada M, Hasuike T, Yoshikawa A, Namimatsu E, Yoshizumi T. Radiation dose reduction and coronary assessability of prospective electrocardiogram-gated computed tomography coronary angiography: comparison with retrospective electrocardiogram-gated helical scan. J Am Coll Cardiol. 2008 Oct 28;52(18):1450-5.

137. de Vos CB, Crijns HJ, Tieleman RG. The fibrillating atrial myocardium visualized: an unexploited source of information. Heart rhythm : the official journal of the Heart Rhythm Society. 2009 Aug;6(8):1247-8.

138. De Vos CB, Pison L, Pisters R, Schotten U, Cheriex EC, Prins MH, et al. Atrial fibrillatory wall motion and degree of atrial remodeling in patients with atrial fibrillation: a tissue velocity imaging study. Journal of cardiovascular electrophysiology. 2009 Dec;20(12):1374-81.

139. Duytschaever M, Heyse A, de Sutter J, Crijns H, Gillebert T, Tavernier R, et al. Transthoracic tissue Doppler imaging of the atria: a novel method to determine the atrial fibrillation cycle length. Journal of cardiovascular electrophysiology. 2006 Nov;17(11):1202-9.

140. Cuculich PS, Wang Y, Lindsay BD, Faddis MN, Schuessler RB, Damiano RJ, Jr., et al. Noninvasive characterization of epicardial activation in humans with diverse atrial fibrillation patterns. Circulation. 2010 Oct 5;122(14):1364-72.

141. Androulakis A, Aznaouridis KA, Aggeli CJ, Roussakis GN, Michaelides AP, Kartalis AN, et al. Transient ST-segment depression during paroxysms of atrial 
fibrillation in otherwise normal individuals: relation with underlying coronary artery disease. J Am Coll Cardiol. 2007 Nov 6;50(19):1909-11.

142. de Bono JP, Stoll VM, Joshi A, Rajappan K, Bashir Y, Betts TR. Cavotricuspid isthmus dependent flutter is associated with an increased incidence of occult coronary artery disease. Europace. 2010 September;12(12):1774-7.

143. Kralev S, Schneider K, Lang S, Suselbeck T, Borggrefe M. Incidence and severity of coronary artery disease in patients with atrial fibrillation undergoing first-time coronary angiography. PLoS One. 2011;6(9):e24964. 
CHAPTER X | DISCUSSION 
CHAPTER XI CONCLUSION \& SUMMARY 


\section{CONCLUSION AND SUMMARY}

By means of the present AF management algorithm, we (physicians) still allocate a benign prognosis with low stroke risk to those with apparently idiopathic AF. The results collected in this thesis reveal that in spite of the alleged unknown origin of the arrhythmia in idiopathic AF patients, atrial remodelling and subclinical cardiovascular disease are already present in the majority of these patients. Follow-up shows that patients originally diagnosed with idiopathic AF develop cardiovascular disease more often, at younger age and with a more severe disease profile compared to healthy sinus rhythm controls. In addition, the presence of mild cardiovascular disease, even when found in the absence of significant atrial remodelling seems of prognostic importance. This thesis contains an important message concerning the fundamental basis of AF onset in these presumed healthy patients. It shows that the arrhythmia might act as a harbinger of concealed underlying heart disease. The results demonstrated in this thesis could be an important step towards new diagnostic and treatment paradigms regarding AF patients. 


\section{SAMENVATTING (VOOR NIET-MEDICI)}

Boezemfibrilleren is de meest voorkomende ritmestoornis binnen de cardiologie en kan gepaard gaan met hartkloppingen, kortademigheid en vermoeidheid ten gevolge van een verhoogde en onregelmatige hartslag. Bovendien hebben mensen die lijden aan deze ritmestoornis een verhoogd risico op het ontwikkelen van een hersen- of hartinfarct en hartfalen. Dit risico kan gelukkig sterk worden beperkt door het tijdig voorschrijven van de juiste medicatie. Meestal wordt de ritmestoornis uitgelokt door het bereiken van een oudere leeftijd of onder meer door hoge bloeddruk, kleplijden, longziekten of een eerder doorgemaakt hartinfarct of hartoperatie. Soms is het echter zo dat de ritmestoornis optreedt zonder dat de routine onderzoeken uitlokkende factoren tonen voor het ontstaan van de ritmestoornis. Dit wordt idiopathisch boezemfibrilleren genoemd. Tot nu toe werd gedacht dat deze op het oog gezonde groep patiënten een gunstige prognose had met een laag risico op beroertes. Medicijnen welke het risico op beroertes verminderen werden dan ook niet of nauwelijks voorgeschreven aan deze patiënten.

De resultaten verzameld in dit proefschrift laten zien dat, ondanks de vermeend afwezige oorzaak van de ritmestoornis in patiënten met idiopathisch boezemfibrilleren, het hart reeds aanpassingen heeft ondergaan welke de ritmestoornis kunnen uitlokken en in stand kunnen houden (HOOFDSTUK 2-4) en dat een vroeg stadium van onderliggende cardiovasculaire ziekten reeds aanwezig is in het grootste deel van deze patiënten (HOOFDSTUK 6, 8-9). Wanneer we patiënten oorspronkelijk gediagnosticeerd met idiopathisch boezemfibrilleren gedurende langere tijd vervolgen zien we dat cardiovasculaire ziekte (o.a. hoge bloeddruk, kransslagaderlijden, hartfalen, beroertes, suikerziekte) in deze groep vaker optreedt dan in een vergelijkbaar gezonde groep mensen zonder de ritmestoornis. Daarnaast treden deze cardiovasculaire ziekten op een jongere leeftijd op, met een ernstiger ziekteprofiel, en heeft een minimale aanwezigheid van een van deze ziekten al een groot effect op de prognose van patiënten met boezemfibrilleren (HOOFDSTUK $5+7$ ).

Dit proefschrift bevat een belangrijke boodschap aangaande de basis voor het ontstaan van boezemfibrilleren in deze verondersteld gezonde patiëntengroep. Hierbij functioneert de ritmestoornis als een soort van alarmbel voor de aanwezigheid van nog onontdekte onderliggende cardiovasculaire ziekten. De resultaten verschaffen nieuwe inzichten welke gebruikt kunnen worden in de diagnostische work-up en behandeling van patiënten met boezemfibrilleren. 
CHAPTER XII

\section{DANKWOORD}


Dit dankwoord zal niet beginnen met hoe zwaar het schrijven van het proefschrift is geweest, ik heb het gezien als een verrijking. Bovendien heeft de researchtijd mij juist ook ruimte gegeven om 'dienst-/afdelingsvrij' te genieten van mijn gezin, hobby's, huis, familie en vrienden. Het feit dat ik zelf de afgelopen jaren (vooralsnog) vrij van boezemfibrilleren ben gebleven, heb ik aan een groot aantal mensen te danken. Een deel wil ik noemen..

Allerliefste Anne, wie kan ik meer danken dan jou? Je bent een fantastische vrouw en moeder voor mij en onze kinderen, iedereen die jou ook maar een beetje kent zal dit beamen. Zo snel als we van start zijn gegaan dendert het voort, en elke B\&A-actie makt ons nog gelukkiger samen. Zonder enig probleem combineer jij ons gezin, je werk als bijna-kinderarts, onze familie en vrienden. Wat zou ik zonder jou moeten?

$\mathrm{xx}$

Prof. dr. Crijns, beste Harry, dit is oprecht ons verhaal geworden. Dank voor alle vrijheid, de motiverende woorden wanneer nodig en de (veelal nachtelijke/weekend/vakantie) uren die je aan dit proefschrift hebt besteed!

De leden van de beoordelingscommissie: Prof. dr. Schotten, Prof. dr. Van Gelder, Prof. dr. Gorgels, Prof. dr. Smeets, Prof. dr. Stehouwer ben ik dankbaar voor het kritisch doorlezen van mijn proefschrift.

Prof. dr. Penn \& dr. Pulles-Heintzberger, zonder $u$ had de cardiologie wellicht nooit mijn interesse gekregen, dank!

dr. Cheriex, beste Miel, bedankt voor het in mij gestelde vertrouwen en het bieden van de mogelijkheid om te starten met de opleiding tot cardioloog.

Robert Tieleman \& Nicole Lencer, ik als zenuwachtige derdejaars geneeskunde op het bankje voor jullie kamer, achter die deur Nicole met grote geruststellende glimlach en Robert relaxt met voeten op bureau. Dank voor jullie vertrouwen!!

Kevin Vernooy; dr. dr ik D(onke)r, (hoe vaak was je nu ook alweer gepromoveerd?); Jurren van Opstal; Rutger Haest; Yuri Blaauw, bedankt voor jullie voorbeeld, en persisterende interesse!! Uiteraard wil ik ook de rest van de 'oude' assistenten club bedanken voor de meer dan prettige introductie als coassistent en later ANIOS in de klinische cardiologie. En voor de huidige garde: ik zie er vast naar uit om met jullie te gaan samenwerken! Dr. Laurent Pison, bedankt voor je bereidwilligheid altijd en overal de AF-poli en cardioversies te superviseren.

Miriam \& Nadine, wat een luxe om voor alles en nog wat altijd bij jullie terecht te kunnen, bedankt voor jullie interesse en gezelligheid. Alle research-dames, meiden van de poli, cardiac CT team, en CT laboranten, bedankt voor de fijne werksfeer. 
Mijn vrij-mi-cardioversie-buddy's ook wel "boezem"-vrienden: Ron, jij bent een researcher pur sang, wat was ik blij toen jij besloot om nog 2 jaar bij te tekenen voor een pre-post-doc tijd! Dank voor al je hulp bij het tot stand komen van dit proefschrift, je kritische blik en je altijd aanwezige drive naar nieuwe vraagstellingen. Als iemand het verdient om copromotor te zijn dan ben jij het! Wellicht zetten we onze samenwerking straks voort in de kliniek.. Ione(ke)/Limi/lli: Did you have your Vivaldi today? Wat ben jij een fantastische collega! Ik ken oprecht niemand die zoveel interesse in zijn collega's heeft en zo een trouwe vriendin is als jij, voor iedereen maak je tijd vrij in je drukke schema. Heel veel dank voor je vrolijkheid op de kamer en voor je interesse in ons gezin. Theo: ik kan geen betere opvolger voor mijn poli bedenken, jammer dat we elkaar nu tijdens de opleiding gaan mislopen; Masih (PYPD), wat een relaxte achterbuurman.

Alle andere (oud)leden van het researchhol: Cees, dankzij jou i.c.m. de andere "batsers" ben ik hier terecht gekomen. Bedankt voor het wegwijs maken in klinisch onderzoek gedurende mijn studententijd, en de meer dan productieve samenwerking in de electro-echocardiografie; Luc, ik denk dat wij elkaar nog nooit gesproken hebben zonder te lachen, fantastisch! Onze samenwerking in de steering-committee van DayOut 2012 had ik niet willen missen! (alhoewel...); Robby N. dank voor overzees overleg, Robert, buiten jouw weten om heb je voor mij vaak als voorbeeld gediend, waarvoor dank! Mark, trotse papa, Geniet! Sandra, zonder jou zat dit boekje zonder statistiek, bedankt! Casper, Frederique, Caroline \& Martijn, Marije, Miguel, Ruud Nondeju!, allen bedankt voor het dagelijkse vertier.

Maarten, van duomaatje tot research-pal. De koffies op de vierde waren altijd prettig, vaak hard nodig en immer in goede balans voor wat betreft de te delen ellende/vreugde. Het heeft gewerkt, 2 promoties in september 2012!

Twan, mènne Maat! Nog nooit heb ik een man zo zien huilen om het feit dat hij als paranimf werd gevraagd ("och, dit is maar 'n klein pepertje...") Ik weet zeker dat, mocht ik alsnog in een aanval van boezemfibrilleren schieten tijdens de verdediging, niemand de resterende tijd beter vol kan krijgen dan jij...

Dennis, ontzettende paranimf! De vele nachtelijke uren aan conversaties vanaf jouw 'couch' staan nog vers in mijn geheugen! Wie had ooit gedacht dat het daadwerkelijk zover zou komen? Fantastisch dat ik jou hier naast mij heb staan. Bedankt voor je trouwe vriendschap!

Carlijn, Eelco, Gijs, Annabel \& Bram, ons kennismakingsdiner zal ik nooit vergeten! Wat heerlijk dat we samen met jullie in Groningen, Biddinghuizen of Maastricht lekker mochten afschakelen. Laten we dat voortzetten! 
CHAPTER XII | DANKWOORD

Harry \& Richard, onze surrogaat-vaders. Lieve Richard, wat leg je ons altijd in de watten. Ik kan nu al niet wachten op het Haarlemse taartje waarmee we het afronden van mijn proefschrift kunnen vieren. Harry, ik kijk enorm tegen je op. Ondanks dat wij beiden het ziekenhuis niet vreemd zijn zal ik de momenten waarop we dit samen vanuit een heel ander perspectief hebben beleefd niet meer vergeten. Dank voor je bijdrage aan de allereerste bladzijde.

Lex, Teuntje, Kevin, Marc-Joep, Annemiek, Sem, Kiki, Christiane (dank voor het kritisch doorlezen van dit proefschrift), Dennis, Billie, Pax (wat ben ik trots jouw peetoom te mogen zijn, we gaan er iets gaafs van maken!), Camiel, Mandy, Ron, Nicole, Anouk \& Tycho wat boffen wij met jullie om ons heen.

Lieve opa \& oma, hoe sterk onze band al was, hij is in de afgelopen tijd alleen nog maar sterker geworden. Ik prijs mij diep gelukkig met het feit dat jullie al deze belangrijke stappen in mijn leven mogen meemaken.

Lieve Pierre \& Marijke, zonder jullie had ik dit proefschrift nooit kunnen afronden. Wat hebben jullie veel voor ons gezin gedaan, en wat zijn we daar dankbaar voor. Altijd mochten we jullie bellen wanneer de nood hoog was. En als de nood een keer wat minder hoog was, stond er bij thuiskomst na een lange dag dan toch gewoon een pannetje met eten klaar op het aanrecht. Ik hoop dat ik nog lang een droge korst brood bij jullie mag blijven eten!

Lieve pap en mam, "Met jouw hand in de mijne" was ooit deel van de tekst van mijn allereerste publicatie (Weijs 1984). Sinds die tijd blijf ik jullie met de afdeling cardiologie Maastricht confronteren, wat een rotstreek eigenlijk. Zeker nu ik zelf vader ben, besef ik hoe ongelofelijk pittig dit voor jullie moet zijn geweest. Jullie hebben mij mijn basis gegeven en daar waar nodig altijd gestimuleerd en de mogelijkheid geboden om te blijven studeren en terecht te komen waar ik nu ben, bedankt!

Julia, lief meisje, als je eens wist hoe moeilijk ik het vind om in 1 zin weer te geven wat jij voor mij betekent.. Als wij jou na een lange dag werken komen ophalen van de crèche, weet je niet hoe snel je naar ons toe moet lopen om ons alweer de dikste knuffel ooit te geven. Je maakt me de gelukkigste papa op de wereld.

Tuur, stoere man, jij bent de kroon op dit werk.

En nu terug naar de kliniek ....... 
CHAPTER XIII ABOUT THE AUTHOR \& PUBLICATIONS 
CHAPTER XIII | ABOUT THE AUTHOR AND PUBLICATIONS

\section{ABOUT THE AUTHOR}

Bob Weijs was born on the $12^{\text {th }}$ of January 1984 in Heerlen (the Netherlands). After completing secondary school at Eijkhagen College in Landgraaf in 2001, he started his medical training at the Faculty of Health, Medicine and Life Sciences, University of Maastricht. After electives in paediatric cardiology (prof. dr. T. Delhaas, dr. C. PullesHeintzberger), cardiology (drs. N. Uszko-Lencer) and a scientific internship cardiology (dr. R. Tieleman), he obtained his medical degree in 2007. From 2007-2008 he worked as a cardiology resident at the Maastricht University Medical Centre (MUMC). In 2008, he started working as a PhD-fellow under supervision of prof. dr. H. Crijns at the department of cardiology and cardiovascular research institute Maastricht (CARIM). Apart from scientific research in the field of atrial fibrillation, he worked as a medical doctor in the MUMC specialised outpatient clinic for atrial fibrillation, focused on cardiac CT acquisition and assessment at the MUMC radiology department ( $>900$ cases, supervisor: prof. dr. J. Wildberger), was involved in education of medical students and acted as sub-investigator of multiple studies conducted by pharmaceutical and device companies. He presented his work at several national and international medical congresses, and received the runner-up prize of the Young Investigators "Wim van der Giessen" Award at the ACS Symposium, Utrecht (the Netherlands). The scientific results obtained during this period form the basis of this thesis. In June 2012 he continued his training in clinical cardiology and will be working from this position in Atrium Medical Centre Heerlen, VieCuri Hospital Venlo and the MUMC respectively. 
CHAPTER XIII | ABOUT THE AUTHOR AND PUBLICATIONS

\section{PUBLICATIONS}

Original research, letters and case reports

Weijs B, Pisters R, Haest RJ, Kragten JA, Joossen IAPG, Versteylen M, Timmermans CCMM, Pison L, Blaauw Y, Hofstra L, Wildberger J, Crijns HJGM. Patients originally diagnosed with idiopathic atrial fibrillation more often suffer from insidious coronary artery disease compared to healthy sinus rhythm control patients.

Heart Rhythm 2012, in press (IF 4.1)

Weijs B, de Vos CB, Tieleman RG, Cheriex EC, Limantoro I, Pisters R, Crijns HJGM. The occurrence of cardiovascular disease during 5 year follow up in patients with idiopathic atrial fibrillation.

Europace 2012, in press (IF 2.0)

Limantoro I, Weijs B, Crijns HJGM, Pisters R. The impact of atrial fibrillation on the quality of life of the elderly: the calm before the storm?

Europace 2012, in press (IF 2.0)

Weijs B, de Vos CB, Limantoro I, Tieleman RG, Crijns HJGM. The presence of an atrial electromechanical delay in idiopathic atrial fibrillation as determined by tissue Doppler imaging.

International journal of Cardiology. 2012 Apr 5;156(1):121-2 (IF 7.1)

Weijs B, Pisters R, Nieuwlaat R, Breithardt G, Le Heuzey JY, Vardas PE, Limantoro I, Schotten U, Lip GYH, Crijns HJGM. Idiopathic atrial fibrillation revisited in a large longitudinal clinical cohort.

Europace 2011, 2012 Feb;14(2):184-90 (IF 2.0)

Weijs B, de Vos CB, Tieleman RG, Pisters R, Cheriex EC, Prins MH, Crijns HJGM. Clinical and echocardiographic correlates of intra-atrial conduction delay.

Europace. 2011 Dec;13(12):1681-1687 (IF 2.0)

Weijs B, Blaauw Y, Rennenberg RJMW, Schurgers LJ, Timmermans CCMM, Pison L, Hofstra L, Kroon AA, Wildberger J, Crijns HJGM. Patients using Vitamin K antagonists show increased levels of coronary calcification: an observational study in low-risk atrial fibrillation patients.

European Heart Journal. 2011 Oct;32(20):2555-62 (IF 10.5)

Weijs B, Smulders M, Alzand BSN. Semi-final masked hypertension. Netherlands journal of Medicine. 2010 October; 68(10): 328 (IF 1.5) 
Weijs B, van Paassen P, Bekkers SCAM. Giant atria in a patient with systemic lupus erythematosus.

Netherlands journal of Medicine. 2010 November; 68 (11): 378 (IF 1.5)

De Vos CB, Weijs B, Crijns HJGM, Cheriex EC, Palmans A, Habets J, Prins MH, Pisters R, Nieuwlaat R, Tieleman RG. Atrial tissue Doppler imaging for prediction of new-onset atrial fibrillation.

Heart. 2009 May; 95(10):835-40 (IF 4.7)

\section{Abstracts}

Weijs B, Pisters R, Nieuwlaat R, Lip GY, Crijns HJGM. Idiopathic atrial fibrillation: does age matter?

Circulation, November 2010; vol 122, Issue 21: S_15070

Weijs B, Laufer EM, Blaauw Y, Rennenberg RJ, Schurgers LJ, Hofstra L, Crijns HJGM. The use of vitamin $\mathrm{K}$ antagonists is associated with increased coronary artery calcification in low risk atrial fibrillation patients.

Heart Rhythm, May 2010; vol 7, Issue 5: S_197

de Vos CB, Weijs B, Crijns HJ, Cheriex EC, Prins M, Pisters R, Nieuwlaat R, Tieleman RG. Atrial Tissue Doppler Imaging for Prediction of New Onset Atrial Fibrillation Circulation, Oct 2008; vol 118: S_1069

Weijs B, de Vos CB, Crijns HJ, Broos C, van Boxtel A, Palmans A, Habets J, Cheriex EC, Tieleman RG. Tissue Doppler Imaging to Identify Patients with a Substrate Vulnerable for Atrial Fibrillation

Circulation, Oct 2007; vol 116: II-570 
CHAPTER XIII | ABOUT THE AUTHOR AND PUBLICATIONS

\section{Presentations}

Weijs B, Pisters R, Haest RJ, Kragten JA, Joossen IAPG, Versteylen M, Timmermans CCMM, Pison L, Blaauw Y, Hofstra L, Wildberger J, Crijns HJGM. Idiopathic atrial fibrillation as a vascular disease rather than an arrhythmia.

- ACS Symposium, Sept 2011, Utrecht, the Netherlands

- Boston AF symposium, Jan 2012, Boston, Massachusetts, USA

Weijs B, de Vos CB, Tieleman RG, Cheriex EC, Limantoro I, Pisters R, Crijns HJGM. The occurrence of cardiovascular disease during 5 year follow up in patients with idiopathic atrial fibrillation.

- Boston AF symposium, Jan 2012, Boston, Massachusetts, USA

Weijs B, Crijns HJGM. Lone boezemfibrilleren: beperken tot anti-aritmica? (Invited speaker)

- Dutch Society of Cardiology Congress, Apr 2011, Arnhem, the Netherlands

Weijs B, Pisters R, Nieuwlaat R, Lip GYH, Crijns HJGM. Idiopathic atrial fibrillation: does age matter?

- Dutch Society of Cardiology Congress, Nov 2010, Egmond a/Zee, the Netherlands

- American Heart Association Scientific Sessions, Nov 2010, Chicago, Illinois, USA

Weijs B, Laufer EM, Blaauw Y, Rennenberg RJ, Schurgers LJ, Hofstra L, Crijns HJGM. The use of vitamin $\mathrm{K}$ antagonists is associated with increased coronary artery calcification in low risk atrial fibrillation patients.

- Heart Rhythm Society Scientific Sessions, May 2010, Denver, Colorado, USA

Weijs B, de Vos CB, Crijns HJGM, Broos C, van Boxtel A, Zhang E, Palmans A, Habets J, Cheriex EC, Tieleman RG. Tissue Doppler Imaging to Identify Patients with a Substrate Vulnerable for Atrial Fibrillation.

- American Heart Association Scientific Sessions, Nov 2007, Orlando, Florida, USA 
CHAPTER XIII | ABOUT THE AUTHOR AND PUBLICATIONS 
CHAPTER XIII | ABOUT THE AUTHOR AND PUBLICATIONS 
